\title{
Optimized recovery and minimally invasive liver surgery
}

Citation for published version (APA):

Wong-Lun-Hing, E. M. (2017). Optimized recovery and minimally invasive liver surgery. [Doctoral Thesis, Maastricht University]. Datawyse / Universitaire Pers Maastricht. https://doi.org/10.26481/dis.20170519ewlh

Document status and date:

Published: 01/01/2017

DOI:

10.26481/dis.20170519ewlh

Document Version:

Publisher's PDF, also known as Version of record

\section{Please check the document version of this publication:}

- A submitted manuscript is the version of the article upon submission and before peer-review. There can be important differences between the submitted version and the official published version of record.

People interested in the research are advised to contact the author for the final version of the publication, or visit the DOI to the publisher's website.

- The final author version and the galley proof are versions of the publication after peer review.

- The final published version features the final layout of the paper including the volume, issue and page numbers.

Link to publication

\footnotetext{
General rights rights.

- You may freely distribute the URL identifying the publication in the public portal. please follow below link for the End User Agreement:

www.umlib.nl/taverne-license

Take down policy

If you believe that this document breaches copyright please contact us at:

repository@maastrichtuniversity.nl

providing details and we will investigate your claim.
}

Copyright and moral rights for the publications made accessible in the public portal are retained by the authors and/or other copyright owners and it is a condition of accessing publications that users recognise and abide by the legal requirements associated with these

- Users may download and print one copy of any publication from the public portal for the purpose of private study or research.

- You may not further distribute the material or use it for any profit-making activity or commercial gain

If the publication is distributed under the terms of Article $25 \mathrm{fa}$ of the Dutch Copyright Act, indicated by the "Taverne" license above, 


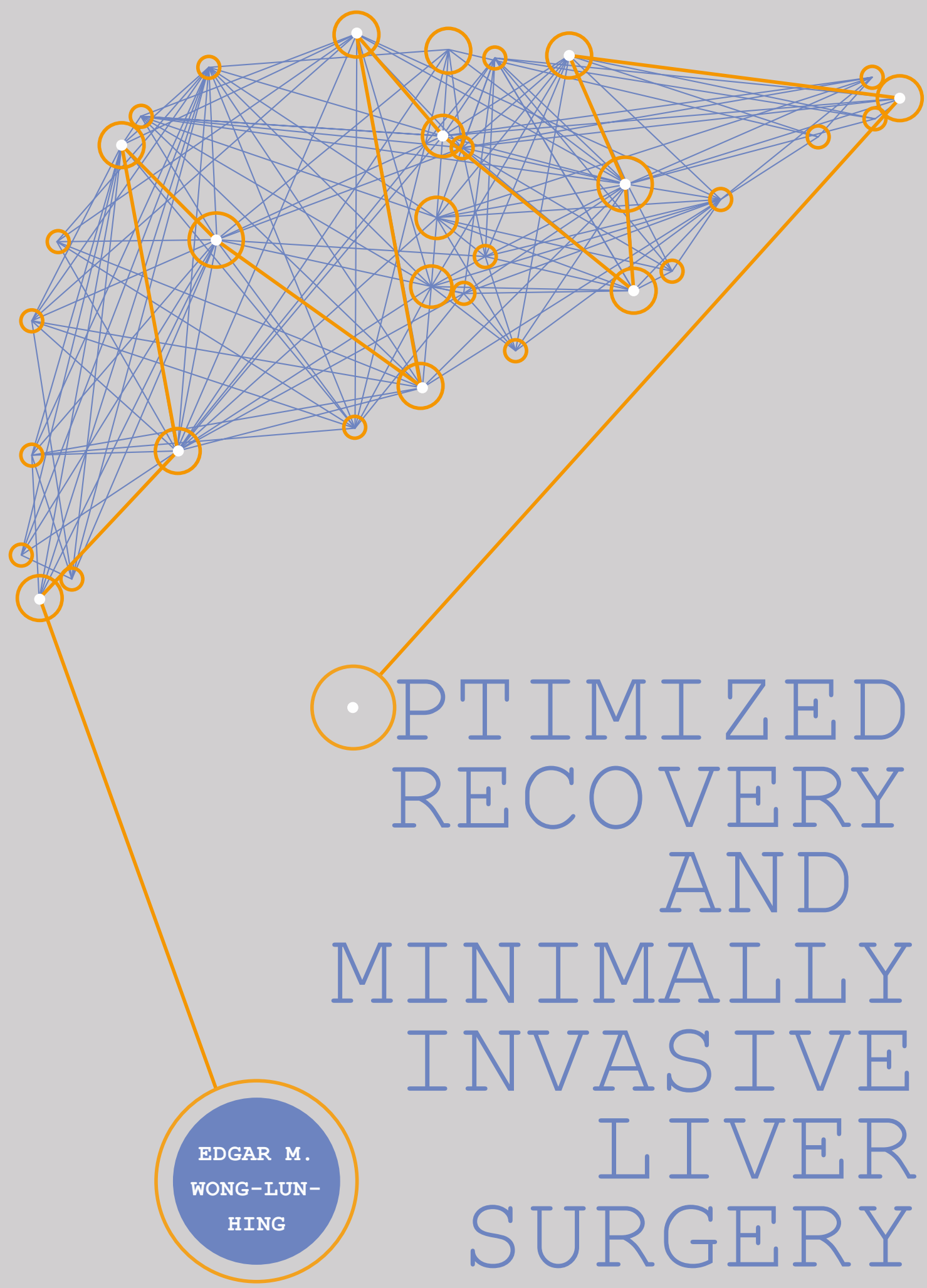


Parts of the research described in this thesis were financially supported by grants from Profiling Fund (Maastricht UMC+) and EAES Research. The author of the thesis was funded by NUTRIM, School for Nutrition, Toxocology and Metabolism of Maastricht University.

Cover: Juul Langenberg Lay-out: Datawyse, Universitaire Pers Maastricht Printed by: Datawyse, Universitaire Pers Maastricht ISBN: 9789461596918

๑) E.M. Wong-Lun-Hing, 2017

All rights reserved. No part of this publication may be reproduced, stored in a retrieval system or transmitted in any form or by any means, without permission of the author, or, when appropriate, of the publishers of the publications.

The publication of this theis was financially supported by: Applied Medical, Nutricia, Covidien, ChipSoft, JBA, Afdeling Chirurgie Jeroen Bosch Ziekenhuis, NUTRIM, Maastricht University, MEMIC and CTCM. 


\title{
OPTIMIZED RECOVERY AND MINIMALLY INVASIVE LIVER SURGERY
}

\author{
PROEFSCHRIFT \\ Ter verkrijging van de graad van doctor \\ aan de Universiteit Maastricht, \\ op gezag van de Rector Magnificus, Prof. dr. Rianne Letschert, \\ volgens het besluit van het College van Decanen, \\ in het openbaar te verdedigen \\ op vrijdag 19 mei 2017 om 12:00 uur \\ door \\ Edgar Marinus Wong-Lun-Hing \\ geboren op 22 september 1984 te 's-Hertogenbosch
}


Promotor

Prof. dr. C.H.C. Dejong

\section{Copromotor}

Dr. R.M. van Dam

Beoordelingscommissie

Prof. dr. G.L. Beets (voorzitter )

Dr. M.T. de Boer (UMCG)

Prof. dr. W.F.F.A. Buhre

Prof. dr. R.W.J. van der Hulst

Prof. dr. J.N. Primrose (University Hospital Southampton) 


\section{TABLE OF CONTENTS}

Chapter 1 General introduction and outline of thesis

Part I OPTIMIZED RECOVERY AFTER HEPATIC SURGERY

Chapter 2 A survey in the hepatopancreatobiliary community on ways to enhance patient recovery

Chapter 3 A systematic review of outcomes in patients undergoing liver surgery in an enhanced recovery after surgery pathways

Chapter 4 Is current perioperative practice in hepatic surgery based on enhanced recovery after surgery (ERAS) principles?

Chapter 5 Post-operative pain control using continuous i.m. bupivacaine infusion plus patient-controlled analgesia compared with epidural analgesia after major hepatectomy

Chapter 6 Abandoning prophylactic abdominal drainage after hepatic surgery: 10 years of no-drain policy in an ERAS environment

Part II IAPAROSCOPIC LIVER SURGERY

Chapter 7 Laparoscopic liver resection in the Netherlands: how far are we?

Chapter 8 Open versus laparoscopic left lateral hepatic sectionectomy within an enhanced recovery ERAS programme (ORANGE II - Trial): study protocol for a randomised controlled trial

Chapter 9 Randomised controlled trial of open versus laparoscopic left lateral hepatic sectionectomy within an enhanced recovery ERAS ${ }^{\circledR}$

programme (ORANGE II - Study)

Chapter 10 Open versus laparoscopic hemihepatectomy within an ERAS programme (ORANGE II PLUS - Trial): study protocol for a randomised controlled trial 
Chapter 11 Summary, discussion and future perspectives

Chapter 12 Nederlandse samenvatting

Chapter 13 Valorisation

233

Dankwoord

237

List of Publications

243

Curriculum Vitae

247 
Chapter

General introduction and outline of thesis 



\section{SECTION 1: LIVER SURGERY}

Partly adapted from "Laparoscopic liver surgery in the Netherlands: how far are we?" Dig Surg. 2012;29(1):70-8.

\section{HISTORY OF LIVER SURGERY AND ANATOMY}

For any type of surgical intervention intricate knowledge and understanding of the anatomy is of key importance. This is also true for liver surgery. Ancient Mesopotamian clay liver models were the first to describe the liver anatomy.[1] Among the early pioneers in the field of liver surgery were Glisson, Wendel and Cantlie[2, 3], but the first "real" liver resection was performed by Langenbuch in 1887.[4, 5] It took until the 1950 's before a detailed understanding of liver anatomy became available through the work of Couinaud.[6] He made casts of the liver and found that the liver could be divided into eight segments based on the portal and hepatic vein blood distribution. Each segment is numbered and has its own specific in- and outflow structures: portal triad and hepatic vein. The portal vein divides the liver into inferior and superior segments, whereas the hepatic veins demarcate the right and left hepatic lobes. The right lobe is divided by the right hepatic vein into an anterior and posterior segment. The left hepatic vein divides the left lobe into the medial and lateral segments. In the portal triad itself an efferent bile duct and an afferent hepatic artery and portal vein (Figure 1) can be recognised. This understanding now forms the basis of modern functional and surgical liver anatomy.[5]

There are now two widely accepted terminology systems: the Bismuth[7] and Brisbane $2000[8,9]$ nomenclature. They both have evolved from Couinaud's and Takasaki's[10] work, but the suggested nomenclatures are still not completely appropriate and both require further revisions. The nomenclatures still contain segmentations that are inappropriate for embryological and surgical reasons. There is a demand for a uniform nomenclature.[11]

Two other major developments that made liver surgery evolve into a widely accepted intervention were the introduction of ultrasound and the improved control of bleeding. With ultrasound during surgery clinicians were able to find small liver tumours[12] and the anatomy of biliary and vascular structures could be exactly defined[13-15] and allowed anatomical resections.[16] Control of bleeding during hepatic surgery added to increased safety and can be achieved in various ways, but depends on the quality of the liver parenchyma, characteristics of the tumour to be resected and of course the preference and experience of the surgeon. Most techniques have arisen from the original Pringle maneuver[17] and can be divided into inflow occlusion alone or combined in- and outflow occlusion. The most commonly 
used occlusion methods are hepatic pedicle clamping (continuous or intermittent Pringle maneuver $[18,19])$ and selective inflow occlusion (segmental or hemihepatic $[20,21])$. Occasionally, e.g. in cases of extreme bleeding or major liver resection, also total or selective hepatic vascular exclusion (THVE or SHVE, inflow and outflow occlusion of the whole liver or the lobe to be resected), or hepatic vascular exclusion with preservation of caval flow (HVEPC).can be used.[22-24]

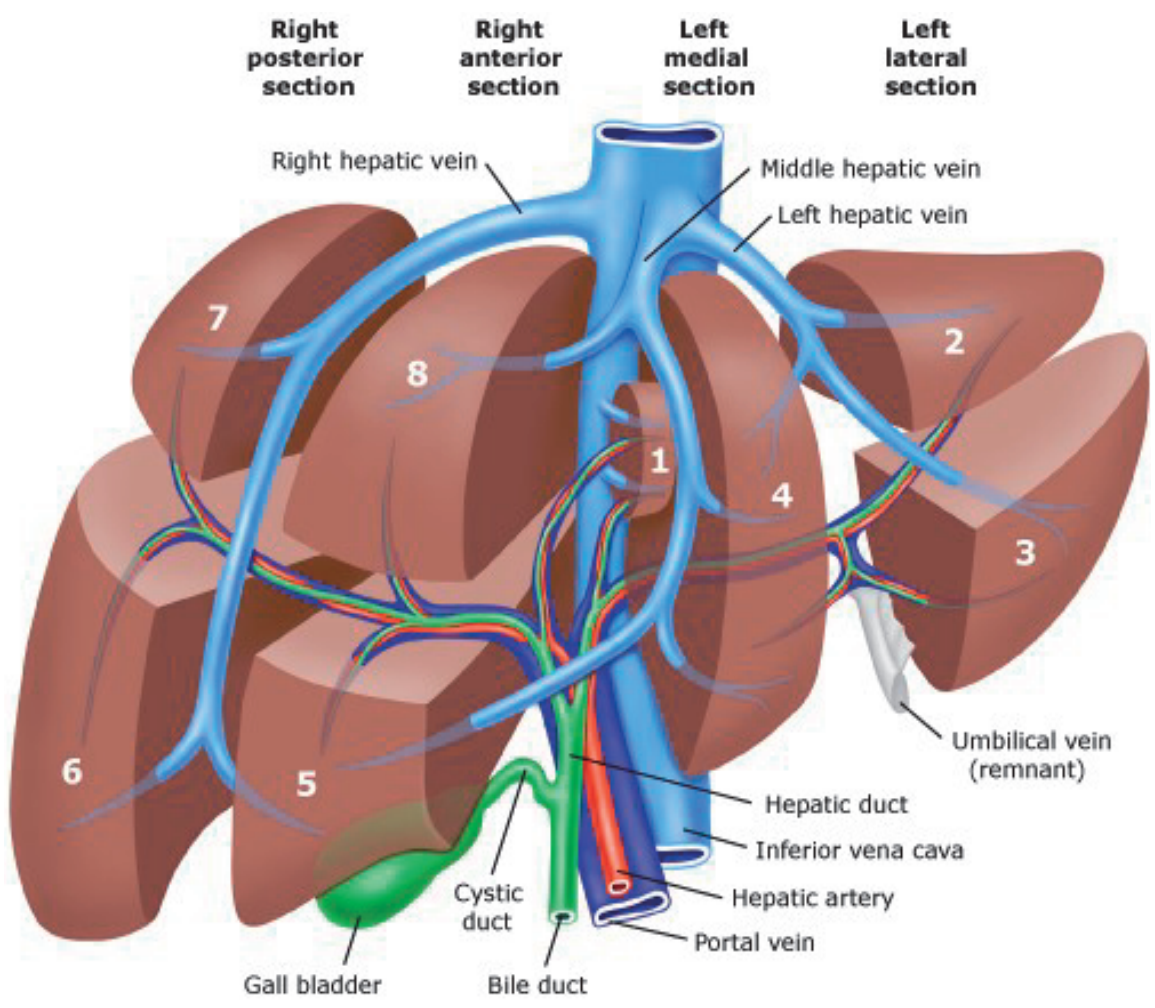

Figure 1. Segments of the human liver and current surgical nomenclature of liver sections.

Reprinted with permission from Macmillan Publishers Ltd:, Siriwardena A.K. et al. Management of colorectal cancer presenting with synchronous liver metastases, Nature Reviews Clinical Oncology, 11(8):446-59, 2014

Technology has driven the majority of advances in surgery over the past decade. At first significant advantages (e.g. smaller incisions, fewer incisional hernias and adhesions, reduced post-operative morbidity) that laparoscopy brought to performing gallbladder surgery were recognized, and along came the desire to apply this innovation in surgery to all operations, limited only by the imagination and the surgeon's technical ability.[25] Until fairly recently, only open liver resections were performed, but during the last decade of the 20th century the first laparoscopic liver resections were successfully completed. No prospective or randomised controlled evidence to 
support a wide adoption of the laparoscopic technique in liver surgery is available, but many expert centres have retrospectively shown benefits in liver surgery. The assumed benefits will be discussed later in this chapter.

The surgical anatomy for laparoscopic hepatectomy is in principle the same as during open procedures. However, the minimally invasive approach can be more difficult due to a lack of experience compared to open liver surgery, even if surgeons have prior laparoscopic experiences. The difference in access to the abdominal cavity and the resulting difference in intra-abdominal perspective, with a more caudate view from videoendoscope to the surgical field, require surgeons to operate in difficult angles with instruments that only allow for limited range of motion and tactile feedback. In addition, the laparoscopic approach further limits optimal exposure by presenting a two-dimensional image to the surgeon.

Laparoscopic resection for tumours located in the posterior parts of the liver (segments: I, VI and VII) is more difficult than for tumours in anterior locations (segments: II, III, IV, V, VIII).[26-30] The difficulties relate to maintaining hemostasis at the transection plane, controlling hemorrhage, mobilizing the liver and visualizing and working within the deeper regions of the liver.[27, 31-35] Essential for laparoscopic liver surgery is the positioning of trocars and adequate mobilization of the liver. This not only depends on the location of the tumour $[26,36]$ and the type of resection to be performed, but also on the surgeon's preference. For laparoscopic procedures of anterior segments the laparoscope is usually inserted at the umbilicus, and two to four trocars for manipulation are additionally placed.[27, 36, 37] For resection of the superior or posterior segment of the right hepatic lobe, a lateral approach is considered more convenient.[27, 38] Key to success in all procedures is to achieve triangulation for good access and visualization of the liver anatomy.

\section{RELUCTANCE OF DUTCH SURGEONS}

Compared to countries that have traditionally always played a pioneering role in liver surgery, such as France, the Netherlands lagged behind concerning the implementation of liver surgery. Many surgeons considered an open partial liver resection to be major surgery, associated with considerable mortality and morbidity. Dutch surgeons remained reluctant to perform this type of surgery.[39] This is illustrated by the fact that only 10 to 130 partial liver resections (including benign tumours) were performed between 1984 and 1987. During the end of the 1980's and 1990's several series on the experience with open hepatic resection were published by different Dutch centres.[40, 41] 
The laparoscopic technique for liver resections was introduced in the Netherlands during the 1990's, but it was mainly used for diagnostic laparoscopies and liver biopsies. Later the indications were extended to fenestration of liver cysts and anatomic liver resections [42-47]. The group of Cuesta et al. was in 1995 the first to report two cases of limited laparoscopic liver surgery of segment II and IV in the Netherlands.[48] In the years thereafter only one article from the same group was published reporting on a series of laparoscopically operated patients $(n=10)$. A few years later, in 2001, a small retrospective series $(n=10)$ was published that demonstrated encouraging results concerning operative blood loss, post-operative complications and hospital length of stay after wedge and left lateral hepatectomy. Seven patients underwent a minor laparoscopic resection and three underwent fenestration of hepatic cysts. The authors concluded that laparoscopic treatment should be considered in selected patients with benign and malignant lesions in the left lobe or anterior segments of the liver.[49] The foundation of the Dutch Liver Collaborative Group in 2003 gave a new impulse to minimally invasive liver surgery and after the initial reports on minimally invasive liver surgery three articles were published on laparoscopic treatment of polycystic liver disease.[50-52] Later series of 26 laparoscopic liver resections provided evidence that this procedure could be performed safely in the Netherlands.[53]

\section{OPEN VS. LAPAROSCOPIC HEPATECTOMY}

Today liver surgery is predominantly performed for malignant indications, resection of colorectal liver metastases (CLM) in particular, as it offers the only changes of cure and long-term survival. Operative techniques, chemotherapy and perioperative care have evolved and have resulted in post-operative mortality rates of $<5 \%$, morbidity rates ranging between $30 \%$ and 50\%[54-57], and with 5-year survival rates of approximately 30-60\%.[57-63] The "cure" rate based on actual 10-year survivors is around $25-35 \% .[57,63,64]$

While the first limited laparoscopic liver resection in the Netherlands was performed in 1995, the first laparoscopic liver resections had already been performed 5 years earlier by Reich[65] and Gagner.[66] Four years thereafter, Azagra et al.[67] reported the first anatomic liver resection (segment 2-3 resection). In the following years the minimally invasive technique was further developed and adopted, resulting in the first laparoscopic left lateral sectionectomy for living liver donation[68, 69] and the first reports on robotic liver surgery.[70, 71] Initially, laparoscopic liver resection was challenging because of the difficulties concerning safe mobilization and exposure of this fragile and heavy organ.[35, 72, 73] In expert centres laparoscopic resection of benign liver tumours seemed feasible and safe.[38, 74] Also for malignant tumours there appeared to be a benefit with regards to short-term post-operative outcomes and adequate surgical margins could be achieved.[75, 76] Surgeons with extensive 
experience in laparoscopy and hepatic surgery have also performed laparoscopic major hepatic resections with satisfactory outcomes.[47, 77, 78]

Overall the quality of evidence on the merits of laparoscopic liver surgery is low (GRADE C).[79] Reviews by Nguyen et al. and Reddy et al. showed favourable outcomes after laparoscopic resection.[80, 81] Patient benefits included less operative blood loss[31, 82], less post-operative pain[27, 33, 83] and narcotic requirement, improved cosmetic aspects[27, 28], and a shorter length of hospital stay[27, 28, 33, 8285 ] with post-operative morbidity and mortality comparable to open liver resection. In addition, the minimally invasive approach seems to be cost-effective.[86, 87] The decreased cost is based on savings in hospital ward costs and likely related to a significantly shorter hospital stay for laparoscopic liver surgery.[88] Potential limitations and disadvantages of laparoscopic liver resection include a considerable learning curve, potential bleeding which may be more difficult to control laparoscopically, inadequate assessment of the liver for additional lesions, and increased risk for gas embolism.[81, 89] Carbon dioxide (CO2) embolism may occur when high-pressure pneumoperitoneum is used. $[72,90]$ However, $\mathrm{CO} 2$ embolism is rare and usually well tolerated, as the gas dissolves rapidly.[83] Other concerns have been raised about the potential dissemination of malignant cells during laparoscopic resection.[91-93] Some authors have suggested that tumour dissemination does not increase by laparoscopy[32, 94, 95], and recent reports regarding this subject show long term survival rates comparable with open surgery. $[28,73,75,96]$ In line with this, during a consensus meeting of over 300 experts in 2008 (The Louisville Statement), it was concluded, based on the available evidence and expert opinions, that laparoscopic liver surgery was a safe and effective approach to the management of surgical liver disease in the hands of trained surgeons with experience in hepatobiliary and laparoscopic surgery. However, the experts also concluded that there is still a need for controlled prospective trials, and that prudent dissemination is warranted with adequate training standards and credentialing to ensure consistent standards and clinical outcomes.[97]

In parallel to these refinements in surgical technique, considerable changes in perioperative care were witnessed in the last decade of the previous millennium. Among these was the introduction of multimodal perioperative care, which will be addressed in the next section. 


\section{SECTION 2: ENHANCED RECOVERY AFTER SURGERY (ERAS ${ }^{\circledR}$ )}

\section{MULTIMODAL CARE PROGRAMME}

The concept of a multimodal approach in perioperative surgical care originated from the Danish surgeon Henrik Kehlet. During the 1990's he pioneered in this field by investigating the surgical stress response caused by anaesthesia or analgesia[98-100] and the influence of exercise on post-operative fatigue.[101] By continuing his efforts he became the first to describe a combination of several elements in a multimodal protocol that reduced post-operative surgical stress-induced dysfunction and morbidity.[102-104]

His work culminated in the publication of a multimodal "fast-track" strategy that optimized several aspects of the perioperative management of patients undergoing major abdominal surgery[105-107] and the foundation of the Enhanced Recovery After Surgery (ERAS ${ }^{\circledR}$ ) collaboration of five European centres in 2001. The ERAS protocol consists of about 20 elements during the pre-, intra- or post-operative phase, see Figure 2. At first this fast-track concept was explored and tested in colorectal surgery. Several groups have since then demonstrated that recovery could be accelerated with reduced length of hospital stay and post-operative morbidity in colorectal surgery.[108-119] Consequently, these results were bundled with expert opinions in evidence-based consensus guidelines in 2005[117] and 2009[120].

\section{ERAS $^{\circledR}$ ELEMENTS}

Encouraged by good results in colorectal surgery[119] liver surgeons of the ERAS ${ }^{\odot}$ group in Maastricht, Edinburgh and Tromsö undertook to implement the ERAS concept for patients undergoing open hepatic resection. Elements in the protocol were evaluated and adjusted to provide optimal care to liver surgical patients. Each item of the ERAS liver programme is presented below with a recommendation based on scientific evidence.

\section{PREOPERATIVE EDUCATION}

During counselling there should be emphasis on the recovery period and expectations of the patient, concerning pain control, early mobilization, resumption of intake and time of discharge. This has been demonstrated to allow earlier recovery.[121124] Patients exhibiting denial or anxiety can also profit from extensive counselling. $[125,126]$ 

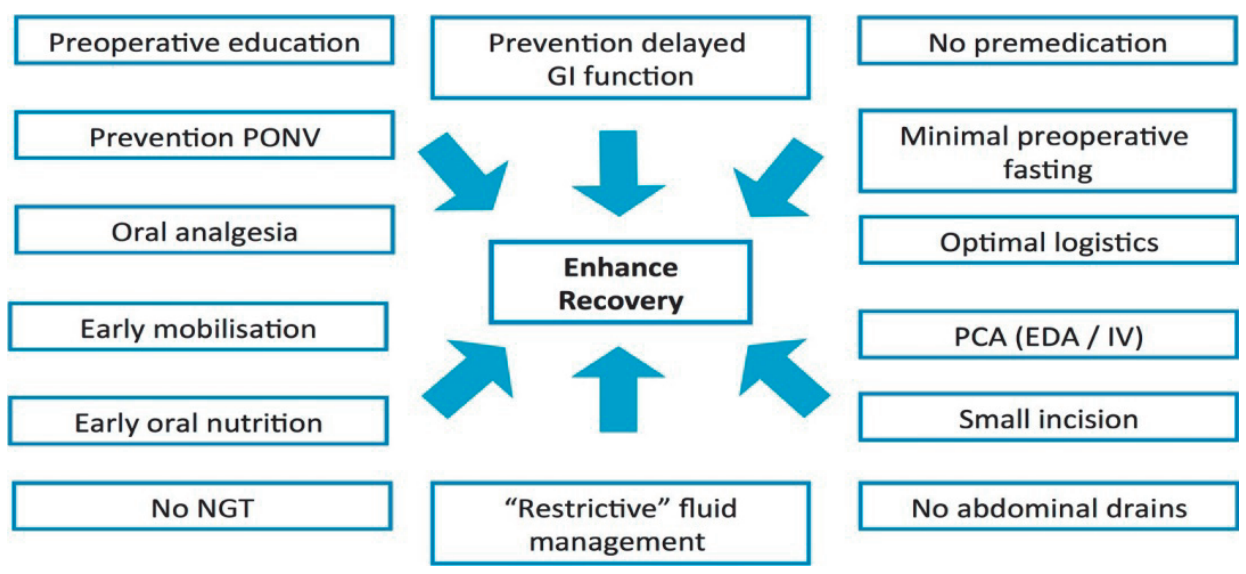

Figure 2. Elements of the ERAS liver programme

\section{PREOPERATIVE FASTING \& CARBOHYDRATE LOADING}

Where patients used to be denied intake of food from the night before surgery, it is now generally recommended to allow patients to be fasted for liquids only for 2 hours and for solids for 6 hours preoperatively.[127-129] Reviews have demonstrated that preoperative fasting does not prevent complications, e.g. aspiration. [130, 131] On the contrary, patients able to have a normal preoperative intake are in a more anabolic state to benefit from post-operative nutrition and have less risk of insulin resistance and post-operative hyperglycaemia.[132-134]

\section{PREANAESTHETIC MEDICATION}

Provision of long-acting anxiolytic premedication could negatively influence gastrointestinal motility and, although it is safe to use short-acting benzodiazepines in day surgery[135], its efficacy for major surgery remains unclear. Patients who receive sleeping medication at home can continue this in hospital. In addition, analgesic premedication has no demonstrated effect on post-operative pain relief.[136]

\section{ANTITHROMBOTIC PROPHYLAXIS}

As for most major surgical procedures, antithrombotic prophylaxis should be provided in liver surgery. Low molecular weight heparin (LMWH) has been demonstrated to be safe and effective[137-140] and should be preferred over unfractionated heparin due to an increased compliance.[141] It has even been proposed to prolong thromboprophylaxis with LMWH after major abdominal or pelvic surgery since it significantly reduces the risk of venous thromboembolism (VTE) without increasing mor- 
bidity. However, with an increased number of minimally invasive surgical procedures and the current trend for fast-track recovery the risk of post-operative VTE may be lower.[142] However, there is the risk of developing an epidural hematoma when epidural analgesia is used. Prophylactic doses of LMWH should be given no later than 12 hours prior to insertion and removal of epidural catheters.[143, 144] An alternative to LMWH thrombotic prophylaxis, so called mechanical prophylaxis (elastic compression stockings), can also be (additionally) used until patients are fully mobilized.

\section{ANTIBIOTIC PROPHYLAXIS}

The optimal antibiotic regimen has not been described, but prophylaxis should be active against both aerobic and anaerobic bacteria. In colorectal surgery it has been frequently demonstrated that antibiotic prophylaxis is effective in reducing infectious complications.[145] Two studies investigating the use of antibiotic prophylaxis after liver surgery have shown contradicting data.[146, 147] However, for hepatectomy (clean-contaminated surgery) antimicrobial prophylaxis may be essential, because of the relatively long operation time and relatively large blood loss.[148] A systemic infection after liver surgery can lead to liver failure, as sepsis could further jeopardize the liver function, already at risk after major resection. In addition, hyperglycemia induced by surgical stress and reduced liver function may cause dysregulation of liver metabolism and immune function resulting in adverse post-operative outcomes.[149] Newer generations of antibiotics should be avoided and reserved for secondary infectious complications.

\section{ANAESTHESIA}

The optimal anaesthetic method for liver resection is yet to be described in literature, however it is important to provide well balanced anaesthesia. The hepatic clearance of drugs may be diminished after parenchymal resection.[150] A frequently used technique is intravenous induction of anaesthesia with short-acting drugs like propofol and remifentanil[151], and maintenance of anaesthesia with a volatile agent such as isoflurane or sevoflurane.[152] Infusion of fluids should be restricted until after the parenchymal resection. Peripheral vasodilatation may be helpful to lower the central venous pressure $(<5 \mathrm{mmHg})$ as this has been associated with decreased blood loss. Also, vasopressors like phenylephrine or norepinephrine may be considered to maintain an adequate mean arterial blood pressure.[153] Intraoperative use of epidural analgesia has not been shown to improve recovery after liver surgery, but it may prevent gastrointestinal paralysis[154, 155], block stress hormone release and attenuate post-operative insulin resistance.[156] 


\section{INTRAOPERATIVE FLUID MANAGEMENT}

The discussion on optimal intraoperative i.v. fluid management is currently hotly debated. Post-operative complication rates and hospital stay seem to be reduced after elective surgery, if patients are not fluid overloaded and are only subjected to more restrictive, but balanced fluid therapy.[157-159] The problem lies in the type of protocol that needs to be followed (definition of restrictive management) and in the way of monitoring the response to fluid administration. Especially during major hepatectomy it necessary to expand the intravascular volume, but maintain a low central venous pressure (CVP). A high CVP may increase blood loss, transfusion requirements and length of hospital stay.[160] From a surgical perspective, CVP monitoring is recommended to minimize back bleeding during parenchymal transection (CVP $<5 \mathrm{mmHg}$ )[161-164] and anaesthesiologists use it to avoid the administration of excessive IV fluids.[159] It may however not be necessary at all to monitor the CVP and less invasive and peripheral monitoring may be sufficient to provide adequate fluid management.[153, 165-167] A monitoring device to consider for use and recommended in a guideline of the National Institute for Health and Care Excellence (NICE) is the CardioQ-ODM (Deltex Medical). This device assesses cardiac output and intravascular fluid status. The available data support a clinical benefit and a cost saving when the CardioQ-ODM is used in patients undergoing major or high-risk surgery in whom a clinician would consider using invasive cardiac monitoring.[168]

\section{PREVENTION OF INTRAOPERATIVE HYPOTHERMIA}

Maintenance of intraoperative normothermia (>36 OC) is an important target. Hypothermia is known to induce endocrine-metabolic responses and sympathetic reflexes, and negatively affects the fibrinolytic-coagulatory balance resulting in increased bleeding. Infusion of warmed fluids and use of upper-body forced-air heating covers has demonstrated to help maintain a normal body temperature. This resulted in fewer wound infections[169], less cardiac complications[170] and reduced bleeding and transfusion requirements.[171]

\section{POST-OPERATIVE NAUSEA AND VOMITING (PONV) PROPHYLAXIS}

To enable an early start of intake after surgery and to facilitate a quick return to a normal diet it is important to identify possible risk factors (e.g. history of motion sickness or PONV, female sex, opioid analgesia, certain volatile anaesthesia) that may induce nausea and vomiting.[172, 173] Convincing evidence is available to suggest that several drugs, such as cyclizine, droperidol, granisetron, metoclopramide, ondansetron and dexamethasone, reduce PONV. Treatment should be given using a multimodal approach and should be based on the risks per individual patient.[174, 175] 


\section{SURGICAL INCISIONS}

The type and length of the incision used for surgery may affect patient recovery.[176] Transverse or curved incisions may reduce pain, pulmonary dysfunction and incidence of incisional hernia after abdominal procedures [177, 178], while other trials have found no advantage of transverse incisions.[179, 180] It is also to be expected that laparoscopic resections will lead to a lower incidence of incisional hernia compared with the open surgical technique.[181] Depending on the type of hepatic resection a bilateral subcostal or J-shaped incision can be used to gain sufficient access. The length of incision should be reduced to an incision of minimum length.

\section{USE OF INTRA-ABDOMINAL DRAINS AND SEALANTS}

Drainage of the peritoneal cavity after elective liver surgery is still routinely used. Advantages of drain placement, such as removal of bile due to leakage and tissue debris to prevent subphrenic infection, detection of post-operative haemorrhage and removal of ascites in patients with liver cirrhosis, have been reported.[182, 183] Other studies have indicated that the risks (high rates of intra-abdominal and wound infections by retrograde contamination, impaired pulmonary function, increased pain and discomfort) may be greater than the benefits.[184] A meta-analysis by Gurusamy et al [185] showed that there were no significant differences in morbidity, mortality and reoperation rates between patients with or without an abdominal drain after uncomplicated elective hepatic surgery. Alternatives to prevent leakage of bile or blood in the form of sealants applied to the resectional plane of the liver have not been proven to be of additional value.[186] Therefore, drains and sealants should no longer be used as a standard. If a drain is placed, close monitoring of the drain production is needed to allow removal as quickly as possible.

\section{NASOGASTRIC INTUBATION}

After liver surgery nasogastric tubes (NGT) should not be used routinely. Evidence has clearly demonstrated that routine nasogastric decompression must be avoided. $[187,188]$ The use of an NGT is even associated with an increased risk of developing post-operative pulmonary complications.[189, 190] If a tube is placed it should be removed immediately after surgery.

\section{POST-OPERATIVE ANALGESIA}

Post-operative pain control should aim at sparing opioids.[191] Effective analgesia may reduce the incidence of post-operative complications and may facilitate early recovery and mobilization.[106, 192] Epidural analgesia has been considered superi- 
or to patient-controlled intravenous analgesia for post-operative pain relief after major upper abdominal operations[154, 193] and may reduce pulmonary morbidity.[194] However, the use of epidural analgesia after hepatectomy is still debated. Epidural analgesia may not function adequately in up to $30 \%$ of the patients[195] and can lead to serious complications (epidural abscess or haematoma[196]). Therefore, other analgesic options must not be excluded. Safe and effective alternatives to epidural analgesia after liver surgery are wound catheters with a local anaesthetic[197-199] or intrathecal morphine.[200, 201] If a mid-thoracic epidural analgesia is used, evidence has indicated that removal after a two-day period is feasible.[202] Additional combined oral analgesia (paracetamol and an non-steroidal antiinflammatory drug) should be standardly provided, although the synergetic effect for major abdominal procedures has yet to be established.[203, 204]

\section{PREVENTION OF POST-OPERATIVE ILEUS}

Delayed gastrointestinal functioning should be prevented, as it is an important cause of delayed discharge after abdominal surgery. No single approach has demonstrated the ability to prevent or treat post-operative ileus.[205, 206] Interventions that may help are avoidance of preoperative fasting[207, 208] and avoiding mechanical bowel preparation[209], use of epidural-local anaesthetics[154], avoidance of fluid overload[159], implementation of minimally-invasive surgical techniques[210], use of oral magnesium oxide ( $1 \mathrm{~g}$ twice daily commenced on the evening of surgery and used until discharge)[202, 211], coffee intake[212], use of chewing gum [213]and modification of pain management strategies to limit opioid administration.[214, 215]

\section{URINARY CATHETER}

If epidural catheters are used, patients are also given urinary catheters to avoid urinary retention. However, the risk of urinary retention after only 24 hours urinary bladder catheterisation has been reported to be low and removal of catheter the day after surgery does not seem to increase the recatheterisation rate.[216, 217] Other studies support the use of suprapubic bladder drainage instead of urethral catheterisation. Suprapubic catheters are associated with lower rates of urinary tract infection and less discomfort in patients undergoing abdominal surgery.[218-220] It is recommended to use urinary bladder drainage for the duration of thoracic epidural analgesia. Earlier removal of urinary drainage may be considered before the epidural is stopped to allow early mobilization. 


\section{START OF ORAL INTAKE}

Denying patients early feeding and keeping them on a 'nil by mouth' regimen has no clear advantage. A quick return to a normal diet has been shown to be safe for both major upper abdominal, colorectal and liver surgery and it may reduce the risk of infection and length of hospital stay.[188, 221-223] In 2009 the European Society for Clinical Nutrition and Metabolism (ESPEN) has advised to manage patients in modern surgical practice within an enhanced recovery protocol and thereby have them eating normal food within 1-3 days. Also, routine perioperative nutritional supplementation is advised to be only used for patients with severe preoperative undernutrition or in patients who cannot meet their caloric requirements within 7-10 days after surgery.[224]

\section{MOBILISATION}

Early mobilization is essential to prevent increased insulin resistance and muscle loss, decreases muscle strength, pulmonary function, and tissue oxygenation[113], and to decrease the risk of thromboembolism. However, this can only be facilitated with adequate post-operative pain control and, if possible, absence of abdominal drains and urinary catheters. Therefore, daily goals for mobilization with assistance from nurses or physiotherapists must be defined.

\section{ERAS PROGRAMME FOR LIVER SURGERY}

In line with earlier results from colorectal surgery, van Dam et al. [225] and Koea et al.[201] showed a significantly reduced length of hospital stay when patients were managed within a multimodal enhanced recovery programme for liver surgery. In addition to this, a further reduction in length of stay was possible when patients undergoing liver surgery were operated laparoscopically.[53]

Considering the aforementioned evidence for the specific perioperative care elements, a multimodal evidence-based ERAS programme for liver surgery can be proposed. Table 1 shows a summary of the elements with their respective level of recommendation. If these elements are combined with clear discharge criteria and adequate minimization of delay after functional recovery[226] (often linked to social or logistic problems or problems in homecare support), patients may be offered the optimal strategy for a safe and rapid recovery and consequent discharge. 
Table1. ERAS liver programme recommendations

\begin{tabular}{|c|c|c|}
\hline Element & Evidence level & Recommendation grade \\
\hline Preoperative counselling & B & Strong \\
\hline Minimal preoperative fasting & B & Strong \\
\hline No pre-anaesthetic premedication & B & Moderate \\
\hline Antithrombotic prophylaxis & A & Strong \\
\hline Antibiotic prophylaxis & A & Strong \\
\hline Balanced anaesthesia with short-acting agents & C & Strong \\
\hline Epidural anaesthesia / analgesia & B & Weak \\
\hline Balanced intraoperative fluid management & A & Strong \\
\hline Prevention of hypothermia & A & Strong \\
\hline PONV prophylaxis & B & Strong \\
\hline Incision of minimal length & C & Strong \\
\hline No routine drainage of the peritoneal cavity & C & Low \\
\hline No nasogastric drainage & A & Strong \\
\hline Provision of oral analgesia & A & Strong \\
\hline Prevention of post-operative ileus & B & Moderate \\
\hline Early removal of urinary catheter & D & Weak \\
\hline Early start oral intake & A & Strong \\
\hline Early mobilisation & C & Moderate \\
\hline
\end{tabular}

Quality of evidence and recommendations were evaluated according to the GRADE guidelines[227]: $A=$ High, $\mathrm{B}=$ Moderate, $\mathrm{C}=$ Low, $\mathrm{D}=$ Very low.

\section{SECTION 3: EVIDENCE-BASED MEDICINE (EBM) IN SURGERY}

Performing surgery and providing perioperative care based on evidence-based principles[228] has not always been standard. An EBM approach has been lacking for years and there are still many surgeons and centres that work with dogmatic routines for which often no evidence is available, rather than routines based on sound research and evidence. In 1996 Horton[229] already described the absence of well designed studies in the surgical community. A vast majority of research articles published in surgical journals at that time were case series. Nowadays we value case series as the weakest evidence available. Therefore, a large proportion of early surgical literature may be considered to be of questionable value.[229]

Slowly the opinion and attitude of surgeons has changed, and the evidence-based approach is now part of daily practice in various fields of surgery by quality improvements through well-designed trials, study groups, auditing[230-235] and adoption of consensus guidelines.[97, 117, 236-242] Many surgeons are eager to try and adopt new techniques. Minimally invasive surgery has become popular among surgeons. 
This is of course inherent to the aim of improving surgical techniques and outcome, but should not lead to over enthusiastic adoption and dissemination of innovations without good evidence. A good example of this so-called overadoption is the laparoscopic cholecystectomy. This procedure was quickly adopted and became the dominant technique for removal of the gallbladder with no or ambiguous evidence in favour of it and increase in procedure related morbidity.[243] Nowadays it is seemingly without a doubt that laparoscopic cholecystectomy is to be preferred over open cholecystectomy, however the route to this adoption is questionable. Practice in the surgical community should be driven by evidence first with high respect for patient safety and surgeon preference should come second. In liver surgery a similar trend can be observed. Despite the consensus that laparoscopic liver surgery is only safe and effective in experienced hands and the urgent need for trials providing level A evidence[97], many surgeons have started to use the technique without evidence to support this. Not only are there no definitive conclusions regarding the short-term efficacy of laparoscopic liver resection, but also data on oncological outcomes, such as survival and resection margins, costs, patient-reported outcomes and incidence of incisional hernia are inconclusive or have yet to be presented.

The opposite may be true for the adoption of an enhanced recovery programme in liver surgery. As described in the previous section of this chapter, perioperative care has changed significantly. The multimodal concept has been extensively studied in colorectal surgery and has disseminated to other disciplines.[53, 225, 244-251] In addition, for most elements in the ERAS programme there is solid evidence.[238] To date such ERAS protocols seem underadopted, also in hepatic surgery. In many centres a formal standardized care pathway has not been implemented and, although some evidence-based elements may be adopted as part of "modern" current practice, perioperative care can still be further optimized to attenuate stress, improve recovery, lower morbidity and improve cost efficiency.[226]

The surgical community has become aware that it is necessary to improve surgical practice based on properly obtained data and to develop methods to implement this evidence.[252] Standardization of surgical techniques and perioperative care based on evidence will help to eliminated bias and confounding, will allow comparison in trials and will increase the external validity of study results. Surely, as is known from literature and the different elements in the ERAS programme, there is abundant knowledge available. Urbach et al.[253] have nicely stipulated: "The immediate challenge to improving the quality of surgical care is not discovering new knowledge, but rather how to integrate what we already know into practice". The delay of integrating this evidence in practice is multifactorial and may be dependent on the professional setting (attitude and culture), patients, organization of care processes, resources, leadership, cultural and social settings, and the political environment.[254, 255] 


\section{SECTION 4: OUTLINE OF THE THESIS}

The aim of this thesis was to explore the current role, dissemination and worldwide adoption of an ERAS programme in liver surgery, to investigate and evaluate the potential role of specific (new) elements of the ERAS programme, to evaluated the implementation status of (laparoscopic) liver surgery from a Dutch as well as an international perspective, and to compare open and laparoscopic liver surgery in a randomised controlled setting.

\section{PART I: OPTIMIZED RECOVERY AFTER HEPATIC SURGEY}

We explore the role of the ways to enhanced patient recovery with an international survey (Chapter 2). A systematic review of patients undergoing liver surgery in an enhanced recovery after surgery pathways systematically examines the outcome (Chapter 3). We evaluate whether the current perioperative practice in hepatic surgery is actually based on the ERAS principles (Chapter 4). The last two chapters of part I of this thesis explore specific elements of the ERAS programme: post-operative analgesia and abdominal drainage. We explore an alternative for epidural analgesia after major hepatectomy (Chapter 5). Finally, we describe and investigate the results of a standard no-drain policy after hepatectomy (Chapter 6).

\section{PART II: LAPAROSCOPIC LIVER SURGERY}

In the second part of this thesis we provide a systematic review on the introduction of laparoscopic liver surgery, investigate the initial experience with laparoscopic liver resections and report on the current status of laparoscopic liver surgery in the Netherlands (Chapter 7). In the aim to compare open and laparoscopic liver surgery in a randomised controlled study we present the study protocol for the ORANGE II - Trial and the primary results (Chapter 8 -9). Finally, we present the protocol of an ongoing RCT comparing open versus laparoscopic hemihepatectomy within an ERAS programme (Chapter 10). 


\section{REFERENCES}

1. Cavalcanti de, A.M.A. and C. Martins, History of liver anatomy: Mesopotamian liver clay models. HPB (Oxford), 2013. 15(4): p. 322-3.

2. Foster, J.H., History of liver surgery. Arch Surg, 1991. 126(3): p. 381-7.

3. van Gulik, T.M. and J.W. van den Esschert, James Cantlie's early messages for hepatic surgeons: how the concept of pre-operative portal vein occlusion was defined. HPB (Oxford), 2010. 12(2): p. 81-3.

4. Hardy, K.J., Liver surgery: the past 2000 years. Aust N Z J Surg, 1990. 60(10): p. 811-7.

5. Bismuth, H., R. Eshkenazy, and A. Arish, Milestones in the evolution of hepatic surgery. Rambam Maimonides Med J, 2011. 2(1): p. e0021.

6. Couinaud, C., Lobes et segments hépatiques. Presse Med, 1954. 62:709.

7. Bismuth, H., Revisiting liver anatomy and terminology of hepatectomies. Ann Surg, 2013. 257(3): p. 383-6.

8. Strasberg, S.M., Nomenclature of hepatic anatomy and resections: a review of the Brisbane 2000 system. J Hepatobiliary Pancreat Surg, 2005. 12(5): p. 351-5.

9. Strasberg, S.M. and C. Phillips, Use and dissemination of the brisbane 2000 nomenclature of liver anatomy and resections. Ann Surg, 2013. 257(3): p. 377-82.

10. Takasaki, K., Glissonean pedicle transection method for hepatic resection: a new concept of liver segmentation. J Hepatobiliary Pancreat Surg, 1998. 5(3): p. 286-91.

11. Makuuchi, M., Could we or should we replace the conventional nomenclature of liver resections? Ann Surg, 2013. 257(3): p. 387-9.

12. Gosink, B.B., Evaluation of hepatic neoplasms. AJR Am J Roentgenol, 1980. 134(3): p. 621.

13. Makuuchi, M., H. Hasegawa, and S. Yamazaki, Intraoperative ultrasonic examination for hepatectomy. Ultrasound Med Biol, 1983. Suppl 2: p. 493-7.

14. Makuuchi, M., H. Hasegawa, and S. Yamazaki, [Development on segmentectomy and subsegmentectomy of the liver due to introduction of ultrasonography]. Nihon Geka Gakkai Zasshi, 1983. 84(9): p. 913-7.

15. Bismuth, H. and D. Castaing, [Peroperative echography in hepatobiliary surgery]. Ann Gastroenterol Hepatol (Paris), 1984. 20(4): p. 221-3.

16. Bismuth, H., D. Houssin, and D. Castaing, Major and minor segmentectomies "reglees" in liver surgery. World J Surg, 1982. 6(1): p. 10-24.

17. Pringle, J.H., V. Notes on the Arrest of Hepatic Hemorrhage Due to Trauma. Ann Surg, 1908. 48(4): p. 541-9.

18. van den Broek, M.A., J.G. Bloemen, S.A. Dello, et al., Randomized controlled trial analyzing the effect of 15 or 30 min intermittent Pringle maneuver on hepatocellular damage during liver surgery. J Hepatol, 2011. 55(2): p. 337-45.

19. Dello, S.A., K.W. Reisinger, R.M. van Dam, et al., Total intermittent Pringle maneuver during liver resection can induce intestinal epithelial cell damage and endotoxemia. PLoS One, 2012. 7(1): p. e30539.

20. Castaing, D., O.J. Garden, and H. Bismuth, Segmental liver resection using ultrasoundguided selective portal venous occlusion. Ann Surg, 1989. 210(1): p. 20-3.

21. Goseki, N., S. Kato, S. Takamatsu, et al., Hepatic resection under the intermittent selective portal branch occlusion by balloon catheter. J Am Coll Surg, 1994. 179(6): p. 673-8.

22. Belghiti, J., R. Noun, E. Zante, et al., Portal triad clamping or hepatic vascular exclusion for major liver resection. A controlled study. Ann Surg, 1996. 224(2): p. 155-61.

23. Smyrniotis, V., C. Farantos, G. Kostopanagiotou, et al., Vascular control during hepatectomy: review of methods and results. World J Surg, 2005. 29(11): p. 1384-96.

24. Zhu, P., W.Y. Lau, Y.F. Chen, et al., Randomized clinical trial comparing infrahepatic inferior vena cava clamping with low central venous pressure in complex liver resections involving the Pringle manoeuvre. Br J Surg, 2012. 99(6): p. 781-8.

25. Wernsing, D.S., The evolving role of laparoscopy in the surgical management of oncology patients. COMMUNITY ONCOLOGY, 2006. 3(8): p. 507-511. 
26. Kaneko, H., S. Takagi, and T. Shiba, Laparoscopic partial hepatectomy and left lateral segmentectomy: technique and results of a clinical series. Surgery, 1996. 120(3): p. 468-75.

27. Cherqui, D., E. Husson, R. Hammoud, et al., Laparoscopic liver resections: a feasibility study in 30 patients. Ann Surg, 2000. 232(6): p. 753-62.

28. Gigot, J.F., D. Glineur, J. Santiago Azagra, et al., Laparoscopic liver resection for malignant liver tumors: preliminary results of a multicenter European study. Ann Surg, 2002. 236(1): p. 90-7.

29. Vibert, E., A. Kouider, and B. Gayet, Laparoscopic anatomic liver resection. HPB (Oxford), 2004. 6(4): p. 222-9.

30. Cho, J.Y., H.S. Han, Y.S. Yoon, et al., Feasibility of laparoscopic liver resection for tumors located in the posterosuperior segments of the liver, with a special reference to overcoming current limitations on tumor location. Surgery, 2008. 144(1): p. 32-8.

31. Morino, M., I. Morra, E. Rosso, et al., Laparoscopic vs open hepatic resection: a comparative study. Surg Endosc, 2003. 17(12): p. 1914-8.

32. Laurent, A., D. Cherqui, M. Lesurtel, et al., Laparoscopic liver resection for subcapsular hepatocellular carcinoma complicating chronic liver disease. Arch Surg, 2003. 138(7): 33.p. 763-9; discussion 769.

33. Buell, J.F., M.J. Thomas, T.C. Doty, et al., An initial experience and evolution of laparoscopic hepatic resectional surgery. Surgery, 2004. 136(4): p. 804-11.

34. Dulucq, J.L., P. Wintringer, C. Stabilini, et al., Laparoscopic liver resections: a single center experience. Surg Endosc, 2005. 19(7): p. 886-91.

35. Dagher, I., J.M. Proske, A. Carloni, et al., Laparoscopic liver resection: results for 70 patients. Surg Endosc, 2007. 21(4): p. 619- 24.

36. Han, H.S., J.Y. Cho, and Y.S. Yoon, Techniques for performing laparoscopic liver resection in various hepatic locations. J Hepatobiliary Pancreat Surg, 2009. 16(4): p. 427-32.

37. Otsuka, Y., M. Tsuchiya, T. Maeda, et al., Laparoscopic hepatectomy for liver tumors: proposals for standardization. J Hepatobiliary Pancreat Surg, 2009. 16(6): p. 720-5.

38. Gagner, M., T. Rogula, and D. Selzer, Laparoscopic liver resection: benefits and controversies. Surg Clin North Am, 2004. 84(2): p. 451-62.

39. de Jong, K.P., E.J. Hesselink, J.S. Lameris, et al., [Partial liver resection]. Ned Tijdschr Geneeskd, 1989. 133(48): p. 2381-4.

40. de Jong, K.P., J.D. Blankensteijn, E.J. Hesselink, et al., [Partial hepatectomy for benign or malignant liver diseases; experience in 94 patients]. Ned Tijdschr Geneeskd, 1989. 133(48): p. 2385-8.

41. van Ooijen, B., T. Wiggers, S. Meijer, et al., Hepatic resections for colorectal metastases in The Netherlands. A multiinstitutional 10- year study. Cancer, 1992. 70(1): p. 28-34.

42. Miles, W.F., S. Paterson-Brown, and O.J. Garden, Laparoscopic contact hepatic ultrasonography. Br J Surg, 1992. 79(5): p. 419-20.

43. Cuesta, M.A., S. Meijer, P.J. Borgstein, et al., Laparoscopic ultrasonography for hepatobiliary and pancreatic malignancy. Br J Surg, 1993. 80(12): p. 1571-4.

44. Windsor, J.A. and O.J. Garden, Laparoscopic ultrasonography. Aust N Z J Surg, 1993. 63(1): p. 1-2.

45. Gouma, D.J., L.T. de Wit, E. Nieveen van Dijkum, et al., Laparoscopic ultrasonography for staging of gastrointestinal malignancy. Scand J Gastroenterol Suppl, 1996. 218: p. 43-9.

46. Nieveen van Dijkum, E.J., L.T. de Wit, O.M. van Delden, et al., Staging laparoscopy and laparoscopic ultrasonography in more than 400 patients with upper gastrointestinal carcinoma. J Am Coll Surg, 1999. 189(5): p. 459-65

47. van Gulik, T., Open versus laparoscopic resection for liver tumours. HPB (Oxford), 2009. 11(6): p. 465-8.

48. Cuesta, M.A., S. Meijer, M.A. Paul, et al., Limited laparoscopic liver resection of benign tumors guided by laparoscopic ultrasonography: report of two cases. Surg Laparosc Endosc, 1995. 5(5): p. 396-401.

49. Berends, F.J., S. Meijer, W. Prevoo, et al., Technical considerations in laparoscopic liver surgery. Surg Endosc, 2001. 15(8): p. 794-8.

50. Schipper, H.G. and P.A. Kager, Diagnosis and treatment of hepatic echinococcosis: an overview. Scand J Gastroenterol Suppl, 2004(241): p. 50-5.

51. van Keimpema, L., J.P. Ruurda, M.F. Ernst, et al., Laparoscopic fenestration of liver cysts in polycystic liver disease results in a median volume reduction of 12.5\%. J Gastrointest Surg, 2008. 12(3): p. 477-82. 
52. van Keimpema, L. and K. Hockerstedt, Treatment of polycystic liver disease. Br J Surg, 2009. 96(12): p. 1379-80.

53. Stoot, J.H., R.M. van Dam, O.R. Busch, et al., The effect of a multimodal fast-track programme on outcomes in laparoscopic liver surgery: a multicentre pilot study. HPB (Oxford), 2009. 11(2): p. 140-4.

54. Belghiti, J., K. Hiramatsu, S. Benoist, et al., Seven hundred forty-seven hepatectomies in the 1990s: an update to evaluate the actual risk of liver resection. J Am Coll Surg, 2000. 191(1): p. 38-46.

55. Jarnagin, W.R., M. Gonen, Y. Fong, et al., Improvement in perioperative outcome after hepatic resection: analysis of 1,803 consecutive cases over the past decade. Ann Surg, 2002. 236(4): p. 397-406; discussion 406-7.

56. Dimick, J.B., R.M. Wainess, J.A. Cowan, et al., National trends in the use and outcomes of hepatic resection. J Am Coll Surg, 2004. 199(1): p. 31-8.

57. Rees, M., P.P. Tekkis, F.K. Welsh, et al., Evaluation of long-term survival after hepatic resection for metastatic colorectal cancer: a multifactorial model of 929 patients. Ann Surg, 2008. 247(1): p. 125-35.

58. Scheele, J., R. Stang, A. Altendorf-Hofmann, et al., Resection of colorectal liver metastases. World J Surg, 1995. 19(1): p. 59-71.

59. Jamison, R.L., J.H. Donohue, D.M. Nagorney, et al., Hepatic resection for metastatic colorectal cancer results in cure for some patients. Arch Surg, 1997. 132(5): p. 505-10; discussion 511.

60. Ruers, T. and R.P. Bleichrodt, Treatment of liver metastases, an update on the possibilities and results. Eur J Cancer, 2002. 38(7): p. 1023-33.

61. Choti, M.A., J.V. Sitzmann, M.F. Tiburi, et al., Trends in long-term survival following liver resection for hepatic colorectal metastases. Ann Surg, 2002. 235(6): p. 759-66.

62. Fong, Y., M. Gonen, D. Rubin, et al., Longterm survival is superior after resection for cancer in highvolume centers. Ann Surg, 2005. 242(4): p. 540-4; discussion 544-7.

63. van Dam, R.M., T.M. Lodewick, M.A. van den Broek, et al., Outcomes of extended versus limited indications for patients undergoing a liver resection for colorectal cancer liver metastases. HPB (Oxford), 2014. 16(6): p. 550-9.

64. Tomlinson, J.S., W.R. Jarnagin, R.P. DeMat-teo, et al., Actual 10-year survival after resection of colorectal liver metastases defines cure. J Clin Oncol, 2007. 25(29): p. 4575-80.

65. Reich, H., F. McGlynn, J. DeCaprio, et al., Laparoscopic excision of benign liver lesions. Obstet Gynecol, 1991. 78(5 Pt 2): p. 956-8.

66. Gagner, M., M. Rheault, and J. Dubuc, Laparoscopic partial hepatectomy for liver tumor. Surg Endosc, 1992(6): p. 97-98.

67. Azagra, J.S., M. Goergen, E. Gilbart, et al., Laparoscopic anatomical (hepatic) left lateral segmentectomy-technical aspects. Surg Endosc, 1996. 10(7): p. 758-61.

68. Cherqui, D., O. Soubrane, E. Husson, et al., Laparoscopic living donor hepatectomy for liver transplantation in children. Lancet, 2002. 359(9304): p. 392-6.

69. Soubrane, O., D. Cherqui, O. Scatton, et al., Laparoscopic left lateral sectionectomy in living donors: safety and reproducibility of the technique in a single center. Ann Surg, 2006. 244(5): p. 815-20.

70. Giulianotti, P.C., A. Coratti, M. Angelini, et al., Robotics in general surgery: personal experience in a large community hospital. Arch Surg, 2003. 138(7): p. 777-84.

71. Vibert, E., C. Denet, and B. Gayet, Major digestive surgery using a remote-controlled robot: the next revolution. Arch Surg, 2003. 138(9): p. 1002-6.

72. Cherqui, D., Laparoscopic liver resection. Br J Surg, 2003. 90(6): p. 644-6.

73. Shimada, M., M. Hashizume, S. Maehara, et al., Laparoscopic hepatectomy for hepatocellular carcinoma. Surg Endosc, 2001. 15(6): p. 541-4.

74. Descottes, B., D. Glineur, F. Lachachi, et al., Laparoscopic liver resection of benign liver tumors. Surg Endosc, 2003. 17(1): p. 23-30.

75. Vibert, E., T. Perniceni, H. Levard, et al., Laparoscopic liver resection. Br J Surg, 2006. 93(1): p. 67-72.

76. Topal, B., S. Fieuws, R. Aerts, et al., Laparoscopic versus open liver resection of hepatic neoplasms: comparative analysis of shortterm results. Surg Endosc, 2008. 22(10): p. 2208-13.

77. Pulitano, C. and L. Aldrighetti, The current role of laparoscopic liver resection for the treatment of liver tumors. Nat Clin Pract Gastroenterol Hepatol, 2008. 5(11): p. 648-54. 
78. Vigano, L., C. Tayar, A. Laurent, et al., Laparoscopic liver resection: a systematic review. J Hepatobiliary Pancreat Surg, 2009. 16(4): p. 410-21.

79. Guyatt, G.H., A.D. Oxman, G.E. Vist, et al., GRADE: an emerging consensus on rating quality of evidence and strength of recommendations. BMJ, 2008. 336(7650): p. 924- 6.

80. Nguyen, K.T., T.C. Gamblin, and D.A. Geller, World review of laparoscopic liver resection-2,804 patients. Ann Surg, 2009. 250(5): p. 831-41.

81. Reddy, S.K., A. Tsung, and D.A. Geller, Laparoscopic liver resection. World J Surg, 2011 . 35(7): p. 147886.

82. Simillis, C., V.A. Constantinides, P.P. Tekkis, et al., Laparoscopic versus open hepatic resections for benign and malignant neoplasms--a meta-analysis. Surgery, 2007. 141(2): p. 203-211.

83. Farges, O., P. Jagot, P. Kirstetter, et al., Prospective assessment of the safety and benefit of laparoscopic liver resections. J Hepatobiliary Pancreat Surg, 2002. 9(2): p. 242-8.

84. Kaneko, H., Laparoscopic hepatectomy: indications and outcomes. J Hepatobiliary Pancreat Surg, 2005. 12(6): p. 438-43.

85. Chang, S., A. Laurent, C. Tayar, et al., Laparoscopy as a routine approach for left lateral sectionectomy. Br J Surg, 2007. 94(1): p. 58-63.

86. Polignano, F.M., A.J. Quyn, R.S. de Figueiredo, et al., Laparoscopic versus open liver segmentectomy: prospective, case-matched, intention-to-treat analysis of clinical outcomes and cost effectiveness. Surg Endosc, 2008. 22(12): p. 2564-70.

87. Vanounou, T., J.L. Steel, K.T. Nguyen, et al., Comparing the clinical and economic impact of laparoscopic versus open liver resection. Ann Surg Oncol, 2010. 17(4): p. 998-1009.

88. Cleary, S.P., H.S. Han, M. Yamamoto, et al., The comparative costs of laparoscopic and open liver resection: a report for the 2nd International Consensus Conference on Laparoscopic Liver Resection. Surg Endosc, 2016.

89. Nguyen, K.T., T.C. Gamblin, and D.A. Geller, World Review of Laparoscopic Liver Resection-2,804 Patients. Ann Surg, 2009.

90. Hashizume, M., M. Shimada, and K. Sugimachi, Laparoscopic hepatectomy: new approach for hepatocellular carcinoma. J Hepatobiliary Pancreat Surg, 2000. 7(3): p. 270-5.

91. Johnstone, P.A., D.C. Rohde, S.E. Swartz, et al., Port site recurrences after laparoscopic and thoracoscopic procedures in malignancy. J Clin Oncol, 1996. 14(6): p. 1950-6.

92. Targarona, E.M., J. Martinez, A. Nadal, et al., Cancer dissemination during laparoscopic surgery: tubes, gas, and cells. World J Surg, 1998. 22(1): p. 55-60; discussion 60- 1.

93. Gutt, C.N., V. Riemer, Z.G. Kim, et al., Impact of laparoscopic surgery on experimental hepatic metastases. Br J Surg, 2001. 88(3): p. 371-5.

94. Mala, T., B. Edwin, I. Gladhaug, et al., A comparative study of the short-term outcome following open and laparoscopic liver resection of colorectal metastases. Surg Endosc, 2002. 16(7): p. 1059-63.

95. Cherqui, D., A. Laurent, C. Tayar, et al., Laparoscopic liver resection for peripheral hepatocellular carcinoma in patients with chronic liver disease: midterm results and perspectives. Ann Surg, 2006. 243(4): p. 499-506.

96. Teramoto, K., T. Kawamura, S. Takamatsu, et al., Laparoscopic and thoracoscopic partial hepatectomy for hepatocellular carcinoma. World J Surg, 2003. 27(10): p. 131-6.

97. Buell, J.F., D. Cherqui, D.A. Geller, et al., The international position on laparoscopic liver surgery: The Louisville Statement, 2008. Ann Surg, 2009. 250(5): p. 825-30.

98. Kehlet, H., Epidural analgesia and the endocrine-metabolic response to surgery. Update and perspectives. Acta Anaesthesiol Scand, 1984. 28(2): p. 125-7.

99. Kehlet, $\mathrm{H}$., The modifying effect of anesthetic technique on the metabolic and endocrine responses to anesthesia and surgery. Acta Anaesthesiol Belg, 1988. 39(3): p. 143-6.

100. Scott, N.B., T. Mogensen, A. Greulich, et al., No effect of continuous i.p. infusion of bupivacaine on postoperative analgesia, pulmonary function and the stress response to surgery. Br J Anaesth, 1988. 61(2): p. 165-8.

101. Christensen, T., J.G. Stage, H. Galbo, et al., Fatigue and cardiac and endocrine metabolic response to exercise after abdominal surgery. Surgery, 1989. 105(1): p. 46-50. 
102. Bardram, L., P. Funch-Jensen, P. Jensen, et al., Recovery after laparoscopic colonic surgery with epidural analgesia, and early oral nutrition and mobilisation. Lancet, 1995. 345(8952): p. 763-4.

103. Moiniche, S., J.B. Dahl, J. Rosenberg, et al., Colonic resection with early discharge after combined subarachnoid-epidural analgesia, preoperative glucocorticoids, and early postoperative mobilization and feeding in a pulmonary high-risk patient. Reg Anesth, 1994. 19(5): p. 352-6.

104. Bardram, L., P.M. Funch Jensen, P. Jensen, et al., [Two days' hospital stay after laparoscopic colon resection]. Ugeskr Laeger, 1996. 158(42): p. 5920-4.

105. Kehlet, H., Organizing postoperative accelerated recovery programs. Reg Anesth, 1996. 21(6 Suppl): p. 149-51.

106. Kehlet, H., Multimodal approach to control postoperative pathophysiology and rehabilitation. $\mathrm{Br} J$ Anaesth, 1997. 78(5): p. 606-17.

107. Kehlet, H., Acute pain control and accelerated postoperative surgical recovery. Surg Clin North Am, 1999. 79(2): p. 431-43

108. Delaney, C.P., V.W. Fazio, A.J. Senagore, et al., 'Fast track' postoperative management protocol for patients with high co-morbidity undergoing complex abdominal and pelvic colorectal surgery. $\mathrm{Br} \mathrm{J}$ Surg, 2001. 88(11): p. 1533-8.

109. Wilmore, D.W. and H. Kehlet, Management of patients in fast track surgery. BMJ, 2001. 322(7284): p. 473-6.

110. Basse, L., J.L. Madsen, and H. Kehlet, Normal gastrointestinal transit after colonic resection using epidural analgesia, enforced oral nutrition and laxative. Br J Surg, 2001. 88(11): p. 1498-500.

111. Henriksen, M.G., M.B. Jensen, H.V. Hansen, et al., Enforced mobilization, early oral feeding, and balanced analgesia improve convalescence after colorectal surgery. Nutrition, 2002. 18(2): p. 147-52.

112. Basse, L., H.H. Raskov, D. Hjort Jakobsen, et al., Accelerated postoperative recovery programme after colonic resection improves physical performance, pulmonary function and body composition. $\mathrm{Br} J$ Surg, 2002. 89(4): p. 446-53.

113. Kehlet, H. and D.W. Wilmore, Multimodal strategies to improve surgical outcome. Am J Surg, 2002. 183(6): p. 630-41.

114. Anderson, A.D., C.E. McNaught, J. MacFie, et al., Randomized clinical trial of multimodal optimization and standard perioperative surgical care. Br J Surg, 2003. 90(12): p. 1497-504.

115. Delaney, C.P., M. Zutshi, A.J. Senagore, et al., Prospective, randomized, controlled trial between a pathway of controlled rehabilitation with early ambulation and diet and traditional postoperative care after laparotomy and intestinal resection. Dis Colon Rectum, 2003. 46(7): p. 851-9.

116. Basse, L., J.E. Thorbol, K. Lossl, et al., Colonic surgery with accelerated rehabilitation or conventional care. Dis Colon Rectum, 2004. 47(3): p. 271-7; discussion 277-8.

117. Fearon, K.C., O. Ljungqvist, M. Von Meyenfeldt, et al., Enhanced recovery after surgery: a consensus review of clinical care for patients undergoing colonic resection. Clin Nutr, 2005. 24(3): p. 466-77.

118. Zutshi, M., C.P. Delaney, A.J. Senagore, et al., Randomized controlled trial comparing the controlled rehabilitation with early ambulation and diet pathway versus the controlled rehabilitation with early ambulation and diet with preemptive epidural anesthesia/ analgesia after laparotomy and intestinal resection. Am J Surg, 2005. 189(3): p. 268-72.

119. Varadhan, K.K., K.R. Neal, C.H. Dejong, et al., The enhanced recovery after surgery (ERAS) pathway for patients undergoing major elective open colorectal surgery: a meta-analysis of randomized controlled trials. Clin Nutr, 2010. 29(4): p. 434-40.

120. Lassen, K., M. Soop, J. Nygren, et al., Consensus review of optimal perioperative care in colorectal surgery: Enhanced Recovery After Surgery (ERAS) Group recommendations. Arch Surg, 2009. 144(10): p. 961-9.

121. Disbrow, E.A., H.L. Bennett, and J.T. Owings, Effect of preoperative suggestion on postoperative gastrointestinal motility. West J Med, 1993. 158(5): p. 488-92.

122. Halaszynski, T.M., R. Juda, and D.G. Silverman, Optimizing postoperative outcomes with efficient preoperative assessment and management. Crit Care Med, 2004. 32(4 Suppl): p. S76-86.

123. Forster, A.J., H.D. Clark, A. Menard, et al., Effect of a nurse team coordinator on outcomes for hospitalized medicine patients. Am J Med, 2005. 1 8(10): p. 1 48-53. 
124. Blay, N. and J. Donoghue, The effect of preadmission education on domiciliary recovery following laparoscopic cholecystectomy. Aust J Adv Nurs, 2005. 22(4): p. 14-9.

125. Egbert, L.D., G.E. Battit, C.E. Welch, et al., Reduction of Postoperative Pain by Encouragement and Instruction of Patients. A Study of Doctor-Patient Rapport. N Engl J Med, 1964. 270:: p. 825-7.

126. Kiecolt-Glaser, J.K., G.G. Page, P.T. Marucha, et al., Psychological influences on surgical recovery. Perspectives from psychoneuroimmunology. Am Psychol, 1998. 53(11): p. 1209-18.

127. Raeder, J.C., [Prevention of aspiration-preoperative fasting. Time for reevaluation of old routines?]. Tidsskr Nor Laegeforen, 1993. 1 3(4): p. 472-4.

128. Soreide, E., S. Fasting, and J. Raeder, New preoperative fasting guidelines in Norway. Acta Anaesthesiol Scand, 1997. 41(6): p. 799.

129. Soreide, E., L.I. Eriksson, G. Hirlekar, et al., Pre-operative fasting guidelines: an update. Acta Anaesthesiol Scand, 2005. 49(8): p. 1041-7.

130. Ljungqvist, O. and E. Soreide, Preoperative fasting. Br J Surg, 2003. 90(4): p. 400-6.

131. Brady, M., S. Kinn, and P. Stuart, Preoperative fasting for adults to prevent perioperative complications. Cochrane Database Syst Rev, 2003(4): p. CD004423.

132. Hausel, J., J. Nygren, M. Lagerkranser, et al., A carbohydrate-rich drink reduces preoperative discomfort in elective surgery patients. Anesth Analg, 2001. 93(5): p. 1344- 50.

133. Soop, M., J. Nygren, P. Myrenfors, et al., Preoperative oral carbohydrate treatment attenuates immediate postoperative insulin resistance. Am J Physiol Endocrinol Metab, 2001. 280(4): p. E576-83.

134. Soop, M., G.L. Carlson, J. Hopkinson, et al., Randomized clinical trial of the effects of immediate enteral nutrition on metabolic responses to major colorectal surgery in an enhanced recovery protocol. $\mathrm{Br}$ J Surg, 2004. 91(9): p. 1 38-45.

135. Walker, K.J. and A.F. Smith, Premedication for anxiety in adult day surgery. Cochrane Database Syst Rev, 2009(4): p. CD002192.

136. Moiniche, S., H. Kehlet, and J.B. Dahl, A qualitative and quantitative systematic review of preemptive analgesia for postoperative pain relief: the role of timing of analgesia. Anesthesiology, 2002. 96(3): p. 725-41.

137. Clagett, G.P., F.A. Anderson, Jr., W. Geerts, et al., Prevention of venous thromboembolism. Chest, 1998. 1 4(5 Suppl): p. 531S- 560S.

138. Collins, R., A. Scrimgeour, S. Yusuf, et al., Reduction in fatal pulmonary embolism and venous thrombosis by perioperative administration of subcutaneous heparin. Overview of results of randomized trials in general, orthopedic, and urologic surgery. N Engl J Med, 1988. 318(18): p. 1 62-73.

139. Wille-Jorgensen, P., M.S. Rasmussen, B.R. Andersen, et al., Heparins and mechanical methods for thromboprophylaxis in colorectal surgery. Cochrane Database Syst Rev, 2003(4): p. CD001217.

140. Negus, J.J., J.J. Gardner, O. Tann, et al., Thromboprophylaxis in major abdominal surgery for cancer. Eur J Surg Oncol, 2006. 32(9): p. 911-6.

141. Koch, A., S. Bouges, S. Ziegler, et al., Low molecular weight heparin and unfractionated heparin in thrombosis prophylaxis after major surgical intervention: update of previous meta-analyses. $\mathrm{Br} \mathrm{J}$ Surg, 1997. 84(6): p. 750-9.

142. Rasmussen, M.S., L.N. Jorgensen, and P. Wille-Jorgensen, Prolonged thromboprophylaxis with low molecular weight heparin for abdominal or pelvic surgery. Cochrane Database Syst Rev, 2009(1): p. CD004318.

143. Bergqvist, D., B. Lindblad, and T. Matzsch, Risk of combining low molecular weight heparin for thromboprophylaxis and epidural or spinal anesthesia. Semin Thromb Hemost, 1993. 19 (1 Suppl):: p. 147-51.

144. Vandermeulen, E.P., H. Van Aken, and J. Vermylen, Anticoagulants and spinal-epidural anesthesia. Anesth Analg, 1994. 79(6): p. 1 65-77.

145. Nelson, R.L., A.M. Glenny, and F. Song, Antimicrobial prophylaxis for colorectal surgery. Cochrane Database Syst Rev, 2009(1): p. CD00181.

146. Wu, C.C., D.C. Yeh, M.C. Lin, et al., Prospective randomized trial of systemic antibiotics in patients undergoing liver resection. Br J Surg, 1998. 85(4): p. 489-93. 
147. Sano, K., T. Takayama, and M. Makuuchi, Prophylactic antibiotics in hepatectomy (in Japanese). Geka (Surgery), 2002(64): p. 1635-9.

148. Togo, S., K. Tanaka, K. Matsuo, et al., Duration of antimicrobial prophylaxis in patients undergoing hepatectomy: a prospective randomized controlled trial using flomoxef. J Antimicrob Chemother, 2007. 59(5): p. 964-70.

149. Wrighton, L.J., K.R. O'Bosky, J.P. Namm, et al., Postoperative management after hepatic resection. J Gastrointest Oncol, 2012. 3(1): p. 41-7.

150. Walia, A., Anesthetic management for liver resection. J Gastrointest Surg, 2006. 10(2): p. 168-9.

151. Park, G.R., T.N. Evans, J. Hutchins, et al., Reducing the demand for admission to intensive care after major abdominal surgery by a change in anaesthetic practice and the use of remifentanil. Eur J Anaesthesiol, 2000. 17(2): p. 1 1-9.

152. Nishiyama, T., T. Yokoyama, and K. Hanaoka, Effects of sevoflurane and isoflurane anesthesia on arterial ketone body ratio and liver function. Acta Anaesthesiol Scand, 1999. 43(3): p. 347-51.

153. Lentschener, C. and Y. Ozier, Anaesthesia for elective liver resection: some points should be revisited. Eur J Anaesthesiol, 2002. 19(11): p. 780-8.

154. Jorgensen, H., J. Wetterslev, S. Moiniche, et al., Epidural local anaesthetics versus opioidbased analgesic regimens on postoperative gastrointestinal paralysis, PONV and pain after abdominal surgery. Cochrane Database Syst Rev, 2000(4): p. CD001893.

155. Miedema, B.W. and J.O. Johnson, Methods for decreasing postoperative gut dysmotility. Lancet Oncol, 2003. 4(6): p. 365-72.

156. Uchida, I., T. Asoh, C. Shirasaka, et al., Effect of epidural analgesia on postoperative insulin resistance as evaluated by insulin clamp technique. Br J Surg, 1988. 75(6): p. 557-62.

157. Nisanevich, V., I. Felsenstein, G. Almogy, et al., Effect of intraoperative fluid management on outcome after intraabdominal surgery. Anesthesiology, 2005. 103(1): p. 25- 32.

158. Brandstrup, B., H. Tonnesen, R. Beier-Holgersen, et al., Effects of intravenous fluid restriction on postoperative complications: comparison of two perioperative fluid regimens: a randomized assessorblinded multicenter trial. Ann Surg, 2003. 238(5): p. 641-8.

159. Lobo, D.N., K.A. Bostock, K.R. Neal, et al., Effect of salt and water balance on recovery of gastrointestinal function after elective colonic resection: a randomised controlled trial. Lancet, 2002. 359(9320): p. 1812-8.

160. Smyrniotis, V., G. Kostopanagiotou, K. Theodoraki, et al., The role of central venous pressure and type of vascular control in blood loss during major liver resections. Am J Surg, 2004. 187(3): p. 398-402.

161. Jones, R.M., C.E. Moulton, and K.J. Hardy, Central venous pressure and its effect on blood loss during liver resection. Br J Surg, 1998. 85(8): p. 1058-60.

162. Wang, W.D., L.J. Liang, X.Q. Huang, et al., Low central venous pressure reduces blood loss in hepatectomy. World J Gastroenterol, 2006. 12(6): p. 935-9.

163. Lesurtel, M., M. Selzner, H. Petrowsky, et al., How should transection of the liver be performed?: a prospective randomized study in 100 consecutive patients: comparing four different transection strategies. Ann Surg, 2005. 242(6): p. 814-22, discussion 822-3.

164. McNally, S.J., E.J. Revie, L.J. Massie, et al., Factors in perioperative care that determine blood loss in liver surgery. HPB (Oxford), 2012. 14(4): p. 236-41.

165. Choi, S.J., M.S. Gwak, J.S. Ko, et al., Can peripheral venous pressure be an alternative to central venous pressure during right hepatectomy in living donors? Liver Transpl, 2007. 13(10): p. 1414-21.

166. Solus-Biguenet, H., M. Fleyfel, B. Tavernier, et al., Non-invasive prediction of fluid responsiveness during major hepatic surgery. Br J Anaesth, 2006. 97(6): p. 808-16.

167. Venn, R., A. Steele, P. Richardson, et al., Randomized controlled trial to investigate influence of the fluid challenge on duration of hospital stay and perioperative morbidity in patients with hip fractures. Br J Anaesth, 2002. 88(1): p. 65-71.

168. National Institute for Health and Clinical Excellence. Medical technologies guidance MTG3: CardioQODM oesophageal doppler monitor. March 201 . http://www.nice. org.uk/MTG3 (accessed 03/28/2016). 
169. Kurz, A., D.I. Sessler, and R. Lenhardt, Perioperative normothermia to reduce the incidence of surgical-wound infection and shorten hospitalization. Study of Wound Infection and Temperature Group. N Engl J Med, 1996. 334(19): p. 1209-15.

170. Frank, S.M., L.A. Fleisher, M.J. Breslow, et al., Perioperative maintenance of normothermia reduces the incidence of morbid cardiac events. A randomized clinical trial. JAMA, 1997. 277(14): p. 1 27-34.

171. Schmied, H., A. Kurz, D.I. Sessler, et al., Mild hypothermia increases blood loss and transfusion requirements during total hip arthroplasty. Lancet, 1996. 347(8997): p. 289-92.

172. Apfel, C.C., P. Kranke, L.H. Eberhart, et al., Comparison of predictive models for postoperative nausea and vomiting. Br J Anaesth, 2002. 88(2): p. 234-40.

173. Rusch, D., L. Eberhart, A. Biedler, et al., Prospective application of a simplified risk score to prevent postoperative nausea and vomiting. Can J Anaesth, 2005. 52(5): p. 478-84.

174. Carlisle, J.B. and C.A. Stevenson, Drugs for preventing postoperative nausea and vomiting. Cochrane Database Syst Rev, 2006. 3(3): p. CD004125.

175. Gan, T.J., T.A. Meyer, C.C. Apfel, et al., Society for Ambulatory Anesthesia guidelines for the management of postoperative nausea and vomiting. Anesth Analg, 2007. 105(6): p. 1615-28, table of contents.

176. O'Dwyer PJ, M.J., McDermott EW, Murphy JJ, O'Higgins NJ, Patient recovery following cholecystectomy through a $6 \mathrm{~cm}$ or $15 \mathrm{~cm}$ transverse subcostal incision: a prospective randomized clinical trial. Postgrad Med J, 1992. 68(804): p. 817-9.

177. Grantcharov, T.P. and J. Rosenberg, Vertical compared with transverse incisions in abdominal surgery. Eur J Surg, 2001. 167(4): p. 260-7.

178. Halm, J.A., H. Lip, P.I. Schmitz, et al., Incisional hernia after upper abdominal surgery: a randomised controlled trial of midline versus transverse incision. Hernia, 2009. 13(3): p. 275-80.

179. Brown, S.R., P.J. Goodfellow, I.J. Adam, et al., A randomised controlled trial of transverse skin crease vs. vertical midline incision for right hemicolectomy. Tech Coloproctol, 2004. 8(1): p. 15-8.

180. Greenall, M.J., M. Evans, and A.V. Pollock, Midline or transverse laparotomy? A random controlled clinical trial. Part I: Influence on healing. Br J Surg, 1980. 67(3): p. 188- 90.

181. Andersen, L.P., M. Klein, I. Gogenur, et al., Incisional hernia after open versus laparoscopic sigmoid resection. Surg Endosc, 2008. 22(9): p. 2026-9.

182. Bona, S., A. Gavelli, and C. Huguet, The role of abdominal drainage after major hepatic resection. Am J Surg, 1994. 167(6): p. 593-5.

183. Fuster, J., J.M. Llovet, J.C. Garcia-Valdecasas, et al., Abdominal drainage after liver resection for hepatocellular carcinoma in cirrhotic patients: a randomized controlled study. Hepatogastroenterology, 2004. 51(56): p. 536-40.

184. Liu, C.L., S.T. Fan, C.M. Lo, et al., Abdominal drainage after hepatic resection is contraindicated in patients with chronic liver diseases. Ann Surg, 2004. 239(2): p. 194- 201.

185. Gurusamy, K.S., K. Samraj, and B.R. Davidson, Routine abdominal drainage for uncomplicated liver resection. Cochrane database of systematic reviews, 2007(3): p. CD006232.

186. de Boer, M.T., J.M. Klaase, C. Verhoef, et al., Fibrin sealant for prevention of resection surface-related complications after liver resection: a randomized controlled trial. Ann Surg, 2012. 256(2): p. 229-34.

187. Cheatham, M.L., W.C. Chapman, S.P. Key, et al., A meta-analysis of selective versus routine nasogastric decompression after elective laparotomy. Ann Surg, 1995. 221(5): p. 469-76; discussion 476-8.

188. Lassen, K., J. Kjaeve, T. Fetveit, et al., Allowing normal food at will after major upper gastrointestinal surgery does not increase morbidity: a randomized multicenter trial. Ann Surg, 2008. 247(5): p. 721-9.

189. Nelson, R., B. Tse, and S. Edwards, Systematic review of prophylactic nasogastric decompression after abdominal operations. Br J Surg, 2005. 92(6): p. 673-80.

190. Pessaux, P., J.M. Regimbeau, F. Dondero, et al., Randomized clinical trial evaluating the need for routine nasogastric decompression after elective hepatic resection. Br J Surg, 2007. 94(3): p. 297-303.

191. Kehlet, H. and K. Holte, Effect of postoperative analgesia on surgical outcome. Br J Anaesth, 2001. 87(1): p. 62-72.

192. Liu, S.S., R.L. Carpenter, D.C. Mackey, et al., Effects of perioperative analgesic technique on rate of recovery after colon surgery. Anesthesiology, 1995. 83(4): p. 757-65. 
193. Werawatganon, T. and S. Charuluxanun, Patient controlled intravenous opioid analgesia versus continuous epidural analgesia for pain after intra-abdominal surgery. Cochrane Database Syst Rev, 2005(1): p. CD004088.

194. Ballantyne, J.C., D.B. Carr, S. deFerranti, et al., The comparative effects of postoperative analgesic therapies on pulmonary outcome: cumulative meta-analyses of randomized, controlled trials. Anesth Analg, 1998. 86(3): p. 598-612.

195. McLeod, G., H. Davies, N. Munnoch, et al., Postoperative pain relief using thoracic epidural analgesia: outstanding success and disappointing failures. Anaesthesia, 2001. 56(1): p. 75-81.

196. Weinberg, L., N. Scurrah, K. Gunning, et al., Postoperative changes in prothrombin time following hepatic resection: implications for perioperative analgesia. Anaesth Intensive Care, 2006. 34(4): p. 438-43.

197. Liu, S.S., J.M. Richman, R.C. Thirlby, et al., Efficacy of continuous wound catheters delivering local anesthetic for postoperative analgesia: a quantitative and qualitative systematic review of randomized controlled trials. J Am Coll Surg, 2006. 203(6): p. 914-32.

198. Basu, S., A. Tamijmarane, D. Bulters, et al., An alternative method of wound pain control following hepatic resection: a preliminary study. HPB (Oxford), 2004. 6(3): p. 186-9.

199. Forastiere, E., M. Sofra, D. Giannarelli, et al., Effectiveness of continuous wound infusion of $0.5 \%$ ropivacaine by On-Q pain relief system for postoperative pain management after open nephrectomy. Br J Anaesth, 2008. 101(6): p. 841-7.

200. De Pietri, L., A. Siniscalchi, A. Reggiani, et al., The use of intrathecal morphine for postoperative pain relief after liver resection: a comparison with epidural analgesia. Anesth Analg, 2006. 102(4): p. 1 5763.

201. Koea, J.B., Y. Young, and K. Gunn, Fast track liver resection: the effect of a comprehensive care package and analgesia with single dose intrathecal morphine with gabapentin or continuous epidural analgesia. HPB Surg, 2009. 2009:: p. 271986.

202. Basse, L., D. Hjort Jakobsen, P. Billesbolle, et al., A clinical pathway to accelerate recovery after colonic resection. Ann Surg, 2000. 232(1): p. 51-7.

203. Ong, C.K., R.A. Seymour, P. Lirk, et al., Combining paracetamol (acetaminophen) with nonsteroidal antiinflammatory drugs: a qualitative systematic review of analgesic efficacy for acute postoperative pain. Anesth Analg, 2010. 1 0(4): p. 1 70-9.

204. Hyllested, M., S. Jones, J.L. Pedersen, et al., Comparative effect of paracetamol, NSAIDs or their combination in postoperative pain management: a qualitative review. Br J Anaesth, 2002. 88(2): p. 199214.

205. Augestad, K.M. and C.P. Delaney, Postoperative ileus: impact of pharmacological treatment, laparoscopic surgery and enhanced recovery pathways. World J Gastroenterol, 2010. 16(17): p. 2067-74.

206. Story, S.K. and R.S. Chamberlain, A comprehensive review of evidence-based strategies to prevent and treat postoperative ileus. Dig Surg, 2009. 26(4): p. 265-75.

207. Fearon, K.C. and R. Luff, The nutritional management of surgical patients: enhanced recovery after surgery. Proc Nutr Soc, 2003. 62(4): p. 807-11.

208. Nygren, J., A. Thorell, and O. Ljungqvist, Preoperative oral carbohydrate nutrition: an update. Curr Opin Clin Nutr Metab Care, 2001. 4(4): p. 255-9.

209. Guenaga, K.K., D. Matos, and P. Wille-Jorgensen, Mechanical bowel preparation for elective colorectal surgery. Cochrane Database Syst Rev, 2009(1): p. CD001544.

210. Abraham, N.S., C.M. Byrne, J.M. Young, et al., Meta-analysis of non-randomized comparative studies of the short-term outcomes of laparoscopic resection for colorectal cancer. ANZ J Surg, 2007. 77(7): p. 508-16.

211. Hendry, P.O., R.M. van Dam, S.F. Bukkems, et al., Randomized clinical trial of laxatives and oral nutritional supplements within an enhanced recovery after surgery protocol following liver resection. $\mathrm{Br} J$ Surg, 2010. 97(8): p. 1 98-206.

212. Muller, S.A., N.N. Rahbari, F. Schneider, et al., Randomized clinical trial on the effect of coffee on postoperative ileus following elective colectomy. Br J Surg, 2012. 99(11): p. 1530-8. 
213. Parnaby, C.N., A.J. MacDonald, and J.T. Jenkins, Sham feed or sham? A meta-analysis of randomized clinical trials assessing the effect of gum chewing on gut function after elective colorectal surgery. Int J Colorectal Dis, 2009. 24(5): p. 585-92.

214. Behm, B. and N. Stollman, Postoperative ileus: etiologies and interventions. Clin Gastroenterol Hepatol, 2003. 1(2): p. 71-80.

215. Ferraz, A.A., V.E. Cowles, R.E. Condon, et al., Nonopioid analgesics shorten the duration of postoperative ileus. Am Surg, 1995. 61(12): p. 1079-83.

216. Basse L, W.M., Kehlet H, Is urinary drainage necessary during continuous epidural analgesia after colonic resection? Reg Anesth Pain Med, 2000. 25(5): p. 498-501.

217. Zaouter, C., P. Kaneva, and F. Carli, Less urinary tract infection by earlier removal of bladder catheter in surgical patients receiving thoracic epidural analgesia. Reg Anesth Pain Med, 2009. 34(6): p. 542-8.

218. Sethia, K.K., J.B. Selkon, A.R. Berry, et al., Prospective randomized controlled trial of urethral versus suprapubic catheterization. Br J Surg, 1987. 74(7): p. 624-5.

219. O'Kelly, T.J., A. Mathew, S. Ross, et al., Optimum method for urinary drainage in major abdominal surgery: a prospective randomized trial of suprapubic versus urethral catheterization. Br J Surg, 1995. 82(10): p. 1367-8.

220. Ratnaval, C.D., P. Renwick, R. Farouk, et al., Suprapubic versus transurethral catheterisation of males undergoing pelvic colorectal surgery. Int J Colorectal Dis, 1996. 11(4): p. 177-9.

221. Andersen, H.K., S.J. Lewis, and S. Thomas, Early enteral nutrition within $24 \mathrm{~h}$ of colorectal surgery versus later commencement of feeding for postoperative complications. Cochrane Database Syst Rev, 2006(4): p. CD004080.

222. Lewis, S.J., H.K. Andersen, and S. Thomas, Early enteral nutrition within $24 \mathrm{~h}$ of intestinal surgery versus later commencement of feeding: a systematic review and meta-analysis. J Gastrointest Surg, 2009. 13(3): p. 569-75.

223. Lewis, S.J., M. Egger, P.A. Sylvester, et al., Early enteral feeding versus "nil by mouth" after gastrointestinal surgery: systematic review and meta-analysis of controlled trials. Bmj, 2001. 323(7316): p. 773-6.

224. Braga, M., O. Ljungqvist, P. Soeters, et al., ESPEN Guidelines on Parenteral Nutrition: surgery. Clin Nutr, 2009. 28(4): p. 378-86.

225. van Dam, R.M., P.O. Hendry, M.M. Coolsen, et al., Initial experience with a multimodal enhanced recovery programme in patients undergoing liver resection. Br J Surg, 2008. 95(8): p. 969-75.

226. Maessen, J., C.H. Dejong, J. Hausel, et al., A protocol is not enough to implement an enhanced recovery programme for colorectal resection. Br J Surg, 2007. 94(2): p. 224-31.

227. Guyatt, G.H., A.D. Oxman, R. Kunz, et al., Going from evidence to recommendations. BMJ, 2008. 336(7652): p. 1049-51.

228. Sackett, D.L., W.M. Rosenberg, J.A. Gray, et al., Evidence based medicine: what it is and what it isn't. BMJ, 1996. 312(7023): p. 71-2.

229. Horton, R., Surgical research or comic opera: questions, but few answers. Lancet, 1996. 347(9007): p. 984-5.

230. Burt, B.M., K. Brown, W. Jarnagin, et al., An audit of results of a no-drainage practice policy after hepatectomy. Am J Surg, 2002. 184(5): p. 441-5.

231. Dimick, J.B., J.A. Cowan, Jr., L.M. Colletti, et al., Hospital teaching status and outcomes of complex surgical procedures in the United States. Arch Surg, 2004. 139(2): p. 137-41.

232. Forbes, T.L., D.K. Lawlor, G. Derose, et al., National audit of the recent utilization of endovascular abdominal aortic aneurysm repair in Canada: 2003 to 2004. J Vasc Surg, 2005. 42(3): p. 410-4.

233. Boddy, A.P., J.M. Bennett, S. Ranka, et al., Who should perform laparoscopic cholecystectomy? A 10year audit. Surg Endosc, 2007. 21(9): p. 1492-7.

234. Thompson, A.M., T. Rapson, F.J. Gilbert, et al., Hospital volume does not influence longterm survival of patients undergoing surgery for oesophageal or gastric cancer. Br J Surg, 2007. 94(5): p. 578-84.

235. van Gijn, W., M.W. Wouters, K.C. Peeters, et al., Nationwide outcome registrations to improve quality of care in rectal surgery. An initiative of the European Society of Surgical Oncology. J Surg Oncol, 2009. 99(8): p. 491-6. 
236. Sauerland, S., L. Angrisani, M. Belachew, et al., Obesity surgery: evidence-based guidelines of the European Association for Endoscopic Surgery (EAES). Surg Endosc, 2005. 19(2): p. 200-21.

237. Hirsch, A.T., Z.J. Haskal, N.R. Hertzer, et al., ACC/AHA 2005 Practice Guidelines for the management of patients with peripheral arterial disease (lower extremity, renal, mesenteric, and abdominal aortic): a collaborative report from the American Association for Vascular Surgery/Society for Vascular Surgery, Society for Cardiovascular Angiography and Interventions, Society for Vascular Medicine and Biology, Society of Interventional Radiology, and the ACC/ AHA Task Force on Practice Guidelines (Writing Committee to Develop Guidelines for the Management of Patients With Peripheral Arterial Disease): endorsed by the American Association of Cardiovascular and Pulmonary Rehabilitation; National Heart, Lung, and Blood Institute; Society for Vascular Nursing; TransAtlantic Inter-Society Consensus; and Vascular Disease Foundation. Circulation, 2006. 1 3(11): p. e463-654.

238. Lassen, K., M. Soop, J. Nygren, et al., Consensus review of optimal perioperative care in colorectal surgery: Enhanced Recovery After Surgery (ERAS) Group recommendations. Arch Surg, 2009. 144(10): p. 961-9.

239. Jarnagin, W., W.C. Chapman, S. Curley, et al., Surgical treatment of hepatocellular carcinoma: expert consensus statement. HPB (Oxford), 2010. 12(5): p. 302-10.

240. Smith, A.J., D.K. Driman, K. Spithoff, et al., Guideline for optimization of colorectal cancer surgery and pathology. J Surg Oncol, 2010. 101(1): p. 5-12.

241. Kaufmann, M., M. Morrow, G. von Minckwitz, et al., Locoregional treatment of primary breast cancer: consensus recommendations from an International Expert Panel. Cancer, 2010. 1 6(5): p. 1 84-91.

242. Garden, O.J., M. Rees, G.J. Poston, et al., Guidelines for resection of colorectal cancer liver metastases. Gut, 2006. 55 Suppl 3: p. iii1-8.

243. Denis, J.L., Y. Hebert, A. Langley, et al., Explaining diffusion patterns for complex health care innovations. Health Care Manage Rev, 2002. 27(3): p. 60-73.

244. Tovar, E.A., R.A. Roethe, M.D. Weissig, et al., One-day admission for lung lobectomy: an incidental result of a clinical pathway. Ann Thorac Surg, 1998. 65(3): p. 803-6.

245. Podore, P.C. and E.B. Throop, Infrarenal aortic surgery with a 3-day hospital stay: A report on success with a clinical pathway. J Vasc Surg, 1999. 29(5): p. 787-92.

246. Trondsen, E., O. Mjaland, J. Raeder, et al., Day-case laparoscopic fundoplication for gastrooesophageal reflux disease. Br J Surg, 2000. 87(12): p. 1708-11.

247. Rasmussen, S., B.B. Kristensen, S. Foldager, et al., [Accelerated recovery program after hip fracture surgery]. Ugeskr Laeger, 2002. 165(1): p. 29-33.

248. Brustia, P., A. Renghi, L. Gramaglia, et al., Mininvasive abdominal aortic surgery. Early recovery and reduced hospitalization after multidisciplinary approach. J Cardiovasc Surg (Torino), 2003. 44(5): p. 629-35.

249. Barbieri, A., K. Vanhaecht, P. Van Herck, et al., Effects of clinical pathways in the joint replacement: a meta-analysis. BMC Med, 2009. 7:: p. 32-43.

250. Grantcharov, T.P. and H. Kehlet, Laparoscopic gastric surgery in an enhanced recovery programme. Br J Surg, 2010. 97(10): p. 1547-51.

251. di Sebastiano, P., L. Festa, A. De Bonis, et al., A modified fast-track program for pancreatic surgery: a prospective single-center experience. Langenbecks Arch Surg, 201. 396(3): p. 345-51.

252. Fingerhut, A., F. Borie, and C. Dziri, How to teach evidence-based surgery. World J Surg, 2005. 29(5): p. 592-5.

253. Urbach, D.R. and N.N. Baxter, Reducing variation in surgical care. BMJ, 2005. 330(7505): p. 1401-2.

254. Ferlie, E.B. and S.M. Shortell, Improving the quality of health care in the United Kingdom and the United States: a framework for change. Milbank Q, 2001. 79(2): p. 281-315.

255. Grol, R. and J. Grimshaw, From best evidence to best practice: effective implementation of change in patients' care. Lancet, 2003. 362(9391): p. 1225-30. 


\section{PART}

OPTIMIZED RECOVERY AFTER HEPATIC

SURGERY 



\section{Chapter}

\section{A survey in the hepatopancreatobiliary community on ways to enhance patient recovery}

Wong-Lun-Hing EM, Lodewick TM, toot JHMB, Bemelmans MHA, Olde Damink SWM, Dejong CHC, van Dam RM 


\section{ABSTRACT}

\section{OBJECTIVE}

Both laparoscopic techniques and multimodal enhanced recovery (ERAS) programmes have been shown to improve recovery and reduce length of hospital stay. Interestingly, evidence-based care programmes are not widely implemented, whereas new, minimally invasive surgical procedures are often adopted with very little evidence to support their effectiveness. The present survey aimed to shed light on experiences of the adoption of both methods of optimizing recovery.

\section{METHODS}

An international, web-based, 18-question, electronic survey was composed in 2010. The survey was sent out to 673 hepatopancreatobiliary (HPB) centres worldwide in June 2010 to investigate experiences with laparoscopic liver surgery, fast-track recovery programmes and surgery-related equipoise in open and laparoscopic techniques and to assess opinions on strategies for adopting laparoscopic liver surgery in HPB surgical practice.

\section{RESULTS}

A total of 507 centres responded (response rate: $75.3 \%$ ), 161 of which finished the survey completely. All units reported performing open liver resections, 24.2\% performed open living donor resections, $39.1 \%$ carried out orthotopic liver transplantations, $87.6 \%$ had experience with laparoscopic resections and $2.5 \%$ performed laparoscopic living donor resections. A median of 50 (range: 2-560) open and 9.5 (range: 1-80) laparoscopic liver resections per surgical unit were performed in 2009. Patients stayed in hospital for a median of 7 days (range: 2-15 days) after uncomplicated open liver resection and a median of 4 days (range: 1-10 days) after uncomplicated laparoscopic liver resection. Only $28.0 \%$ of centres reported experience with fasttrack programmes in liver surgery. The majority considered the instigation of a RCT or a prospective register comparing the outcomes of open and laparoscopic techniques to be necessary.

\section{CONCLUSION}

Worldwide dissemination of laparoscopic liver resection is substantial, although laparoscopic volumes are low in the majority of HPB centres. The adoption of ERAS programmes in liver surgery is limited and should be given greater attention. 


\section{INTRODUCTION}

In recent years, laparoscopic liver resection and enhanced recovery programmes have been introduced in liver surgery with the aim of accelerating post-operative recovery and shortening hospital length of stay (LoS). Like open liver resection, laparoscopic resection of liver lesions can be applied safely in both malignant and benign disease.[1-7] Large prospective case series suggest that laparoscopic liver surgery may be superior to open liver surgery in terms of perioperative blood loss, postoperative pain, time to recovery, LoS, cosmetic appearance and quality of life.[5,8-10] Survival rates after laparoscopic and open resection of hepatocellular carcinoma and hepatic colorectal metastases seem to be comparable.[1,5]

Similarly, fast-track programmes have proven to be useful, feasible and safe in liver surgery.[11-15] Such programmes can also enhance recovery and reduce LoS. Enhanced recovery after surgery (ERAS) programmes rely mainly on optimizing perioperative care and reducing stress responses to surgery through the provision of adequate preoperative patient counselling, optimized anaesthesia and analgesia, quick resumption of oral intake and early mobilization.[12,16-18] In liver resection, earlier resumption of oral intake, faster post-operative recovery and a significant reduction in median LoS (from 8 days to 6 days) was shown when patients were managed within a multimodal ERAS programme.[12]

A small pilot study in liver surgery suggested that laparoscopic liver surgery within an ERAS setting led to a potentially accelerated recovery and further reduction in LoS from7 days to 5 days.[11] Moreover, the combining of laparoscopy and an ERAS strategy is most likely to result in a synergetic effect, as recently proven in a randomized controlled trial (RCT) in the context of colonic surgery.[19]

Despite the fairly robust evidence that many specific elements of fast-track programmes can enhance recovery and reduce LoS, little evidence on the use of these programmes in liver surgery has been published. This suggests that the adoption of ERAS programmes in liver surgery worldwide is low. Current surgical practice is based on evidence and any change in daily routines should be supported by sound data.[20] In this respect, the current fairly liberal adoption of laparoscopic liver surgery contrasts with the relative lack of adoption of enhanced recovery programmes.

An international web-based survey was composed to evaluate worldwide experiences with laparoscopic liver surgery and fast-track recovery programmes, and surgeryrelated equipoise in open and laparoscopic strategies, and to assess opinions on strategies for the adoption of laparoscopic liver surgery in daily hepatopancreatobiliary (HPB) surgical practice. 


\section{METHODS}

\section{STUDY DESIGN}

An online electronic survey, consisting of 18 questions subdivided according to five main domains, was developed. Questions on the different topics were initially composed by two research fellows (EMW-L-H and TML) and two liver surgeons (RMvD and JHMBS). The definitive set of questions was then administered using SurveyMonkey $^{\mathrm{TM}}$ (SurveyMonkey, Inc., Palo Alto, CA, USA). Items in the first domain included several questions on experience in open and laparoscopic liver surgery and covered types and numbers of liver resections. Items in the second domain concerned recovery and LoS after uncomplicated open or laparoscopic liver resection. Items in the third domain surveyed experience with enhanced recovery or fast-track perioperative care programmes such as ERAS programmes. The fourth part of the survey was developed to evaluate opinions on the necessity of an RCT and on the value of a prospective registry comparing outcomes in open and laparoscopic liver surgery. Items in the final domain evaluated current opinions on and considerations for participating in such a trial. Incomplete responses were excluded from analysis.

\section{STUDY POPULATION}

An invitation to complete this survey was sent by e-mail to 673 HPB centres worldwide in June 2010. Subsequent e-mail reminders were sent out in August and September 2010. Only one surgeon per HPB unit was asked to participate. Figure 1 describes the respondent inclusion and exclusion process. The participation period closed and analyses were conducted in November 2010.

\section{STATISTICS}

Survey data were extracted into an Excel database. Statistical analysis was performed using SPSS Version 18.0 (SPSS, Inc., Chicago, IL, USA) and GraphPad Prism Version 5 (GraphPad Software, Inc., La Jolla, CA, USA). Basic analyses were performed using descriptive statistics including counts, percentages, means with standard deviations and medians with ranges and interquartile ranges (IQRs). Subgroup analysis was performed to investigate potentially relevant differences among regions and centre experiences using the Mann-Whitney U-test or chi-squared test. All countries were assigned to one of the following six regions: Europe; North America; Central and South America; Asia; Oceania, and Africa. An experienced laparoscopic HPB centre was defined as a surgical unit performing 20 or more laparoscopic liver resections annually.[21] 
HBP centres approached $(n=673)$

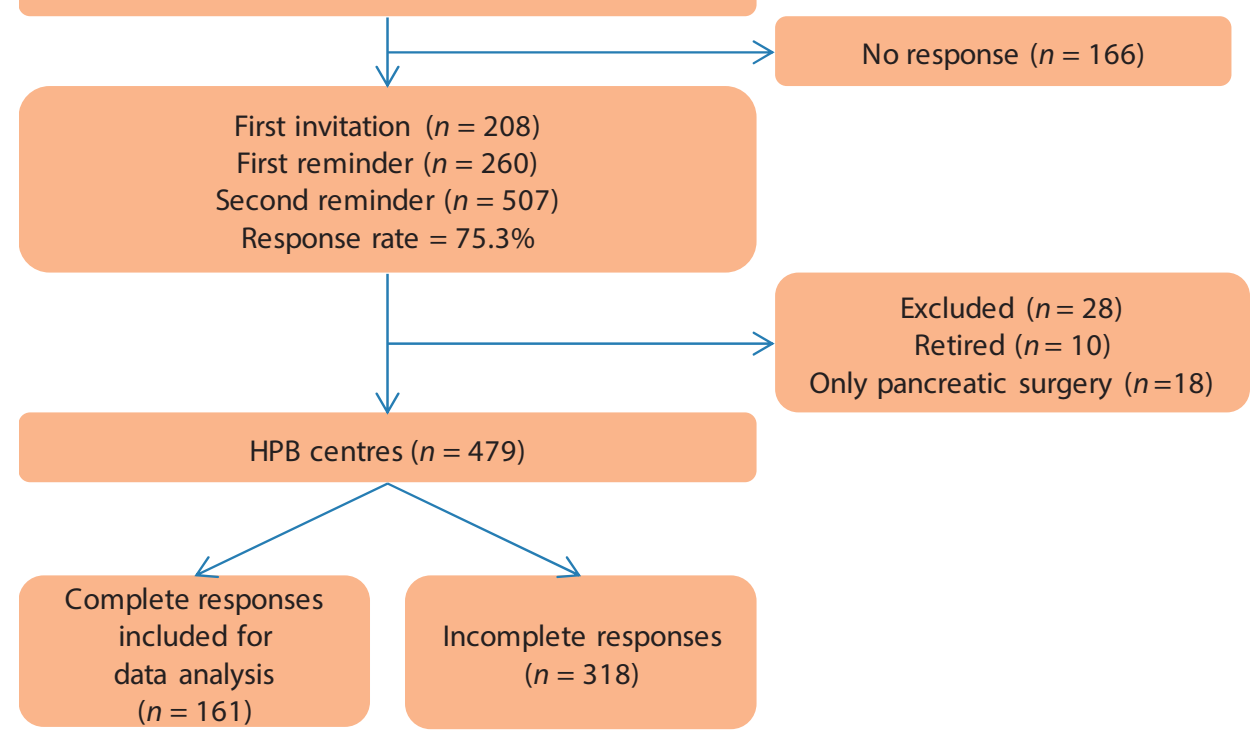

Figure 1. Flowchart showing the respondent inclusion and exclusion process.

\section{RESULTS}

\section{PARTICIPATION}

A total of 507 centres (one surgeon per centre) responded (response rate 75.3\%). Incomplete responses were excluded from data analysis, leaving complete responses from 161 centres. Centres in 39 different countries participated; these were divided into groups according to the six global regions (Fig. 2). The regions that provided the highest response rates were Europe (45\%) and North America (26\%), with the USA ( $\mathrm{n}$ $=34)$, Italy $(n=16)$, Canada $(n=8)$ and the Netherlands $(n=8)$ representing the top four countries providing complete responses. 


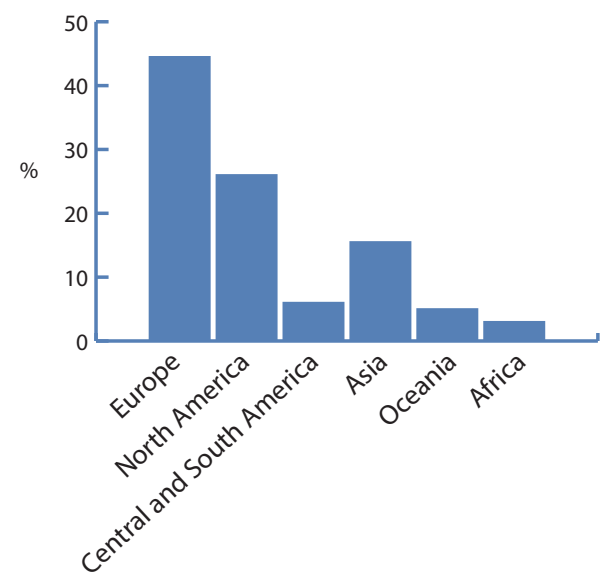

Figure 2. Centres $(n=161)$ included in the data analysis by region

\section{TYPES OF LIVER RESECTION}

Open resection of liver lesions was performed by $100 \%$ of the units. Overall, $87.6 \%$ of responding units reported experience with laparoscopic resection of liver lesions, $39.1 \%$ with orthotopic liver transplantation, $24.2 \%$ with open living donor resection and $2.5 \%$ with laparoscopic living donor resection. Table 1 shows the percentages of HPB centres performing different types of liver surgery and the differences among regions.

\section{EXPERIENCE}

A total of $42.0 \%$ of responding centres indicated that their data represented precise numbers. The remaining centres provided estimations that were as accurate as possible. A wide range in the number of resections performed was observed among HPB centres. In 2009, the median number of open resections for liver lesions performed was 50 (range: $2-560 ; \mathrm{IQR}=50$ ) per surgical unit. In the same year, the median number of laparoscopic resections of liver lesions performed was 9.5 (range: 1-80; IQR = 15) per centre. Worldwide figures for open and laparoscopic liver resections and differences among regions are shown in Table 2. Of the participating centres, $26.6 \%$ could be classified as experienced laparoscopic liver centres based on their completion of at least 20 laparoscopic liver resections per year (Table 3). Experienced laparoscopic centres seemed to be more frequently located in the Americas than in other continents $(44.2 \%$ vs. $13.5 \% ; \mathrm{P}<0.001)$. 
Table 1. Centres performing types of procedure, by region, $n(\%)$

\begin{tabular}{|l|l|l|l|l|l|l|l|} 
& Europe & $\begin{array}{l}\text { North } \\
\text { America }\end{array}$ & $\begin{array}{l}\text { Central and } \\
\text { South America }\end{array}$ & Asia & Oceania & Africa Worldwide \\
\hline Open resection of liver lesions & 72 & 42 & 10 & 24 & 8 & 5 & $161(100.0)$ \\
\hline Laparoscopic resection of liver lesions & 61 & 41 & 10 & 19 & 7 & 3 & $141(87.6)$ \\
\hline Orthotopic liver transplantation & 29 & 17 & 5 & 7 & 4 & 1 & $63(39.1)$ \\
\hline Open living donor resection & 15 & 10 & 4 & 7 & 2 & 1 & $39(24.2)$ \\
\hline Laparoscopic living donor resection & 1 & 1 & 1 & 1 & 0 & 0 & $4(2.5)$ \\
\hline
\end{tabular}

Table 2. Number of resections per surgical unit per year (2009) liver resection

\begin{tabular}{l|l|c|}
\hline Region & \multicolumn{2}{l}{ Liver resections performed in 2009, median (range)/IQR } \\
\hline & Open resection & \multicolumn{2}{l}{ Laparoscopic liver resection } \\
\hline Europe & $5.0(1-61) / 9.0$ & $5.0(1-61) / 9.0$ \\
\hline North America & $45.0(6-200) / 42.5$ & $19.0(2-80) / 21.0$ \\
\hline Central and South America & $32.5(12-80) / 23.5$ & $10.0(3-30) / 18.0$ \\
\hline Asia & $50.0(5-560) / 62.3$ & $6.0(1-80) / 5.0$ \\
\hline Oceania & $57.5(15-150) / 110.0$ & $9.0(1-20) / 7.0$ \\
\hline Africa & $50.0(5-120) / 115.0$ & $4.5(3-13) / 7.8$ \\
\hline Worldwide & $50.0(2-560) / 50.0$ & $9.5(1-80) / 15.0$ \\
\hline
\end{tabular}

$I Q R$, interquartile range.

\section{HOSPITAL LENGTH OF STAY AND FAST-TRACK CARE PROGRAMMES}

The reported median hospital LoS after uncomplicated liver resection was 7 days (range: 2-15 days) after open surgery and 4 days (range: 1-10 days) after laparoscopic surgery. Differences among regions are shown in Table 4. In addition, a subgroup analysis showed that experienced centres achieved a significantly shorter median LoS after laparoscopic liver resection compared with inexperience centres [3.4 days (range: $1-7$ days) vs. 4.2 days (range: $1-10$ days); $P=0.013$ ]. Half of the HPB centres $(50.1 \%)$ had experience with fast-track perioperative care programmes in colonic, hepatic or pancreatic surgery or a combination of these fields. Only $28.0 \%$ had experience with these programmes in liver surgery. Results per region are shown in Table 5. 
Table 3. Numbers of laparoscopic liver surgery centres demonstrating experience defined by a volume of $>20$ laparoscopic resections per year

\begin{tabular}{|l|l|}
\hline Region & Experienced laparoscopic liver centres, $n /$ laparoscopic liver centres, $(\%)$ \\
\hline Europe & $10 / 59(16.9 \%)$ \\
\hline North America & $20 / 41(48.8 \%)$ \\
\hline Central and South America & $3 / 9(33.3 \%)$ \\
\hline Asia & $3 / 19(15.8 \%)$ \\
\hline Oceania & $1 / 7(14.3 \%)$ \\
\hline Africa & $0 / 4$ \\
\hline Worldwide & $37 / 139(26.6 \%)$ \\
\hline
\end{tabular}

IQR, interquartile range.

\section{NECESSITY FOR AN RCT}

The majority (59.4\%) of HPB centres considered that an RCT comparing outcomes in open and laparoscopic liver surgery prior to the further adoption of laparoscopic liver surgery was necessary. A total of $49.1 \%$ considered that a combination of such an RCT and a prospective multicentre registry should be mandatory; $36.4 \%$ considered that a prospective multicentre registry alone would be sufficient and $4.2 \%$ deemed a prospective hospital registry adequate. Of the surgical units that performed both open and laparoscopic left lateral sectionectomy (LLS) within a fast-track/ ERAS programme, $82.9 \%$ indicated that they would consider participating in an RCT. Level A evidence to support the superiority of the laparoscopic technique was still considered necessary by the majority of respondents. A total of $94.3 \%$ of participants with experience in both open and laparoscopic LLS, both within and without fast-track or ERAS programmes, would also consider participating in a prospective registry. Overall, $83.3 \%$ of liver units without experience in laparoscopic liver surgery indicated a desire to participate in hands-on training in laparoscopic liver surgery and/or a proctor programme.

Table 4. Length of stay after uncomplicated liver resection

\begin{tabular}{l|l|l|}
\hline Region & \multicolumn{2}{|l}{ Length of stay, days, median (range)/IQR } \\
\hline & After open resection & After laparoscopic resection \\
\hline Europe & $7.0(4-12) / 3.0$ & $5.0(2-10) / 1.0$ \\
\hline North America & $5.0(4-8) / 2.0$ & $3.0(1-5) / 1.5$ \\
\hline Central and South America & $5.0(2-7) / 1.8$ & $2.5(1-5) / 2.0$ \\
\hline Asia & $7.0(5-15) / 2.0$ & $4.0(3-10) / 2.0$ \\
\hline Oceania & $5.0(3-7) / 1.8$ & $4.0(2-5) / 1.5$ \\
\hline Africa & $8.0(4-10) / 5.5$ & $4.5(2-7) / 4.5$ \\
\hline Worldwide & $7.0(2-15) / 3.0$ & $4.0(1-10) / 2.0$
\end{tabular}

$I Q R$, interquartile range. 
Table 5. Centres with experience in fast-track perioperative care programmes

\begin{tabular}{|l|l|l|l|l|}
\hline \multirow{2}{*}{ Region Experience with ERAS programmes in a specific type of surgery, $n /$ total $n(\%)$} \\
\hline & No experience & In colon surgery & In liver surgery & In pancreatic surgery \\
\hline Europe & $31 / 72(43.1 \%)$ & $36 / 72(50.0 \%)$ & $22 / 72(30.6 \%)$ & $14 / 72(19.4 \%)$ \\
\hline North America & $25 / 42(59.5 \%)$ & $6 / 42(14.3 \%)$ & $9 / 42(21.4 \%)$ & $8 / 42(19.0 \%)$ \\
\hline $\begin{array}{l}\text { Central and South } \\
\text { America }\end{array}$ & $5 / 10(50.0 \%)$ & $4 / 10(40.0 \%)$ & $3 / 10(30.0 \%)$ & $1 / 10(10.0 \%)$ \\
\hline Asia & $15 / 24(62.5 \%)$ & $8 / 24(33.3 \%)$ & $4 / 24(16.7 \%)$ & $3 / 24(12.5 \%)$ \\
\hline Oceania & $2 / 8(25.0 \%)$ & $5 / 8(62.5 \%)$ & $6 / 8(75.0 \%)$ & $2 / 8(25.0 \%)$ \\
\hline Africa & $4 / 5(80.0 \%)$ & $1 / 5(20.0 \%)$ & $1 / 5(20.0 \%)$ & $0 / 5$ \\
\hline Worldwide & $82 / 161(50.9 \%)$ & $60 / 161(37.3 \%)$ & $45 / 161(28.0 \%)$ & $28 / 161(17.4 \%)$ \\
\hline
\end{tabular}

ERAS, enhanced recovery after surgery.

\section{DISCUSSION}

This study aimed to assess the worldwide experience and dissemination of two recently introduced strategies to accelerate recovery after liver surgery. It demonstrates that the majority of HPB centres perform liver surgery in the absence of an enhanced recovery perioperative care programme, and that the majority of HPB centres perform laparoscopic liver surgery. This study also shows substantial variance in hospital LoS among centres and regions. Lastly, this study demonstrates the presence of clinical equipoise in laparoscopic and open liver resection in the HPB community.[22,23] Clinical equipoise refers to a context in which there is no preference or certainty of therapeutic superiority for either laparoscopic or open liver surgery. The majority of liver centres considered that an RCT was necessary to prove the laparoscopic technique to be equal or superior to open surgery.

The results show a high level of dissemination of laparoscopic liver surgery. Both lowand high-volume centres, amounting to $87.6 \%$ of HPB units, perform liver resections laparoscopically. Although the laparoscopic procedure is frequently used, many centres in this study have limited experience in laparoscopic liver resection. By contrast, responding centres displayed limited adoption of enhanced recovery programmes in liver surgery (one in four). The liberal adoption of laparoscopic liver surgery, even in low-volume HPB centres, is seemingly in conflict with current standards of evidencebased practice in the medical community. Neither is it in keeping with recommendations expressed in an expert consensus (the Louisville Consensus), which concluded that laparoscopic liver surgery was safe and effective in the hands of experienced and trained surgeons.[24] In line with the available evidence for fast-track principles in liver surgery,[11-15] proof of the merits of laparoscopic vs. open liver surgery is also limited and no RCTs have been undertaken. However, a recent literature review and meta-analysis of available prospective and retrospective studies comparing 
open with laparoscopic liver resections both found short- and long-term outcomes favourable for the laparoscopic procedure. Not only was LoS markedly shorter, but blood loss and complications were found to be reduced and oncologic outcomes did not differ between the two techniques.[25,26]

Low-volume centres in this study reported a significantly longer hospital LoS compared with high-volume centres. In addition, LoS after open and laparoscopic liver surgery varied substantially among regions. The surgeon's progress along the laparoscopic learning curve influences LoS because laparoscopic liver resection is technically demanding and requires expertise in both advanced laparoscopic skills and open liver surgery.[27] This is in line with the findings of a meta-analysis of studies reporting on 20 or more laparoscopic procedures, which indicated that a laparoscopic approach led to a significant reduction in morbidity and LoS.[21] In addition, differences in standard of care and discharge criteria may also contribute to the variance in LoS reported in the literature (3-20 days after open and 6-32 days after laparoscopic liver resection).[25] Substantial distinctions at a cultural level may lie at the root of the observed variance in LoS. In some regions patients are discharged to a home care institution early in their recovery process (e.g. in North America), whereas in other world regions the provision of protocol-based care and the associated logistics may be lacking. This may lead to a difference in expectations on both the patient's and surgeon's part as to when a patient might be ready for discharge. Thus, LoS is a poor outcome parameter that hampers comparison and is hard to interpret. The implementation of a structured care programme with well-defined recovery and discharge criteria, as used within ERAS protocols, might improve the comparability of clinical outcomes in future (multicentre) trials.

Laparoscopy and enhanced recovery programmes should not be seen as separate methods of improving post-operative recovery and outcomes such as morbidity rates and LoS. On the contrary, it is likely that the implementation of both will result in a synergetic improvement. Enhanced recovery programmes in liver surgery have already been shown to reduce hospital LoS.[12-15] The additional benefit of an ERAS strategy in a laparoscopic setting was recently demonstrated in a trial in colonic surgery and a small pilot study in liver surgery.[11,19] This worldwide survey unveils experiences in enhanced recovery programmes and laparoscopic liver surgery, and deliberations on the need for RCTs in liver surgery. Although the present study achieved a response rate of $>75 \%$, only $23.9 \%$ of respondents completed the survey in full, which limited the study findings. However, representatives of 161 liver surgery centres worldwide shared their results and opinions.

The use of a survey may be seen as limiting the study because results are strongly dependent on the type of respondents, questions and response rate. In addition, the 
group profile of responding centres may have been subject to response bias. Centres of considerable volume and those performing laparoscopic liver surgery may have been more likely to respond.

The issue of importance does not concern a choice between laparoscopic liver resection and an ERAS strategy, but, rather, how both paths can be adequately adopted. The majority of responders still consider an RCT of laparoscopic surgery to be necessary. It could be argued that as more liver centres adopt laparoscopic techniques, opportunities to conduct an RCT may be diminished by patient and surgeon preferences. According to some surgeons, laparoscopic liver resection is without doubt therapeutically superior, whereas for others this remains to be proven. In addition, in the Louisville Consensus of 2008, experts concluded that the accrual of patients for an RCT would be slow as a result of low overall numbers.

The ORANGE II Trial, currently enrolling patients, will be the first RCT (combined with a prospective registry) to provide evidence on laparoscopic vs. open liver resection.[28] As for enhanced recovery programmes, many centres are likely to have already implemented multiple ERAS elements as part of modern care. Further trials are needed to assess compliance with recovery protocols[29,30], specific elements of enhanced recovery programmes and the possible reduction of medical expenses.

\section{CONCLUSION}

The worldwide dissemination of laparoscopic liver resection is substantial, although the average volume of laparoscopic resections carried out in the majority of HPB centres is low. The adoption of enhanced recovery programmes in liver surgery is limited and the issue warrants greater attention. Both strategies are associated with faster recovery and may work synergistically. Given the increasing strength of the role of evidence-based medicine in current surgical practice, more evidence is required. 


\section{REFERENCES}

1. Nguyen KT, Gamblin TC, Geller DA. (2009) World review of laparoscopic liver resection - 2804 patients. Ann Surg 250:831-841.

2. Abu Hilal M, Pearce NW. (2008) Laparoscopic left lateral liver sectionectomy: a safe, efficient, reproducible technique. Dig Surg 25:305-308.

3. Dagher I, Lainas P, Carloni A, Caillard C, Champault A, Smadja C et al. (2008) Laparoscopic liver resection for hepatocellular carcinoma. Surg Endosc 22:372-378.

4. Dagher I, Proske JM, Carloni A, Richa H, Tranchart H, Franco D. (2007) Laparoscopic liver resection: results for 70 patients. Surg Endosc 21:619-624.

5. Lee KF, Cheung YS, Chong CN, Tsang YY, Ng WW, Ling E et al. (2007) Laparoscopic versus open hepatectomy for liver tumours: a case-control study. Hong Kong Med J 13:442-448.

6. O'Rourke N, Fielding G. (2004) Laparoscopic right hepatectomy: surgical technique. J Gastrointest Surg 8:213-216.

7. Troisi R, Montalti R, Smeets P, van Huysse J, van Vlierberghe H, Colle I et al. (2008) The value of laparoscopic liver surgery for solid benign hepatic tumours. Surg Endosc 22:38-44.

8. Laurence JM, Lam VW, Langcake ME, Hollands MJ, Crawford MD, Pleass HC. (2007) Laparoscopic hepatectomy, a systematic review. ANZ J Surg 77:948-953.

9. Abu Hilal M, McPhail MJ, Zeidan B, Zeidan S, Hallam MJ, Armstrong T et al. (2008) Laparoscopic versus open left lateral hepatic sectionectomy: a comparative study. Eur J Surg Oncol 34:1285-1288.

10. Alkari B, Owera A, Ammori BJ. (2008) Laparoscopic liver resection: preliminary results from a UK centre. Surg Endosc 22:2201-2207.

11. Stoot JH, van Dam RM, Busch OR, van Hillegersberg R, De Boer M, Olde Damink SW et al. (2009) The effect of a multimodal fasttrack programme on outcomes in laparoscopic liver surgery: a multicentre pilot study. HPB 11:140-144.

12. van Dam RM, Hendry PO, Coolsen MM, Bemelmans MH, Lassen K, Revhaug A et al. (2008) Initial experience with a multimodal enhanced recovery programme in patients undergoing liver resection. $\mathrm{Br} J$ Surg 95:969-975.

13. Lin DX, Li X, Ye QW, Lin F, Li LL, Zhang QY. (2011) Implementation of a fast-track clinical pathway decreases postoperative length of stay and hospital charges for liver resection. Cell Biochem Biophys 61:413-419.

14. MacKay G, O’Dwyer PJ. (2008) Early discharge following liver resection for colorectal metastases. Scott Med J 53:22-24.

15. Spelt L, Ansari D, Sturesson C, Tingstedt B, Andersson R. (2011) Fast-track programmes for hepatopancreatic resections: where do we stand? HPB 13:833-838.

16. Kehlet H, Wilmore DW. (2002) Multimodal strategies to improve surgical outcome. Am J Surg 183:630641.

17. Lassen K, Soop M, Nygren J, Cox PB, Hendry PO, Spies C et al. (2009) Consensus review of optimal perioperative care in colorectal surgery: Enhanced Recovery After Surgery (ERAS) Group recommendations. Arch Surg 144:961-969.

18. Wind J, Polle SW, Fung Kon Jin PH, Dejong CH, von Meyenfeldt MF, Ubbink DT et al. (2006) Systematic review of enhanced recovery programmes in colonic surgery. Br J Surg 93:800-809.

19. Vlug MS, Wind J, Hollmann MW, Ubbink DT, Cense HA, Engel AF et al. (2011) Laparoscopy in combination with fast track multimodal management is the best perioperative strategy in patients undergoing colonic surgery: a randomized clinical trial (LAFA.study). Ann Surg 254:868-875.

20. Ubbink DT, Legemate DA. (2004) Evidencebased surgery. Br J Surg 91:1091-1092.

21. Simillis C, Constantinides VA, Tekkis PP, Darzi A, Lovegrove R, Jiao L et al. (2007) Laparoscopic versus open hepatic resections for benign and malignant neoplasms - a meta-analysis. Surgery 141:203-21

22. Freedman B. (1987) Equipoise and the ethics of clinical research. N Engl J Med 317:141-145.

23. Rodrigues HC, Oerlemans AJ, van den Berg PP. (2011) [The need for uncertainty in clinical research equipoise.] Ned Tijdschr Geneeskd 155:A3846. 
24. Buell JF, Cherqui D, Geller DA, O'Rourke N, lannitti D, Dagher I et al. (2009) The international position on laparoscopic liver surgery: the Louisville Statement, 2008. Ann Surg 250:825-830.

25. Mirnezami R, Mirnezami AH, Chandrakumaran K, Abu Hilal M, Pearce NW, Primrose JN et al. (2011) Short- and longterm outcomes after laparoscopic and open hepatic resection: systematic review and metaanalysis. HPB 13:295-308.

26. Nguyen KT, Marsh JW, Tsung A, Steel JJ, Gamblin TC, Geller DA. (2011) Comparative benefits of laparoscopic vs. open hepatic resection: a critical appraisal. Arch Surg 146:348-356.

27. van Gulik T. (2009) Open versus laparoscopic resection for liver tumours. HPB 11:465- 468.

28. van Dam RM, Wong-Lun-Hing EM, van Breukelen GJ, Stoot JH, van der Vorst JR, Bemelmans MH et al. (2012) Open versus laparoscopic left lateral hepatic sectionectomy within an enhanced recovery ERAS(R) programme (ORANGE II Trial): study protocol for a randomized controlled trial. Trials 13:54.

29. Maessen J, Dejong CH, Hausel J, Nygren J, Lassen K, Andersen J et al. (2007) A protocol is not enough to implement an enhanced recovery programme for colorectal resection. Br J Surg 94:224-231.

30. Spanjersberg WR, Reurings J, Keus F, van Laarhoven CJ. (2011) Fast track surgery versus conventional recovery strategies for colorectal surgery. Cochrane Database Syst Rev (2):CD007635. 



\section{Chapter 3}

A systematic review of outcomes in patients undergoing liver surgery in an enhanced recovery after surgery pathways

Coolsen MME, Wong-Lun-Hing EM, van Dam RM, van der Wilt AA, Slim K, Lassen K, Dejong CHC

HPB (Oxford). 2013 Apr;15(4):245-51 


\section{ABSTRACT}

\section{OBJECTIVE}

Enhanced recovery after surgery (ERAS) or fast-track protocols have been implemented in different fields of surgery to attenuate the surgical stress response and accelerate recovery. The objective of this study was to systematically review the literature on outcomes of ERAS protocols applied in liver surgery.

\section{METHODS}

The MEDLINE, EMBASE, PubMed and Cochrane Library databases were searched for randomized controlled trials (RCTs), case-control studies and case series published between January 1966 and October 201 comparing adult patients undergoing elective liver surgery in an ERAS programme with those treated in a conventional manner. The primary outcome measure was hospital length of stay (LoS). Secondary outcome measures were time to functional recovery, and complication, readmission and mortality rates.

\section{RESULTS}

A total of 307 articles were found, six of which were included in the review. These comprised two RCTs, three case-control studies and one retrospective case series. Median LoS ranged from 4 days in an ERAS group to 1 days in a control group. Morbidity, mortality and readmission rates did not differ significantly between the groups. Only two studies assessed time to functional recovery. Functional recovery in these studies was reached 2 days before discharge.

\section{CONCLUSION}

This systematic review suggests that ERAS protocols can be successfully implemented in liver surgery. Length of stay is reduced without compromising morbidity, mortality or readmission rates. 


\section{INTRODUCTION}

Liver resection is the preferred treatment for a variety of primary and secondary liver tumours. Major abdominal surgical procedures such as hepatic resections cause a considerable surgical stress reaction and possible derangements in metabolic and pulmonary functions. Specific complications after hepatic resection include postoperative haemorrhage in the first hours to days after surgery, biliary leakage, intraabdominal abscess and liver failure in a later post-operative stage.[1] Improved operative techniques and insight into perioperative management have lowered mortality after liver resection to its current level of well below $5 \%$, but morbidity rates remain high and range between $30 \%$ and 50\%.[2-4]

In the past decade, multimodal enhanced recovery after surgery (ERAS) protocols or fast-track pathways have been applied in different forms of surgery. These pathways were developed to attenuate the surgical stress response and improve recovery, thereby decreasing post-operative complications and post-operative length of stay (LoS) in hospital.[5] ERAS protocols have gained territory quickly because of the associated cost efficiency derived from the reduction in LoS, an important issue in today's context of rapidly increasing health care costs and the consequent need for optimization. To date, studies that show ERAS protocols that reduce LoS and morbidity rates and improve patient satisfaction have been published in the contexts of vascular surgery[6,7], musculoskeletal surgery[8],breast surgery[9] and different forms of abdominal surgery.[10-12]

Enhanced recovery after surgery protocols have also been implemented in liver surgery, but their effectiveness has not been studied extensively. The present systematic review was performed to evaluate the effects of ERAS protocols in liver surgery on time to recovery following surgery and post-operative hospital LoS, and to examine the effects of the implementation of such protocols on complication and readmission rates following liver surgery.

\section{METHODS}

\section{SEARCH STRATEGY}

A systematic search was performed in PubMed, the Cochrane Library, EMBASE and MEDLINE for studies published between January 1966 and October 2011. Languages were restricted to English, Dutch and German. The following search terms were applied using the Boolean operators 'AND' and 'OR': 'clinical pathway', 'critical pathway', 'enhanced recovery', 'accelerated', 'perioperative' and 'fast track', combined 
with 'liver', 'hepatic' and 'resection'. Synonyms of terms were also used in the search. The reference lists of selected papers were hand- searched for articles that were not retrieved in the database search. If necessary, authors of relevant articles were contacted to obtain additional information.

\section{INCLUSION AND EXCLUSION CRITERIA}

Studies were considered eligible for inclusion if they met all of the following inclusion criteria: (i) they reported on adult patients undergoing elective open or laparoscopic liver surgery; (ii) they described an enhanced recovery programme with at least four different perioperative elements, and (iii) they reported outcomes including LoS, post-operative morbidity and mortality, and readmission rates. Studies were excluded if they: (i) described a single intervention in perioperative care rather than a group of interventions combined in an enhanced recovery programme; (ii) reported on emergency, non-elective or transplantation surgery, and (iii) reported a nonsystematic review. Table 1 lists a summary of ERAS items applicable to liver surgery. The items are supported by varying levels of evidence.[13] Perioperative care is considered to fall within an ERAS protocol when at least four different items are included, covering the pre-, intra- and post-operative periods. [14,15]

\section{OUTCOME MEASURES}

The primary outcome measure of this systematic review was hospital LoS. Secondary outcome measures were time to functional recovery, complication rates, readmissions and mortality rates. Criteria for functional recovery were: good pain control with oral analgesia only; tolerance for solid food; no requirement for i.v. fluids; passage of stool, and independent mobility at the preoperative level.[16] Study selection and data selection Abstracts and titles of studies identified by the search were read by two authors (MMEC and AAvdW), each of whom independently made a first selection of studies. These first selections were compared and, in the event that the inclusion of a study required discussion, a third reviewer (RMvD) was consulted. Second and final selections were made independently by each of the two authors after reading the full-text articles. Both randomized as well as non-randomized studies were eligible for inclusion as long as they met the inclusion criteria. The methodological quality of the included studies was assessed using the MINORS (methodological index for non-randomized studies) criteria[17], a checklist scoring eight methodological items for non-comparative studies (maximum of 16 points) and an additional four items for comparative studies (maximum of 24 points). Missing data were obtained by contacting the authors of the relevant studies. 
Table 1. Summary of ERAS elements applicable to liver surgery

\begin{tabular}{l|l}
\hline Evidence based & Probably useful \\
\hline No oral bowel prep & Preoperative counseling \\
\hline $\begin{array}{l}\text { Preop feeding: } \mathrm{CHO} \text { loading up to } 2 \mathrm{~h} \text { before surgery } \\
\text { No pre-anaesthetic medication }\end{array}$ & Intravenous analgesia \\
\hline Anti-thrombotic Prophylaxis & Stimulation of bowel movement with laxatives \\
\hline Single dose antibiotics & Early and scheduled mobilisation \\
\hline Epidural analgesia & Audit \\
\hline Prevention of Post-operative Nausea and Vomiting (PONV) & \\
\hline Avoiding hypothermia & \\
\hline No routine drainage of peritoneal cavity & \\
\hline No post-operative nasogastric intubation & \\
\hline Good fluid balance & \\
\hline Removal of urinary catheter on day 1 & \\
\hline Normal food at will after surgery from day 1 & \\
\hline
\end{tabular}

Evidence based: separate items are graded level 1 or level 2 evidence (according to the guidelines of the Oxford Centre for Evidence Based Medicine ${ }^{13}$ ).

Probably useful: evidence is less strong, but felt to be useful since the items are most probably quality enhancing, are associated generally with a low incidence of adverse effects and low costs.

Data on the following factors were extracted from the included articles: postoperative LoS; number of patients included; patient ages; types of surgery; discharge criteria; functional recovery; mortality; morbidity; readmissions, and protocol adherence.

\section{STATISTICAL ANALYSIS}

As the search strategy did not identify any randomized controlled trials (RCTs) evaluating the outcomes of ERAS protocols against those of traditional care, the MOOSE (meta-analysis of observational studies in epidemiology) checklist for meta-analysis of observational studies was used to assess the possibility of conducting a metaanalysis.[18] The included studies were considered to be too heterogeneous to support this and therefore no attempt at meta-analysis was made. Results are subsequently presented in tables and figures.

\section{RESULTS}

\section{SELECTED ARTICLES AND CHARACTERISTICS OF THE STUDIES}

The literature search produced 307 articles, of which 300 were excluded after their abstracts had been read in the first round of selection because they did not concern the 
evaluation of a fast-track programme in liver surgery (Fig. 1). After evaluation of the remaining seven papers, one was excluded because it was a nonsystematic review.[19]

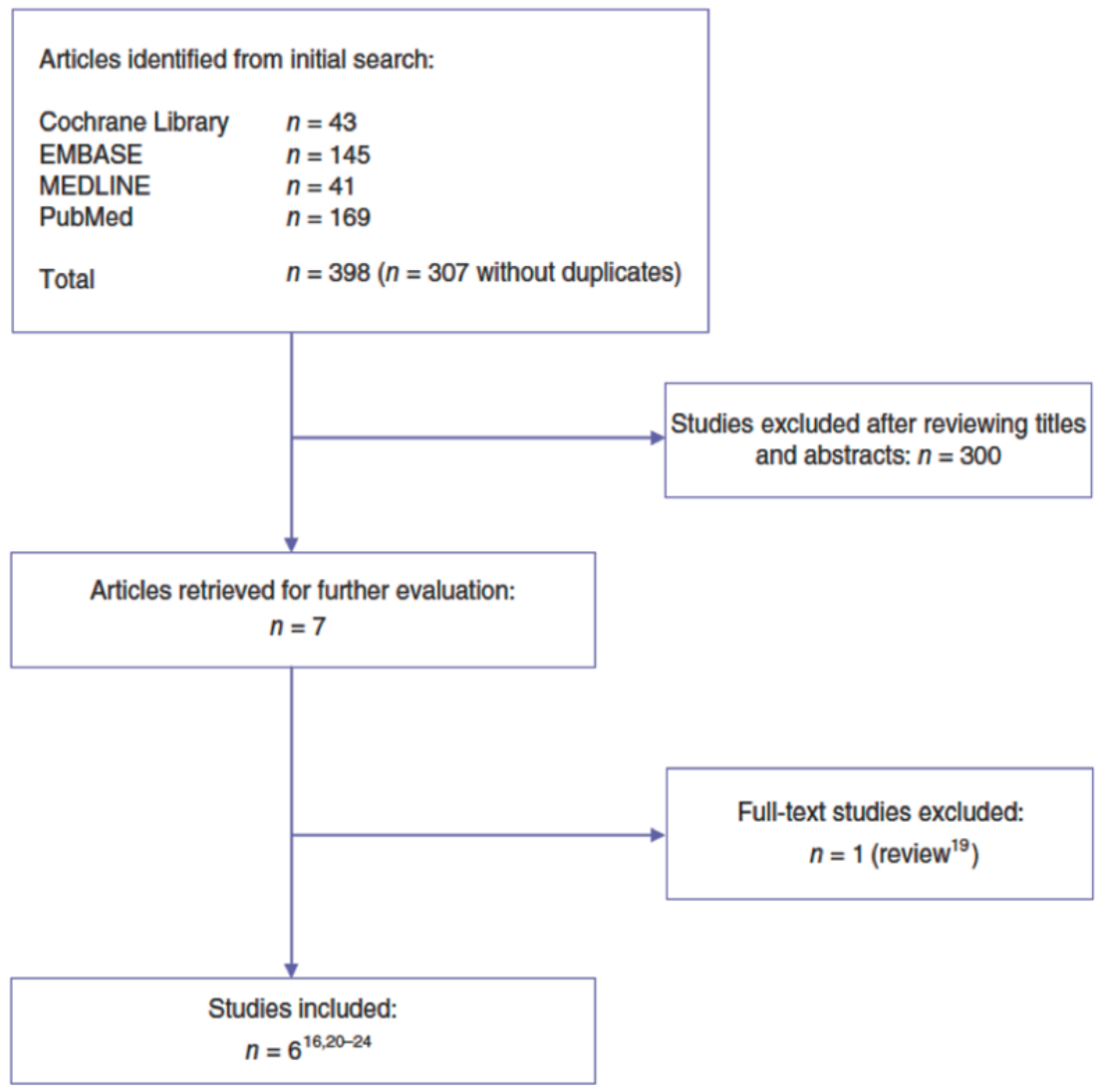

Figure 1. Selection of studies for systematic review

Finally, six papers were included in this systematic review. The details of the included studies are shown in Table 2.

There were no reports of RCTs evaluating the outcomes of an ERAS programme against those of traditional care. In two RCTs, both study groups were treated in an ERAS programme. One of these RC evaluated the use of laxatives and oral nutritional supplements within an ERAS programme[20] and one assessed different forms of post-operative analgesia in two groups managed in a fast-track programme.[21] Three case-control studies and one retrospective case series were also included.[16,22-24] All studies included patients undergoing various forms of liver resection, including (extended) hemi-hepatectomy, metastasectomy, sectionectomy, cen- 
tral resection and repeat hepatectomy. One study did not include major hepatectomies; all patients in this study underwent laparoscopic liver resection.[20]

Table 2. Study characteristics and quality assessment

\begin{tabular}{|c|c|c|c|c|c|c|c|c|}
\hline \multirow[t]{2}{*}{ Study } & \multirow[t]{2}{*}{$\begin{array}{l}\text { Type of } \\
\text { surgery }\end{array}$} & \multirow[t]{2}{*}{$\begin{array}{l}\text { Study } \\
\text { design }\end{array}$} & \multirow{2}{*}{$\begin{array}{l}\text { Patients in } \\
\text { study/control } \\
\text { groups, } n\end{array}$} & \multirow{2}{*}{$\begin{array}{l}\text { Consecutive } \\
\text { series of } \\
\text { patients }\end{array}$} & \multirow{2}{*}{$\begin{array}{l}\text { Length of } \\
\text { follow-up }\end{array}$} & \multicolumn{2}{|c|}{$\begin{array}{l}\text { Age, years, median } \\
\text { (years) }\end{array}$} & \multirow[t]{2}{*}{$\begin{array}{l}\text { MINORS } \\
\text { score }\end{array}$} \\
\hline & & & & & & $\begin{array}{l}\text { ERAS } \\
\text { group }\end{array}$ & $\begin{array}{l}\text { Control } \\
\text { group }\end{array}$ & \\
\hline $\begin{array}{l}\text { Van Dam } \\
\text { et al. } \\
2008\end{array}$ & $\begin{array}{l}\mathrm{HE}, \mathrm{EHE}, \mathrm{ME} \text {, } \\
\mathrm{SE}, \mathrm{CR}, \mathrm{RHE}\end{array}$ & $\mathrm{CC}$ & $61 / 100$ & Yes & 30 & $62(24-82)$ & $60(20-81)$ & $18 / 24$ \\
\hline $\begin{array}{l}\text { Lin et al. } \\
2011\end{array}$ & $\begin{array}{l}\text { SE, HE, EHE, } \\
\text { CR }\end{array}$ & $\mathrm{CC}$ & $56 / 61$ & Yes & 30 & $57(23-73)$ & $55(22-81)$ & $17 / 24$ \\
\hline $\begin{array}{l}\text { Stoot et } \\
\text { al. } 2009\end{array}$ & $\begin{array}{l}\text { Laparoscopic: } \\
\text { ME, SE, LLS }\end{array}$ & CC & $13 / 13$ & Yes & $\begin{array}{l}3-6 \\
\text { months }\end{array}$ & $55(34-82)$ & 45 (26-70) & $19 / 24$ \\
\hline $\begin{array}{l}\text { Hendry } \\
\text { et al } \\
2010\end{array}$ & $\begin{array}{l}\text { HE, ME, SE, } \\
\text { CR }\end{array}$ & $\mathrm{RCT}$ & $68^{*}$ & Yes & 30 & $62(53-69)$ & - & $13 / 16$ \\
\hline $\begin{array}{l}\text { Koea et } \\
\text { al. } 2009\end{array}$ & $\begin{array}{l}\mathrm{HE}, \mathrm{EHE}, \mathrm{ME}, \\
\text { SE }\end{array}$ & $\mathrm{RCT}$ & $100^{*}$ & Yes & 30 & $60(23-83)$ & - & $11 / 16$ \\
\hline $\begin{array}{l}\text { McKay et } \\
\text { al. } 2008\end{array}$ & $\mathrm{HE}, \mathrm{SE}$ & $\begin{array}{l}\text { RS case } \\
\text { series }\end{array}$ & 12 & yes & $?$ & $60(43-74)$ & - & $8 / 16$ \\
\hline
\end{tabular}

aPatients in the control and experimental arms were all treated according to ERAS protocols.

ERAS, enhanced recovery after surgery; $\mathrm{HE}$, hemi-hepatectomy; $\mathrm{EHE}$, extended hemi-hepatectomy; ME, metastasectomy; SE, segmentectomy; $\mathrm{CR}$, central resection; RHE, repeat hemi-hepatectomy; LLS, left lateral sectionectomy; CC, Case-controle; $\mathrm{RCT}$, randomized controlled trial; RS, Retrospective.

All studies included a consecutive series of patients. Follow-up was 30 days in four studies and 3-6 months in one study. One study did not report the duration of follow-up.

Age and other patient characteristics did not differ significantly among the patient groups described in the selected studies. Methodological quality assessed using the MINORS criteria was scored in the range of 17-19 points (of a maximum of 24 points) in case-control studies. Non-comparative studies achieved MINORS scores in the range of 8-13 points (of a maximum of 16 points).

Most studies described the enhanced recovery programme in detail. A summary of the specific ERAS elements included in the different studies is shown in Table 3. Fourteen protocol elements were identified. Most studies included the majority of these elements; one study included only seven elements. 


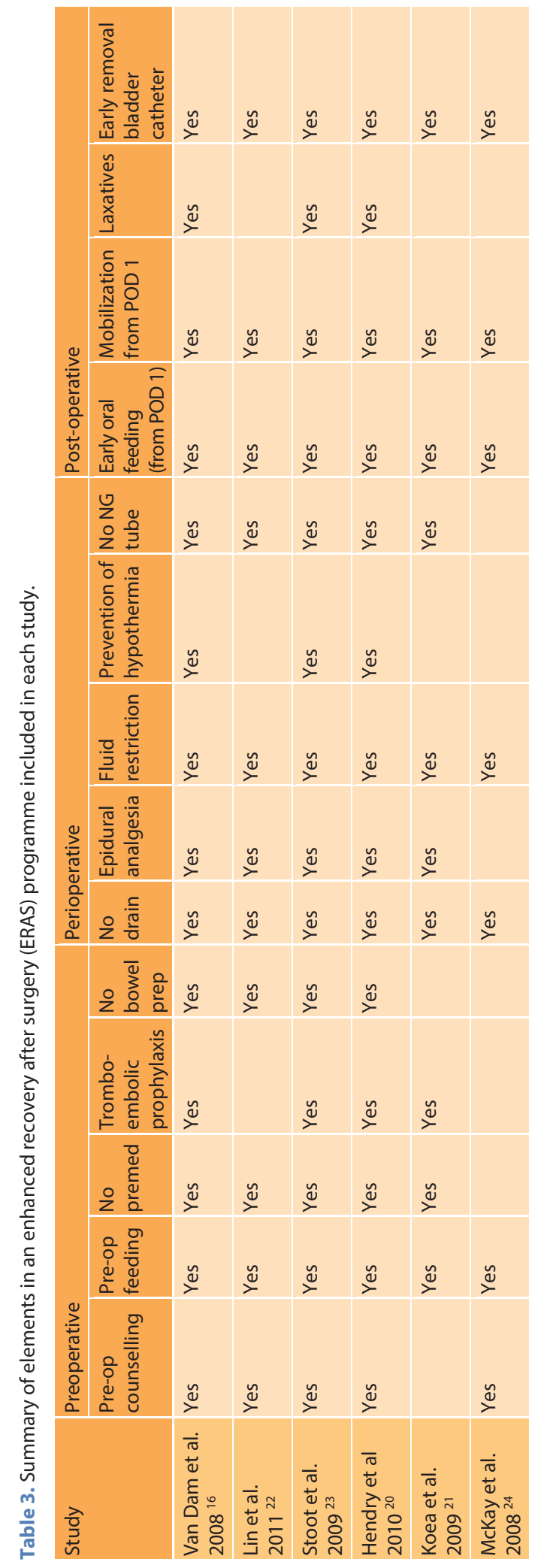




\section{PRIMARY AND SECUNDARY OUTCOME MEASURES}

Table 4 outlines post-operative outcomes after implementation of an ERAS programme. Hospital LoS decreased significantly in the three comparative studies after ERAS implementation, in which median LoS was 5-7 days in the ERAS groups and 711 days in the traditional care groups.

In the non-comparative studies, post-operative LoS after liver resection ranged between 4 days and 7 days. In the study by Stoot et al.[21], all patients underwent laparoscopic liver resection. The median post-operative LoS was 5 days in the ERAS group and 7 days in the traditional care group; however, this difference was not statistically significant and the study did not include major liver resections. It is noteworthy that only two studies[17,20] assessed time to functional recovery and the reasons for delayed discharge. In both studies time to functional recovery was achieved 2 days prior to actual discharge from hospital. The main reasons for later discharge were concern for complications or extensive surgery, low patient confidence, and transport-related or other social problems.

Table 4. Post-operative outcome after implementation of a clinical pathway

\begin{tabular}{|c|c|c|c|c|c|}
\hline Study & Type of surgery & $\begin{array}{l}\text { Length of hospital } \\
\text { stay (days; Study } \\
\text { group vs control) }\end{array}$ & $\begin{array}{l}\text { Morbidity } \\
\text { (\%; Study group } \\
\text { vs control) }\end{array}$ & $\begin{array}{l}\text { Mortality (\%; } \\
\text { Study group } \\
\text { vs control) }\end{array}$ & $\begin{array}{l}\text { Readmissions } \\
\text { (\%; Study group } \\
\text { vs control) }\end{array}$ \\
\hline $\begin{array}{l}\text { Van Dam et al. } \\
2008\end{array}$ & $\begin{array}{l}\text { HE, EHE, ME, SE, } \\
\text { CR, RHE }\end{array}$ & 6 vs $8(p<0.001)$ & 41 vs 31 (ns) & 0 vs 2 (ns) & 13 vs 10 (ns) \\
\hline Lin et al. 2011 & SE, HE, EHE, CR & 7 vs $11(p<0.001)$ & 46.4 vs 43.3 (ns) & 1.8 vs 1.6 (ns) & 7.1 vs 3.3 (ns) \\
\hline Stoot et al. 2009 & $\begin{array}{l}\text { Laparoscopic: } \\
\text { ME, SE, LLS }\end{array}$ & $\begin{array}{l}5 \text { vs } 7 \text { (ns) } \\
\text { Functional recovery: } \\
3 \text { vs } 5(p=0.04)\end{array}$ & 15.3 vs 15.3 (ns) & 0 vs 0 (ns) & 0 vs 0 (ns) \\
\hline Hendry et al 2010 & $\mathrm{HE}, \mathrm{ME}, \mathrm{SE}, \mathrm{CR}$ & $\begin{array}{l}6 \\
\text { Functional recovery: }\end{array}$ & 17 & 2 & 5 \\
\hline Koea et al. 2009 & HE, EHE, ME, SE & $\begin{array}{l}4.7 \pm 0.9 \text { (intrathecal } \\
\text { morphine) } \\
6.8 \pm 1.2 \text { (epidural) }\end{array}$ & 19 & 0 & 4 \\
\hline McKay et al. 2008 & HE, SE & $4(2-7)$ & 16.6 & 0 & 0 \\
\hline
\end{tabular}

[HE: hemihepatectomy, EHE, extended hemihepatectomy, ME: metastasectomy, SE: segmentectomy, CR: central resection, $\mathrm{RHE}$, repeat hemihepatectomy, LLS: left lateral sectionectomy]

Table 5 shows the extent of protocol adherence. The level of adherence to protocol was moderate in the studies included. Generally, nasogastric tubes were either not used or were immediately removed after surgery. The proportion of patients requiring the reinsertion of a nasogastric tube was low. In the study groups, intra- abdominal drains were used in only $2-13 \%$ of patients. The majority of patients re- 
sumed oral fluid intake on the day of surgery and achieved a normal diet on days 1 or 2. The percentage of patients mobilized on the first post-operative day was low, with rates of $20-28 \%$ reported in only two studies.[20,21] In one study full mobilization was achieved on day 3 by $85 \%$ of patients.[16]

Tabel 5. Adherence to protocol

\begin{tabular}{|c|c|c|c|c|c|c|}
\hline Protocol element & $\begin{array}{l}\text { Van Dam et } \\
\text { al. } 2008^{16} \\
\text { (ERAS vs } \\
\text { control) }\end{array}$ & $\begin{array}{l}\text { Lin et al. } \\
2011^{22} \\
\text { (ERAS vs } \\
\text { control) }\end{array}$ & $\begin{array}{l}\text { Stoot et al. } \\
2009^{23} \\
\text { (ERAS vs } \\
\text { control) }\end{array}$ & $\begin{array}{l}\text { Koea et al. } \\
2009^{21} \text { (ERAS, } \\
n=100)\end{array}$ & $\begin{array}{l}\text { Hendry et al. } \\
2010^{20} \\
(\text { ERAS, } n=68)\end{array}$ & $\begin{array}{l}\text { McKay et al. } \\
2008^{24} \\
(\text { ERAS, } n=12)\end{array}$ \\
\hline $\begin{array}{l}\text { No NG tube or } \\
\text { removed directly } \\
\text { after surgery }\end{array}$ & 92 vs $0 \%$ & NA & 0 vs $38 \%$ & $100 \%$ & $100 \%$ & NA \\
\hline NG tube reinserted & 4 vs $0 \%$ & 3.5 vs $1.6 \%$ & 0 vs $15 \%$ & NA & NA & NA \\
\hline $\begin{array}{l}\text { Intra-abdominal } \\
\text { drain }\end{array}$ & 2 vs $66 \%$ & 0 vs $1.6 \%$ & 0 vs $46 \%$ & $2 \%$ & $13 \%$ & $0 \%$ \\
\hline $\begin{array}{l}\text { Oral fluid intake POD } \\
0 \text { (ERAS), } \% \text { or days, } \\
\text { median (range) }\end{array}$ & $92 \%$ & NA & $\begin{array}{l}1(0-2) \text { vs } \\
1(0-6)\end{array}$ & NA & $94 \%$ & $100 \%$ \\
\hline $\begin{array}{l}\text { Resumption normal } \\
\text { food, \% or days, } \\
\text { median (range) }\end{array}$ & $\begin{array}{l}1(0-3) \text { vs } \\
3(0-14)\end{array}$ & NA & $\begin{array}{l}1(0-2) \text { vs } \\
1(0-6)\end{array}$ & $20 \%$ on day 1 & $\begin{array}{l}37 \% \text { on day } 1 \\
91 \% \text { on day } 2\end{array}$ & NA \\
\hline $\begin{array}{l}\text { Full mobilisation } \\
\text { (ERAS) }\end{array}$ & $\begin{array}{l}85 \% \text { on day } \\
3\end{array}$ & NA & NA & $20 \%$ on day 1 & $28 \%$ on day 1 & NA \\
\hline $\begin{array}{l}\text { Functional recovery } \\
\text { criteria met on day }\end{array}$ & NA & NA & 3 vs 5 & NA & 4 & NA \\
\hline
\end{tabular}

NG, nasogastric; PoD, post-operative day; NA = data not available]

\section{DISCUSSION}

This systematic review examined the use of ERAS protocols in liver surgery in three case-control studies, two RCTs and one case series. The results suggest that an enhanced recovery protocol can be successfully implemented in liver surgery. Hospital LoS was reduced and functional recovery was accelerated without compromising morbidity or mortality rates, and readmission rates were not significantly increased. The present results are in line with a recent review describing the use of fast-track protocols in hepatopancreatic resections.[25]

At least four items in the pre-, peri- and post-operative periods must be included in an ERAS protocol for the protocol to be considered of value.[14,15] The studies in this review incorporated an average of 12 of 14 items (range: 7-14 items). In large series of patients undergoing liver surgery, LoS varies between 8 days and 14 days.[3,4] All of the studies included in this review reported a shorter LoS in the ERAS study group. Two studies assessed time to functional recovery, which was significantly lower than 
total LoS. In many studies, LoS is reported as a primary outcome parameter. However, the use of this outcome may not always be appropriate as discharge is often delayed by a variety of other factors that may be unrelated to the true outcomes of the procedure.[26] The present authors therefore propose that time to functional recovery should be used as an outcome measure rather than LoS.

Morbidity rates reported in the literature vary from $38 \%$ to $45 \%[4,27]$ and are comparable with the complication rates reported in the studies in the present review. However, it should be noted that complications in the studies included here were not always reported using a validated classification system (e.g. Clavien-Dindo or Accordion classification $[28,29])$. This makes it more difficult to make meaningful comparisons of morbidity among the different centres.

The reporting of adherence to the various elements of the protocol was rather low in the included studies, especially as far as the introduction of normal diet and fluids was concerned. As Maessen et al.[30] have observed, the reporting of adherence to protocol seems to be problematic in a considerable number of international studies. This impedes comparisons among studies.[30] The use of self-report patient diaries and continuous education of nurses and staff may represent strategies for overcoming this difficulty.

Overall, the methodological quality of the studies included in the present review, as assessed according to the MINORs criteria, was acceptable. However, this systematic review is limited by the fact that no RCTs comparing fast-track with standard care were available for inclusion (the RCTs included treated both the patient and control groups according to an ERAS protocol) and only case series and comparative studies using historical controls were included. The studies included were considered to be too heterogeneous to allow a meta-analysis. Another limitation of this review is that the individual studies used slightly different study protocols, with the result that the items incorporated in the various protocols are not identical and thus these studies are not fully comparable. However, a recent study by Ahmed et al.[31] compared adherence to protocol in two groups of patients undergoing colorectal surgery and showed that outcome was unaltered in the study group in which adherence to some elements of the study protocol (e.g. preoperative carbohydrate loading and early fluid and diet introduction) was significantly lower. From this, it seems reasonable to conclude that not every item of an ERAS protocol makes an independent contribution to enhanced recovery, but, rather, it is the combination of different items in a structured care pathway that determines the outcome. This might also to some degree reflect a Hawthorne, or trial, effect, indicating a positive effect resulting from the implementation per se of a complex and comprehensive intervention. 
Kehlet first introduced ERAS protocols in colon surgery in 1997.[32] Now, 15 years later, several items drawn from ERAS protocols are increasingly implemented in modern care worldwide. However, in many surgical fields, ERAS protocols have not yet been accepted as standard care. In the context of liver surgery, ERAS was first described in 2008 [24], since when only five studies examining an ERAS protocol in this field have been published[16,20-23] and three of these were performed by the same study group.[16,21,23] This seems to illustrate a limited international implementation of ERAS protocols in liver surgery.

Although the methodology used in the studies included is not optimal, the results are consistent and seem to indicate clear advantages in terms of recovery. Although most centres today perform a proportion of resections laparoscopically, the present results serve to illustrate what can be achieved in open surgery and hence serve as a backdrop against which advances in technique and subsequent results can be compared.

In summary, this systematic review shows that it is feasible and safe to implement an ERAS protocol in hepatic surgery. The available evidence suggests that LoS is shortened without comprising morbidity, mortality or readmission rates. In view of the limited number of studies and the discrepancies in reporting among them, the present authors recommend the application of a standardized system of classifying complications, the accurate reporting of adherence to protocol, and the use of time to functional recovery as a primary outcome measure in future studies in order to enhance quality and comparability. 


\section{REFERENCES}

1. van den Broek MA, van Dam RM, van Breukelen GJ, Bemelmans MH, Oussoultzoglou E, Pessaux P et al. (2011) Development of a composite endpoint for randomized controlled trials in liver surgery. $\mathrm{Br} J$ Surg 98:1138- 145.

2. Belghiti J, Hiramatsu K, Benoist S, Massault P, Sauvanet A, Farges O. (2000) Seven hundred forty-seven hepatectomies in the 1990s: an update to evaluate the actual risk of liver resection. J Am Coll Surg 191:38-46.

3. Dimick JB, Wainess RM, Cowan JA, Upchurch GR, Jr, Knol JA, Colletti LM. (2004) National trends in the use and outcomes of hepatic resection. J Am Coll Surg 199:31- 38.

4. Jarnagin WR, Gonen M, Fong Y, DeMatteo RP, Ben-Porat L, Little S et al. (2002) Improvement in perioperative outcome after hepatic resection: analysis of 1803 consecutive cases over the past decade. Ann Surg 236:397-407.

5. Kehlet H, Wilmore DW. (2002) Multimodal strategies to improve surgical outcome. Am J Surg 183:630641.

6. Brustia P, Renghi A, Gramaglia L, Porta C, Cassatella R, De Angelis R et al. (2003) Mininvasive abdominal aortic surgery. Early recovery and reduced hospitalization after multidisciplinary approach. J Cardiovasc Surg (Torino) 44:629-635.

7. Podore PC, Throop EB. (1999) Infrarenal aortic surgery with a 3-day hospital stay: a report on success with a clinical pathway. J Vasc Surg 29:787-792.

8. Barbieri A, Vanhaecht K, Van Herck P, Sermeus W, Faggiano F, Marchisio S et al. (2009) Effects of clinical pathways in the joint replacement: a meta-analysis. BMC Med 7:32.

9. Arsalani-Zadeh R, ElFadl D, Yassin N, Mac-Fie J. (2011) Evidence-based review of enhancing postoperative recovery after breast surgery. Br J Surg 98:181-196.

10. Rawlinson A, Kang P, Evans J, Khanna A. (2011) A systematic review of enhanced recovery protocols in colorectal surgery. Ann R Coll Surg Engl 93:583-588.

11. McCarty TM, Arnold DT, Lamont JP, Fisher TL, Kuhn JA. (2005) Optimizing outcomes in bariatric surgery: outpatient laparoscopic gastric bypass. Ann Surg 242:494-498; discussion 498-501.

12. Kirsh EJ,Worwag EM, Sinner M, Chodak GW. (2000) Using outcome data and patient satisfaction surveys to develop policies regarding minimum length of hospitalization after radical prostatectomy. Urology 56:101-106; discussion 106-107.

13. Phillips B, Ball C, Sackett D, Badenoch D, Straus S, Haynes B et al. (2011) Levels of evidence and grades of recommendations. Oxford Centre for Evidence-Based Medicine. Available at http://www.cebm.net/ index. aspx?o=1025 (last accessed 19 September 2012).

14. Varadhan KK, Neal KR, Dejong CH, Fearon KC, Ljungqvist O, Lobo DN. (2010) The enhanced recovery after surgery (ERAS) pathway for patients undergoing major elective open colorectal surgery: a metaanalysis of randomized controlled trials. Clin Nutr 29:434-440.

15. Wind J, Polle SW, Fung Kon Jin PH, Dejong CH, von Meyenfeldt MF, Ubbink DT et al. (2006) Systematic review of enhanced recovery programmes in colonic surgery. Br J Surg 93:800-809.

16. van Dam RM, Hendry PO, Coolsen MM, Bemelmans MH, Lassen K, Revhaug A et al. (2008) Initial experience with a multimodal enhanced recovery programme in patients undergoing liver resection. $\mathrm{Br} J$ Surg 95:969-975.

17. Slim K, Nini E, Forestier D, Kwiatkowski F, Panis Y, Chipponi J. (2003) Methodological index for nonrandomized studies (MINORS): development and validation of a new instrument. ANZ J Surg 73:712716.

18. Stroup DF, Berlin JA, Morton SC, Olkin I, Williamson GD, Rennie D et al. (2000) Meta-analysis of observational studies in epidemiology: a proposal for reporting. Meta-analysis of Observational Studies in Epidemiology (MOOSE) group. JAMA 283:2008-2012.

19. van Gulik T. (2009) Open versus laparoscopic resection for liver tumours. HPB 11:465-468. 


\section{Chapter 3}

20. Hendry PO, van Dam RM, Bukkems SF, McKeown DW, Parks RW, Preston T et al. (2010) Randomized clinical trial of laxatives and oral nutritional supplements within an enhanced recovery after surgery protocol following liver resection. Br J Surg 97:1198- 1206.

21. Koea JB, Young Y, Gunn K. (2009) Fast-track liver resection: the effect of a comprehensive care package and analgesia with singledose intrathecal morphine with gabapentin or continuous epidural analgesia. HPB Surg 2009:271986.

22. Lin DX, Li X, Ye QW, Lin F, Li LL, Zhang QY. (2011) Implementation of a fast-track clinical pathway decreases postoperative length of stay and hospital charges for liver resection. Cell Biochem Biophys 61:413-419.

23. Stoot JH, van Dam RM, Busch OR, van Hillegersberg R, De Boer M, Olde Damink SW et al. (2009) The effect of a multimodal fasttrack programme on outcomes in laparoscopic liver surgery: a multicentre pilot study. HPB 11:140-144.

24. MacKay G, O'Dwyer PJ. (2008) Early discharge following liver resection for colorectal metastases. Scott Med J 53:22-24.

25. Spelt L, Ansari D, Sturesson C, Tingstedt B, Andersson R. (2011) Fasttrack programmes for hepatopancreatic resections: where do we stand? HPB 13:833-838.

26. Maessen JM, Dejong CH, Kessels AG, von Meyenfeldt MF. (2008) Length of stay: an inappropriate readout of the success of enhanced recovery programmes. World J Surg 32:971-975.

27. McColl RJ, You X, Ghali WA, Kaplan G, Myers R, Dixon E. (2008) Recent trends of hepatic resection in Canada: 1995-2004. J Gastrointest Surg 12:1839-1846; discussion 1846.

28. Clavien PA, Barkun J, de Oliveira ML, Vauthey JN, Dindo D, Schulick RD et al. (2009) The Clavien-Dindo classification of surgical complications: five-year experience. Ann Surg 250:187-196.

29. Strasberg SM, Linehan DC, Hawkins WG. (2009) The accordion severity grading system of surgical complications. Ann Surg 250:177-186.

30. Maessen J, Dejong CH, Hausel J, Nygren J, Lassen K, Andersen J et al. (2007) A protocol is not enough to implement an enhanced recovery programme for colorectal resection. Br J Surg 94:224-231.

31. Ahmed J, Khan S, Gatt M, Kallam R, MacFie J. (2010) Compliance with enhanced recovery programmes in elective colorectal surgery. Br J Surg97:754-758.

32. Kehlet H. (1997) Multimodal approach to control postoperative pathophysiology and rehabilitation. $\mathrm{Br}$ J Anaesth 78:606-617. 


\section{Chapter 4}

\section{Is current perioperative practice in hepatic surgery based on enhanced recovery after surgery (ERAS) principles?}

Wong-Lun-Hing EM, van Dam RM, Heijnen LA, Busch OR, Terkivatan T, van Hillegersberg R, Slooter GD, Klaase JM, de Wilt JH, Bosscha K, Neumann UP, Topal B, Aldrighetti LA, Dejong CHC

World J Surg. 2014 May;38(5):1127-40 


\section{ABSTRACT}

\section{OBJECTIVE}

The worldwide introduction of multimodal enhanced recovery programs has also changed perioperative care in patients who undergo liver resection. This study was performed to assess current perioperative practice in liver surgery in 11 European HPB centres and compare it to enhanced recovery after surgery (ERAS) principles.

\section{METHODS}

In each unit, 15 consecutive patients ( $N=165)$ who underwent hepatectomy between 2010 and 2012 were retrospectively analysed. Compliance was classified as "full', " partial", or "poor" whenever $\geq 80, \geq 50$, or $<50 \%$ of the 22 ERAS protocol core items were met. The primary study end point was overall compliance with the ERAS core program per unit and per perioperative phase.

\section{RESULTS}

Most patients were operated on for malignancy (91\%) and $56 \%$ were minor hepatectomies. The median number of implemented ERAS core items was 9 (range $=7$ 12) across all centres. Compliance was partial in the preoperative (median 2 of 3 items, range $=1-3$ ) and perioperative phases (median 5 of 10 items, range: $4-7$ ). Median post-operative compliance was poor (median 2 of 9 items, range $=0-4$ ). A statistically significant difference was observed between median length of stay and median time to recovery (7 vs. 5 days, $\mathrm{P}<0.001$ ).

\section{CONCLUSION}

Perioperative care among centres that perform liver resections varied substantially. In current HPB surgical practice, some elements of the ERAS program, e.g., preoperative counselling and minimal fasting, have already been implemented. Elements in the perioperative phase (avoidance of drains and nasogastric tube) and postoperative phase (early resumption of oral intake, early mobilization, and use of recovery criteria) should be further optimized. 


\section{INTRODUCTION}

A multimodal enhanced-recovery perioperative care program for elective abdominal surgery was introduced by Kehlet et al. [1] at the end of the last century. The enhanced-recovery concept combines several evidence-based aspects of perioperative care into a structured care pathway, thereby enabling accelerated post-operative recovery and potentially reducing post-operative morbidity. Within the surgical community, several groups, such as the international enhanced recovery after surgery (ERAS) collaboration, have embraced and studied the enhanced recovery concept. This led to the successful introduction of a new standard in perioperative care for colorectal surgery patients [2]. In recent years the same principles have also been applied in the perioperative care of liver surgery patients, and a few studies have shown that the program is feasible, safe, and effective for resection of hepatic tumours [3-10].

Actual data on the status of current practice and whether multimodal clinical pathways in liver surgery have been implemented are scarce. Over time, several elements of the ERAS concept have probably been introduced without implementation of a fully formal enhanced-recovery program. A recent survey in the international HPB community showed marginal implementation of ERAS protocols worldwide [11]. Based on the successful introduction and implementation of ERAS programs in various fields of surgery [12-17] and promising results in hepatic surgery, further dissemination of the ERAS concept within the liver surgical field seems desirable. First, to accelerate recovery and reduce length of hospital stay, it is necessary to aim for uniform and evidence-based perioperative management. Moreover, a structured and detailed program with well-defined recovery and discharge criteria can improve comparability of clinical outcomes in clinical audits and future clinical trials. Finally, it is likely that implementation will have a synergetic effect with minimally invasive surgery, as shown in colorectal surgery [18].

It has been suggested that implementation of a structured enhanced-recovery program in liver surgery is hard to achieve since multidisciplinary involvement is essential [19]. However, surgical practice has changed over the years and many ERAS elements may have already been introduced in current practice. Therefore, following an initial electronic survey [11], the aim of this study was to more accurately evaluate current perioperative care by assessing to what extent the different elements of an ERAS program have been implemented in liver surgery in a group of expert HPB units in Europe. 


\section{METHODS}

\section{STUDY DESIGN}

A retrospective analysis of prospectively collected data was conducted to assess current perioperative practice in patients undergoing liver surgery in a number of expert HPB centres in Europe. Fifteen consecutive patients per centre were assessed. All available medical records (patient and nursing charts, surgery and anaesthesia reports) for the different elements in the pre-, intra-, and post-operative phases of admission were reviewed and evaluated using a detailed baseline checklist that consisted of the previously described ERAS elements [4]. This checklist was further developed and adjusted by two hepatic surgeons (RMvD, CHCD) and two researchers (EMWLH, LH). Primary study endpoints were overall compliance with the ERAS core program per unit and per element. Secondary endpoints were day of discharge and time to functional recovery (FR).

\section{ERAS ELEMENTS AND COMPLIANCE}

The program's core elements are displayed in Table 1 and are grouped as pre-, peri (day of surgery), and post-operative elements. If an element in the checklist was marked as "yes", the hospital was able to apply the ERAS element for a particular patient. Details explaining (non)compliance were also added to the "Comments" section of the checklist. Compliance was defined as the degree to which individual units or elements were in accordance with the ERAS program. Units were classified as "fully", "partially" or "poorly" compliant whenever $\geq 80, \geq 50$, or $>50 \%$, respectively, of the assessed 22 ERAS core items were met. Per individual element, an $80 \%$ cut-off value was set to qualify a unit as "compliant." In addition, time to FR was assessed with predefined and previously described criteria [4, 5] (Table 2).

\section{STUDY POPULATION}

Liver units with a declared interest to participate in a random controlled trial (RCT) on laparoscopic liver resection in an ERAS setting [20] were invited by email to participate in this retrospective study. A total of 11 European high-volume centres (25 cases/year)[21] participated (see list below). The last 15 consecutive patients who underwent liver surgery in each hospital were selected and reviewed (open- close procedures and biliodigestive /vascular anastomoses were excluded). Included patients were all admitted and operated on between 2010 and 2012. All patients received perioperative care according to local protocols. 
Table 1. ERAS core protocol elements

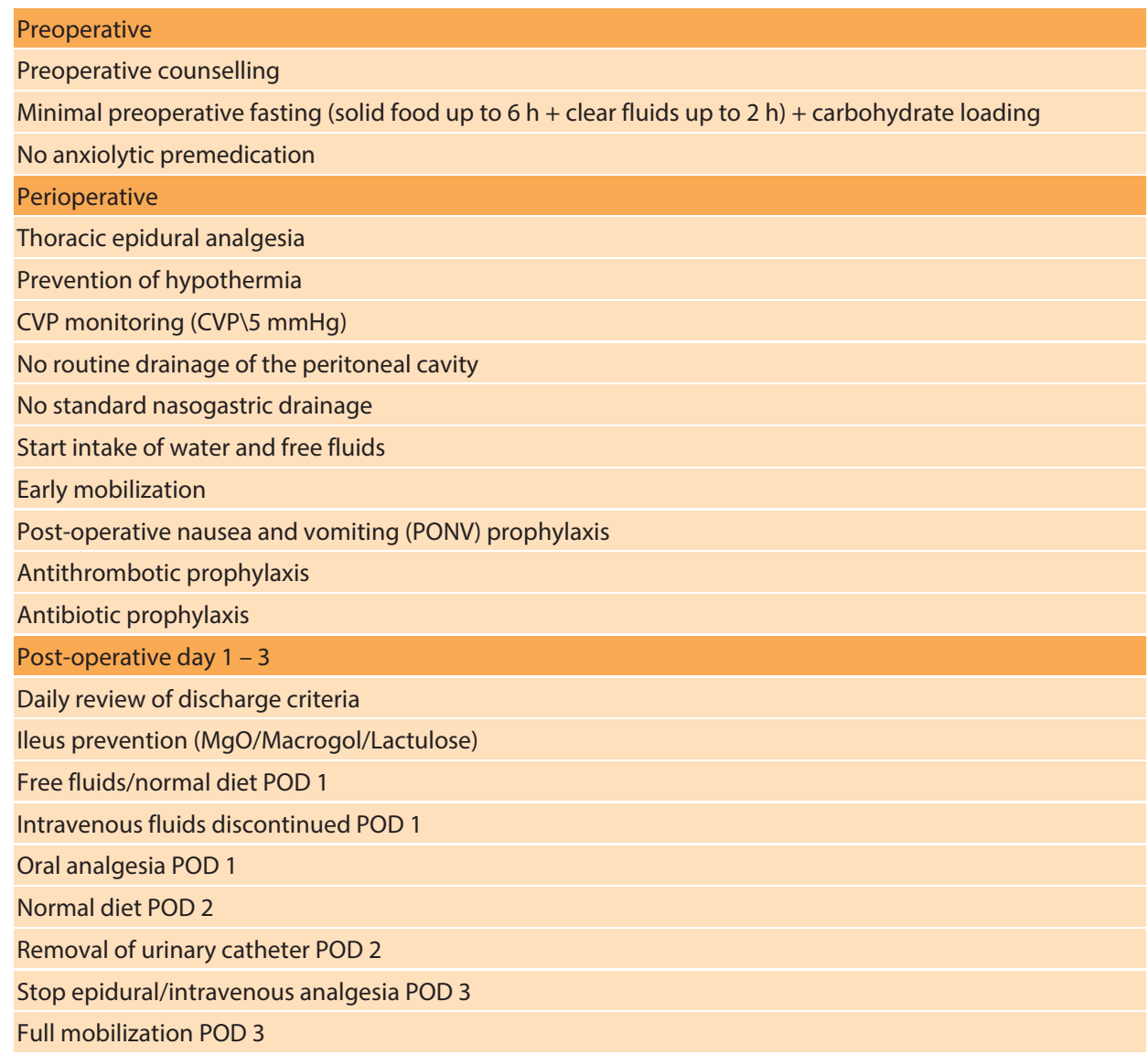

Table 2. Functional recovery criteria

1. Pain control with oral analgesia only

2. No intra-venous fluid support

3. Full mobilization to preoperative level

4. Eating of solid food

5. Normal serum bilirubin or returning toward normal ranges

\section{ERAS EXPERIENCE}

Three of the 11 centres indicated that they had formally implemented ERAS protocol for liver surgery. The implementation of ERAS principles in these three centres was achieved by multidisciplinary involvement, including a liver surgeon, an anaesthetist, recovery ward nursing staff, and a researcher. In addition, all Dutch centres in this study had already gained experience with the ERAS program for colonic surgery as 
most of them participated in a nationwide structured implementation plan [22, 23]. The other hospitals were aware of the ERAS programs for liver and colonic surgery, but a structured implementation and evaluation had not yet been performed. Centres that had implemented the ERAS liver surgery program used the FR criteria (Table 2) to assess readiness for discharge. In the other centres the operating surgeon or physician on call was responsible for discharge and no strict criteria were applied.

\section{DATA AND STATISTICS}

Data were anonymously collected in an Oracle 10 database (Oracle Corp., Redwood Shores, CA, USA) with OpenClinica trial software for online data capture and management (Ikaza Research, Cambridge, MA, USA) and analysed using SPSS ver. 19 (SPSS Inc., Chicago, IL, USA). Basic analyses were performed using descriptive statistics. To describe the compliance in the complete cohort based on results of individual centres, a random-effect logistic regression analysis was used. This adjusts for the heterogeneity of compliance among centres. The constant in the logistic regression model was transformed to an overall cohort compliance, except for three items that did not fit into the model (weighted median was used in these cases). Comparison between groups was performed using the Mann-Whitney $U$ and Wilcoxon signedranks tests as appropriate. All statistical tests were two-sided, and $\mathrm{P}<0.05$ was considered statistically significant.

\section{RESULTS}

\section{PATIENT AND SURGICAL CHARACTERISTICS}

A total of 165 patients were included in this study. Baseline patient characteristics are given in Table 3. Surgical details with regard to type of incision and resection are given in Table 4. Overall morbidity and the distribution of post-operative surgical complications according to the Clavien-Dindo grading system can be found in Table 5.

\section{PRIMARYENDPOINTS}

Overall compliance with the ERAS core elements varied among the assessed centres (Fig. 1). None of the participating hospitals were shown to be "fully" compliant with the complete set of core ERAS elements. Centres provided a median number of 9 (range = 7-12) of pre-, peri-, and post-operative care items according to the ERAS protocol. Five hospitals were partially compliant (11 or more items) and the remaining six hospitals were poorly compliant to the core elements. A summary of the overall compliance per ERAS element across all units ( $\mathrm{N}=165$ patients) is given in Tables 6 and 7 . 
Table 3. Baseline characteristics of patients $(N=165)$

\begin{tabular}{|l|c|}
\hline Median age, years (range) & $62(19-89)$ \\
\hline Male gender & $83(50)$ \\
\hline ASA grade & \\
\hline I & $21(13)$ \\
\hline II & $111(67)$ \\
\hline III & $32(19)$ \\
\hline Missing & $1(1)$ \\
\hline Malignancy & $150(91)$ \\
\hline
\end{tabular}

Values in parentheses are percentages, unless indicated otherwise.

ASA American Society of Anaesthesiologists

Table 4. Surgical characteristics of patients $(N=165)$

\begin{tabular}{|c|c|}
\hline Incision & \\
\hline Laparoscopic & $22(13)$ \\
\hline Kocher's/J-shaped & $81(49)$ \\
\hline Bilateral subcostal & $19(12)$ \\
\hline Mercedes & $12(7)$ \\
\hline Median & $13(8)$ \\
\hline Other $^{\mathrm{a}}$ & $11(7)$ \\
\hline NA & $7(4)$ \\
\hline \multicolumn{2}{|l|}{ Liver resection } \\
\hline Minor (<3 segments or non-anatomical) & $93(56)$ \\
\hline Major ( $\geq 3$ segments) & $45(27)$ \\
\hline Simultaneous non-hepatic & $27(16)$ \\
\hline \multicolumn{2}{|l|}{ Type } \\
\hline Wedge resection/segmentectomy & $46(28)$ \\
\hline Bisegmentectomy & $23(14)$ \\
\hline Right hepatectomy & $24(15)$ \\
\hline Left hepatectomy & $2(1)$ \\
\hline Deroofing/enucleation & $1(1)$ \\
\hline Extended right hepatectomy & $4(2)$ \\
\hline Extended left hepatectomy & $2(1)$ \\
\hline Multiple wedge resections/segmentectomies & $35(21)$ \\
\hline Major ( $\geq 3$ segments) & $10(6)$ \\
\hline Other $^{\mathrm{b}}$ & $28(17)$ \\
\hline Major ( $\geq 3$ segments) & $3(2)$ \\
\hline
\end{tabular}

Values in parentheses are percentages, NA not available a Thoracoabdominal and xiphopubic incisions

b Hepatic resections combined with RFA or nonhepatic procedures 


\section{Chapter 4}

Table 5. Morbidity $(\mathrm{N}=165)$

\begin{tabular}{|l|c|}
\hline Overall morbidity & $47(28)$ \\
\hline Clavien-Dindo & $8(5)$ \\
\hline Grade I & $26(16)$ \\
\hline Grade II & $6(4)$ \\
\hline Grade IIla & $2(1)$ \\
\hline Grade IIIb & $5(3)$ \\
\hline Grade IVa & - \\
\hline Grade IVb & - \\
\hline Grade V (death) & $3(2)$ \\
\hline Readmissions & \\
\hline
\end{tabular}

Values in parentheses are percentages

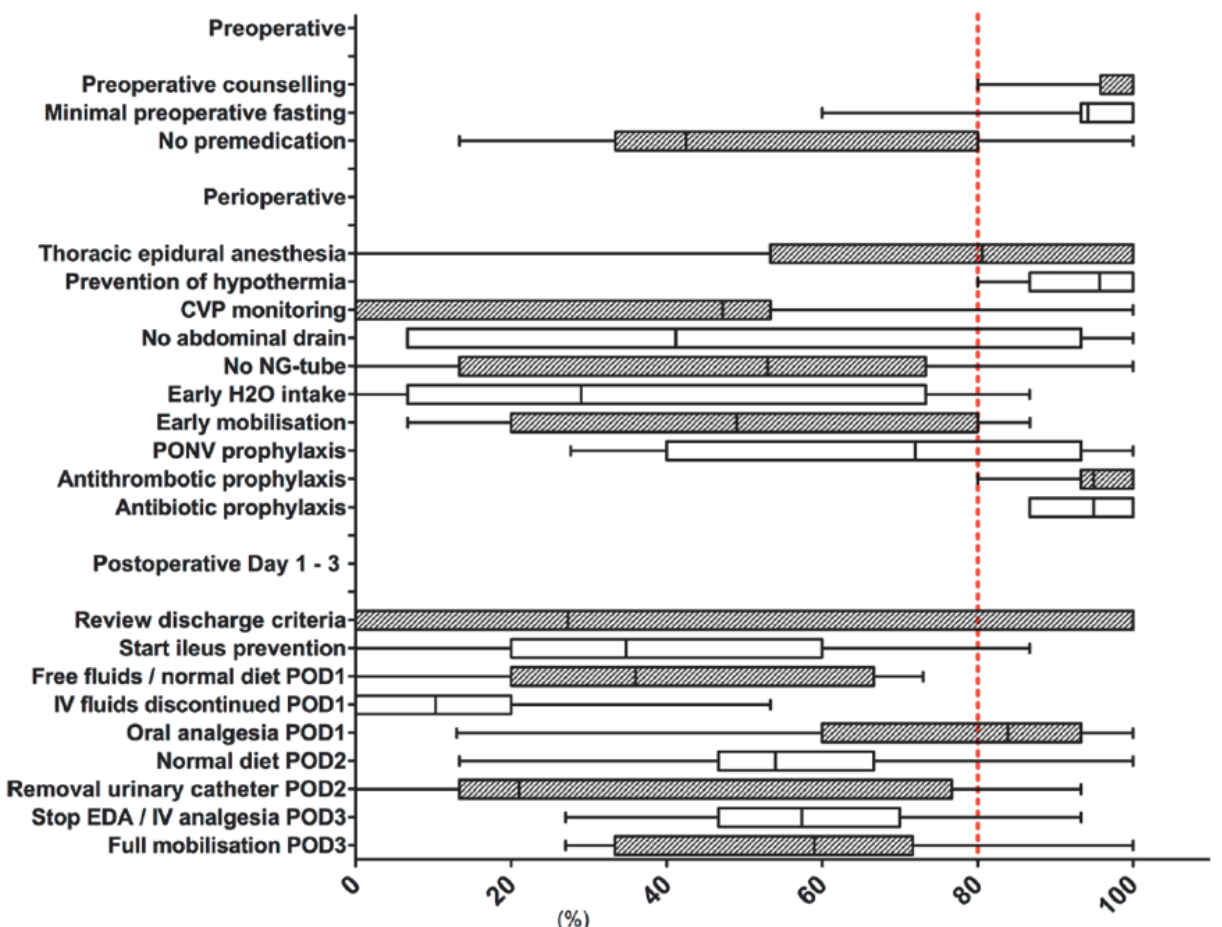

Figure 1. Box plots of overall compliance per ERAS core elements of 11 participating centres. Box plots resemble the $25-75 \%$ confidence intervals. Black vertical line within a box is the median value. The vertical dotted line represents the $80 \%$ compliance cut-off value. 
Table 6. Compliance with ERAS elements

\begin{tabular}{|c|c|c|}
\hline & $\begin{array}{l}\text { N/total } \\
\text { N (\%) }\end{array}$ & $\begin{array}{l}\text { Overall median } \\
\text { compliance } \\
\text { (range) }\end{array}$ \\
\hline \multicolumn{3}{|l|}{ Preoperative } \\
\hline Preoperative counselling & $162 / 165(98)$ & $96(80-100)$ \\
\hline Assessment of discharge arrangements & $120 / 165(73)$ & $73(0-100)^{a}$ \\
\hline Assessment of mobility & $122 / 164(74)$ & $74(0-100)^{\mathrm{a}}$ \\
\hline Daily review of discharge criteria & $45 / 165(27)$ & $27(0-100)^{a}$ \\
\hline Normal oral diet up to $6 \mathrm{~h}+$ clear fluid intake up to $2 \mathrm{~h}$ & $155 / 165(94)$ & $94(60-100)$ \\
\hline No anxiolytic premedication & $91 / 162(56)$ & $43(13-100)$ \\
\hline \multicolumn{3}{|l|}{ Perioperative } \\
\hline Thoracic epidural anaesthesia (EDA) & $119 / 165(72)$ & $81(80-100)$ \\
\hline Prevention of hypothermia & $157 / 160(98)$ & $96(80-100)$ \\
\hline Laparoscopy / right subcostal incision & $102 / 159(64)$ & $65(13-87)$ \\
\hline CVP monitoring (CVP $<5 \mathrm{mmHg}$ ) & $47 / 102(46)$ & $47(0-100)$ \\
\hline No post-operative nasogastric tube & $72 / 161(45)$ & $53(0-100)$ \\
\hline No routine use of abdominal drain & $76 / 165(46)$ & $41(7-100)$ \\
\hline \multicolumn{3}{|l|}{ Post-operative day (POD) 0} \\
\hline PONV prophylaxis & $110 / 164(67)$ & $82(40-100)$ \\
\hline Antithrombotic prophylaxis & $157 / 164(96)$ & $95(80-100)$ \\
\hline Antibiotic prophylaxis & $155 / 162(96)$ & $95(87-100)$ \\
\hline Oral fluid intake & $100 / 162(62)$ & $42(7-87)$ \\
\hline Mobilisation at all & $13 / 150(9)$ & $6(7-87)$ \\
\hline Start oral analgesia & $86 / 163(51)$ & $51(7-100)$ \\
\hline Use of patient-controlled analgesia (EDA or IV) & $132 / 165(80)$ & $83(0-93)$ \\
\hline \multicolumn{3}{|l|}{ POD 1} \\
\hline Nasogastric tube removed & $107 / 160(67)$ & $66(0-100)$ \\
\hline Tolerance of free fluids / normal diet & $63 / 165(38)$ & $36(0-73)$ \\
\hline Mobilisation at all / out of bed & $82 / 160(51)$ & $50(7-87)$ \\
\hline No intravenous fluids & $17 / 165(10)$ & $10(0-53)$ \\
\hline Oral analgesia & $129 / 165(78)$ & $84(13-93)$ \\
\hline Use of patient-controlled analgesia (EDA / IV) & $114 / 165(69)$ & $75(0-93)$ \\
\hline CAD removal & $14 / 161(9)$ & $5(0-60)$ \\
\hline Flatulence and/or stool & $15 / 148(10)$ & $10(0-20)$ \\
\hline \multicolumn{3}{|l|}{ POD 2} \\
\hline Normal diet & $101 / 165(61)$ & $54(13-80)$ \\
\hline Mobilisation out of bed & $118 / 159(74)$ & $76(13-93)$ \\
\hline No intravenous fluids & $34 / 165(21)$ & $19(0-67)$ \\
\hline Oral analgesia & $135 / 165(82)$ & $86(13-93)$ \\
\hline Use of patient-controlled analgesia (EDA / IV) & $91 / 165(55)$ & $54(0-87)$ \\
\hline Urinary catheter removal & $41 / 159(26)$ & $21(0-93)$ \\
\hline Flatulence and/or stool & $59 / 145(41)$ & $41(0-67)$ \\
\hline
\end{tabular}




\begin{tabular}{|l|l|l|}
\hline & $\begin{array}{l}\text { N/total } \\
\mathrm{N}(\%)\end{array}$ & $\begin{array}{l}\text { Overall median } \\
\text { compliance } \\
\text { (range) }\end{array}$ \\
\hline POD 3 & $120 / 165(73)$ & $73(13-93)$ \\
\hline Normal diet & $81 / 151(57)$ & $86(27-93)$ \\
\hline Full mobilisation & $76 / 165(46)$ & $56(0-73)$ \\
\hline No intravenous fluids & $139 / 165(84)$ & $90(13-93)$ \\
\hline Oral analgesia & $46 / 165(28)$ & $25(0-87)$ \\
\hline Use of Patient Controlled Analgesia (EDA / IV) & $85 / 157(54)$ & $52(0-93)$ \\
\hline Urinary catheter removal & $108 / 154(70)$ & $71(13-93)$ \\
\hline Flatulence and/or Stool & $61 / 165(37)$ & $35(0-87)$ \\
\hline Use of cathartics / laxatives & & \\
\hline
\end{tabular}

Overall median compliance represents all assessed centres $(N=11)$

CVP central venous pressure, PONV post-operative nausea and vomiting,

IV intravenous,.

a Weighted median

\section{PRIMARY ENDPOINTS}

Overall compliance with the ERAS core elements varied among the assessed centres (Fig. 1). None of the participating hospitals were shown to be "fully" compliant with the complete set of core ERAS elements. Centres provided a median number of 9 (range $=7-12$ ) of pre-, peri-, and post-operative care items according to the ERAS protocol. Five hospitals were partially compliant (11 or more items) and the remaining six hospitals were poorly compliant to the core elements. A summary of the overall compliance per ERAS element across all units ( $N=165$ patients) is given in Tables 6 and 7.

\section{PREOPERATIVE}

Median compliance of the centres with preoperative core items was partial $(66 \%, 2$ of 3 elements, range $=1-3$ ). All centres provided preoperative counselling, predominantly on procedural issues and complications. Three centres provided extensive counselling, with attention to post-operative elements such as early oral feeding and mobilization, FR, and discharge criteria. No record of preoperative counselling could be found for $2 \%$ of the patients. For $94 \%(60-100)$ of the patients, preoperative fasting was reduced to a minimum. Anxiolytic premedication was not given to $43 \%$ (13$100)$ of the patients. 
Table 7. Compliance with ERAS core elements per centre

\begin{tabular}{|c|c|c|c|c|c|c|c|c|c|c|c|}
\hline & \multicolumn{11}{|c|}{ Centres } \\
\hline & A & B & C & D & $\mathrm{E}$ & $\mathrm{F}$ & G & $\mathrm{H}$ & I & J & K \\
\hline \multicolumn{12}{|l|}{ Preoperative } \\
\hline Preoperative counselling (\%) & 100 & 100 & 100 & 100 & 100 & 100 & 100 & 80 & 93 & 100 & 100 \\
\hline Minimal preoperative fasting (\%) & 60 & 100 & 100 & 100 & 100 & 100 & 100 & 80 & 93 & 100 & 100 \\
\hline No anxiolytic premedication (\%) & 13 & 67 & 80 & 40 & 40 & 27 & 80 & 100 & 87 & 20 & 53 \\
\hline \multicolumn{12}{|l|}{ Perioperative } \\
\hline Thoracic epidural analgesia (\%) & 100 & 93 & 100 & 80 & 87 & 93 & 100 & 53 & 7 & 0 & 80 \\
\hline Prevention of hypothermia (\%) & 87 & 93 & 93 & 100 & 80 & 100 & 100 & 100 & 87 & 100 & 100 \\
\hline CVP monitoring (\%) & 13 & 33 & 13 & 53 & 7 & 0 & 0 & 100 & 20 & 73 & 0 \\
\hline $\begin{array}{l}\text { No routine drainage of the peritoneal } \\
\text { cavity }(\%)\end{array}$ & 67 & 53 & 100 & 93 & 100 & 27 & 53 & 7 & 7 & 7 & 87 \\
\hline No standard nasogastric drainage (\%) & 27 & 40 & 13 & 67 & 73 & 7 & 53 & 0 & 13 & 87 & 100 \\
\hline Start intake of water/free fluids (\%) & 7 & 40 & 80 & 0 & 47 & 13 & 67 & 0 & 0 & 80 & 87 \\
\hline Early mobilization (\%) & 7 & 47 & 33 & 53 & 20 & 13 & 80 & 87 & 40 & 87 & 73 \\
\hline PONV prophylaxis (\%) & 80 & 27 & 93 & 73 & 93 & 47 & 100 & 40 & 93 & 33 & 60 \\
\hline Antithrombotic prophylaxis (\%) & 93 & 80 & 93 & 93 & 100 & 100 & 100 & 100 & 100 & 93 & 100 \\
\hline Antibiotic prophylaxis (\%) & 100 & 100 & 87 & 93 & 100 & 87 & 93 & 100 & 93 & 100 & 87 \\
\hline \multicolumn{12}{|l|}{ Post-operative days $1-3$} \\
\hline Daily review of discharge criteria (\%) & 0 & 0 & 0 & 100 & 0 & 0 & 100 & 0 & 0 & 0 & 100 \\
\hline lleus prevention (\%) & 27 & 13 & 40 & 87 & 27 & 60 & 20 & 27 & 0 & 80 & 27 \\
\hline Free fluids/normal diet POD 1 (\%) & 20 & 33 & 20 & 73 & 47 & 33 & 67 & 0 & 7 & 53 & 67 \\
\hline $\begin{array}{l}\text { Intravenous fluids discontinued POD } \\
1(\%)\end{array}$ & 0 & 0 & 0 & 0 & 0 & 0 & 53 & 0 & 33 & 20 & 7 \\
\hline Oral analgesia POD 1 (\%) & 100 & 87 & 93 & 100 & 60 & 93 & 93 & 13 & 73 & 53 & 93 \\
\hline Normal diet POD 2 (\%) & 40 & 67 & 47 & 100 & 53 & 67 & 40 & 13 & 73 & 100 & 73 \\
\hline Removal of urinary catheter POD $2(\%)$ & 0 & 47 & 7 & 13 & 13 & 7 & 0 & 27 & 40 & 93 & 33 \\
\hline $\begin{array}{l}\text { Stop epidural/intravenous analgesia } \\
\text { POD } 3(\%)\end{array}$ & 27 & 80 & 53 & 73 & 53 & 33 & 60 & 60 & 93 & 60 & 40 \\
\hline Full mobilization POD 3 (\%) & 27 & 73 & 60 & 80 & 40 & 27 & 33 & 67 & 100 & 33 & 33 \\
\hline
\end{tabular}

Total $\mathrm{N}=165$, with 15 patients per centre

CVP central venous pressure, PONV post-operative nausea and vomiting, POD post-operative day

\section{PERIOPERATIVE}

Median compliance with perioperative core items was partial (50\%, 5 of 10 elements, range $=4-7)$. Ninety-six per cent (87-100) of the patients received active prevention of hypothermia and $81 \%(0-100)$ received thoracic epidural anaesthesia. In $13 \%(0-$ $13)$, the procedure was laparoscopically performed, and in $49 \%$ (26-100), a right subcostal incision was used. In $47 \%$ (0-100) of the patients, the central venous pressure (CVP) was closely monitored and kept below $5 \mathrm{mmHg}$ during parenchymal tran- 
section. In $53 \%$ (0-100) of the patients, nasogastric tubes (NGT) were removed immediately after the operation, and in $41 \%$ (7-100), abdominal drains were not used. In contrast to antithrombotic and antibiotic prophylaxes, prophylaxis for postoperative nausea and vomiting (PONV) was frequently provided, but not as per routine in all patients.

\section{POST-OPERATIVE}

Median compliance of the centres with post-operative core items was poor $(22 \%, 2$ of 9 elements, range $=0-6)$. Early oral fluid intake, directly after surgery, was commenced in only $42 \%$ (7-87) of the patients on POD 0 , and only $36 \%(0-73)$ tolerated free fluids or a normal diet on POD 1 (independent of the extent of liver surgery). After surgery patient-controlled intravenous ( $P C I A)$ or epidural analgesia (PCEA) was started in $83 \%(0-93)$ of the patients as the standard of care. Oral analgesia was provided to $90 \%$ (13-93) of patients, but in $14 \%$ oral pain medication was not started until POD 2. Mobilization was achieved in only $50 \%$ (13-93) of the patients on POD 1. In $56 \%$ (0-73) of the patients, IV support was discontinued on POD 3. Urinary catheters were removed on POD 3 in $52 \%(0-93)$, and they were usually not removed until the day of or the day after thoracic epidural anaesthesia was discontinued. Signs of return of bowel function (flatulence and/or stool) were seen in $71 \%$ (13-93) of patients on POD 3.

\section{SECONDARY ENDPOINTS}

Data on the day of discharge and the time to FR are depicted in Fig. 2. The median length of stay (LOS) after surgery was 7 (range $=1-27$ ) days and 31,49 , and $64 \%$ of all patients were discharged on POD 5, 6, and 7, respectively. Using the FR criteria, a majority of the patients could be considered functionally recovered on median POD 5 (1-24). This difference between discharge and time to FR was statistically significant $(P<0.001)$. Eighty-one per cent $(N=133)$ of the patients were not discharged on the day that FR criteria were fulfilled. In $29 \%$ of patients, complications were responsible for prolonged hospitalization (Table 5). Although time to FR and LOS were in favour of the centres that were partially compliant with the ERAS program, differences did not reach statistical significance (Figs. 3, 4). 


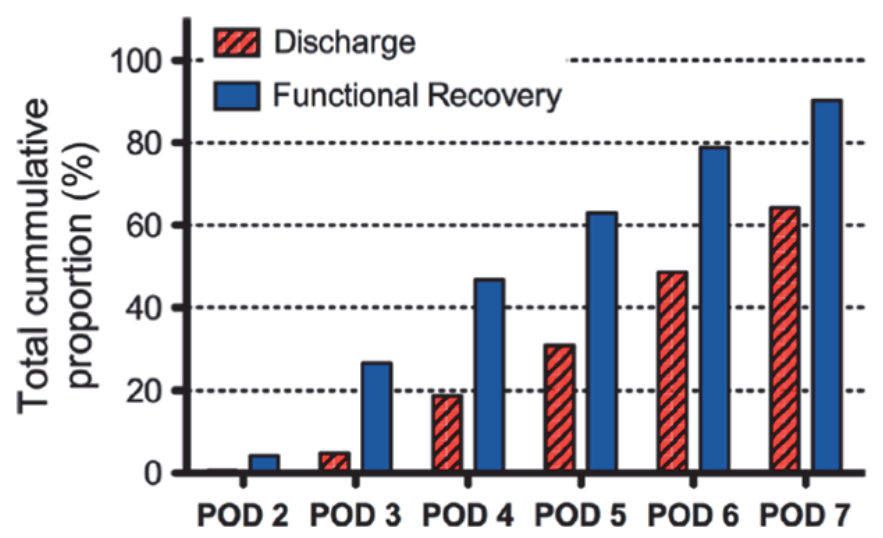

Figure 2. Discharge versus functional recovery, $P<0.001$. Cumulative proportion of all patients $(N=165)$ who were discharged on POD 2-7 and who were functionally recovered (FR). POD post-operative day

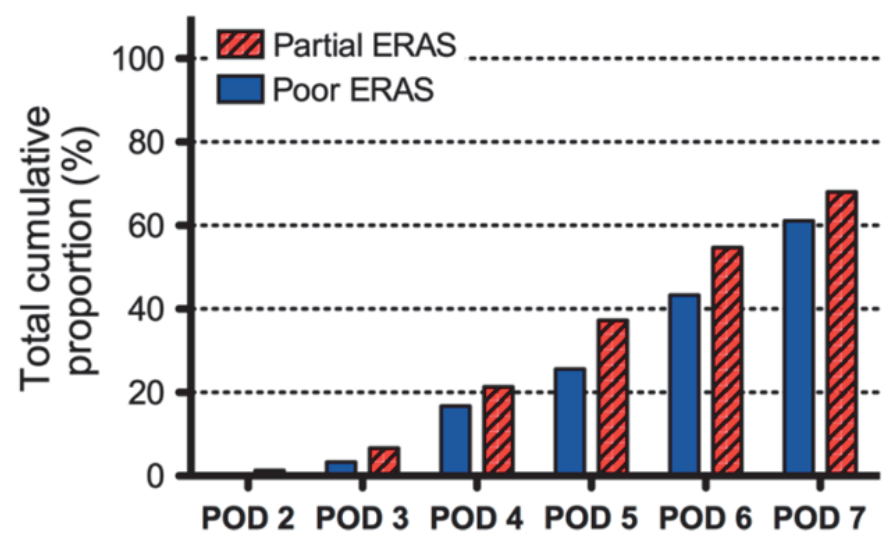

Figure 3. Discharge in partial ERAS centres $(N=5)$ versus poor ERAS centres $(N=6), P=0.166$. Cumulative proportion of patients who were discharged on POD 2-7 


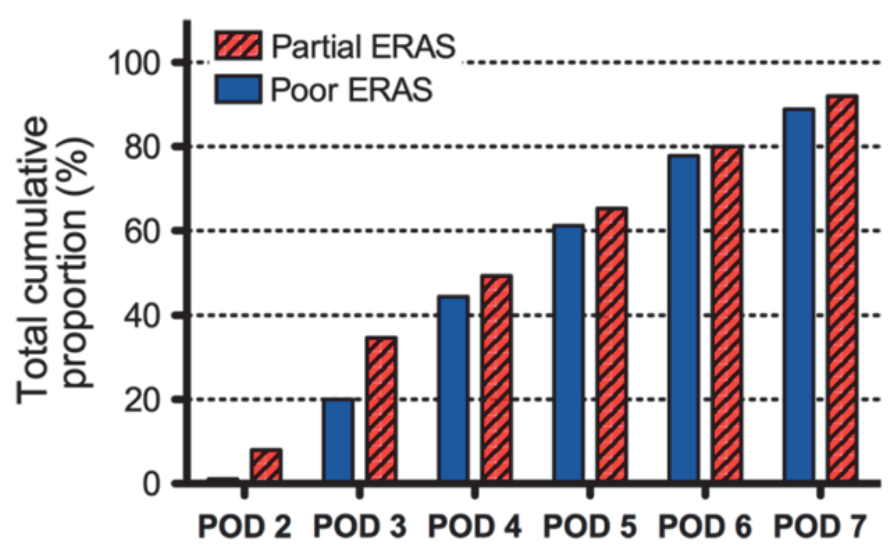

Figure 4 Functional recovery in partial ERAS centres $(N=5)$ versus poor ERAS centres $(N=6), P=0.149$. Cumulative proportion of patients who were functionally recovered on POD 2-7

\section{DISCUSSION}

This study evaluated the current perioperative care in 11 high-volume European liver surgery centres by assessing compliance with an ERAS program. Perioperative care varied considerably among the centres. All of the participating institutions had already adopted a median of 9 (range $=7-12$ ) elements of the ERAS care program as part of modern surgical practice. None of the centres had implemented the complete set of core elements. Interestingly, pre- and perioperative elements had the best implementation, but the centres were especially poor at complying with ERAS elements in the post-operative phase. In addition, a significant discrepancy between the patient's recovery and actual discharge was observed.

Every centre consistently provided preoperative counselling, limited the fasting period, actively prevented hypothermia during surgery, and systematically administered antithrombotic and antibiotic prophylaxes. Also, PONV prophylaxis, the use of epidural anaesthesia, and patient-controlled analgesia already had a prominent place. In contrast to the aforementioned care elements, other ERAS components were absent or suboptimally implemented. The partial or poor compliance and wide variation among the centres mirror this.

During the preoperative phase, anxiolytic medication was commonly used. Two striking perioperative observations were the widespread use of abdominal drains and NGT. In addition, the CVP during parenchymal transection was poorly documented. In the post-operative phase, the resumption of oral intake, removal of the urinary catheter, use of laxatives, and mobilization were only poorly implemented. 
Based upon previous studies, it is known that preoperative counselling on the role and expectations of the patient in the recovery period could further optimize postoperative recovery and satisfaction $[24,25]$. Also, the use of anxiolytic premedication could negatively influence gastrointestinal motility and, although it is safe to use short-acting benzodiazepines in day surgery [26], their efficacy for major surgery remains unclear.

Important accumulated evidence for the perioperative phase has shown that the necessity of abdominal drains can be questioned after uncomplicated liver resection [27]. Equally, it is well known that it is safe to remove NGTs directly after abdominal surgery [28]. The use of an NGT is even associated with an increased risk of developing post-operative pulmonary complications $[28,29]$.

There is an ongoing discussion concerning central venous pressure monitoring (CVP $<5-10 \mathrm{mmHg}$ ). Low CVP can be utilized to minimize back bleeding during parenchymal transection and to avoid excessive administration of IV fluids [30- 32]. However, it could be argued that CVP monitoring is not strictly necessary in minor hepatectomies, which represent a majority in the present study.

Lastly, patient-controlled analgesia may help to reduce opioid use and its associated side effects [33]. However, there is debate concerning the role of epidural catheters (EDA). Although frequently used in the participating centres, they are no longer used in an increasing number of other hospitals that perform liver surgery. Not only can the technique be contraindicated, e.g., because of the presence of coagulopathy, it can also cause potentially serious complications such as epidural hematoma, abscess, or paralysis [34]. The epidural catheterization is more time-consuming than intravenous analgesia and fails to provide adequate analgesia in $20 \%$ of the patients [35].

It may be felt that ERAS principles are not uniformly applicable to all patients and other factors (e.g., age, comorbidity, indication for surgery, and extent of liver resection) could play a role. There are good alternatives to core elements that would not deter from the ERAS principles. Post-operative pain has traditionally been managed by intravenous or epidural analgesia. It can be argued whether the inclusion of thoracic epidural analgesia as a core element reflects current clinical practice. The use of wound catheters with a local anaesthetic [36-38] or the use of intrathecal morphine [39] has been shown to be safe and effective also in an ERAS setting for liver surgery $[40,41]$. Furthermore, alternatives to reduce CVP or monitor it could serve as a substitute and may be sufficient $[42,43]$.

In the post-operative phase, the still abundant use of NGTs could explain why early intake of water on POD 0 was achieved in only less than one third of the patients and 
why only half of the patients tolerated a normal diet on POD 2. A quick return to a normal diet has been shown to be safe for both major upper abdominal and colorectal surgeries [44, 45]. In addition, to promote the return of normal bowel function or prevent a post-operative ileus, standard use of laxatives has been shown to be effective $[4,5]$. Lastly, few patients mobilized out of bed before POD 2. The use of drains, lack of daily mobilization goals, and relatively late removal of catheters can explain this observation.

A secondary outcome was the length of hospital stay versus the time to FR. It is generally agreed that it is medically justified to discharge patients when criteria for full FR are met $[4,5,20]$. In keeping with literature data [4, 19], a discrepancy was found between discharge and time to FR. A majority of patients (63\%) principally were functionally recovered on median POD 5 (range $=1-24$ ), while only $31 \%$ were discharged at that time. Factors influencing this delay could have been poor organization of discharge logistics, cultural differences, and deviant patient expectations. Unfortunately, it was not possible to assess all five FR criteria because serum bilirubin values were inconsistently available. Bilirubin values were therefore assumed normal since the majority of the liver resections in this study were minor procedures.

The retrospective assessment of the data, the selection of participating centres, and their varying experience with ERAS principles may have biased our results. However, this design was deliberately chosen so as to not influence the behaviour of medical and nursing staff in perioperative care during a full prospective assessment. Both large and small hepatic centres were allowed to participate and this could also have influenced our results. However, the large number of minor resections in this study and the participation of several high-volume European centres with varying experience with ERAS protocols do provide a reflection of daily practice in liver surgery and therefore increase external validity.

Based on this study several recommendations can be made that could eventually lead to further optimization of care and potentially improve post-operative outcomes. Change of current practice and implementation of an enhanced-recovery care pathway are desirable but will require multidisciplinary efforts $[19,46]$. Although counselling is already part of preoperative care in that information on the procedure and possible complications is provided, there should be more emphasis on the recovery period with respect to pain control, early mobilization, resumption of intake, and time of discharge. Furthermore, administration of preoperative anxiolytic medication should not be the standard. Recommendations for the perioperative phase include the selective monitoring of the CVP and abandoning the standard use of abdominal drains and the dogmatic use of NGT. For patients undergoing liver surgery, the use of NGTs is not needed at all and seems very conservative. In combina- 
tion with adequate PONV prophylaxis, a safe and quick return to a normal diet may be facilitated. In addition, laxatives can be provided in a standard manner, urinary catheters should be removed earlier, and daily mobilization goals should be determined. Lastly, predefined discharge criteria should be checked daily to minimize a delay in discharge after FR.

The findings of this study are clinically relevant to liver surgeons as they aim for a universally accepted and standardized perioperative care program. The findings may help to provide the standardization needed for comparability in clinical audits and trials. Future research should clarify the role of the individual components in ERAS programs and investigate to what extent an element contributes to the improvement of outcomes. Several recent studies [8-10] have already demonstrated the additional value of ERAS programs with predefined discharge criteria. In addition, safe and effective alternatives or new elements should be embraced.

\section{CONCLUSION}

Perioperative care among centres that perform liver resections varied substantially and elements of enhanced recovery programs had already been implemented as part of daily surgical practice. Other elements can be further optimized based on ERAS principles. This may standardize care and improve recovery after liver surgery. 


\section{REFERENCES}

1. Kehlet H, Wilmore DW (2002) Multimodal strategies to improve surgical outcome. Am J Surg 183(6):630-641

2. Spanjersberg WR, Reurings J, Keus F, van Laarhoven CJ (2011) Fast track surgery versus conventional recovery strategies for colorectal surgery. Cochrane Database Syst Rev 2:CD007635

3. MacKay G, O'Dwyer PJ (2008) Early discharge following liver resection for colorectal metastases. Scott Med J 53(2):22-24

4. van Dam RM, Hendry PO, Coolsen MM, Bemelmans MH, Lassen K, Revhaug A et al (2008) Initial experience with a multimodal enhanced recovery programme in patients undergoing liver resection. $\mathrm{Br} J$ Surg 95(8):969-975

5. Hendry PO, van Dam RM, Bukkems SF, McKeown DW, Parks RW, Preston T et al (2010) Randomized clinical trial of laxatives and oral nutritional supplements within an enhanced recovery after surgery protocol following liver resection. Br J Surg 97(8):1198- 1206

6. Lin DX, Li X, Ye QW, Lin F, Li LL, Zhang QY (2011) Implementation of a fast-track clinical pathway decreases postoperative length of stay and hospital charges for liver resection. Cell Biochem Biophys 61(2):413-419

7. Coolsen MM, Wong-Lun-Hing EM, van Dam RM, van der Wilt AA, Slim K, Lassen K et al (2013) A systematic review of outcomes in patients undergoing liver surgery in an enhanced recovery after surgery pathways. HPB (Oxford) 15(4):245-251

8. Sanchez-Perez B, Aranda-Narvaez JM, Suarez-Munoz MA, Eladel-Delfresno M, Fernandez-Aguilar JL, Perez-Daga JA et al (2012) Fast-track program in laparoscopic liver surgery: theory or fact? World J Gastrointest Surg 4(11):246-250

9 Ni CY, Yang Y, Chang YQ, Cai H, Xu B, Yang F et al (2013) Fast-track surgery improves postoperative recovery in patients undergoing partial hepatectomy for primary liver cancer: a prospective randomized controlled trial. Eur J Surg Oncol 39(6):542-547

10. Schultz NA, Larsen PN, Klarskov B, Plum LM, Frederiksen HJ, Christensen BM et al (2013) Evaluation of a fast-track programme for patients undergoing liver resection. Br J Surg 100(1):138-143

11. Wong-Lun-Hing EM, Lodewick TM, Stoot JH, Bemelmans MH, Olde Damink SH, Dejong CH et al (2012) A survey in the hepatopancreatobiliary community on ways to enhance patient recovery. HPB (Oxford) 14(12):818-827

12. Brustia P, Renghi A, Gramaglia L, Porta C, Cassatella R, De Angelis R et al (2003) Mininvasive abdominal aortic surgery. Early recovery and reduced hospitalization after multidisciplinary approach. J Cardiovasc Surg (Torino) 44(5):629-635

13. Barbieri A, Vanhaecht K, Van Herck P, Sermeus W, Faggiano F, Marchisio S et al (2009) Effects of clinical pathways in the joint replacement: a meta-analysis. BMC Med 7:32

14. Arsalani-Zadeh R, ElFadI D, Yassin N, Mac- Fie J (2011) Evidence-based review of enhancing postoperative recovery after breast surgery. Br J Surg 98(2):181-196

15. Rawlinson A, Kang P, Evans J, Khanna A (2011) A systematic review of enhanced recovery protocols in colorectal surgery. Ann R Coll Surg Engl 93(8):583-588

16. Spelt L, Ansari D, Sturesson C, Tingstedt B, Andersson R (2011) Fast-track programmes for hepatopancreatic resections: where do we stand? HPB (Oxford) 13(12):833-838

17. Lassen K, Coolsen MM, Slim K, Carli F, de Aguilar-Nascimento JE, Schafer M et al (2012) Guidelines for perioperative care for pancreaticoduodenectomy: enhanced recovery after surgery (ERAS) society recommendations. Clin Nutr 31(6):817-830

18. Vlug MS, Wind J, Hollmann MW, Ubbink DT, Cense HA, Engel AF et al (2011) Laparoscopy in combination with fast track multimodal management is the best perioperative strategy in patients undergoing colonic surgery: a randomized clinical trial (LAFA- study). Ann Surg 254(6):868-875

19. Maessen J, Dejong CH, Hausel J, Nygren J, Lassen K, Andersen J et al (2007) A protocol is not enough to implement an enhanced recovery programme for colorectal resection. Br J Surg 94(2):224-231 
20. van Dam RM, Wong-Lun-Hing EM, van Breukelen GJ, Stoot JH, van der Vorst JR, Bemelmans MH et al (2012) Open versus laparoscopic left lateral hepatic sectionectomy within an enhanced recovery ERAS programme (ORANGE II-Trial): study protocol for a randomized controlled trial. Trials 13(1):54

21. Fong Y, Gonen M, Rubin D, Radzyner M, Brennan MF (2005) Long-term survival is superior after resection for cancer in high- volume centers. Ann Surg 242(4):540-544 discussion 544-547

22. Maessen JM, Hoff C, Jottard K, Kessels AG, Bremers AJ, Havenga K et al (2009) To eat or not to eat: facilitating early oral intake after elective colonic surgery in the Netherlands. Clin Nutr 28(1):29-33

23. Gillissen F, Hoff C, Maessen JM, Winkens B, Teeuwen JH, von Meyenfeldt MF et al (2013) Structured synchronous implementation of an enhanced recovery program in elective colonic surgery in 33 hospitals in The Netherlands. World J Surg 37(5):1082-1093. doi:10.1007/s00268-013-1938-4

24. Disbrow EA, Bennett HL, Owings JT (1993) Effect of preoperative suggestion on postoperative gastrointestinal motility. West J Med 158(5):488-492

25. Kiecolt-Glaser JK, Page GG,Marucha PT, MacCallum RC, Glaser R (1998) Psychological influences on surgical recovery. Perspectives from psychoneuroimmunology. Am Psychol 53(11):1209-1218

26. Walker KJ, Smith AF (2009) Premedication for anxiety in adult day surgery. Cochrane Database Syst Rev 4:CD002192

27. Gurusamy KS, Samraj K, Davidson BR (2007) Routine abdominal drainage for uncomplicated liver resection. Cochrane Database Syst Rev 3:CD006232

28. Nelson R, Tse B, Edwards S (2005) Systematic review of prophylactic nasogastric decompression after abdominal operations. Br J Surg 92(6):673-680

29. Pessaux P, Regimbeau JM, Dondero F, Plasse M, Mantz J, Belghiti J (2007) Randomized clinical trial evaluating the need for routine nasogastric decompression after elective hepatic resection. Br J Surg 94(3):297-303

30. Lesurtel M, Selzner M, Petrowsky H, McCormack L, Clavien PA (2005) How should transection of the liver be performed? A prospective randomized study in 100 consecutive patients: comparing four different transection strategies. Ann Surg 242(6): 814-822 discussion 822-823

31. Wang WD, Liang LJ, Huang XQ, Yin XY (2006) Low central venous pressure reduces blood loss in hepatectomy. World J Gastroenterol 12(6):935-939

32. McNally SJ, Revie EJ, Massie LJ, McKeown DW, Parks RW, Garden OJ et al (2012) Factors in perioperative care that determine blood loss in liver surgery. HPB (Oxford) 14(4):236-241

33. Ong CK, Seymour RA, Lirk P, Merry AF (2010) Combining paracetamol (acetaminophen) with nonsteroidal antiinflammatory drugs: a qualitative systematic review of analgesic efficacy for acute postoperative pain. Anesth Analg 1 0(4):1170-1179

34. Cook TM, Counsell D, Wildsmith JA (2009) Major complications of central neuraxial block: report on the third national audit pro-ject of the Royal College of Anaesthetists. Br J Anaesth 102(2):179-190

35. McLeod G, Davies H, Munnoch N, Bannister J, MacRae W (2001) Postoperative pain relief using thoracic epidural analgesia: outstanding success and disappointing failures. Anaesthesia 56(1):75-81

36. Basu S, Tamijmarane A, Bulters D, Wells JK, John TG, Rees M (2004) An alternative method of wound pain control following hepatic resection: a preliminary study.HPB(Oxford) 6(3):186-189

37. Liu SS, Richman JM, Thirlby RC, Wu CL (2006) Efficacy of continuous wound catheters delivering local anesthetic for postoperative analgesia: a quantitative and qualitative systematic review of randomized controlled trials. J Am Coll Surg 203(6):914-932

38. Forastiere E, Sofra M, Giannarelli D, Fabrizi L, Simone G (2008) Effectiveness of continuous wound infusion of $0.5 \%$ ropivacaine by on-Q pain relief system for postoperative pain management after open nephrectomy. Br J Anaesth 101(6):841-847

39. De Pietri L, Siniscalchi A, Reggiani A, Masetti M, Begliomini B, Gazzi M et al (2006) The use of intrathecal morphine for postoperative pain relief after liver resection: a comparison with epidural analgesia. Anesth Analg 102(4):1157-1163

40. Koea JB, Young Y, Gunn K (2009) Fast track liver resection: the effect of a comprehensive care package and analgesia with single dose intrathecal morphine with gabapentin or continuous epidural analgesia. HPB Surg 2009:271986 
41. Revie EJ, McKeown DW, Wilson JA, Garden OJ, Wigmore SJ (2012) Randomized clinical trial of local infiltration plus patientcontrolled opiate analgesia versus epidural analgesia following liver resection surgery. HPB (Oxford) 14(9):611-618

42. Lentschener C, Ozier Y (2002) Anaesthesia for elective liver resection: some points should be revisited. Eur J Anaesthesiol 19(11):780-788

43. Zhu P, Lau WY, Chen YF, Zhang BX, Huang ZY, Zhang ZW et al (2012) Randomized clinical trial comparing infrahepatic inferior vena cava clamping with low central venous pressure in complex liver resections involving the Pringle manoeuvre. Br J Surg 99(6):781-788

44. Andersen HK, Lewis SJ, Thomas S (2006) Early enteral nutrition within $24 \mathrm{~h}$ of colorectal surgery versus later commencement of feeding for postoperative complications. Cochrane Database Syst Rev 4:CD004080

45. Lassen K, Kjaeve J, Fetveit T, Trano G, Sigurdsson HK, Horn A et al (2008) Allowing normal food at will after major upper gastrointestinal surgery does not increase morbidity: a randomized multicenter trial. Ann Surg 247(5):721-729

46. Ahmed J, Khan S, Gatt M, Kallam R, MacFie J (2010) Compliance with enhanced recovery programmes in elective colorectal surgery. Br J Surg 97(5):754-758 


\section{Chapter 5}

Post-operative pain control using continuous i.m. bupivacaine infusion plus patient-controlled analgesia compared with epidural analgesia after major hepatectomy

Wong-Lun-Hing EM, van Dam RM, Welsh FK, Wells JK, John TG, Cresswell AB, Dejong $\mathrm{CH}$, Rees $\mathrm{M}$

HPB (Oxford). 2014 Jul;16(7):601-9 


\section{ABSTRACT}

\section{OBJECTIVE}

There is debate concerning the best mode of delivery of analgesia following liver resection, with continuous i.m. infusion of bupivacaine $(\mathrm{CIB})$ plus patient-controlled i.v. analgesia (PCA) suggested as an alternative to continuous epidural analgesia (CEA). This study compares these two modalities.

\section{METHODS}

A total of 498 patients undergoing major hepatectomy between July 2004 and July 2011 were included. Group 1 received CIB + PCA $(n=429)$ and Group 2 received CEA $(n=69)$. Groups were analysed on baseline patient and surgical characteristics. Primary endpoints were pain severity scores and total opioid consumption. Secondary endpoints were pain management failures, need for rescue medication, postoperative (opioid-related) morbidity and hospital length of stay (LoS).

\section{RESULTS}

In both groups pain was well controlled and $>70 \%$ of patients had no or minimal pain on PoDs 1 and 2. The numbers of patients experiencing severe pain were similar in both groups: PoD 1 at rest: 0.3\% in Group 1 and 0\% in Group $2(P=1.000)$; PoD 1 on movement: 8\% in Group 1 and 2\% in Group 2 (P = 0.338); PoD 1 at rest: 0\% in Group 1 and 2\% in Group $2(P=0.126)$, and PoD 2 on movement: 5\% in Group 1 and $5 \%$ in Group $2(P=1.000)$. Although the CIB + PCA group required more opioid rescue medication on PoD 0 (53\% versus 22\%; P $<0.001$ ), they used less opioids on PoDs $0-3(P \leq 0.001)$, had lower morbidity ( $26 \%$ versus $39 \% ; P=0.018)$, and a shorter LoS $(7$ days versus 8 days; $P=0.005$ ).

\section{CONCLUSION}

The combination of CIB + PCA provides pain control similar to that provided by CEA, but facilitates lower opioid consumption after major hepatectomy. It has the potential to replace epidural analgesia, thereby avoiding the occurrence of rare but serious complications. 


\section{INTRODUCTION}

The upper abdominal wall incision is a major contributor to post-operative pain after liver resection.[1,2] Given the continuing increases in both the volume and extent of liver surgery, along with the introduction of enhanced recovery programmes[3-7], there is debate about the optimal method of delivering post-operative analgesia. Effective post-operative pain control will reduce the incidence of numerous postoperative complications, can facilitate early mobilization and may result in earlier recovery.[8,9] Pain control is usually achieved by the administration of opioids, which may cause side-effects, such as sedation, respiratory depression, pruritus, hallucinations and post-operative nausea and vomiting (PONV).

Epidural analgesia has been considered superior to i.v. patient-controlled analgesia (PCA) for post-operative pain relief in patients recovering from major upper abdominal operations[10,11], although patient satisfaction with i.v. PCA is higher.[11] However, the use of epidural analgesia after hepatectomy is still subject to debate. Because epidural analgesia can lead to serious complications, such as epidural abscess or haematoma[12], it may be contraindicated when post-operative coagulopathy is expected. $[13,14]$ In addition, epidural methods take time to induce anaesthesia and may not function adequately in up to $30 \%$ of patients.[15]

An alternative analgesic modality for the control of post-operative pain is the continuous infiltration of local anaesthetic using wound catheters placed in the abdominal wall.[16-18] It is nearly a decade since this method of post-operative pain management was introduced in liver surgery and it has shown promising results. $[19,20]$ In other fields of surgery, the use of continuous wound infiltration has suggested a reduction in costs.[21-23] The most recent study, a randomized controlled trial (RCT) performed by Revie et al. in 2012, demonstrated that local wound infiltration combined with i.v. PCA, compared with continuous epidural analgesia (CEA), reduced the time required to fulfil criteria for discharge from hospital, but provided inferior analgesia.[24]

This retrospective study provides insights into the post-operative analgesic merits of i.m. continuous infusion of bupivacaine (CIB) combined with i.v. PCA, compared with mid-thoracic CEA alone after major hepatic surgery. 


\section{METHODS}

\section{PATIENTS}

All open major hepatectomies ( $n=545$ ) performed in the Hepatobiliary Unit of the North Hampshire Hospital in Basingstoke, UK, between July 2004 and July 2011 were included for screening. Data were prospectively collected and stored in a dedicated database by research staff blinded to the type of post-operative analgesia. Data on post-operative milestones, such as day of first oral intake and day of independent mobilization, were retrospectively added to the database after all available documentation for both living and deceased patients had been reviewed. Primary study endpoints were pain severity scores at rest and on movement during the first $48 \mathrm{~h}$ post-operatively, and total opioid requirements during the first $72 \mathrm{~h}$ post-operatively. Secondary endpoints were pain management failures, need for rescue medication, opioid-related morbidity and hospital length of stay (LoS).

\section{SURGERY}

General anaesthesia was induced with i.v. propofol (1.5-2.0 mg/kg) and fentanyl (1-2 $\mathrm{mcg} / \mathrm{kg}$ ), with maintenance using volatile anaesthetics (iso-, des- or sevoflurane) in oxygen and air. For this study, major hepatectomy was defined as resection of at least three liver segments according to Couinaud's classification.[25] Hepatectomies were performed by four liver surgeons (MR, FKSW, TGJ and ABC), of whom only one (TGJ) used epidural catheters as the preferred method of providing post-operative analgesia. Standard transection techniques were used for liver resection under total or selective hepatic vascular exclusion, as described previously.[26,27] Unfavourable intraoperative incidents were graded according to the Satava system for the evaluation of surgical error, adapted for liver surgery.[28] Post-operative morbidity was classified and analysed using the Accordion system for grading surgical complications (with Clavien-Dindo modifications), as described by Strasberg et al.[29,30] Operating time was defined as the time between the first induction of anaesthesia and the patient's departure from the theatre. All patients received antibiotic, and nausea and vomitus (PONV) prophylaxis preoperatively. In the CIB + PCA group, PONV prophylaxis (cyclizine or dexamethason on induction, ondansetron post-operatively) was continued until PCA was removed.

\section{INCISION, WOUND CLOSURE AND CATHETER PLACEMENT}

Access to the abdominal cavity was achieved with a right subcostal incision[31,32] extended to the bed of the right 12th rib laterally and through the upper midline to the level of the xiphoid superiorly (' $L$ ' incision). The skin incision was made by knife; 
diathermy was used through subcutaneous tissue and muscles. Wound closure and catheter placement techniques were also standardized and have been previously described by Basu et al.[19]

\section{DELIVERY OF ANALGESIC DRUGS}

Immediately after wound closure, the i.m. catheters were flushed with a 10-ml bolus of $0.25 \%$ bupivacaine, and continuous i.m. catheter infusions of $0.25 \%$ bupivacaine were commenced at a rate of $3 \mathrm{ml} / \mathrm{h}$ by syringe pump. This was continued for $72 \mathrm{~h}$ post-operatively. Patient-controlled analgesia using morphine $(1 \mathrm{mg}$ bolus with a 5 min lockout) or a fentanyl infusion (20 mcg bolus with a 5-min lockout) was set up. In the CEA group, an epidural catheter was sited before surgery in the thoracic T5-T12 region. This epidural catheter was also used to provide analgesia during surgery (20 $\mathrm{ml}$ bupivacaine $0.25 \%$ ). During emergence from anaesthesia, the patient was transferred to the recovery area, in which the PCA + CIB or CEA was started. The epidural infusion of bupivacaine $0.1 \%$ with $2 \mathrm{mcg} / \mathrm{ml}$ fentanyl was set at $5-15 \mathrm{ml} / \mathrm{h}$. A dedicated pain team unaware of the type of hepatic resection or any concomitant surgical procedure(s) assessed and scored the patients daily until the i.v. or epidural analgesia could be stopped. Pain intensity was scored using a verbal rating scale (VRS) ranging from 0 (no pain) to 4 (worst imaginable pain). The level of sedation was also measured on a 5 -point scale $(0=$ awake, $1=$ dosing intermittently, $2=$ sleeping and easy to wake, 3 = sleeping and difficult to wake, $4=$ unarousable). Wound and urinary catheters were removed at the discretion of the operating surgeon, but usually after $72 \mathrm{~h}$ [midnight on post-operative day (PoD) 3]. Pain management failures in both groups were defined as the need for rescue medication or a switch to a different opioid. The need for rescue medication was defined as any additional epidural, i.v., i.m. or oral administration of an opioid. A switch to a different analgesic protocol was defined as any change in analgesic medication, concentration or infusion rate. In the event of the technical failure of the epidural catheter, the patient was commenced on PCA with morphine or fentanyl. Oral analgesia [acetaminophen, non-steroidal anti-inflammatory drugs (NSAIDs) and opioids] was available in a standard manner to all patients. No standardized enhanced recovery after surgery (ERAS) programme was implemented during this study period.

\section{STATISTICS}

To facilitate comparisons between the two patient groups and the different opioids, all opioids required were converted to an i.v. morphine equivalent (Table 1). Comparisons between groups were performed using Pearson's chi-squared or Fisher's exact test for non-normally distributed categorical variables, as appropriate, and the Mann-Whitney U-test or Kruskal-Wallis test for continuous variables. All statistical 
tests were two-sided. A P-value of $<0.05$ was considered to indicate statistical significance. Statistical analysis was performed using IBM SPSS Statistics for Windows Version 19.0 (IBM Corp., Armonk, NY, USA).

Table 1. Opioid conversion ratios

\begin{tabular}{|c|c|c|}
\hline & Conversion ratio & Reference \\
\hline \multicolumn{3}{|l|}{ Intravenous } \\
\hline Morphine & $1: 1$ & \\
\hline Fentanyl (mcg/ml) & $1: 10$ & [34-36] \\
\hline \multicolumn{3}{|l|}{ Epidural } \\
\hline Fentanyl (mcg/ml) & $3: 10$ & [37] \\
\hline \multicolumn{3}{|l|}{ Oral Medication } \\
\hline Oxycodone & $2: 1$ & [34] \\
\hline Morphine & $3: 1$ & {$[38,34,36]$} \\
\hline Tramadol & $15: 1$ & [34] \\
\hline Codeine & $24: 1$ & [34] \\
\hline
\end{tabular}

Opioid conversion ratios lead to an i.v. morphine $(\mathrm{mg} / \mathrm{ml})$ equivalent.

\section{RESULTS}

\section{GENERAL AND SURGICAL CHARACTERISTICS}

Of 545 patients identified in the database for the study period, a total of 498 patients $(C I B+P C A, n=429 ; C E A, n=69)$ underwent major liver resection and were included in this study. For 41 of the 47 patients excluded, no data on opioid requirements could be retrieved. This was mostly the result of either admission with sedation to the intensive care unit (ICU) or the absence of fluid balance/opioid infusion charts. Of the remaining six excluded patients, four received PCA without $\mathrm{CIB}$, and one received epidural analgesia combined with CIB. No data at all could be retrieved for the final patient. General patient characteristics are shown in Table 2 and surgical characteristics in Table 3.

\section{PRIMARY ENDPOINTS}

The total median opioid consumption in milligrams (i.v. morphine equivalent) was markedly lower in the CIB + PCA group (for all time-points: $\mathrm{P} \leq 0.001$ ). However, postoperative pain was equally well controlled in both groups (Table 4). The maximum percentages of pain scores missing for the complete group of included patients were $27.7 \%$ and $28.3 \%$ on PoDs 1 and 2, respectively. 
Table 2. General characteristics of patients undergoing major hepatectomy in the present series

\begin{tabular}{|c|c|c|c|}
\hline & $\begin{array}{l}\text { Epidural group } \\
(n=69)\end{array}$ & $\begin{array}{l}\text { CIB + PCA group } \\
(n=429)\end{array}$ & P-value \\
\hline Age, years, median (range) & $63(29-84)$ & $63(21-86)$ & 0.695 \\
\hline Male sex, n (\%) & $42(60.9 \%)$ & $269(62.7 \%)$ & 0.770 \\
\hline BMI, kg/m2, median (range) & $24.0(20.0-33.5)$ & $26.0(16.0-44.0)$ & 0.126 \\
\hline \multicolumn{4}{|l|}{ ASA physical status, n (\%) } \\
\hline Class 1 & $2(2.9 \%)$ & $10(2.3 \%)$ & 0.673 \\
\hline Class 2 & $51(73.9 \%)$ & $320(74.6 \%)$ & 0.924 \\
\hline Class 3-5 & $13(18.8 \%)$ & $87(20.3 \%)$ & 0.828 \\
\hline \multicolumn{4}{|l|}{ Number of comorbidities, n (\%) } \\
\hline 0 & $37(53.6 \%)$ & $196(45.7 \%)$ & 0.240 \\
\hline 1 & $19(27.5 \%)$ & $136(31.7 \%)$ & 0.466 \\
\hline 2 & $6(8.7 \%)$ & $61(14.2 \%)$ & 0.190 \\
\hline$\geq 3$ & $7(10.1 \%)$ & $33(7.7 \%)$ & 0.498 \\
\hline \multicolumn{4}{|l|}{ Indication for surgery, n (\%) } \\
\hline Colorectal metastases & $56(81.2 \%)$ & $369(86.0 \%)$ & 0.290 \\
\hline Hepatocellular carcinoma & $1(1.4 \%)$ & $4(0.9 \%)$ & 0.529 \\
\hline Cholangiocarcinoma (intrahepatic and hilar) & $1(1.4 \%)$ & $12(2.8 \%)$ & 1.000 \\
\hline Other malignancies ${ }^{\mathrm{a}}$ & $3(5.8 \%)$ & $32(7.4 \%)$ & 0.453 \\
\hline Benign disease $^{b}$ & $8(10.1 \%)$ & $12(2.6 \%)$ & 0.003 \\
\hline Previous abdominal surgery & $59(85.5 \%)$ & $376(87.6 \%)$ & 0.324 \\
\hline
\end{tabular}

$\mathrm{CIB}+\mathrm{PCA}$, i.m. continuous infusion of bupivacaine plus i.v. patient-controlled analgesia; BMI, body mass index; ASA, American Society of Anesthesiologists.

A P-value of $<0.05$ was considered to indicate statistical significance.

a Other malignancies include metastases of carcinoid, breast cancer, melanoma, neuroendocrine tumour, appendix carcinoma, ovarian carcinoma, squamous cell carcinoma of the vagina, renal cell carcinoma, lymphoma, endometrial carcinoma, gastrointestinal stromal tumour, mixed type hepatocellular carcino$\mathrm{ma} /$ cholangiocarcinoma, lymphoma and keratinizing squamous cell carcinoma.

${ }^{\mathrm{b}}$ Benign diseases include cyst(s), adenoma, focal nodular hyperplasia, haemangioma and angiomyolipoma.

\section{SECONDARY ENDPOINTS}

Intramuscular catheters were removed at a median of PoD 3 (range: PoD 2-5). Data on pain management failures, need for rescue medication and technical failures are shown in Table 4. Overall morbidity was higher in the epidural group (39.1\%) than in the CIB + PCA group (26.1\%) $(P=0.030)$. Complication grades rated on the Accordion system (with Clavien-Dindo modifications), length of hospital stay and readmissions are displayed in Table 5. One death occurred in the epidural group (1.4\%) and two $(0.5 \%)$ occurred in the $\mathrm{ClB}+\mathrm{PCA}$ group $(\mathrm{P}=0.361)$. The patient in the epidural group died from myocardial infarction. In the catheter group, one patient died from liver failure and the other from multi-organ failure caused by severe sepsis after endoscopic retrograde cholangiopancreatography (ERCP) for a bile leak. Specific compli- 
cations per group are shown in Table 6 . No instances of respiratory depression were observed. There were no reported cases of epidural hematoma, abscess formation or paralysis in the group that received an epidural catheter.

Table 3. Operative characteristics of patients undergoing major hepatectomy in the present series

\begin{tabular}{|c|c|c|c|}
\hline & $\begin{array}{l}\text { Epidural group } \\
(n=69)\end{array}$ & $\begin{array}{l}C I B+P C A \text { group } \\
(n=429)\end{array}$ & $P$-value \\
\hline Operating time, min, median (range) & $260(150-475)$ & $260(28-480)$ & 0.356 \\
\hline Blood loss, ml, median (range) & $295(55-844)$ & $369(30-5344)$ & 0.020 \\
\hline \multicolumn{4}{|l|}{ Incision, n (\%) } \\
\hline Right subcostal & $67(97.1 \%)$ & $425(99.1 \%)$ & 0.165 \\
\hline Other $^{a}$ & $2(2.9 \%)$ & $4(0.9 \%)$ & 0.196 \\
\hline \multicolumn{4}{|l|}{$\begin{array}{l}\text { Segmental distribution of } \\
\text { hepatectomies, } \mathrm{n}(\%)\end{array}$} \\
\hline 3 segments & $8(11.6 \%)$ & $65(15.2 \%)$ & 0.438 \\
\hline 3 segments + wedge & $3(4.3 \%)$ & $26(6.1 \%)$ & 0.783 \\
\hline 3 segments + multiple wedge & $1(1.4 \%)$ & $9(2.1 \%)$ & 1.000 \\
\hline 4 segments & $40(58.0 \%)$ & $163(38.0 \%)$ & 0.002 \\
\hline 4 segments + wedge & $5(7.2 \%)$ & $70(16.3 \%)$ & 0.051 \\
\hline 4 segments + multiple wedge & $3(4.3 \%)$ & $25(5.8 \%)$ & 0.783 \\
\hline 5 segments & $5(7.2 \%)$ & $49(11.4 \%)$ & 0.301 \\
\hline 5 segments + wedge & $3(4.3 \%)$ & $13(3.0 \%)$ & 0.475 \\
\hline 5 segments + multiple wedge & $1(1.4 \%)$ & $6(1.4 \%)$ & 1.000 \\
\hline 6 segments & 0 & $3(0.7 \%)$ & 1.000 \\
\hline \multicolumn{4}{|l|}{ Additional procedures, n (\%) } \\
\hline Cholecystectomy & $13(18.8 \%)$ & $66(15.4 \%)$ & 0.478 \\
\hline Lymph node sampling & 0 & $12(2.8 \%)$ & 0.387 \\
\hline Diaphragmatic resection & $3(4.3 \%)$ & $18(4.2 \%)$ & 1.000 \\
\hline Roux-en-Y reconstruction & $1(1.4 \%)$ & $3(0.7 \%)$ & 0.450 \\
\hline Right colectomy & $1(1.4 \%)$ & $2(0.5 \%)$ & 0.361 \\
\hline Incisional hernia repair & 0 & $3(0.7 \%)$ & 1.000 \\
\hline Ablation & 0 & $6(0.7 \%)$ & 1.000 \\
\hline Other $^{b}$ & $2(2.9 \%)$ & $45(11.2 \%)$ & 0.046 \\
\hline \multicolumn{4}{|l|}{ Satava classification, n (\%) } \\
\hline Grade I & 0 & $17(4.0 \%)$ & 0.147 \\
\hline Grade II & 0 & $2(0.5 \%)$ & 1.000 \\
\hline Grade III & 0 & $1(0.2 \%)$ & 1.000 \\
\hline
\end{tabular}

$\mathrm{CIB}+\mathrm{PCA}$, i.m. continuous infusion of bupivacaine plus i.v. patient-controlled analgesia.

A P-value of $<0.05$ was considered to indicate statistical significance.

a Other incisions include abdominal longitudinal incision, Mercedes Benz incision and laparoscopic converted to open surgery.

${ }^{\mathrm{b}}$ See Appendix 1 for details. 
Table 4. Post-operative analgesia in patients undergoing major hepatectomy in the present series

\begin{tabular}{|c|c|c|c|}
\hline & $\begin{array}{l}\text { Epidural group } \\
(n=69)\end{array}$ & $\begin{array}{l}\mathrm{CIB}+\mathrm{PCA} \text { group } \\
(n=429)\end{array}$ & $P$-value \\
\hline Time to discontinuation, days, median (range) & $3(1-5)$ & $4(1-8)$ & 0.001 \\
\hline \multicolumn{4}{|l|}{$\begin{array}{l}\text { Cumulative opioid consumption }{ }^{\mathrm{a}} \text {, mg, median } \\
\text { (range) }\end{array}$} \\
\hline $12 \mathrm{~h}$ & $29.1(0.0-266.0)$ & $17.5(0.0-1015.0)$ & $<0.001$ \\
\hline $24 \mathrm{~h}$ & $91.2(5.0-1546.4)$ & $43.0(0.0-1225.0)$ & $<0.001$ \\
\hline $48 \mathrm{~h}$ & $148.4(6.0-1952.8)$ & $58.0(0.0-1625.0)$ & $<0.001$ \\
\hline $72 \mathrm{~h}$ & $186.1(4.0-1952.8)$ & $61.0(0.0-1650.0)$ & $<0.001$ \\
\hline \multicolumn{4}{|l|}{ VRS score at rest PoD 1, n (\%) } \\
\hline 0 & $41(89.1 \%)$ & $234(73.8 \%)$ & 0.024 \\
\hline 1 & $4(8.7 \%)$ & $69(21.8 \%)$ & 0.047 \\
\hline 2 & $1(2.2 \%)$ & $13(4.1 \%)$ & 1.000 \\
\hline 3 & 0 & $1(0.3 \%)$ & 1.000 \\
\hline 4 & 0 & 0 & \\
\hline \multicolumn{4}{|l|}{ VRS score on movement PoD 1, n (\%) } \\
\hline 0 & 29 (65.9\%) & 92 (29.4\%) & $<0.001$ \\
\hline 1 & $11(19.4 \%)$ & $148(46.8 \%)$ & 0.006 \\
\hline 2 & $3(6.8 \%)$ & $52(16.4 \%)$ & 0.118 \\
\hline 3 & $1(2.3 \%)$ & $20(6.3 \%)$ & 0.491 \\
\hline 4 & 0 & $4(1.3 \%)$ & 1.000 \\
\hline \multicolumn{4}{|l|}{ VRS score at rest PoD 2, n (\%) } \\
\hline 0 & 42 (93.3\%) & 273 (87.5\%) & 0.256 \\
\hline 1 & $2(4.4 \%)$ & $32(10.3 \%)$ & 0.284 \\
\hline 2 & 0 & $7(2.2 \%)$ & 0.603 \\
\hline 3 & $1(2.2 \%)$ & 0 & 0.126 \\
\hline 4 & 0 & 0 & \\
\hline \multicolumn{4}{|l|}{ VRS score on movement PoD 2, n (\%) } \\
\hline 0 & $26(59.1 \%)$ & 134 (42.8\%) & 0.042 \\
\hline 1 & $15(34.1 \%)$ & $118(37.7 \%)$ & 0.632 \\
\hline 2 & $1(2.3 \%)$ & 45 (14.4\%) & 0.027 \\
\hline 3 & $1(2.3 \%)$ & $16(5.1 \%)$ & 0.706 \\
\hline 4 & $1(2.3 \%)$ & 0 & 0.124 \\
\hline Pain management failures, PoD $0-3^{b}, \mathrm{n}(\%)$ & 22 (31.9\%) & 231 (53.8\%) & 0.001 \\
\hline \multicolumn{4}{|l|}{ Opioid rescue medication ${ }^{\mathrm{c}}, \mathrm{n}(\%)$} \\
\hline PoD 0 & 15 (21.7\%) & 228 (53.1\%) & $<0.001$ \\
\hline PoD 1 & $3(4.3 \%)$ & $8(1.9 \%)$ & 0.185 \\
\hline PoD 2 & $5(7.2 \%)$ & $6(1.4 \%)$ & 0.010 \\
\hline PoD 3 & $6(8.7 \%)$ & $5(1.2 \%)$ & 0.002 \\
\hline Switch to different analgesic protocol ${ }^{\mathrm{d}}, \mathrm{n}(\%)$ & $14(20.3 \%)$ & $6(1.4 \%)$ & $<0.001$ \\
\hline
\end{tabular}




\begin{tabular}{|l|l|l|l|}
\hline & $\begin{array}{l}\text { Epidural group } \\
(n=69)\end{array}$ & $\begin{array}{l}\text { CIB + PCA group } \\
(n=429)\end{array}$ & $P$-value \\
\hline Technical failure & $14(20.3 \%)$ & $114(26.6 \%)$ & 0.268 \\
\hline Dislocation & $7(10.9 \%)$ & $4(0.9 \%)$ & $1(0.2 \%)$ \\
\hline Leakage & $4(6.3 \%)$ & $109(25.8 \%)$ & \\
\hline Occlusion & $3(4.7 \% \%)$ & 100 & \\
\hline
\end{tabular}

$\mathrm{CIB}+$ PCA, i.m. continuous infusion of bupivacaine plus i.v. patient-controlled analgesia; PoD, postoperative day; VRS, verbal rating scale (0-4).

A P-value of $<0.05$ was considered to indicate statistical significance.

aExpressed as i.v. morphine equivalent (any route).

bPain management failure: need for rescue medication or switch to different opioid.

'Rescue medication: any additional intravenous, epidural, intramuscular or oral opioid.

${ }^{\mathrm{d} S}$ witch to different analgesic protocol: change of drug, concentration or infusion rate.

Table 5. Post-operative outcomes in patients undergoing major hepatectomy in the present series

\begin{tabular}{|l|l|l|l|}
\hline & $\begin{array}{l}\text { Epidural group } \\
(n=69)\end{array}$ & $\begin{array}{l}\text { CIB + PCA group } \\
(n=429)\end{array}$ & \\
\hline $\begin{array}{l}\text { Complications (Accordion } \\
\text { Classification), } n(\%)\end{array}$ & & $16(3.7 \%)$ & 0.737 \\
\hline Grade I & $3(4.3 \%)$ & $31(7.2 \%)$ & 0.057 \\
\hline Grade II & $10(14.5 \%)$ & $14(3.3 \%)$ & 0.235 \\
\hline Grade III & 0 & $40(9.3 \%)$ & 0.130 \\
\hline Grade IV & $11(15.9 \%)$ & $7(1.6 \%)$ & 0.361 \\
\hline Grade V & $2(2.9 \%)$ & $2(0.5 \%)$ & 0.361 \\
\hline Grade VI (death) & $1(1.4 \%)$ & $7(3-95)$ & 0.005 \\
\hline $\begin{array}{l}\text { Length of stay, days, median } \\
\text { (range) }\end{array}$ & $8(3-80)$ & $15(3.5 \%)$ & 1.000 \\
\hline Readmissions $(<30$ days), $n(\%)$ & $2(2.9 \%)$ & & \\
\hline
\end{tabular}

$\mathrm{CIB}+\mathrm{PCA}$, i.m. continuous infusion of bupivacaine plus i.v. patient-controlled analgesia.

A $P$-value of $<0.05$ was considered to indicate statistical significance.

\section{DISCUSSION}

This study compared the analgesic value of CEA with that of CIB + PCA following major hepatectomy. Data for this large, retrospective cohort show that CIB + PCA provided analgesic control equivalent to that of CEA. No significant differences in the numbers of patients experiencing severe pain were observed between the two groups and the majority of patients in both groups had no or minimal pain during the first $48 \mathrm{~h}$ post-operatively. Strikingly, the CIB + PCA group consumed significantly lower total volumes of opioids, had lower post-operative morbidity and a decreased hospital LoS. 
The present findings would appear to indicate that post-operative pain was well controlled in both groups and that very few patients experienced severe pain on PoDs 1 and 2. In addition, most patients ( $>70 \%)$ in both groups had zero or minimal pain at rest or on movement. There is little practical difference between level 0 and level 1 pain, but 'no pain' and 'severe pain' lie at either end of any pain intensity scale and thus it seems safe to conclude that the present findings are reliable. The use of CIB + PCA also led to a substantial decrease in opioid consumption without compromising pain control. The decrease in opioid consumption was expected and can be explained by two factors. Unlike those in the CIB + PCA group, patients with epidurals were not able to control their opioid administration. In addition, the local analgesic effect of bupivacaine reduces the need for i.v. opioid infusion. Interestingly, patients with wound catheters were discharged 1 day earlier than those in the epidural group, at a median of 7 days rather than 8 days $(P=0.005)$.

Table 6. Morbidity in patients undergoing major hepatectomy in the present series

\begin{tabular}{|c|c|c|c|}
\hline & $\begin{array}{l}\text { Epidural group } \\
(n=69)\end{array}$ & $\begin{array}{l}\text { CIB + PCA group } \\
(n=429)\end{array}$ & $P$-value \\
\hline Overall morbidity, $n(\%)$ & $27(39.1 \%)$ & $112(26.1 \%)$ & 0.030 \\
\hline \multicolumn{4}{|l|}{ Complications, $n$ (\%) } \\
\hline Bile leak & $2(2.9 \%)$ & $16(3.7 \%)$ & \\
\hline Liver failure & $13(18.8 \%)$ & $43(10.0 \%)$ & \\
\hline Sepsis & 0 & $5(1.2 \%)$ & \\
\hline Abdominal abscess & $1(1.4 \%)$ & $4(0.9 \%)$ & \\
\hline lleus & 0 & $5(1.2 \%)$ & \\
\hline Pneumonia & $3(4.3 \%)$ & $11(2.6 \%)$ & \\
\hline Pleural effusion & $1(1.4 \%)$ & $4(0.9 \%)$ & \\
\hline Myocardial infarction & $1(1.4 \%)$ & $2(0.5 \%)$ & \\
\hline Wound infection & $1(1.4 \%)$ & $11(2.6 \%)$ & \\
\hline Renal failure & $2(2.9 \%)$ & $7(1.6 \%)$ & \\
\hline Post-operative haemorrhage & 0 & $4(0.9 \%)$ & \\
\hline Peritonitis & 0 & $2(0.5 \%)$ & \\
\hline Ascites & $1(1.4 \%)$ & $8(1.9 \%)$ & \\
\hline Biliary stricture/stenosis & 0 & $4(0.9 \%)$ & \\
\hline Multi-organ failure & $1(1.4 \%)$ & $4(0.9 \%)$ & \\
\hline Pneumothorax & 0 & $2(0.5 \%)$ & \\
\hline Urinary tract infection & $2(2.9 \%)$ & $6(1.4 \%)$ & \\
\hline Atrial fibrillation & $3(4.3 \%)$ & $2(0.5 \%)$ & \\
\hline Other & $2(2.9 \%)$ & $12(2.8 \%)$ & \\
\hline Analgesia-related morbidity (all), $n(\%)$ & $29(45.3 \%)$ & $169(41.4 \%)$ & 0.558 \\
\hline Pruritus & $14(20.3 \%)$ & 92 (21.4\%) & \\
\hline Hallucinations & $7(10.1 \%)$ & 80 (18.6\%) & \\
\hline Dizziness & $4(5.8 \%)$ & $32(7.5 \%)$ & \\
\hline
\end{tabular}




\begin{tabular}{|l|l|l|l|}
\hline & $\begin{array}{l}\text { Epidural group } \\
(n=69)\end{array}$ & $\begin{array}{l}\text { CIB + PCA group } \\
(n=429)\end{array}$ & $P$-value \\
\hline Hypotension requiring treatment & $5(7.2 \%)$ & 0 & \\
\hline Acute confused episode & $3(4.3 \%)$ & $4(0.9 \%)$ & \\
\hline Wound infection & $1(1.4 \%)$ & $11(2.6 \%)$ & \\
\hline Urinary retention & 0 & $3(0.7 \%)$ & \\
\hline Sedation score PoD 1 & & & $\mathbf{0 . 0 0 4}$ \\
\hline 0 & $37(82.2 \%)$ & $215(59.9 \%)$ & $\mathbf{0 . 0 1 5}$ \\
\hline 1 & $8(17.8 \%)$ & $129(35.9 \%)$ & 0.392 \\
\hline 2 & 0 & $15(4.2 \%)$ & \\
\hline
\end{tabular}

CIB PCA, i.m. continuous infusion of bupivacaine plus i.v. patient-controlled analgesia; PoD, post-operative day. A $P$-value of 0.05 was considered to indicate statistical significance.

Other complications include: haematoma at resection area $(n$ 1), transient ischaemic attack $(n$ 1), Horner's syndrome $(n 1)$, pulmonary embolism $(n$ 1), respiratory failure $(n 1)$, alcohol withdrawal $(n)$ ), deep vein thrombosis $(n 1)$, infected line $(n 1)$, allergic reaction $(n 1)$, sacral pressure sore $(n 1)$, cellulites $(n 1)$, partial portal vein thrombosis $(n 1)$, axillary nerve palsy $(n 1)$ and cerebral infarct $(n 1)$.

An increased need for rescue medication in the CIB +PCA group was observed. In most patients rescue medication was given on the day of surgery ( $P O D 0$ ), but this was countered by an increased need for rescue medication and a switch to i.v. opioids in the CEA group on PoDs 1-3. In addition, CIB + PCA was continued for 1 day longer than epidural analgesia. This mainly reflects the practicalities of managing epidurals, as it is part of post-operative practice to remove the catheter after $72 \mathrm{~h}$ unless otherwise clinically indicated. The high percentage $(53.1 \%)$ of patients requiring rescue medication may be explained by the possibility that the local analgesic effect of the bupivacaine infusion may have been suboptimal directly after surgery. The epidural analgesia was started prior to the incision, whereas the wound catheters were commenced immediately after wound closure. It may take time for bupivacaine to reach all adjacent tissue and associated nerve endings. Unlike a correctly functioning epidural analgesic, which provides a complete block, bupivacaine infusion exhibits only a local effect and additional opioids may be required.

Another important result refers to the finding that when one of the catheters was dislodged or occluded (often by a faulty connector or by the faulty insertion of the catheter into the connector), pain control was adequately maintained by just one catheter. This is supported by the stagnant opioid consumption on PoDs 2 and 3 with adequate maintenance of pain control. This implies that a single infusing catheter combined with PCA may be sufficient to control post-operative pain.

The findings of this study are in keeping with those of earlier reports on the beneficial results of this technique with regard to pain control, opioid consumption and recovery.[16,19,24,33] It has been claimed that epidural analgesia is superior to PCA for post-operative pain relief in patients recovering from major upper abdominal 
operations.[10,11] However, the present study shows that when PCA is combined with CIB via i.m. catheters, equivalent pain control can be achieved. As Khorgami et al.[34] demonstrated in a recent RCT, the technique of local interfascial analgesia is also feasible for midline incisions.

The present results confirm the clinical applicability of wound catheters. Not only does this analgesic approach provide equivalent pain control with reduced opioid intake, but it also represents a quicker and very likely cheaper method of doing so. Abandoning the use of epidural analgesia eliminates the risk for epidural-related complications (haematoma, abscess and nerve damage) and may improve costeffectiveness as anaesthetic time may be shortened and the CIB + PCA combination does not require specialist supervision on the ward. The lower total opiate dose received may also reduce opiate-associated side effects. In patients in whom experts aim to achieve faster post-operative recovery within the context of an ERAS programme, the use of CIB + PCA may result in a further reduction in the time required to meet recovery criteria. The partly retrospective design of this study resulted in the incomplete availability of pain scores. The complete availability of pain data might have altered the comparability of the groups and might have implied an increased superiority or inferiority of either of the two analgesic modalities. In addition, an inherent bias of surgeon preference influencing outcomes cannot be excluded. The strengths of this study include its use of a large and uninterrupted cohort of patients submitted to major liver resection in an expert centre, whereas other prospective series are considerably smaller. The patients investigated in this study represent a population at risk for post-operative coagulopathy and the development of epidural hematoma. It would be interesting for future research to compare patient-controlled epidural analgesia with CIB + PCA and to look into the number and location of wound catheters needed to achieve the optimal local analgesic effect. Lastly, it would be interesting to compare the local wound infusion technique with that of the transversus abdominis plane block[35], which can also be regarded as safe and effective after abdominal surgery.

\section{CONCLUSION}

Continuous i.m. bupivacaine infusion with i.v. PCA provides equivalent pain control and a lower level of opioid consumption compared with CEA following major hepatectomy. The CIB + PCA technique could replace that of epidural analgesia with the potential for greater safety, improved post-operative outcomes and a reduced hospital LoS. 


\section{REFERENCES}

1. Scott NB, Mogensen T, Greulich A, Hjortso NC, Kehlet H. (1988) No effect of continuous i.p. infusion of bupivacaine on postoperative analgesia, pulmonary function and the stress response to surgery. $\mathrm{Br} J$ Anaesth 61:165-168.

2. Rozen WM, Tran TM, Ashton MW, Barrington MJ, Ivanusic JJ, Taylor GI. (2008) Refining the course of the thoracolumbar nerves: a new understanding of the innervation of the anterior abdominal wall. Clin Anat 21:325-333.

3. MacKay G, O'Dwyer PJ. (2008) Early discharge following liver resection for colorectal metastases. Scott Med J 53:22-24.

4. van Dam RM, Hendry PO, Coolsen MM, Bemelmans MH, Lassen K, Revhaug A et al. (2008) Initial experience with a multimodal enhanced recovery programme in patients undergoing liver resection. $\mathrm{Br} J$ Surg 95:969-975.

5. Koea JB, Young Y, Gunn K. (2009) Fast track liver resection: the effect of a comprehensive care package and analgesia with singledose intrathecal morphine with gabapentin or continuous epidural analgesia. HPB Surg 2009:271986.

6. Hendry PO, van Dam RM, Bukkems SF, McKeown DW, Parks RW, Preston T et al. (2010) Randomized clinical trial of laxatives and oral nutritional supplements within an enhanced recovery after surgery protocol following liver resection. Br J Surg 97:1198- 1206.

7. Lin DX, Li X, Ye QW, Lin F, Li LL, Zhang QY. (2011) Implementation of a fast-track clinical pathway decreases postoperative length of stay and hospital charges for liver resection. Cell Biochem Biophys 61:413-419.

8. Liu SS, Carpenter RL, Mackey DC, Thirlby RC, Rupp SM, Shine TS et al. (1995) Effects of perioperative analgesic technique on rate of recovery after colon surgery. Anesthesiology 83:757-765.

9. Kehlet H. (1997) Multimodal approach to control postoperative pathophysiology and rehabilitation. $\mathrm{Br}$ J Anaesth 78:606-617.

10. Jorgensen H, Wetterslev J, Moiniche S, Dahl JB. (2000) Epidural local anaesthetics versus opioid-based analgesic regimens on postoperative gastrointestinal paralysis, PONV and pain after abdominal surgery. Cochrane Database Syst Rev (4)CD001893

11. Werawatganon T, Charuluxanun S. (2005) Patient-controlled intravenous opioid analgesia versus continuous epidural analgesia for pain after intraabdominal surgery. Cochrane Database Syst Rev (1)CD004088.

12. Weinberg L, Scurrah N, Gunning K, McNicol L. (2006) Postoperative changes in prothrombin time following hepatic resection: implications for perioperative analgesia. Anaesth Intensive Care 34:438-443.

13. Matot I, Scheinin O, Eid A, Jurim O. (2002) Epidural anaesthesia and analgesia in liver resection. Anesth Analg 95:1179-1181.

14. Cook TM, Counsell D, Wildsmith JA. (2009) Major complications of central neuraxial block: report on the Third National Audit Project of the Royal College of Anaesthetists. Br J Anaesth 102:179-190.

15. McLeod G, Davies H, Munnoch N, Bannister J, MacRae W. (2001) Postoperative pain relief using thoracic epidural analgesia: outstanding success and disappointing failures. Anaesthesia 56:75-81.

16. Liu SS, Richman JM, Thirlby RC, Wu CL. (2006) Efficacy of continuous wound catheters delivering local anaesthetic for postoperative analgesia: a quantitative and qualitative systematic review of randomized controlled trials. J Am Coll Surg 203:914- 932.

17. Beaussier M, El'Ayoubi H, Schiffer E, Rollin M, Parc Y, Mazoit JX et al. (2007) Continuous preperitoneal infusion of ropivacaine provides effective analgesia and accelerates recovery after colorectal surgery: a randomized, double-blind, placebo-controlled study. Anesthesiology 107:461-468.

18. Forastiere E, Sofra M, Giannarelli D, Fabrizi L, Simone G. (2008) Effectiveness of continuous wound infusion of $0.5 \%$ ropivacaine by $O n-Q$ pain relief system for postoperative pain management after open nephrectomy. Br J Anaesth 101:841-847.

19. Basu S, Tamijmarane A, Bulters D, Wells JK, John TG, Rees M. (2004) An alternative method of wound pain control following hepatic resection: a preliminary study. HPB 6:186-189. 
20. Chan SK, Lai PB, Li PT, Wong J, Karmakar MK, Lee KF et al. (2010) The analgesic efficacy of continuous wound instillation with ropivacaine after open hepatic surgery. Anaesthesia 65:1180-1186.

21. Wurnig PN, Lackner H, Teiner C, Hollaus PH, Pospisil M, Fohsl-Grande B et al. (2002) Is intercostal block for pain management in thoracic surgery more successful than epidural anaesthesia? Eur J Cardiothorac Surg 21:11 5-119.

22. Panaro F, Gheza F, Piardi T, Woehl Jaegle ML, Audet M, Cantu M et al. (2011) Continuous infusion of local anaesthesia after living donor nephrectomy: a comparative analysis. Transplant Proc 43:985-987.

23. Gebhardt R, Mehran RJ, Soliz J, Cata JP, Smallwood AK, Feeley TW. (2013) Epidural versus ON-Q local anaesthetic-infiltrating catheter for post-thoracotomy pain control. J Cardiothorac Vasc Anesth 27:423-426.

24. Revie EJ, McKeown DW, Wilson JA, Garden OJ, Wigmore SJ. (2012) Randomized clinical trial of local infiltration plus patient-controlled opiate analgesia vs. epidural analgesia following liver resection surgery. HPB 14:611-618.

25. Couinaud C. (1957) Le Foie: Études anatomiques et chirurgicales [The Liver: Anatomical and Surgical Studies]. Paris: Masson \& Cie.

26. Rees M, Plant G,Wells J, Bygrave S. (1996) One hundred and fifty hepatic resections: evolution of technique towards bloodless surgery. Br J Surg 83:1526-1529.

27. Shaw IM, Rees M, Welsh FK, Bygrave S, John TG. (2006) Repeat hepatic resection for recurrent colorectal liver metastases is associated with favourable longterm survival. Br J Surg 93:457-464.

28. Kazaryan AM, Rosok BI, Marangos IP, Rosseland AR, Edwin B. (2011) Comparative evaluation of laparoscopic liver resection for posterosuperior and anterolateral segments. Surg Endosc 25:3881-3889.

29. Strasberg SM, Linehan DC, Hawkins WG. (2009) The Accordion severity grading system of surgical complications. Ann Surg 250:177-186.

30. Porembka MR, Hall BL, Hirbe M, Strasberg SM. (2010) Quantitative weighting of postoperative complications based on the Accordion severity grading system: demonstration of potential impact using the American College of Surgeons National Surgical Quality Improvement Program. J Am Coll Surg 210:286-298.

31. Aird LN, Brown CJ. (2012) Systematic review and meta-analysis of electrocautery versus scalpel for surgical skin incisions. Am J Surg 204:216-221.

32. Charoenkwan K, Chotirosniramit N, Rerkasem K. (2012) Scalpel versus electrosurgery for abdominal incisions. Cochrane Database Syst Rev (6)CD005987.

33. Cheong WK, Seow-Choen F, Eu KW, Tang CL, Heah SM. (2001) Randomized clinical trial of local bupivacaine perfusion versus parenteral morphine infusion for pain relief after laparotomy. Br J Surg 88:357359.

34. Khorgami Z, Shoar S, Hosseini Araghi N, Mollahosseini F, Nasiri S, Ghaffari MH et al. (2013) Randomized clinical trial of subcutaneous versus interfascial bupivacaine for pain control after midline laparotomy. Br J Surg 100:743-748.

35. Charlton S, Cyna AM, Middleton P, Griffiths JD. (2010) Perioperative transversus abdominis plane (TAP) blocks for analgesia after abdominal surgery. Cochrane Database Syst Rev (12)CD007705.

36. Palliative Care Expert Group. (2010) Therapeutic Guidelines: Palliative Care 2010 Version 3. Melbourne, Vic: Therapeutic Guidelines Ltd.

37. Palliativedrugs.com Ltd. (2010) Opioid dose conservation ratios. Available at http://www.palliative drugs.com/formulary/en/ opioid-dose-conversion-ratios.html (last accessed 4 October 2012).

38. Eastern Metropolitan Region Palliative Care Consortium (Victoria) - Clinical Working Party. Opioid Conversion Ratios - Guide to Practice 2010. Available at http://www.emrpcc.org.au/wp-content/ uploads/2013/03/EMRPCC-Opioid-Conversion2010-Final2.pdf (last accessed 21 September 2012).

39. Pasero C, Portenoy R, McCaffery M. (1999) Opioid analgesics. In: McCaffery M, Pasero C, eds. Pain: Clinical Manual, 2nd edn. St Louis: Mosby, pp. 161-299.

40. Mundipharma Pty Ltd. (2009) MIMS Narcotic Analgesics Prescribing Guide 2009/2010. Sydney, NSW: Mundipharma Pty Ltd. 


\section{Appendix 1.}

The following (combined) procedures were performed only twice in the study cohort:

Cholecystectomy + biliodigestive anastomosis, skeletonization of the hepatoduodenal ligament, closure of ileostomy, block dissection of the hepatoduodenal ligament, cava resection, node block dissection of the lesser sac, diaphragm + peritoneal nodule resection, cholecystectomy + hepatoduodenal ligament biopsy, deroofing of a liver cyst and excision of peritoneal deposits not in the lesser sac.

\section{The following (combined) procedures were performed only once in the study cohort:}

En bloc gastric resection + cholecystectomy, block dissection of the hepatoduodenal ligament + diathermy ablation, excision of aortocaval lymph node + peritoneal deposit resection, skeletonization of the hepatoduodenal ligament + Roux loop biliary reconstruction + cholecystectomy, block dissection of the lesser sac + excision of the common bile duct + Roux loop reconstruction, colon excision + cholecystectomy, reconstruction of the $v$. cava, right hemicolectomy + diathermy ablation, sleeve resection of the duodenum, posterior pelvic extenteration, en bloc total mesorectal excision + appendicectomy + excision of a mesenteric mass, diaphragm resection and repair of two incisional hernias, cholecystectomy + excision of the greater omentum, exploration of common bile duct + removal of a stone, splenectomy, insertion of terminal ileostomy, gastroduodenal ligament + cholecystectomy, vascular reconstructions, nephrectomy + adrenalectomy, block dissection of the lesser sac + excision of common bile duct + Roux loop reconstruction + repair of an incisional hernia, reconstruction of the bile duct, small bowel resection, small bowel biopsy and resection of part of the diaphragm and lung. 


\section{Chapter}

\section{Abandoning prophylactic abdominal drainage after hepatic surgery: 10 years of no-drain policy in an ERAS environment}

Wong-Lun-Hing EM*, van Woerden $\mathrm{V}^{*}$, Lodewick TM, Bemelmans MH, Olde Damink SWM, Dejong CHC, van Dam RM

* Both authors have contributed equally to this manuscript and share first authorship.

Dig Surg. 2017 Mar 25 


\section{ABSTRACT}

\section{BACKGROUND}

Routine prophylactic abdominal drainage after hepatic surgery is still debated, may be unnecessary, possibly harmful and uncomfortable for patients. This study evaluated the safety of a no-drain policy after liver resection within an ERAS- programme.

\section{METHODS}

All hepatectomies performed without prophylactic drainage during 2005 - 2014 were included. Primary endpoints were resection-surface-related (RSR) morbidity, defined as the presence of post-operative biloma, haemorrhage or abscess, and reinterventions. Secondary endpoints were length of stay (LOS), total post-operative morbidity, the composite endpoint of liver surgery-specific complications, readmissions and 90-day mortality. Uni- and multivariable analyses were performed to identify independent risk factors for RSR-morbidity. A systematic search was performed to compare the results of this study to literature.

\section{RESULTS}

A total of 538 resections were included in the study. The RSR-complication and reintervention rate was $15 \%$ and $12 \%$, respectively. Major liver resection ( $\geq 3$ segments) was an independent risk factor for the development of RSR-morbidity (OR=3.01, 95\% $\mathrm{Cl} 1.61-5.62 ; \mathrm{P}=0.001)$ and need for RSR-reintervention ( $\mathrm{OR}=3.02,95 \% \mathrm{Cl} 1.59-5.73$; $\mathrm{P}=0.001)$.

\section{CONCLUSION}

RSR-morbidity, mortality and reintervention rates after liver surgery without prophylactic drainage in patients, treated within an ERAS programme, were comparable to previously published data. A no-drain policy after partial hepatectomy seems safe and feasible. 


\section{INTRODUCTION}

In the past decades, the quality of perioperative care for hepatic surgery has improved dramatically due to improvements in surgical technique, risk assessment and perioperative care. Prophylactic intra-abdominal drainage is still routinely applied in many hospitals worldwide. However, prophylactic intra-abdominal drainage may be unnecessary[1], uncomfortable and even harmful for the patient. As early as 1915, the British surgeon Major Grey Turner already pointed out the dangers of routine drain use. One hundred years later, the routine use of prophylactic drains in liver surgery is still an on-going debate.[2]

Some studies have reported advantages of prophylactic drain placement such as early drainage of bile leaks, preventing subphrenic collection, detecting postoperative haemorrhage and removing ascites.[3-6] Other studies have indicated that the risks of prophylactic intra-abdominal drains, including drain-related bleeds, ascending intra- abdominal infections by retrograde contamination and impaired pulmonary function, outweigh the benefits.[1, 7, 8] Furthermore, patients with a drain in place experience more abdominal pain and discomfort, have more difficulties to mobilize, need more nursing care and this could contribute to a longer admission and increased costs.[7]

Currently, if used, drains are usually placed near the transection surface or in the subphrenic space, and are often removed on post-operative day (POD) 3 to 5 depending on drain production.[7, 9, 10] Already in 2007, a meta-analysis [11] showed that there were no significant differences in morbidity, mortality and reoperation rates between patients with or without a prophylactic abdominal drain after uncomplicated elective hepatectomy. Post-operative mortality in patients undergoing liver surgery without a drain ranges between $0-3 \%$. Percutaneous or operative reintervention rates in patients without a drain range from $0-18 \%$ and $0-10 \%$ respectively $[1,4,7,8,12-14]$, and do not differ from outcomes after placement of an abdominal drain. Patients with a drain have reported mortality, percutaneous reintervention and reoperation rates between $0-6 \%, 0-36 \%$ and $0-6 \%$, respectively.[1, 4, 7, 8, 12-14] The accumulating evidence suggests that routine abdominal drainage after liver resection is unnecessary and the benefit arguable, but it may be indicated in specific patients.

The Enhanced Recovery After Surgery (ERAS) programme has shown a benefit for patient recovery after liver surgery in recent years.[15-17] The programme has been implemented to optimize pre-, peri- and post-operative care to facilitate a quicker recovery. With the introduction of this programme, the routine use of drains after liver surgery without biliary or vascular reconstruction has been abandoned.[15-17] 
The aim of this study was to examine the post-operative complication and reintervention rates in patients undergoing liver resection that were treated without prophylactic drains in an ERAS environment, to identify risk factors associated with reinterventions for specific complications and to compare the results to earlier studies on drainage following liver resection.

\section{METHODS}

\section{STUDY DESIGN}

All patients undergoing hepatic resection between January 2005 and December 2014 at Maastricht University Medical Centre (MUMC) were included in a prospective database. Patients were retrospectively identified and screened for eligibility in this study. Patients were excluded if a prophylactic abdominal drain was placed, e.g. in the case of hepatic resection traumatic lesions, or if a bilioenteric anastomosis was created. Primary endpoints of this study were RSR-morbidity and reinterventions for RSR-morbidity. RSR-morbidity was defined as the presence of bile leakage, intraabdominal abscess or/and haemorrhage.[18] Reinterventions for RSR-morbidity were considered to be CT- or US- guided percutaneous drainage, reoperation and ERCP with stenting. Data on reinterventions were retrospectively collected from individual patient charts. Secondary endpoints were hospital length of stay (LOS), postoperative morbidity, readmission rate, 90-day mortality and the composite endpoint of liver surgery-specific complications (CEP). A composite endpoint consists of 2 or more specific complications that can be regarded as 1 dichotomous endpoint that occur in 1 patient. The liver surgery-specific CEP consists of ascites, postresectional liver failure, bile leakage, intra-abdominal haemorrhage, intra-abdominal abscess and/or post-operative mortality.[19]

\section{SURGICAL TECHIQUES}

All hepatic resections were performed by 1 of 4 hepatobiliary surgeons (CHCD, RMvD, SWMOD, MHB) or by a senior resident/fellow under the supervision of a hepatobiliary surgeon. Hepatectomies were performed as open or laparoscopic procedures as published previously.[20]

For open procedures, a unilateral right subcostal, a bilateral subcostal (right extended to left), J-shaped or midline incision was used. Intraoperative ultrasound was routinely performed to examine the location of lesions in the liver and the relation to surrounding biliary and vascular structures. Hepatic resection was performed by using a Cavitron Ultrasonic Surgical Aspirator (CUSA system 200 macrodissector, 
Cavitron Surgical Systems, USA) and Argon beam coagulation (Force GSU System, Valleylab, USA), with or without Pringle's manoeuvre. Ultracision Harmonic ACE (Ethicon Endosurgery, Johnson \& Johnson, USA). Central venous pressure was maintained $\leq 5 \mathrm{~cm} \mathrm{H} 2 \mathrm{O}$ during transection to reduce excessive blood loss. During transection, clips and ligatures were used to treat vessels and bile ducts at the resection surface. To avoid post-operative haemorrhage and bile leakage, the resection surface was treated with argon beam coagulation and or sealants at the discretion of the surgeon, although the effectiveness has never been proven.[18]

For laparoscopic procedures patients were placed in supine French position. Access to the abdomen was created by open transumbilical insertion of a $30^{\circ}$ laparoscope. Three or four additional trocars were inserted. The pressure of the pneumoperitoneum was kept $<12 \mathrm{mmHg}$. Parenchymal transection was performed using the Ligasure $5 \mathrm{~mm}$ blunt tip (Covidien, USA) laparoscopic CUSA (Cavitron Surgical Systems, USA) or Harmonic scalpel (Ultracision, Ethicon Endosurgery, Johnson \& Johnson, USA). The portal pedicles were stapled using a vascular stapler (EndoGIA Autosuture, Covidien, USA). Resected specimens were placed in a plastic bag (Endocatch Autosuture, Covidien, USA) and removed through a separate usually suprapubic muscle sparing incision.

\section{NO-DRAIN POLICY}

Since the introduction of ERAS in liver surgery in 2005, the MUMC has a no- drain policy; abdominal drains are no longer part of standard management after hepatectomy. The use of prophylactic abdominal drains was limited to a selected group of indications. They were routinely placed after the creation of bilioenteric anastomoses or biliary reconstructions and in the case of traumatic liver lesions. In some cases, placement of a prophylactic abdominal drain could be considered by the surgeon when a high risk of intra- abdominal fluid collection was expected, e.g. when performing combined procedures, in the case of intra-operative iatrogenic laceration that required drainage, repeat hepatectomies, excessively large resection surfaces or central liver resections. Furthermore, all patients were treated within the ERAS programme. Key principles of this programme have been previously described.[21] Patients were closely monitored during hospitalization based on clinical presentation, vital parameters and standard diagnostic laboratory results. Additional imaging (CT or US) was only performed on clinical findings indicative of post-operative complications. All complications, defined as any deviation from the expected post-operative course $<30$ days and graded according to the Dindo-Clavien classification system[22], were recorded in the electronic patient record system and in a prospectively maintained research database. Data from the electronic patient record system and the research database were crosschecked for missing data. 


\section{SYSTEMATIC LITERATURE SEARCH}

A systematic search was conducted to compare the results of this study with literature following the current recommendations of Preferred Reporting Items for Systematic Reviews and Meta-analysis Approach (PRISMA). Two authors (E.M.W.-L.-H. and V.W.) independently performed the search, study selection, data extraction and critical appraisal of the studies.

\section{Eligibility criteria}

After review of the abstract, the remaining studies were selected for full- text evaluation and inclusion, if: 1) The subject of the study was comparison of the routine use of an abdominal drain versus no-drainage after hepatectomy; 2 ) the study was not an editorial, systematic review or meta-analysis; 3 ) the study compared clinical outcome after abdominal drain versus no-drainage after hepatectomy; and 4) the study was in the English language.

\section{Study selection and quality appraisal}

The search was conducted in Ovid MEDLINE, Embase, PubMed databases to identify all studies comparing the routine use of an abdominal drain versus no-drainage after hepatectomy between 1st January 1990 and 31st December 2014. The following search strategy was used: ([["Hepatectomy"[Mesh] OR "liver resection" OR "liver surgery"] AND ["Drainage"[Mesh] OR "drain*"] NOT ["preoperative drainage" OR "preoperative biliary drainage"]). After removal of duplicates, articles were screened by title, abstract and subsequently full text. In addition, reference lists of all included studies were screened for missed but relevant studies. The methodological quality and risk of bias of the studies was assessed using the Cochrane Handbook for Systematic Reviews.[23] All included studies were consequently graded by using the Oxford Centre for Evidence-Based Medicine levels of evidence.[24] Furthermore, clinical trial registers were searched for ongoing studies.

\section{Data collection}

Two reviewers (E.M.W.-L.-H. and V.W.) independently extracted data from the selected studies on study design, participant characteristics, mortality, image-guided drainage, reoperation, bile leakage / fistula, infected collections, post-operative bleeding and wound infection.

\section{STATISTICAL ANALYSIS}

Continuous data are described as median (range) and categorical data are presented as percentages. The Chi-square / Fisher's exact and Mann-Whitney $U$ tests were used to compare categorical data and continuous data, respectively. Results were consid- 
ered significant when $P \leq 0.05$. Uni- and multivariable analyses were performed to define specific independent risk factors for RSR-reinterventions. Variables included in the univariable analysis: sex, ASA class $\geq 111$, age $<65$ or $\geq 70$ years, median BMl, type of liver resection (major, caudate, repeat, central), blood loss $>2,000 \mathrm{ml}$, preoperative chemotherapy, Pringle manoeuvre and operating time $>240 \mathrm{~min}$. Multivariable analysis was performed with binary logistic regression and $P \leq 0.10$ was used to select variables from univariable analysis. All statistical analyses were performed using IBM SPSS Statistics for Windows, Version 20.0. (Armonk, NY, USA: IBM Corp.).

\section{RESULTS}

\section{GENERAL AND SURGICAL CHARACTERISTICS}

A total of 606 hepatic resections were performed in the study period. All 66 patients that received a drain were excluded from further analysis. Details of this drain group will be addressed later in this section. Furthermore, two patients with missing data were excluded from analysis. A total of 538 patients were analysed. General and surgical characteristics are shown in Table 1.

\section{PRIMARY OUTCOME}

Seventy-nine (15\%) of the 538 patients without a drain developed post-operative RSR-complications. Sixty-seven (12\%) of these patients required surgical, radiological or endoscopic reintervention (Table 2).

Of the variables included in the univariable analyses (Table 3,4), only age $<65$ years, major liver resection, blood loss $>2000 \mathrm{ml}$, Pringle manoeuvre, operating time $>240$ minutes, and preoperative chemotherapy were significantly $(\mathrm{P}<0.1)$ associated with the development major RSR-morbidity ( $\geq$ Dindo-Clavien grade $3 a$ ) or the need for post-operative RSR-reinterventions. After multivariable analyses major liver resection was an independent risk factor $(\mathrm{OR}=3.01,95 \% \mathrm{Cl} 1.61-5.62 ; \mathrm{P}=0.001)$ for the development of major RSR-morbidity, and was also associated with an increased risk of RSR-reinterventions $(\mathrm{OR}=3.02,95 \% \mathrm{Cl} 1.59-5.73 ; \mathrm{P}=0.001)$. 
Chapter 6

Table 1. Baseline patient and surgical characteristics

\begin{tabular}{|c|c|}
\hline & $\begin{array}{l}\text { All patients } \\
N=538(\%)\end{array}$ \\
\hline Sex (male) & $308(57)$ \\
\hline Age, years & $64(55-70)$ \\
\hline $\mathrm{BMI}, \mathrm{kg} / \mathrm{m} 2$ & $25.6(22.9-28.5)$ \\
\hline \multicolumn{2}{|l|}{ ASA physical status } \\
\hline 1 & $85(16)$ \\
\hline ॥ & $339(63)$ \\
\hline$\geq \mathrm{III}$ & $114(21)$ \\
\hline \multicolumn{2}{|l|}{ Indications } \\
\hline Colorectal metastasis & $421(78)$ \\
\hline Benign lesions & $47(9)$ \\
\hline Other malignancy & $29(5)$ \\
\hline $\mathrm{HCC}$ & $24(5)$ \\
\hline Gallbladder carcinoma & $7(1)$ \\
\hline $\mathrm{CCC}$ & $5(1)$ \\
\hline Other & $5(1)$ \\
\hline Preoperative chemotherapy & $271(50)$ \\
\hline \multicolumn{2}{|l|}{ Resection Type } \\
\hline$<1$ segment/ metastasectomy & $213(40)$ \\
\hline Multisegmentectomy & $173(32)$ \\
\hline Right hemihepatectomy & $74(14)$ \\
\hline Right hemihepatectomy +1 segment & $31(6)$ \\
\hline Left hemihepatectomy & $16(3)$ \\
\hline Left hemihepatectomy +1 segment & $2(0.4)$ \\
\hline Right extended hemihepatectomy & $12(2)$ \\
\hline Left extended hemihepatectomy & $3(0.6)$ \\
\hline Central resection & $18(3)$ \\
\hline Caudate lobe resection & $25(5)$ \\
\hline Major hepatectomy ( $\geq 3$ segments) & $226(42)$ \\
\hline Repeat hepatectomy & $57(11)$ \\
\hline Total operating time, min & $200(150-270)$ \\
\hline Intraoperative blood loss, ml & $500(269-1000)$ \\
\hline Pringle & $118(22)$ \\
\hline
\end{tabular}

Values in parentheses are percentages, unless indicated otherwise. Numeric data are presented as median (interquartile range). BMI, Body Mass Index. ASA, American Society of Anaesthesiologists. HCC, Hepatocellular carcinoma. CCC, Cholangiocellular carcinoma. 
Table 2. Primary endpoints

\begin{tabular}{|c|c|}
\hline & $\begin{array}{l}\text { All patients } \\
N=538(\%)\end{array}$ \\
\hline Resection surface-related (RSR) complication rate & $79(15)$ \\
\hline All surgery-related complication rate & $90(20)$ \\
\hline Bile leakage (RSR) & $35(7)$ \\
\hline Haemorrhage (RSR) & $9(2)$ \\
\hline Intra-abdominal abscess (RSR) & $44(8)$ \\
\hline Ascites & $12(2)$ \\
\hline Post-operative liver failure & $17(3)$ \\
\hline Pleural effusion & $18(3)$ \\
\hline Sepsis & $15(3)$ \\
\hline Wound infection & $28(5)$ \\
\hline Reintervention rate for RSR complications & $67(12)$ \\
\hline Reintervention rate & $72(13)$ \\
\hline CT drainage & $55(10)$ \\
\hline ECRP with stenting & $9(2)$ \\
\hline US drainage & $8(2)$ \\
\hline Relaparotomy & $11(2)$ \\
\hline Relaparoscopy & $1(0.2)$ \\
\hline Thoracotomy & $1(0.2)$ \\
\hline Thoracic drainage & $8(2)$ \\
\hline
\end{tabular}

Values in parentheses are percentages.

Multiple complications or reinterventions per patient were possible.

A total of 178 surgery-related complications occurred in 90 patients.

A total of 93 reinterventions occurred in 72 patients.

RSR, Resection surface-related. CT, Computer Tomography. ERCP, Endoscopic Retrograde Cholangiopancreaticography. US, Ultrasound.

\section{SECONDARY OUTCOME MEASURES}

The median LOS was 8 days (6-11). Fifty patients (9\%) were readmitted within 30 days after surgery (Table 5). Mortality within 90 days after surgery was observed in fifteen patients (2.8\%). Within this group, five patients died from sepsis following an intraabdominal abscess or biloma, three patients died from multi-organ failure induced by postresectional liver failure, three patients died from extensive extra-hepatic metastatic disease and subsequent multi-organ failure and four patients died of an acute cardiac arrest of which one was proven in autopsy to be caused by myocardial infarction. 

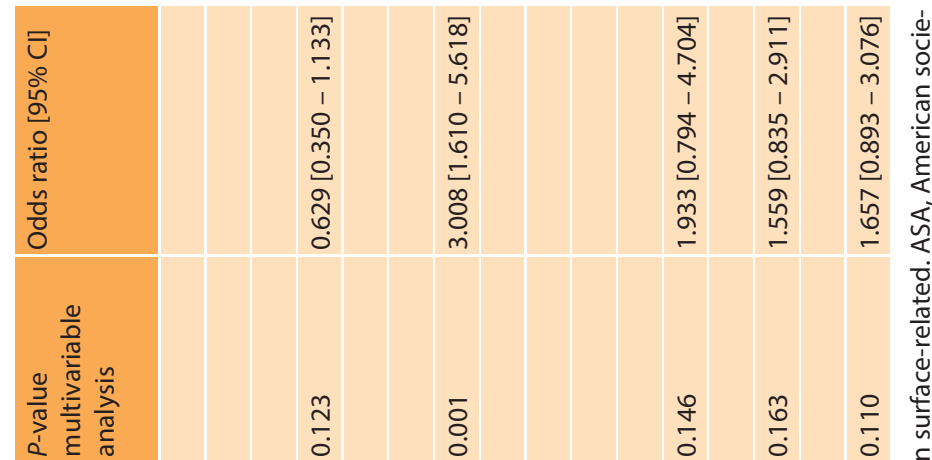

$\stackrel{\frac{7}{0}}{\overline{0}}$

$\bar{\circ}$

$\frac{0}{\circ} \div \frac{0}{0} \div$

ป

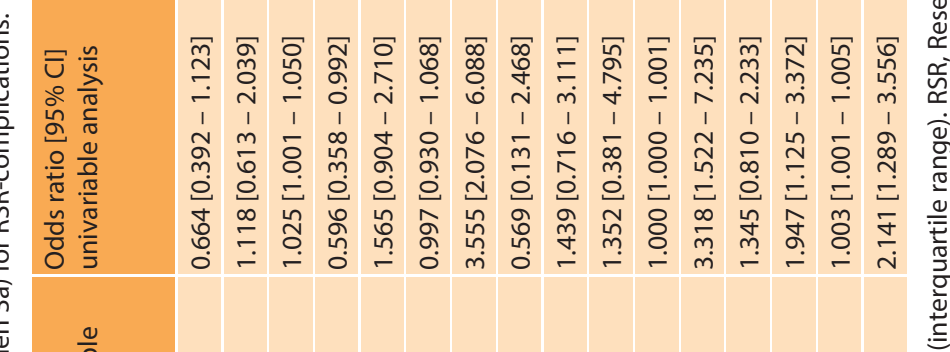

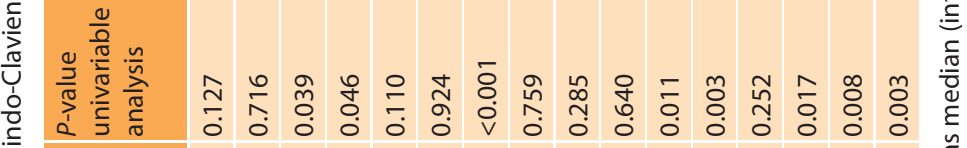

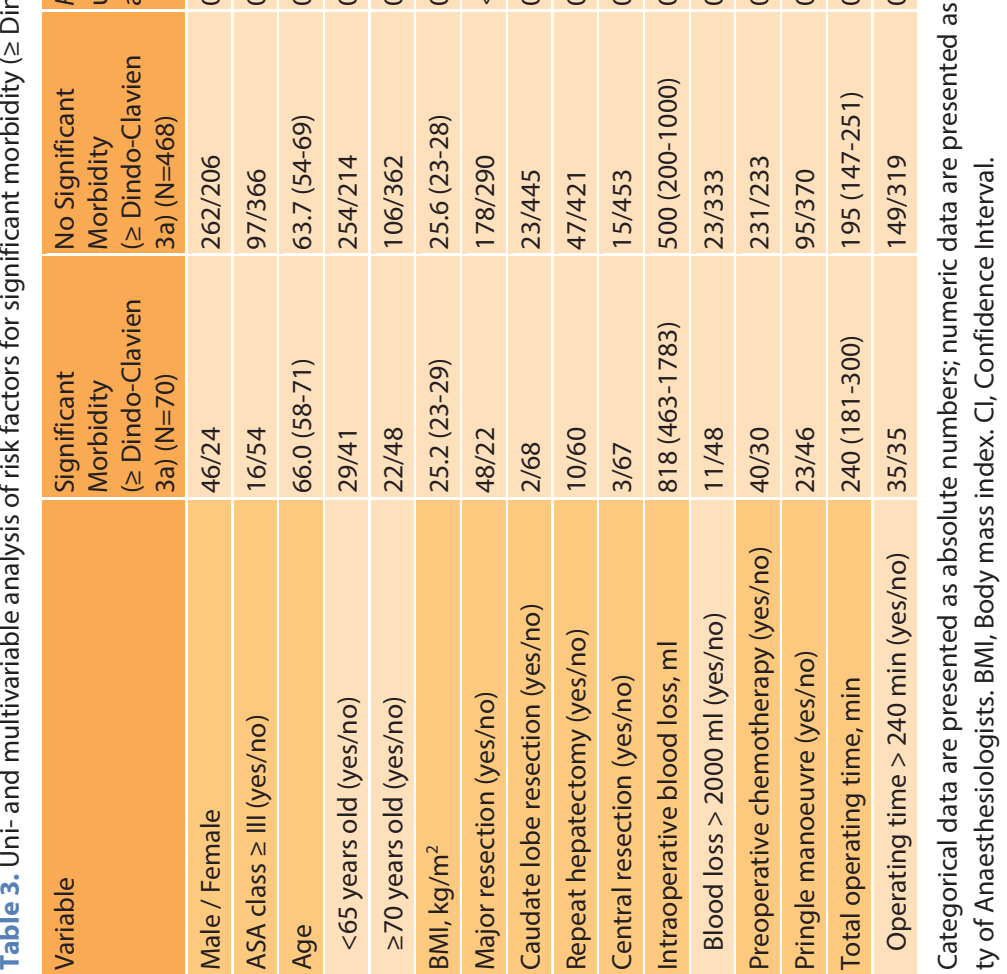



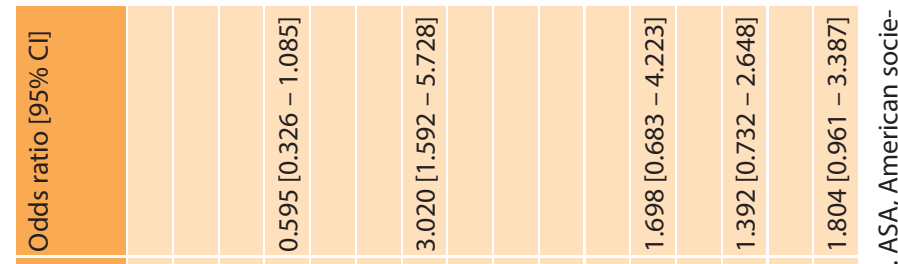



$\bar{\delta}$

$\overline{8}$

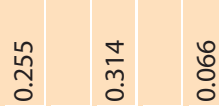

:

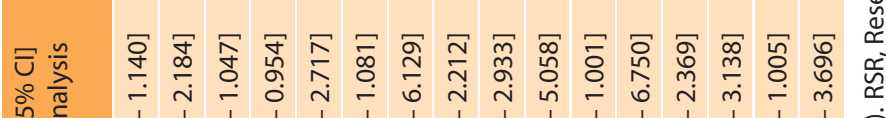

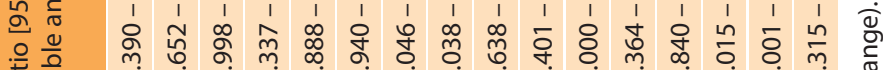

芯

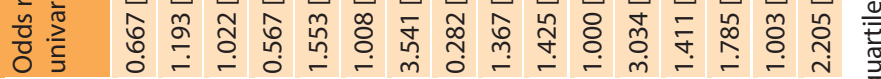

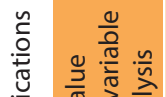

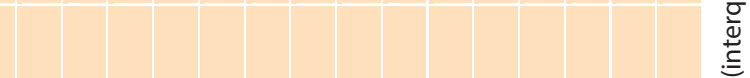

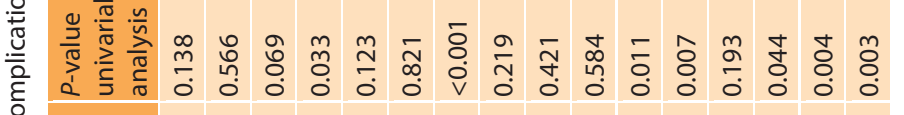

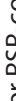

品

.
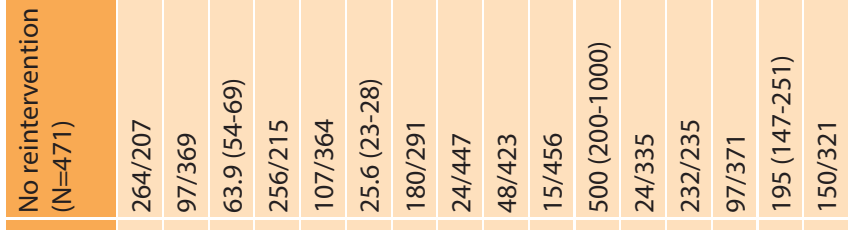

离

흔

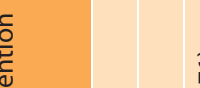

ส হ

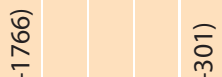

is

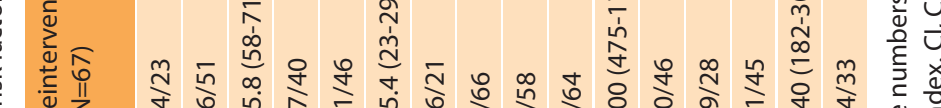
to

瓷

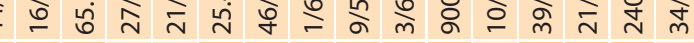


Table 5. Secondary outcomes

\begin{tabular}{|l|c|}
\hline & All patients $N=538(\%)$ \\
\hline Readmission rate & $50(9)$ \\
\hline Length of stay, days & $8(6-11)$ \\
\hline Dindo-Clavien classification & $33(6)$ \\
\hline Grade 1 & $71(13)$ \\
\hline Grade 2 & $55(10)$ \\
\hline Grade 3a & $12(2)$ \\
\hline Grade 3b & $14(3)$ \\
\hline Grade 4 & $13(2)$ \\
\hline Grade 5 (30-day mortality) & $202(38)$ \\
\hline All reported post-operative morbidity & $92(17)$ \\
\hline Major morbidity $\geq$ Dindo-Clavien 3a & $70(13)$ \\
\hline Major RSR morbidity $\geq$ Dindo-Clavien 3a & $84(16)$ \\
\hline Liver surgery-specific CEP & $15(2.8)$ \\
\hline 90-day mortality & $13(2.4)$ \\
\hline Liver related 90-day mortality & \\
\hline
\end{tabular}

Values in parentheses are percentages, unless indicated otherwise. Numeric data are presented as median (interquartile range). RSR, Resection surface-related. CEP, liver surgery-specific composite endpoint (ascites, postresectional liver failure, bile leakage, intra-abdominal haemorrhage, intra-abdominal abscess and operative mortality).

\section{PROPHYLACTIC ABDOMINAL DRAIN GROUP}

Sixty-six patients received a prophylactic abdominal drain and were excluded from this study. Among them were twenty-five patients that required a drain after a bilioenteric anastomosis or another form of biliary reconstruction was created. One patient received a drain after liver surgery for a traumatic lesion. Eight patients obtained a drain because of a difficult repeat hepatectomy. Seven patients received a drain for combined procedures (four colorectal resections, two pancreatic resections and one kidney resection). In five patients a drain was placed after intraoperative iatrogenic lesions of the bile duct, pancreas or spleen. Central resections and large resection surfaces after surgery were indications for drain placement in nine patients. Vascular involvement required drain placement in two patients. Two patients with liver cirrhosis received a prophylactic drain after surgery because of an expected high risk of ascites and subsequent infection. Another two patients received a drain in early 2005 because of protocol deviation by the surgeon. Lastly, in five patients an abdominal drain was placed without any specified indication. In this selected drain group, excluded from analysis, morbidity and mortality were high (10.0\% mortality, $30.0 \%$ RSR-morbidity, $37.5 \%$ major morbidity, $27.5 \%$ reinterventions). 


\section{LITERATURE REVIEW}

The PRISMA flow diagram of the literature search and inclusion of relevant studies is shown in Figure 1. The search resulted in 27 studies that were assessed for eligibility. Finally, ten studies, including five RCT's and five cohort studies (two prospective and three retrospective series), were used to compare the results with those of the present study. The majority of studies included all types of liver resection, except two RCT's that only included patients with an underlying liver disease or a hepatocellular carcinoma in cirrhotic livers. Four studies[1, 4, 7, 8] were graded as level $1 \mathrm{~b}$ evidence, one study[13] was grade level $2 b$ evidence, and the remaining studies[5, 12, 25-27] were cohort studies of grade 4 evidence. No ongoing studies could be identified in clinical trial registers. Table 6 shows a comparison of this study with results from literature.

\section{DISCUSSION}

The use of post-operative drains after liver resection is still subject of debate. This study evaluated a no-drain policy, as part of the ERAS programme, in a tertiary referral centre during 2005-2014. Implementation of a no-drain policy has resulted in an overall surgical morbidity rate of $20 \%$, RSR-complication rate of $15 \%$ and RSRreintervention rate of $12 \%$.

This implies that $88 \%$ of all patients did not require any form of abdominal drainage in the post-operative phase. By not placing a prophylactic drain, they were spared from possible discomfort and harmful drain-related complications. Moreover, in the group of patients that did have an intra-abdominal collection, the majority of them could be treated well with CT- or US-guided drainage and rarely a reoperation was necessary, as is shown in Table 2.

Comparison of results of this study with earlier publications, mainly summarized by Gurusamy et al.[11], confirms the safety and feasibility of the no-drain policy. The 90day mortality of $2.8 \%$ in this study was within the ranges reported in the literature for this type of liver surgery.[1, 4, 7, 8, 11, 13, 14]. Reintervention rates of previous studies $[1,4,7,8,11,13,14]$ vary considerably in studies of both drain and no-drain groups. To date, there is no evidence that abandoning prophylactic drainage increases the need for (radiological) reinterventions.[11] The RSR-reintervention rate of $12 \%$ in this study demonstrates that a no-drain policy does not lead to more reinterventions, higher morbidity or mortality compared to patient with a drain. $[1,4,5,7,8$, $12,13,27]$ 
Major liver resection is a known risk factor for post-operative complications[12, 13, 28-35]. In this study it was identified in multivariable analysis as an independent risk factor for RSR-significant morbidity and RSR-reinterventions. Other known intra-
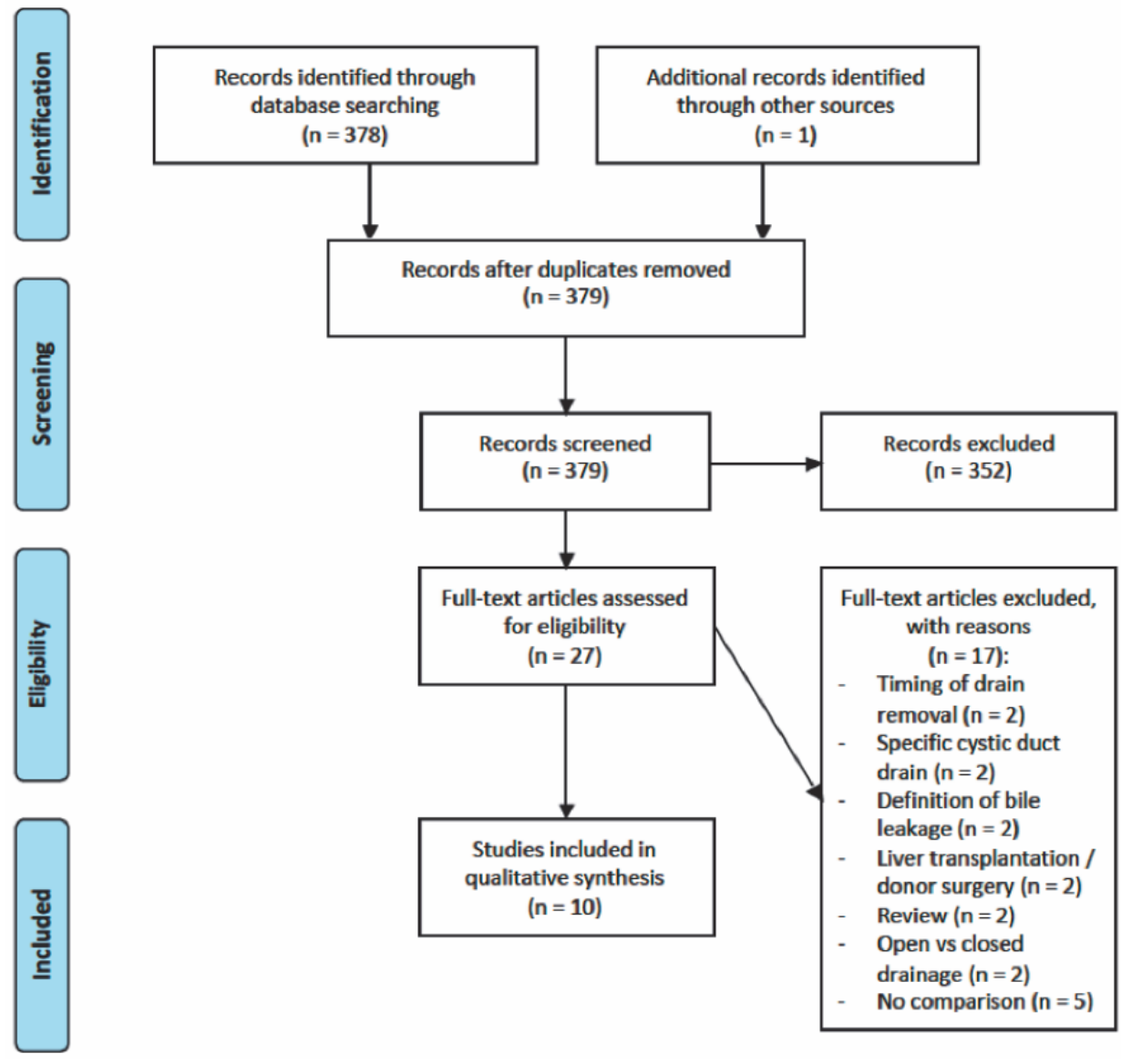

Figure 1. PRISMA flow diagram of the literature search and inclusion of relevant studies

operative predictive determinants, such as prolonged operating time[12, 13, 28, 31, 33, 35], repeat hepatectomy[35-37] and the use of Pringle manoeuvre[31, 38], were not confirmed in this cohort. Preoperative risk factors that have been suggested in preceding literature, among which are the presence of significant comorbidities / ASA III-IV[28-30, 32, 39], an abnormal liver function[13, 28, 30] and chemotherapy[40], were also not confirmed. The fact that major liver resection was found as a risk factor, does not mean that a prophylactic drain needs to be placed routinely. It suggests that there is a subset of patients in which routine post-operative imaging or an ag- 
gressive post-operative imaging strategy needs to be considered. When there is a clinically relevant intra-abdominal collection on ultrasound or $\mathrm{CT}$, a therapeutic radiologically-guided drain can then be placed.

The expertise with and access to radiological reinterventions may vary substantially between institutions, it has changed over time in hospitals worldwide and it could be an important factor. In centres in which radiological reinterventions are less frequently performed, more collections may be inadequately drained. This could lead to a higher reoperation rate. When compared with patients receiving a drain in other studies, the patients from the present study had a low reoperation rate. This may imply that a no-drain placement policy does not lead to more reoperations. Finally, hospital length of stay in other studies was longer.[41] The ERAS-programme could explain this faster recovery.[21, 42]

This study has several strengths that add to the existing body of evidence of RCT's and a meta-analysis on the studied topic. An important strength of this study is the large cohort size. A total of 538 consecutive patients were treated without a drain after implementation of the no-drain policy. As is demonstrated in Table 6, this nodrain cohort is one of the largest cohorts on the subject. In addition, the group of excluded patients with prophylactic drain placement is well described and provides detailed insight in the selection process. Furthermore, patients with bilioenteric anastomoses were excluded from analysis to enable comparison with previously published studies[7, 8, 13]. Among these patients, leakage rates are high, and may confound general results. Another strength of this study is the fact that uni- and multivariable analyses were performed for the identification of risk factors for surfacerelated morbidity. This can aid in the decision making process of abandoning the use of drains after liver surgery. Lastly, all patients were prospectively registered and treated within an ERAS programme consisting of standardized care elements. The minimal use of prophylactic drains is an important element in ERAS programmes and this study advocates a no-drain policy after uncomplicated liver surgery. Drains are thought to affect post-operative mobility and pain control and drains could hamper a swift recovery in uncomplicated cases. 
동

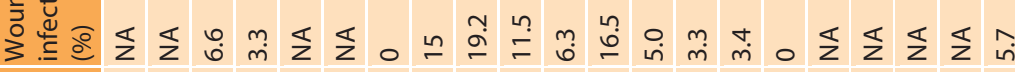

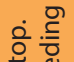

苍商

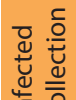

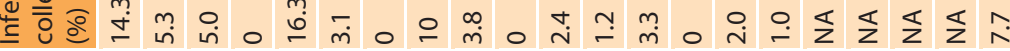

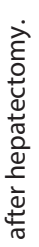

离

हे $\frac{\pi}{0} \frac{\pi}{5}$

$\frac{1}{\sqrt{2}}$

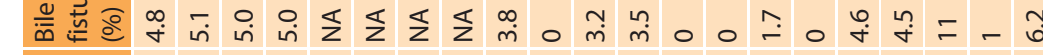

ซิ $\subseteq$

হ

$\stackrel{n}{\grave{0}}$

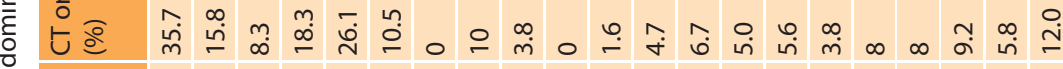

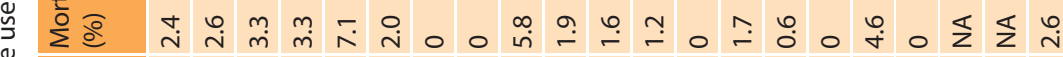

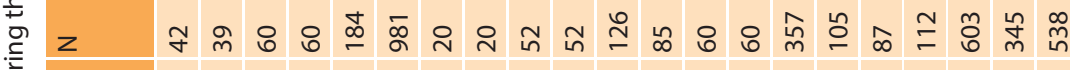

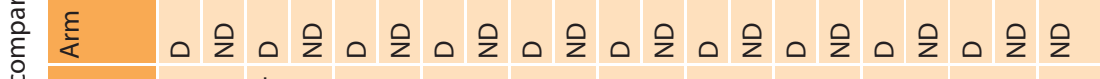

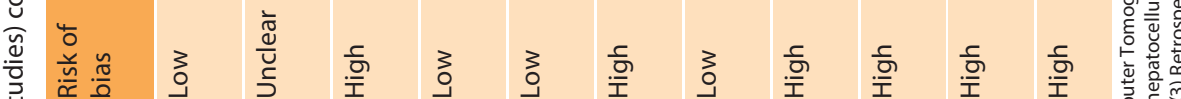

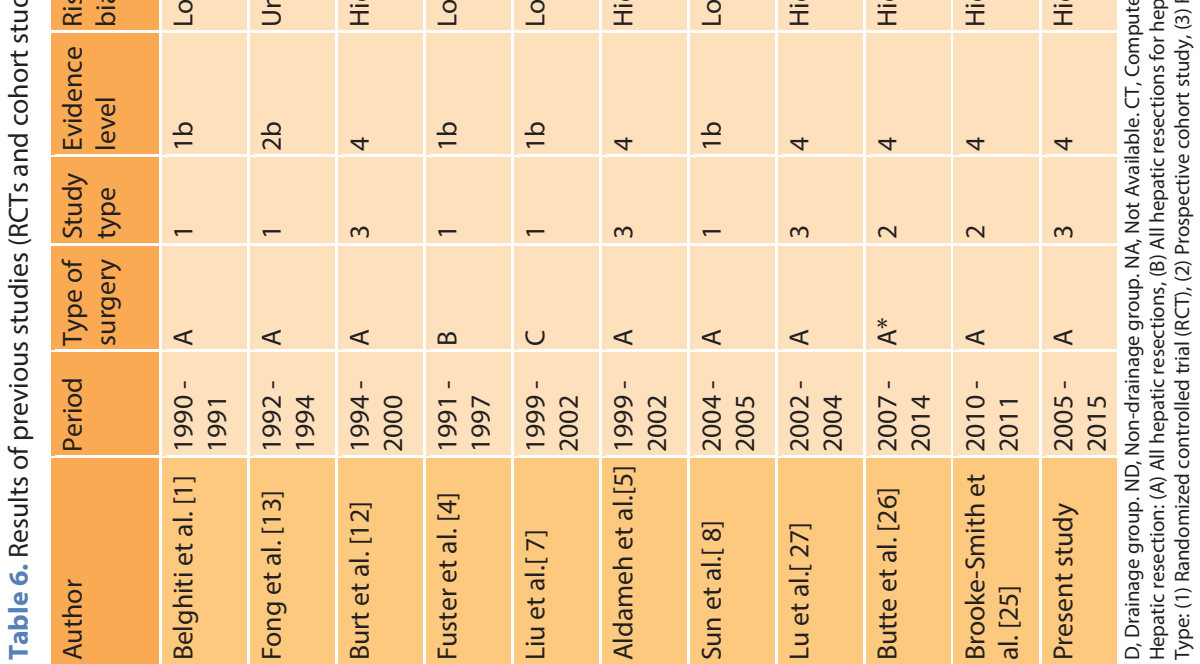


The retrospective analysis of prospectively collected data is a limitation of this study. Although all liver resections in the study period were registered, the final results may have been prone to a form of selection bias, because a small subset of patients was excluded from analysis. This excluded group received an abdominal drain by discretion of the operating surgeon within the studied period. Although no biliary reconstructions were performed in these patients, drains were placed because of major combined procedures, major central liver resections, intraoperative leaks of the bile duct, pancreatic damage and repeat hepatectomy.

The findings of this cohort study confirm the findings of available $\operatorname{RCT}$ 's $[4,7,13]$ and a Cochrane review[11] that routine drainage after uncomplicated liver resection is not necessary. The results of this study show that a no-drain policy is safe and feasible after liver surgery within an ERAS environment. Placement of a prophylactic drain is unlikely to prevent reinterventions for complications and a no-drain policy seems justified in the majority of patients. At most, placement of a drain allows liver surgeons to detect complications in an earlier phase, but routine placement subjects a large group of patients to potential risks and discomfort. Further studies are still necessary and should focus on specific patient groups with predefined risk factors (e.g. underlying liver disease, major resections, biliary reconstructions, intraoperative blood loss and operating time) or should validate risk factors.

\section{CONCLUSION}

A selective no-drain policy within an ERAS environment resulted in a rate of postoperative complications, reinterventions and mortality that is comparable to previously published studies. The routine use of prophylactic abdominal drains after liver surgery therefore seems unnecessary. In patients that undergo a major liver resection, which is an independent risk factor for RSR-related complications, preemptive post-operative imaging can be considered. In a small group of selected patients known to have a high risk of anastomotic leakage, prophylactic drains still have their place, e.g. in the case of biliary reconstruction. 


\section{REFERENCES}

1. Belghiti, J., et al., Drainage after elective hepatic resection. A randomized trial. Ann Surg, 1993. 218(6): p. 748-53.

2. Turner, M.G.G., A note on the abuses and dangers of drainage tubes: With special reference to the danger of serious hæmorrhage from the erosion of large arteries. Br J Surg, 1915. 3(11): p. 552-557.

3. Bona, S., A. Gavelli, and C. Huguet, The role of abdominal drainage after major hepatic resection. Am J Surg, 1994. 167(6): p. 593-5.

4. Fuster, J., et al., Abdominal drainage after liver resection for hepatocellular carcinoma in cirrhotic patients: a randomized controlled study. Hepatogastroenterology, 2004. 51(56): p. 536-40.

5. Aldameh, A., J.L. McCall, and J.B. Koea, Is routine placement of surgical drains necessary after elective hepatectomy? Results from a single institution. J Gastrointest Surg, 2005. 9(5): p. 667-71.

6. Petrowsky, $\mathrm{H}$., et al., Evidence-based value of prophylactic drainage in gastrointestinal surgery: a systematic review and meta-analyses. Ann Surg, 2004. 240(6): p. 1074-84; discussion 1084-5.

7. Liu, C.L., et al., Abdominal drainage after hepatic resection is contraindicated in patients with chronic liver diseases. Ann Surg, 2004. 239(2): p. 194-201.

8. Sun, H.C., et al., Randomized clinical trial of the effects of abdominal drainage after elective hepatectomy using the crushing clamp method. Br J Surg, 2006. 93(4): p. 422-6.

9. Tanaka, K., et al., The effectiveness and appropriate management of abdominal drains in patients undergoing elective liver resection: a retrospective analysis and prospective case series. Surg Today, 2013. 43(4): p. 372-80.

10. Yamazaki, S., et al., Criteria for drain removal following liver resection. The British journal of surgery, 2012. 99(11): p. 1584-90.

11. Gurusamy, K.S., K. Samraj, and B.R. Davidson, Routine abdominal drainage for uncomplicated liver resection. Cochrane database of systematic reviews, 2007(3): p. CD006232.

12. Burt, B.M., et al., An audit of results of a no- drainage practice policy after hepatectomy. Am J Surg, 2002. 184(5): p. 441-5.

13. Fong, Y., et al., Drainage is unnecessary after elective liver resection. Am J Surg, 1996. 171(1): p. 158-62.

14. Kyoden, Y., et al., Value of prophylactic abdominal drainage in 1269 consecutive cases of elective liver resection. J Hepatobiliary Pancreat Sci, 2010. 17(2): p. 186-92.

15. Coolsen, M.M., et al., A systematic review of outcomes in patients undergoing liver surgery in an enhanced recovery after surgery pathways. HPB (Oxford), 2013. 15(4): p. 245-51.

16. Hughes, M.J., S. McNally, and S.J. Wigmore, Enhanced recovery following liver surgery: a systematic review and meta-analysis. HPB (Oxford), 2014. 16(8): p. 699-706.

17. Jones, $C_{\text {., }}$ et al., Randomized clinical trial on enhanced recovery versus standard care following open liver resection. Br J Surg, 2013. 100(8): p. 1015-24.

18. de Boer, M.T., et al., Fibrin sealant for prevention of resection surface-related complications after liver resection: a randomized controlled trial. Ann Surg, 2012. 256(2): p. 229-34.

19. van den Broek, M.A., et al., Development of a composite endpoint for randomized controlled trials in liver surgery. Br J Surg, 201 . 98(8): p. 1 38-45.

20. Dejong, C. and O. Garden, Neoplasms of the liver. 1st ed. Advanced surgical practice, ed. A. Majid and A. Kingsnorth. 2003, London: Greenwich Medical Media.

21. van Dam, R.M., et al., Initial experience with a multimodal enhanced recovery programme in patients undergoing liver resection. Br J Surg, 2008. 95(8): p. 969-75.

22. Dindo, D., N. Demartines, and P.A. Clavien, Classification of surgical complications: a new proposal with evaluation in a cohort of 6336 patients and results of a survey. Ann Surg, 2004. 240(2): p. 205-13.

23. Higgins, J. and S. Green. Cochrane Handbook for Systematic Reviews of Interventions Version 5.1.0. The Cochrane Collaboration [26 June 2016]; Available from: http:// www.cochrane-handbook.org/.

24. Phillips, R., et al. Oxford Centre for Evidence-based Medicine - Levels of Evidence. March 200926 June 2016]; Available from: http://www.cebm.net/oxford-centre-evidence-based-medicine-levels-evidencemarch-2009. 
25. Brooke-Smith, M., et al., Prospective evaluation of the International Study Group for Liver Surgery definition of bile leak after a liver resection and the role of routine operative drainage: an international multicentre study. HPB (Oxford), 2015. 17(1): p. 46-51.

26. Butte, J.M., et al., The role of peri-hepatic drain placement in liver surgery: a prospective analysis. HPB (Oxford), 2014. 16(10): p. 936-42.

27. Lu, L., et al., Abdominal drainage was unnecessary after hepatectomy using the conventional clamp crushing technique. J Gastroin- test Surg, 2006. 10(2): p. 302-8.

28. Aloia, T.A., et al., Predicting poor outcome following hepatectomy: analysis of 2313 hepatectomies in the NSQIP database. HPB (Oxford), 2009. 11(6): p. 510-5.

29. Andres, A., et al., Complications of elective liver resections in a center with low mortality: a simple score to predict morbidity. Arch Surg, 201 . 146(11): p. 1246-52.

30. Breitenstein, S., et al., Novel and simple preoperative score predicting complicationsafter liver resection in noncirrhotic patients. Ann Surg, 2010. 252(5): p. 726-34.

31. Erdogan, D., et al., Morbidity and mortality after liver resection for benign and malignant hepatobiliary lesions. Liver Int, 2009. 29(2): p. 175-80.

32. Farges, O., et al., Incidence and risks of liver resection: an all-inclusive French nationwide study. Ann Surg, 2012. 256(5): p. 697-704; discussion 704-5.

33. Imamura, H., et al., One thousand fifty-six hepatectomies without mortality in 8 years. Arch Surg, 2003. 138(11): p. 1 98-206; discussion 1206.

34. Jarnagin, W.R., et al., Improvement in perioperative outcome after hepatic resection: analysis of 1,803 consecutive cases over the past decade. Ann Surg, 2002. 236(4): p. 397-406; discussion 406-7.

35. Sadamori, $\mathrm{H}_{\text {., }}$ et al., Intractable bile leakage after hepatectomy for hepatocellular carcinoma in 359 recent cases. Dig Surg, 2012. 29(2): p. 149-56.

36. Hirokawa, F., et al., Re-evaluation of the necessity of prophylactic drainage after liver resection. Am Surg, 201 . 77(5): p. 539-44.

37. Zimmitti, G., et al., Greater complexity of liver surgery is not associated with an increased incidence of liver-related complications except for bile leak: an experience with 2,628 consecutive resections. J Gastrointest Surg, 2013. 17(1): p. 57-64; discussion p 64-5.

38. Benzoni, E., et al., Liver resective surgery: a multivariate analysis of postoperative outcome and complication. Langenbecks Arch Surg, 2007. 392(1): p. 45-54.

39. Schroeder, R.A., et al., Predictive indices of morbidity and mortality after liver resection. Ann Surg, 2006. 243(3): p. 373-9.

40. Ishizawa, T., et al. Using a 'no drain' policy in 342 laparoscopic hepatectomies: which factors predict failure? HPB (Oxford), 2013. DOI: 10.1 11/hpb.12165.

41. Gurusamy, K.S., K. Samraj, and B.R. Davidson, Routine abdominal drainage for uncomplicated liver resection. Cochrane Database Syst Rev, 2007(3): p. CD006232.

42. Schultz, N.A., et al., Evaluation of a fasttrack programme for patients undergoing liver resection. $\mathrm{Br} \mathrm{J}$ Surg, 2013. 100(1): p. 138-43. 



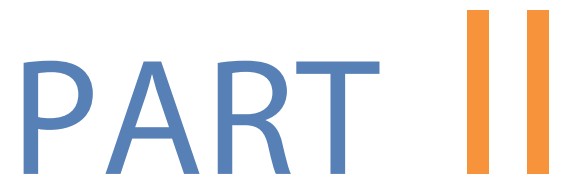

LAPAROSCOPIC LIVER SURGERY 



\section{Chapter}

\section{Laparoscopic liver resection in the Netherlands: how far are we?}

Stoot JH, Wong-Lun-Hing EM, Limantoro I, Visschers R, Busch OR, Van Hillegersberg R, De Jong KM, Rijken AM, Kazemier G, Olde Damink SWM, Lodewick TM, Bemelmans $\mathrm{MH}$, van Dam RM and Dejong $\mathrm{CH}$ for the Dutch Liver Collaborative Group.

Dig Surg. 2012;29(1):70-8 


\section{ABSTRACT}

\section{BACKGROUND}

The objective of this study was to provide a systematic review on the introduction of laparoscopic liver surgery in the Netherlands, to investigate the initial experience with laparoscopic liver resections and to report on the current status of laparoscopic liver surgery in the Netherlands.

\section{METHODS}

A systematic literature search of laparoscopic liver resections in the Netherlands was conducted using PubMed/MEDLINE. Analysis of initial experience with laparoscopic liver surgery was performed by case-control comparison of patients undergoing laparoscopic left lateral sectionectomy matched with patients undergoing the open procedure in the Netherlands between the years 2000 and 2008. Furthermore, a nationwide survey was conducted in 2011 on the current status of laparoscopic liver surgery.

\section{RESULTS}

The systematic review revealed only 6 Dutch reports on actual laparoscopic liver surgery. Matched case-control comparison showed significant differences in the length of hospital stay, blood loss and operation time. Complications did not differ significantly between the two groups (26 vs. 21\%). The 2011 survey showed that 21 centres in the Netherlands performed formal liver resections and that 49 ( $5 \%$ of total) laparoscopic liver resections were performed in 2010.

\section{CONCLUSION}

The systematic review revealed that very few laparoscopic liver resections were performed in the Netherlands in the previous millennium. The matched case-control comparison of laparoscopic and open left lateral resection showed a reduction in hospital length of stay with comparable morbidity. The laparoscopic technique has been slowly adopted in the Netherlands, but its popularity seems to increase in recent years. 


\section{INTRODUCTION}

In the past two decades, the popularity of laparoscopic surgery has grown. The introduction of laparoscopic cholecystectomy [1, 2] has led to an increasing number of indications for this technique, and has encouraged surgeons to develop a laparoscopic approach for many procedures including liver resections.[3] Laparoscopic liver resections are technically demanding and thought to be time-consuming $[4,5]$ but may have several important benefits for the patient compared to open liver surgery.[6-8] The putative advantages of this minimally invasive procedure include reduced blood loss $[6,7]$, less post-operative pain $[5,9,10]$, earlier recovery and shorter post-operative hospital stay [5, 7-12] , and improved cosmetic aspects.[9, 12] Reoperations are reported to be easier due to reduced adhesions. [9-12] Also, openclose procedures with large incisions can be avoided when peritoneal metastases are detected at laparoscopy.

In the Netherlands, the gold standard for liver resection for liver tumours still is the open approach. There is no best level of evidence (level 1) to underpin the supposed major benefits of the laparoscopic approach, but the latter has been proven to be feasible and safe in many international expert centres. A recent consensus statement on laparoscopic liver resections states that resection of segments 2 and 3 by the laparoscopic approach should be the standard if experience is available.[13] In addition, the largest reviews hitherto conducted concluded that laparoscopic liver surgery is feasible and safe in minor as well as major liver resections when performed in experienced centres.[14, 15] However, randomized trials comparing the open and laparoscopic technique for liver resections are still lacking.

The purpose of our study was (1) to provide a historical overview on the introduction and initial experience of laparoscopic liver surgery in the Netherlands against the background of the latest international developments, (2) to report on the present state of laparoscopic liver surgery in the Netherlands, and (3) to provide insight into current and future developments of the minimally invasive liver resection technique within the Netherlands. To this purpose, a systematic review of all Dutch papers reporting on laparoscopic liver surgery was done and key leaders were informally approached. A matched case-control comparison was carried out of laparoscopic versus open liver resections in the Netherlands performed from 2000 to 2008. Finally, recent advances made in the Dutch surgical field of laparoscopic hepatectomies were investigated by means of a nationwide survey. 


\section{METHODS}

\section{SYSTEMATIC REVIEW OF LAPAROSCOPIC LIVER SURGERY IN THE NETHERLANDS - PAST EXPERIENCE}

An online search was performed in PubMed/Embase databases for reports of Dutch groups on their experience with laparoscopic liver surgery in humans. Databases were searched from the earliest data available until 1 June 2011 on a combination of the following search keywords: 'laparoscopy', 'liver surgery', 'hepatic surgery', 'hepatic resection', 'hepatectomy', 'minimally invasive liver surgery', 'minimally invasive hepatic resection', 'Dutch', 'The Netherlands'. Biliary tumours were excluded. Titles and abstracts were screened (E.W.L.H.) and relevant articles selected. The full text of eligible papers was attempted to be retrieved to provide a historical overview. The reference lists of retrieved articles were reviewed for additional potentially relevant studies. To complete the historical picture, key leaders in gastrointestinal surgery were informally queried about their past experience and recollection of the evolution of laparoscopic liver surgery in the Netherlands.

\section{INITIAL EXPERIENCE WITH LAPAROSCIPIC LIVER RESECTIONS AND CASE- CONTROLE COMPARISON - PRESENT STATE}

\section{Patients}

All major liver centres in the Netherlands were contacted during 2008 by phone and/or e-mail and asked to participate in this study. Of the fourteen major HPB centres in the Netherlands, only seven had performed laparoscopic liver resections. Six of these centres agreed to collaborate. Data were obtained retrospectively from six separate prospectively collected databases used in these six HBP units and were pooled for further analysis. All patients who underwent laparoscopic left lateral sectionectomies of the liver in the six centres between 2000 and 2008 were included in this multicentre study. The laparoscopic group of patients was compared in a casematched comparison approach with a group of patients undergoing the same type of liver resection as an open procedure in that era in the 6 participating centres in a proportion of $1: 3$. This approach and the choice to only include left lateral sectionectomies were felt to be justified to eliminate bias as much as possible and increase the external validity of the conclusions. The investigators (J.H.M.B.S. and I.L.) were unaware of the primary outcome or secondary outcomes during the selection process. Patients undergoing left lateral resections in combination with colonic resections were excluded.

In each unit, patients were preoperatively discussed in a multidisciplinary meeting, after evaluation of liver function tests and radiologic liver workup including ab- 
dominal ultrasonography, CT, MRI and/or CT-PET scan. Patients with benign as well as malignant solid liver lesions were included in this study. Patients with cystic lesions of the liver were excluded. Laparoscopic liver resection was considered if the lesion was located in the left lateral segments (segment 2 and 3 according to Couinaud's classification). The choice to perform either a laparoscopic or open procedure was at the discretion of the attending surgeon in consent with the patient. Preoperative information consisted of medical history, preoperative diagnosis and American Society of Anesthesiologists (ASA) classification.

\section{Surgical Procedures}

The open procedure was started with a 15 - to $25-\mathrm{cm}$ incision according to the preference of the surgeon. During operation, the left liver was mobilized, and central venous pressure was maintained at 2-6 $\mathrm{mm} \mathrm{Hg}$. Transection of the liver was performed according to the preference of the surgeon: the Cavitron Ultrasonic Surgical Aspirator (CUSA ; Valleylab, Boulder, Colo., USA) and argon beam coagulator (Bircher Ind., Ltd., Englewood, Colo., USA) with or without the use of Pringle's maneuver, Ultracision Harmonic ACE (Ethicon Endosurgery, Johnson \& Johnson, USA) or Ligasure (Covidien, USA). Only occasionally was the clampcrush technique used. Minor crossing vessels and biliary radicals were divided using polypropylene sutures or clips. The portal pedicles and hepatic veins were divided and ligated with a running polypropylene suture. In some procedures, vascular staplers such as e.g. Autosuture EndoGIA (Covidien) were used. After removal of the liver specimen, the raw surface of the liver remnant was subjected to argon beam coagulation and sealed with TachoSil (Nycomed, Zurich, Switzerland) or Tissuecoll (Baxter, Vienna, Austria) if considered appropriate.

The laparoscopic procedure was performed as described in detail previously.[16] The patient was in the supine French position and abdominal access was achieved by transumbilical open insertion of a laparoscope. Pneumoperitoneum was kept at 10$14 \mathrm{~mm} \mathrm{Hg}$; three or four additional 12- $\mathrm{mm}$ trocars were added, and a $30^{\circ}$ laparoscope was used routinely. The central venous pressure was maintained at 2-6 mm $\mathrm{Hg}$. Hepatic transection of parenchyma and minor crossing vessels and biliary radicals was mainly performed with harmonic scalpel (Ultracision, Ethicon Endosurgery, Johnson \& Johnson, USA) or the Ligasure (Covidien). The segmental portal pedicles and left hepatic vein were stapled using a vascular stapler (EndoGIA Autosuture, Covidien). Resected specimens were placed in a plastic bag (Endocatch Autosuture, Covidien) and removed through a separate incision. 


\section{Parameters and Outcome}

Peri- and post-operative parameters included type of resection, operation time, blood loss, need for transfusion, conversion of laparoscopic to open procedure, postoperative complications, post-operative length of hospital stay and pathologic assessment of the resected liver segment. Blood loss was measured by the suction device and the weight of the gauzes and recorded in operation notes and/or anaesthesia reports. In case of discrepancy, the highest amount was used. Data on surgical technique consisted of information about type of incisions, type of liver resection, method of liver transection, hemorrhage control, use of hemostatic agents, Pringle maneuver, and method of extraction of surgical specimen. In one centre (Maastricht University Medical Centre, MUMC), a multimodal perioperative enhanced recovery program (ERAS) was followed for all patients undergoing liver surgery. $[16,17]$ This was also recorded as a parameter. Criteria for discharge in the ERAS setting were described previously.[16, 17] Discharge in the traditional setting was at the discretion of the attending surgeon.

Primary outcome of the study was hospital length of stay. Secondary outcome measures comprised complications (including mortality and conversion rates), duration of operation and blood loss. Post-operative complications were defined according to the international grading system of Dindo et al.[18]

\section{CURRENT STATUS OF LAPAROSCOPIC LIVER SURGERY - FUTURE DEVELOP- MENTS}

To get an indication of the volumes currently being operated on in Dutch hospitals, and to see whether they had increased in the years following the introduction of the minimally invasive technique, we approached all Dutch hospitals that indicated to perform liver surgery in January 2011 by e-mail. This contained three questions surveying on (1) whether the hospital performed formal liver resections (not only deroofing of cysts), (2) how many open/laparoscopic major or minor hepatic resections were performed in 2010, and (3) whether the provided data were real or estimated numbers. Centres that did not reply on the request to complete the survey were approached by phone in February 2011.

\section{Statistical Analysis}

Data were analysed by J.S., I.L. and R.V; if necessary, an independent statistician was consulted. Continuous variables are expressed as mean ( \pm standard error of the mean). Data were analysed according to the intention to treat principle. Univariable analysis was performed using Pearson's X2 test (or Fisher's exact test where appropriate) to investigate differences between open and laparoscopic procedures regarding sex, indication, pathology, resection margins, ERAS, use of Pringle maneuver, 
method of liver transection, hemorrhage control and hemostatic agents, use of staplers and complications. The Mann-Whitney $U$ test was used for univariable analysis to investigate differences between open and laparoscopic surgery regarding age, ASA classification, tumour diameter, type of incision, complication classification, hospital length of stay (days), duration of operation ( $\mathrm{min}$ ), blood loss ( $\mathrm{ml}$ ) and number of transfusions. The relation between patient characteristics and operative strategy and length of hospital stay was analysed with univariable linear regression analysis. All independent variables with a two-tailed $p$ value below 0.200 were included into a multivariable linear regression model using backward analysis to assess which parameters were significantly and independently related to length of hospital stay. Also, the group effect of open versus laparoscopic resections on post-operative hemoglobin was analysed using multivariable linear regression analysis correcting for preoperative hemoglobin levels. A $p$ value below 0.05 was considered to indicate statistical significance. Statistical analyses were performed using SPSS software (version 15; SPSS Inc., USA).

\section{RESULTS}

\section{SYSTEMIC REVIEW OF LAPAROSCOPIC LIVER SURGERY IN THE NETHERLANDS- PAST EXPERIENCE}

A total of 91 abstracts were retrieved that met the search terms, and after review 19 abstracts remained eligible. Of these 19 articles, 6 reported on actual laparoscopic liver surgery, 12 described the use of laparoscopy and/or laparoscopic ultrasound for staging in patients with hepatic tumours, and one article provided a literature review on liver resection and laparoscopy (Fig. 1 ). The informal interviews and articles eligible for review revealed that the first two laparoscopic liver resections were per formed in Amsterdam in 1995 by the group of Cuesta et al.[19] In the following years, only one article from the same group was published reporting on a series of laparoscopically operated patients $(n=10)$. Seven underwent a minor laparoscopic resection and three underwent fenestration of hepatic cysts.[20] After these initial reports on minimally invasive liver surgery, three articles were published with regard to laparoscopic treatment of polycystic liver disease. [21-23] Later series of 26 laparoscopic liver resections provided evidence that this procedure could be performed safely in the Netherlands. [16] 
Patient's Characteristics Between 2000 and 2008, the laparoscopic approach for hepatic left lateral sectionectomy was performed in 30 patients in 6 centres in the Netherlands (mean age $50 \pm 3$ years) and completed laparoscopically in 27 patients. Five of the laparoscopic liver resections were performed hand-assisted. In the open group, 90 patients were matched for the same type of resection (mean age $52 \pm 2$ years). Demographic data of both groups are reported in Table 1. There were no significant differences in age, ASA classification, indication, resection margins and tumour size.

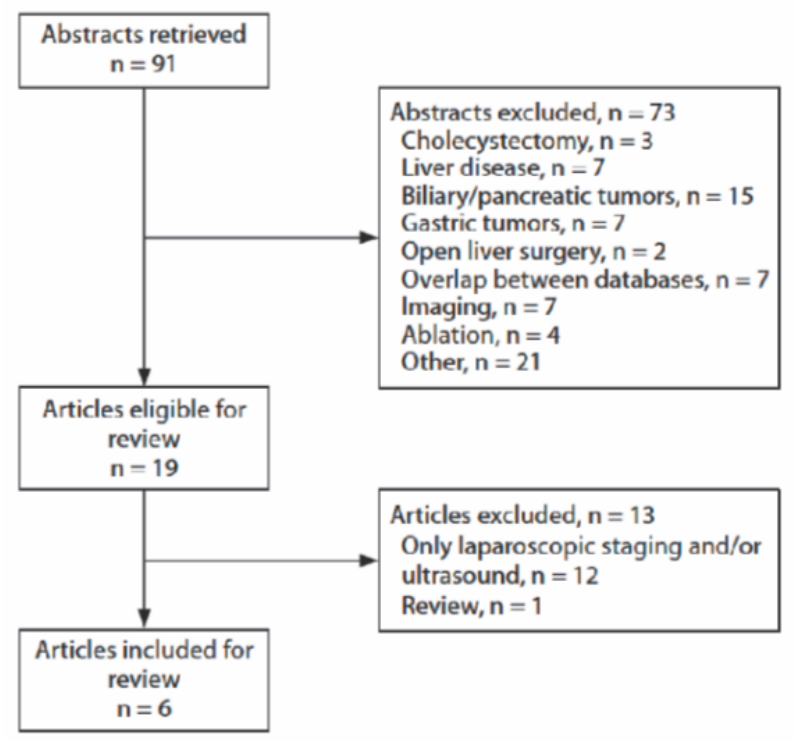

Figure 1. Selection of studies eligible for review. 
Table 1. Clinical and pathological features of the control study

\begin{tabular}{|c|c|c|c|}
\hline & $\begin{array}{l}\text { Laparoscopic group } \\
n=30\end{array}$ & $\begin{array}{l}\text { Open group } \\
n=90\end{array}$ & $p$-value \\
\hline Male / female ${ }^{a}$ & $5 / 25$ & $35 / 55$ & 0.043 \\
\hline Age, years ${ }^{b}$ & $50(3)$ & $52(2)$ & 0.584 \\
\hline $\begin{array}{l}\text { ASA } 1^{b, c} \\
\text { ASA } 2 \\
\text { ASA } 3 \\
\text { ASA } 4\end{array}$ & $\begin{array}{r}10 \\
16 \\
2 \\
0\end{array}$ & $\begin{array}{r}18 \\
38 \\
16 \\
1\end{array}$ & 0.625 \\
\hline Indication (malignant/benign) ${ }^{a}$ & $11 / 19$ & $39 / 51$ & 0.091 \\
\hline Tumour size, $\mathrm{cm}^{\mathrm{b}}$ & $4.8 \pm 0.5$ & $5.3 \pm 0.4$ & 0.673 \\
\hline Pathology (malignant/benign) a,c & $7 / 22$ & $48 / 42$ & 0.007 \\
\hline Resection margins (R0/R1/R2) ${ }^{\mathrm{a}, \mathrm{c}, \mathrm{d}}$ & $19 / 1 / 1$ & $64 / 8 / 2$ & 0.597 \\
\hline ERAS (yes/no) a & $11 / 19$ & $8 / 92$ & 0.001 \\
\hline
\end{tabular}

Values for tumour size are expressed as mean 8 standard error of mean.

a Pearson's_2 test (or Fisher exact test where appropriate).

b Mann-Whitney U test.

c Results do not add up to total values as a result of missing data.

$\mathrm{d}$ In the laparoscopic group, two (R1 and R2) resection margins were positive, both in patients with benign disease (adenoma and hemangioma, respectively). In the open control group the R2 resections were suspected to be benign lesions preoperatively. However, one of these R2 resections proved to be malignant (hepatocellular carcinoma). Of the $\mathrm{R} 1$ resection margins, 3/8 were malignant tumours.

\section{Surgical Procedures and Parameters}

The Pringle maneuver was only used during open surgery (Table 2). The method of liver transection in the open group was different from the approach in the laparoscopic group. Mostly, the CUSA and/or argon beam was used in the open group for liver transection.

\section{Outcome Parameters}

Mean hospital length of stay was $6.0( \pm 0.4)$ days in the laparoscopic group versus 8.1 $( \pm 0.4)$ days in the open group ( $p$ ! 0.001). Complication rates did not differ significantly between the laparoscopic and the open group ( $26 \mathrm{vs.} 21 \%$ ), neither did they differ significantly when complications were graded according to severity intervention score. Three laparoscopic procedures (10\%) were converted to an open procedure (table 3). Reasons for conversion were hemorrhage, an additional lesion in segment IV or the close relation to the left hepatic vein. There were no deaths in the laparoscopic group. In the open group, one of the 90 patients (1.1\%) died due to multiple organ failure after sepsis. 
Table 2. Operative details on transection and hemostasis techniques and use of devices

\begin{tabular}{|c|c|c|}
\hline & Laparoscopic group $n=30(\%)$ & Open group $n=90(\%)$ \\
\hline Use of Pringle manoeuvre & $1(3)^{\mathrm{a}}$ & $20(22)$ \\
\hline \multicolumn{3}{|l|}{ Liver transection } \\
\hline Cusa \pm argonbeam & $3(10)$ & $55(61)$ \\
\hline Ultracision & $21(70)$ & $4(4)$ \\
\hline Ligasure & $4(13)$ & $7(8)$ \\
\hline Hydrojet & & $2(2)$ \\
\hline Cusa + ligasure & & $8(9)$ \\
\hline Diathermia \pm endogia & & $4(4)$ \\
\hline Kelly clamp & & $1(1)$ \\
\hline Endogia & $2(7)$ & $4(4)$ \\
\hline \multicolumn{3}{|l|}{ Haemorrhage control $^{B}$} \\
\hline Diathermia \pm argonbeam & $6(20)$ & $4(4)$ \\
\hline Clips & $6(20)$ & $15(17)$ \\
\hline Prolene & $4(13)$ & $23(26)$ \\
\hline Clips and prolene & $1(3)$ & $39(43)$ \\
\hline Other: use of device & $9(30)$ & $3(3)$ \\
\hline Use of staplers (yes/no) ${ }^{B}$ & $22 / 3^{*}$ & $19 / 68$ \\
\hline \multicolumn{3}{|l|}{ Haemostatic agents ${ }^{B}$} \\
\hline None & $19(63)$ & $39(43)$ \\
\hline Tachosyl & $4(13)$ & $17(19)$ \\
\hline Tissuecoll & $4(13)$ & $25(28)$ \\
\hline Surgicell & $1(3)$ & $1(1)$ \\
\hline Unknown & $1(3)$ & $7(8)$ \\
\hline
\end{tabular}

Figures in parentheses indicate percentages.

a Following conversion to open.

b Results do not add up to total values as a result of missing (non-reported) data.

There was significantly less blood loss in the laparoscopic group compared to the open group $(p<0.001 ;$ Table 3$)$. When corrected for preoperative hemoglobin level, multivariable analysis showed that open resection was significantly related to a decrease in post-operative hemoglobin levels compared to the laparoscopic group (OR $=-0.520, \mathrm{Cl}-1.022$ to $-0.18, \mathrm{p}=0.043)$. None of the patients in the laparoscopic group needed a blood transfusion post-operatively in contrast to 22 blood transfusions in the open group. However, this difference was not significant. The mean duration of operation in the laparoscopic group was significantly shorter than in the open group $(p<0.001 ;$ Table 3$)$. 
Univariable regression analyses showed that several variables were related to differences in length of hospital stay (Table 4). However, after multivariable regression analysis, only ASA classification (OR $=1.598, \mathrm{Cl} 0.738-2.458, \mathrm{p}<0.001)$, complication grade $(\mathrm{OR}=1.680, \mathrm{Cl} 1.124-2.235, \mathrm{p}<0.001)$ and ERAS $(\mathrm{OR}=-2.502, \mathrm{Cl}-4.032$ to $0.972, p=0.002$ ) were independently and significantly related to length of hospital stay.

Table 3. Primary and secondary outcomes (mean 8 SEM)

\begin{tabular}{|c|c|c|c|}
\hline & $\begin{array}{l}\text { Laparoscopic group } \\
n=30(\%)\end{array}$ & $\begin{array}{l}\text { Open group } \\
n=90(\%)\end{array}$ & $p$-value \\
\hline Length of stay (days) $^{a}$ & $6.0 \pm 0.4$ & $8.1 \pm 0.4$ & $<0.001$ \\
\hline Complications $^{\mathrm{b}}$ & $5(26)$ & $19(21)$ & 0.620 \\
\hline Complications (grade)a & & & 0.832 \\
\hline Grade 1 & $4(13)$ & $8(9)$ & \\
\hline Grade 2 & & $4(4)$ & \\
\hline Grade $3 a$ & & $3(3)$ & \\
\hline Grade 3b & $1(3)$ & & \\
\hline Grade 4a & & $2(2)$ & \\
\hline Grade 4b & & $1(1)$ & \\
\hline Grade 5 & & $1(1)$ & \\
\hline Conversions & $3(10)$ & & \\
\hline Reoperation ${ }^{b}$ & $1(3)$ & $3(3)$ & 0.589 \\
\hline Blood loss $(\mathrm{mls})^{\mathrm{a}}$ & $288 \pm 99$ & $608 \pm 97$ & $<0.001$ \\
\hline $\begin{array}{l}\text { Operation time } \\
\text { (minutes) }^{\text {a }}\end{array}$ & $160 \pm 13$ & $231 \pm 11$ & $<0.001$ \\
\hline
\end{tabular}

Figures in parentheses indicate percentages.

a Mann-Whitney $U$ test.

b Pearson's $X^{2}$ test (or Fisher exact test where appropriate). 
Table 4. Univariable linear regression analysis of length of hospital stay

\begin{tabular}{|c|c|c|c|}
\hline Variable & Odds ratio & $95 \% \mathrm{Cl}$ & P-value \\
\hline Age (years) & 0.040 & 0.001 to 0.079 & 0.047 \\
\hline Sex (male/female) & 1.374 & 0.022 to 2.276 & 0.046 \\
\hline Group (open/closed) & 2.012 & 0.571 to 3.452 & 0.007 \\
\hline Indication (malignant/benign) & 1.419 & 0.154 to 2.684 & 0.028 \\
\hline Pathology (malignant/benign) & 1.762 & 0.501 to 3.023 & 0.007 \\
\hline Tumour diameter $(\mathrm{cm})$ & 0.091 & -0.129 to 0.311 & 0.413 \\
\hline Complication $^{\mathrm{a}}$ & 1.559 & 1.025 to 2.093 & $<0.001$ \\
\hline Duration (minutes) & 0.008 & 0.001 to 0.015 & 0.020 \\
\hline ERAS (yes/no) & -1.392 & -3.136 to 0.352 & 0.117 \\
\hline Reoperation & 0.961 & -4.092 to 6.014 & 0.707 \\
\hline $\mathrm{ASA}^{\mathrm{b}}$ & 1.840 & 0.849 to 2.830 & $<0.001$ \\
\hline Stapler (yes/no) & -1.637 & -3.014 to -0.261 & 0.020 \\
\hline Pringle (yes/no) & -0.762 & -2.130 to 0.606 & 0.272 \\
\hline \multicolumn{4}{|l|}{ Transection } \\
\hline Cusa & 1.523 & -1.803 to 4.848 & 0.366 \\
\hline Ultracision & 0.120 & -3.373 to 3.613 & 0.946 \\
\hline Ligasure & 0.309 & -3.536 to 4.155 & 0.874 \\
\hline Hydrojet & 1.400 & -4.565 to 7.365 & 0.643 \\
\hline Cusa and ligasure & 1.525 & -2.540 to 5.590 & 0.459 \\
\hline Other & -0.35 & -5.133 to 4.433 & 0.885 \\
\hline Kelly & 1.400 & -6.410 to 9.210 & 0.723 \\
\hline Endogia & 0.567 & -3.751 to 4.884 & 0.795 \\
\hline \multicolumn{4}{|l|}{ Haemorrhage control } \\
\hline Diathermia & -1.992 & -4.545 to 0.560 & 0.125 \\
\hline Clips & -0.942 & -3.320 to 1.435 & 0.433 \\
\hline Prolene & 1.197 & -0.606 to 3.000 & 0.191 \\
\hline Other & -1.276 & -3.653 to 1.102 & 0.289 \\
\hline \multicolumn{4}{|l|}{ Haemostatic agents } \\
\hline Tachosyl & -0.024 & -5.387 to 5.340 & 0.993 \\
\hline Tissuecol & 0.121 & -5.178 to 5.419 & 0.964 \\
\hline Surgicell & 3.000 & -4.248 to 10.248 & 0.414 \\
\hline None & -0.114 & -5.328 to 5.100 & 0.965 \\
\hline
\end{tabular}

a Complication according to Dindo et al. [18]; increase per unit increase severity.

b Increase per unit increase severity.

The response rate to the nationwide survey was $81 \%$; 30 out of 37 approached hospitals responded. The seven non-responding centres were all district general hospital centres, except one university medical centre. In total, 21 centres performed formal 
liver resections in 2010, the remaining 9 centres only performed deroofing procedures. The total number of hepatic resections performed in 2010 by the responding centres in the Netherlands was 966 . This total number of resections consisted of 444 major and 522 minor hepatectomies (Fig. 2). During 2010, all Dutch hospitals together performed only 49 laparoscopic liver resections; $5 \%$ of all resections (Fig. 3). All these minimally invasive surgical procedures were reported to be minor hepatic resections.

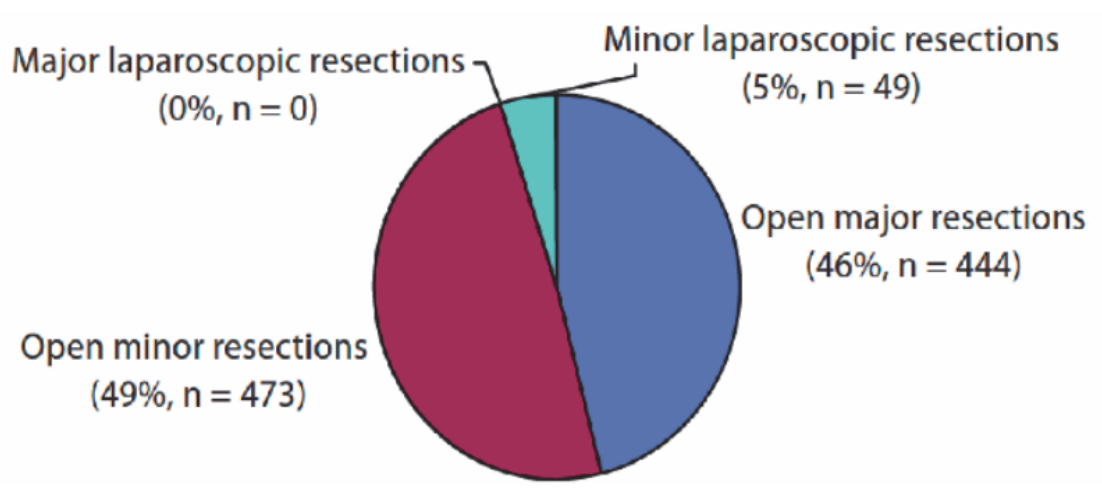

Figure 2. Results of a nationwide survey of laparoscopic and open liver resections performed during 2010 in the Netherlands.

\section{DISCUSSION}

This study provides a historical overview and reports on the initial experience and the current status of laparoscopic liver surgery in the Netherlands. A systematic review of the literature showed that the laparoscopic approach for hepatic resection was introduced in the Netherlands during the 1990s and that some, but limited experience has been gained. It is clear from the data and from additional information obtained by interviewing key leaders that only very few laparoscopic livers were performed in the previous millennium.

Compared to countries that have traditionally always played a pioneering role in (laparoscopic) liver surgery, such as France, the Netherlands have fallen behind with regard to the implementation of the minimally invasive technique. Many surgeons considered an open partial liver resection to be major surgery associated with significant mortality and morbidity. Dutch surgeons remained reluctant to perform this type of surgery.[24] Illustrating this fact is that only 110-130 partial liver resections (including benign tumours) were performed between 1984 and 1987. At the end of the 1980s and 1990s, several series on the experience with open hepatic resection were published by different Dutch centres. $[25,26]$ 


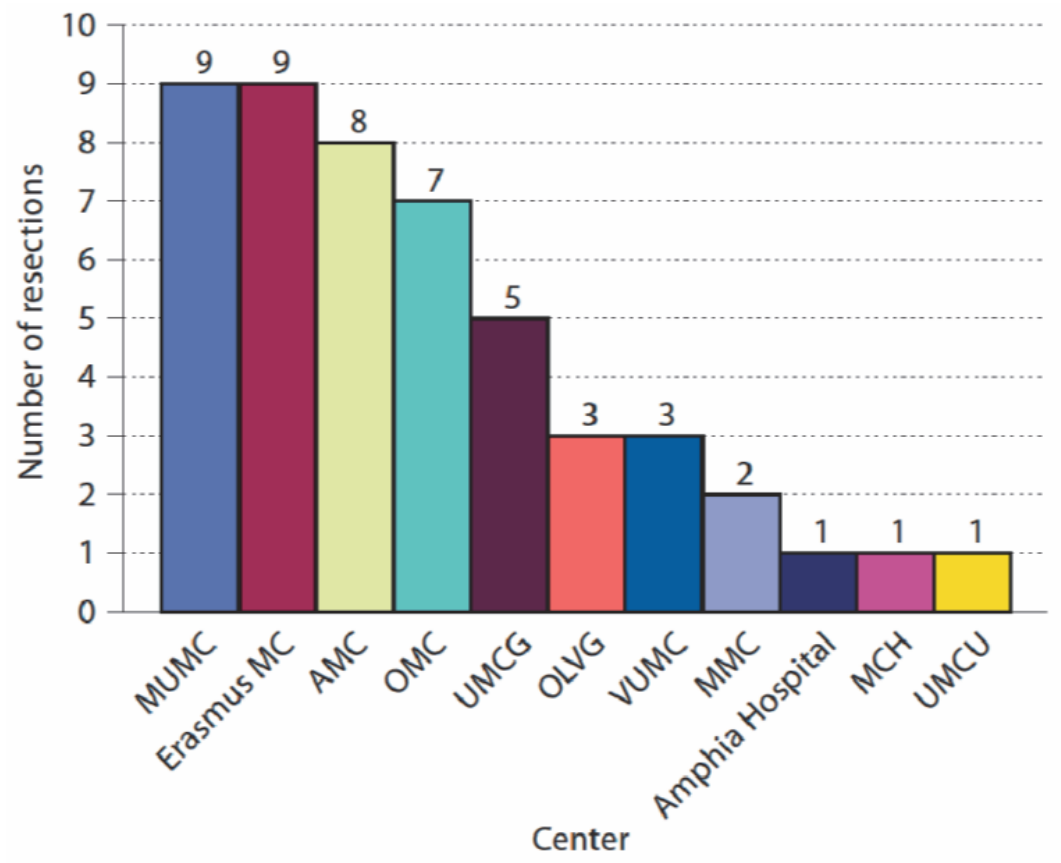

Figure 3. Results of a nationwide survey of total laparoscopic (minor) liver resections performed during 2010 in the Netherlands per centre.

The laparoscopic technique for liver resections was introduced in the Netherlands during the 1990s for diagnostic laparoscopies and liver biopsies. Later, the indications were extended to fenestration of liver cysts and anatomic liver resections. [27-32] The group of Cuesta et al. [19] was in 1995 the first to report two cases of limited laparoscopic liver surgery of segment II and IV in the Netherlands. A few years later, in 2001, a small retrospective series $(n=10)$ was published that demonstrated encouraging results concerning operative blood loss, post-operative complications and hospital length of stay after wedge and left lateral hepatectomy. Furthermore, they concluded that laparoscopic treatment should be considered in selected patients with benign and malignant lesions in the left lobe or frontal segments of the liver.[20]

While the first limited laparoscopic liver resection in the Netherlands was performed in 1995, the first laparoscopic liver resection worldwide, a wedge resection, had already been performed by Gagner's group in 1992. Four years thereafter, Azagra's group reported the first anatomic liver resection.[3] In the following few years, the minimally invasive technique was further developed and adopted, resulting in the first laparoscopic left lateral sectionectomy for living liver donation[33] and the first reports on robotic liver surgery.[34, 35] Initially, laparoscopic liver resection was challenging because of the difficulties concerning safe mobilization and exposure of this 
fragile and heavy organ. $[3,36,37]$ Small, superficial and peripheral lesions in anterolateral segments were considered most amenable to laparoscopic liver resection. Surgeons with extensive experience in laparoscopy and hepatic surgery have performed laparoscopic major hepatic resections with satisfactory outcomes.[28, 38, 39]

Recent large reviews by Reddy et al.[15] and Nguyen et al.[14] show favorable outcomes after laparoscopic resection.[14, 15] Patient benefits included less operative blood loss $[6,7]$, less post-operative pain $[5,9,10]$ and narcotic requirement, improved cosmetic aspects[9, 12] and a shorter length of hospital stay [5, 7-12] with postoperative morbidity and mortality comparable to open liver resection. In addition, the minimally invasive approach seems to be cost-effective.[40, 41] Potential limitations and disadvantages of laparoscopic liver resection include a significant learning curve, potential bleeding which may be more difficult to control laparoscopically, inadequate assessment of the liver for additional lesions, and increased risk for gas embolism.[15, 42] Air embolism may occur when high- pressure pneumoperitoneum is used.[36, 43] However, gas embolism is rare and usually well tolerated.[5] Other concerns have been raised about the potential dissemination of malignant cells during laparoscopic resection.[44-46] Some authors have suggested that tumour dissemination does not increase by laparoscopy [47-49], and recent reports regarding this subject show long-term survival rates comparable to open surgery $[12,37,50,51]$.

At present, after more than 10 years of experience and following advances in laparoscopic technology, the surgical community has accepted that laparoscopic liver surgery is feasible and safe. $[3,7,8,10,51-53]$ This is especially true for resection of left lateral segments and right anterior segments.[4, 9, 11, 54] Some of the advantages reported in literature were also found in the present study. The present multicentre case-control study on laparoscopic left lateral sectionectomies in the Netherlands between 2000 and 2008 demonstrated that length of hospital stay for the laparoscopic approach for left lateral sectionectomies was reduced by 2 days. Furthermore, the laparoscopic approach resulted in faster procedures with reduced blood loss, no occurrence of gas embolisms and comparable morbidity. In a multivariable analysis, length of hospital stay appeared to be related to ASA classification, complications and ERAS.

Left lateral sectionectomy currently is the most common laparoscopic liver resection for solid tumours in the Netherlands. However, only a minority of left lateral sectionectomies were performed laparoscopically between 2000 and 2008. The laparoscopic approach has gained gradual acceptance by Dutch surgeons, but is still not a standard. A structured implementation may allow the Dutch surgical community to catch up with international developments. Recently, van Dam and Topal performed the first major laparoscopic liver resection in the Netherlands (anatomical right hemihepatectomy, Maastricht, 2011). 
The question remains why the laparoscopic left sectionectomy in this study proved to be faster than the open counterpart. Differences in technique in transection of the liver parenchyma and the vascular and biliary structures may have added to a faster transection. Reduced blood loss, either caused by different transection devices or pneumoperitoneum, may reduce the need for prolene stitches and hemostatic clips, which can be time consuming. Lastly, there is no need to close the abdomen after the procedure.

The survey results demonstrate an increase in both totally laparoscopic and totally open liver resections performed in the Netherlands. Although more centres have adopted the laparoscopic approach in recent years, individual centre volumes remain low. Only $5 \%$ of all liver resections were performed laparoscopically, which is significantly less compared to other countries where average percentages of laparoscopic hepatic resections range between 20 and 80\%.[13] If surgeons in the Netherlands aim to increase the portion of laparoscopic liver resections, liver surgery should be further centralized. Furthermore, a central training, proctoring and credentialing infrastructure should be developed to improve the quality of outcome parameters and to allow units to become (high-volume) expert centres.

The foundation of the Dutch Liver Collaborative Group in 2003 gave a new impulse to minimally invasive liver surgery, and is in concordance with recently made recommendations that national and international societies, as well as governing boards, should become involved in the goal of establishing training standards and credentialing.[13] Goals of this workgroup are to facilitate collaboration of medical centres in the field of hepatic surgery, initiate and facilitate research in liver surgery (especially multicentre trials), facilitate training, education and adoption and to establish a quality control and auditing system for Dutch liver surgery centres.

In conclusion, minimally invasive liver surgery is gradually being adopted in the Netherlands. The laparoscopic (left-sided) liver resection is a safe procedure, and it probably results in a shorter hospital length of stay with comparable morbidity. Laparoscopic liver resections appear to be faster. More importantly, ASA classification, complications and ERAS proved to be important prognostic variables for reduced length of hospital stay in Dutch hospitals. In the future, the Dutch Liver Collaborative Group should continue to play an important role in the further adoption and centralization of minimally invasive liver surgery. Conducting an RCT on laparoscopic liver resection may add to the body of evidence supporting broader introduction of minimally invasive liver surgery. 


\section{REFERENCES}

1. Reddick EJ, Olsen DO: Laparoscopic lasercholecystectomy. A comparison with minilapcholecystectomy. Surg Endosc 1989; 3:131-133.

2. Dubois F, Berthelot G, Levard H: Laparoscpic cholecystectomy: historic perspective and personal experience. Surg Laparosc Endosc 1991; 1: 52-57.

3. Dagher I, Proske JM, Carloni A, Richa H, et al: Laparoscopic liver resection: results for 70 patients. Surg Endosc 2007; 21: 619-624.

4. Descottes B, Glineur D, Lachachi $F$, et al: Laparoscopic liver resection of benign liver tumors. Surg Endosc 2003; 17: 23-30.

5. Farges $\mathrm{O}$, Jagot $\mathrm{P}$, Kirstetter $\mathrm{P}$, Marty J, et al: Prospective assessment of the safety and benefit of laparoscopic liver resections. J Hepatobiliary Pancreat Surg 2002; 9: 242-248.

6. Morino M, Morra I, Rosso E, Miglietta C, et al: Laparoscopic vs open hepatic resection: a comparative study. Surg Endosc 2003; 17: 1914-1918.

7. Simillis C, Constantinides VA, Tekkis PP, et al: Laparoscopic versus open hepatic resections for benign and malignant neoplasms - a meta-analysis. Surgery 2007; 141: 203-211.

8. Kaneko H: Laparoscopic hepatectomy: indications and outcomes. J Hepatobiliary Pancreat Surg 2005; 12: 438-443.

9. Cherqui D, Husson E, Hammoud R, Malassagne B, et al: Laparoscopic liver resections:a feasibility study in 30 patients. Ann Surg 2000; 232: 753-762.

10. Buell JF, Thomas MJ, Doty TC, Gersin KS, et al: An initial experience and evolution of laparoscopic hepatic resectional surgery. Surgery 2004; 136: 804-811.

11. Chang S, Laurent A, Tayar C, Karoui M, Cherqui D: Laparoscopy as a routine approach for left lateral sectionectomy. Br J Surg 2007; 94: 58-63.

12. Gigot JF, Glineur D, Santiago Azagra J, Goergen M, et al: Laparoscopic liver resection for malignant liver tumors: preliminaryresults of a multicenter European study. AnnSurg 2002; 236: 90-97.

13. Buell JF, Cherqui D, Geller DA, O'Rourke N, et al: The international position on laparoscopic liver surgery: The Louisville Statement, 2008. Ann Surg 2009; 250: 825- 830.

14. Nguyen KT, Gamblin TC, Geller DA: World review of laparoscopic liver resection-2,804 patients. Ann Surg 2009; 250: 831-841.

15. Reddy SK, Tsung A, Geller DA: Laparoscopic liver resection. World J Surg 2010, Epub ahead of print.

16. Stoot JH, van Dam RM, Busch OR, van Hillegersberg R, et al: The effect of a multimodal fast-track programme on outcomes in laparoscopic liver surgery: a multicentre pilot study. HPB (Oxford) 2009; 11: $140-144$.

17. van Dam RM, Hendry PO, Coolsen MM, et al: Initial experience with a multimodal enhanced recovery programme in patients undergoing liver resection. Br J Surg 2008; 95: 969-975.

18. Dindo D, Demartines N, Clavien PA: Classification of surgical complications: a new proposal with evaluation in a cohort of 6336 patients and results of a survey. Ann Surg 2004; 240: 205-213.

19. Cuesta MA, Meijer S, Paul MA, et al: Limited laparoscopic liver resection of benign tumors guided by laparoscopic ultrasonography: report of two cases. Surg Laparosc Endosc 1995; 5: 396-401.

20. Berends FJ, Meijer S, Prevoo W, et al: Technical considerations in laparoscopic liver surgery. Surg Endosc 2001; 15: 794-798.

21. van Keimpema L, Hockerstedt K: Treatment of polycystic liver disease. Br J Surg 2009; 96: 1379-1380.

22. van Keimpema L, Ruurda JP, Ernst MF, van Geffen HJ, Drenth JP: Laparoscopic fenestration of liver cysts in polycystic liver disease results in a median volume reduction of $12.5 \%$. J Gastrointest Surg 2008; 12: 477-482.

23. Schipper HG, Kager PA: Diagnosis and treatment of hepatic echinococcosis: an overview. Scand J Gastroenterol Suppl 2004;241:50-55.

24. de Jong KP, Hesselink EJ, Laméris JS, Ottow RT, Terpstra OT: Partial liver resection (in Dutch). Ned Tijdschr Geneeskd 1989; 133: 2381-2384. 
25. de Jong KP, Blankensteijn JD, Hesselink EJ, Laméris JS, Terpstra OT: Partial hepatectomy for benign or malignant liver diseases; experience in 94 patients (in Dutch). Ned Tijdschr Geneeskd 1989; 133: 23852388.

26. van Ooijen B, Wiggers T, Meijer S, et al: Hepatic resections for colorectal metastases in The Netherlands. A multiinstitutional 10-year study. Cancer 1992; 70: 28-34.

27. Cuesta MA, Meijer S, Borgstein PJ, Mulder LS, Sikkenk AC: Laparoscopic ultrasonography for hepatobiliary and pancreatic malignancy. Br J Surg 1993; 80: 1571-1574.

28. van Gulik T: Open versus laparoscopic resection for liver tumours. HPB (Oxford) 2009;11:465-468.

29. Miles WF, Paterson-Brown S, Garden OJ: Laparoscopic contact hepatic ultrasonography. Br J Surg 1992; 79: 419-420.

30. Windsor JA, Garden OJ: Laparoscopic ultra- sonography. Aust N Z J Surg 1993; 63: 1-2.

31. Nieveen van Dijkum EJ, de Wit LT, van Delden OM, Kruyt PM, et al: Staging laparoscopy and laparoscopic ultrasonography in more than 400 patients with upper gastrointestinal carcinoma. J Am Coll Surg 1999; 189: 459-465.

32. Gouma DJ, de Wit LT, Nieveen van Dijkum E, Van Delden O, et al: Laparoscopic ultrasonography for staging of gastrointestinal malignancy. Scand J Gastroenterol Suppl 1996; 218: 43-49.

33. Cherqui D, Soubrane O, Husson E, Barshasz E, Vignaux O, et al: Laparoscopic living donor hepatectomy for liver transplantation in children. Lancet 2002; 359: 392-396.

34. Giulianotti PC, Coratti A, Angelini M, Sbrana F, et al: Robotics in general surgery: personal experience in a large community hospital. Arch Surg 2003; 138: 777-784.

35. Vibert E, Denet C, Gayet B: Major digestiv surgery using a remote-controlled robot: the next revolution. Arch Surg 2003; 138: 1002-1006.

36. Cherqui D: Laparoscopic liver resection. Br J Surg 2003; 90: 644-646.

37. Shimada M, Hashizume M, Maehara S, Tsujita E, et al: Laparoscopic hepatectomy for hepatocellular carcinoma. Surg Endosc 2001; 15: 541-544.

38. Pulitano C, Aldrighetti L: The current role of laparoscopic liver resection for the treatment of liver tumors. Nat Clin Pract Gastroenterol Hepatol 2008; 5: 648-654.

39. Vigano L, Tayar C, Laurent A, Cherqui D: Laparoscopic liver resection: a systematic review. J Hepatobiliary Pancreat Surg 2009; 16: 410-421.

40. Polignano FM, Quyn AJ, de Figueiredo RS, Henderson NA, Kulli C, Tait IS: Laparoscopic versus open liver segmentectomy: prospective, case-matched, intention-to-treat analysis of clinical outcomes and cost effectiveness. Surg Endosc 2008; 22: 2564-2570.

41. Vanounou T, Steel JL, Nguyen KT, Tsung A et al: Comparing the clinical and economic impact of laparoscopic versus open liver resection. Ann Surg Oncol 2010; 17: 998-1009.

42. Nguyen KT, Gamblin TC, Geller DA: World review of laparoscopic liver resection - 2,804 patients. Ann Surg 2009; 250: 831-841.

43. Hashizume M, Shimada M, Sugimachi K: Laparoscopic hepatectomy: new approach for hepatocellular carcinoma. J Hepatobiliary Pancreat Surg 2000; 7: 270-275.

44. Johnstone PA, Rohde DC, Swartz SE, Fetter JE, Wexner SD: Port site recurrences after laparoscopic and thoracoscopic procedures in malignancy. J Clin Oncol 1996; 14: 1950-1956.

45. Gutt CN, Riemer V, Kim ZG, Erceg J, Lorenz M: Impact of laparoscopic surgery on experimental hepatic metastases. Br J Surg 2001; 88: 371-375.

46. Targarona EM, Martínez J, Nadal A, Balagué C, et al: Cancer dissemination during laparoscopic surgery: tubes, gas, and cells. World J Surg 1998; 22: 55-60; discussion 60-61.

47. Laurent A, Cherqui D, Lesurtel M, Brunetti F, et al: Laparoscopic liver resection for subcapsular hepatocellular carcinoma complicating chronic liver disease. Arch Surg 2003; 138: 763-769, discussion 769.

48. 48 Mala T, Edwin B, Gladhaug I, Fosse E, et al: A comparative study of the short-term outcome following open and laparoscopic liver resection of colorectal metastases. Surg Endosc 2002; 16: 1059-1063.

49. Cherqui D, Laurent A, Tayar C, Chang S, et al: Laparoscopic liver resection for peripheral hepatocellular carcinoma in patients with chronic liver disease: midterm results and perspectives. Ann Surg 2006; 243: 499- 506. 
50. Teramoto K, Kawamura T, Takamatsu S, Noguchi N, et al: Laparoscopic and thoracoscopic partial hepatectomy for hepatocellular carcinoma. World J Surg 2003; 27: 1131-1136.

51. Vibert E, Perniceni T, Levard H, Denet C, et al: Laparoscopic liver resection. Br J Surg 2006; 93: 67-72.

52. Mala T, Edwin B, Rosseland AR, Gladhaug I, et al: Laparoscopic liver resection: experience of 53 procedures at a single center. J Hepatobiliary Pancreat Surg 2005; 12: 298-303.

53. Dulucq JL, Wintringer P, Stabilini C, Berticelli J, Mahajna A: Laparoscopic liver resections: a single center experience. Surg Endosc 2005; 19: 886-891.

54. Katkhouda N, Hurwitz M, Gugenheim J, Mavor E, et al: Laparoscopic management of benign solid and cystic lesions of the liver. Ann Surg 1999; 229: 460-466. 



\section{Chapter 8}

Open versus laparoscopic left lateral hepatic sectionectomy within an enhanced recovery

ERAS programme (ORANGE II - Trial): study protocol for a randomised controlled trial

van Dam RM, Wong-Lun-Hing EM, van Breukelen GJP, Stoot JHMB, van der Vorst JR, Bemelmans MHA, Olde Damink SWM, Lassen K and Dejong CHC for the ORANGE II Study Group

Trials 2012, 13:54 


\section{ABSTRACT}

\section{BACKGROUND}

The use of laparoscopic liver resection in terms of time to functional recovery, length of hospital stay (LOS), long-term abdominal wall hernias, costs and quality of life (QOL) has never been studied in a randomised controlled trial. Therefore, this is the subject of the international multicentre randomised controlled ORANGE II trial.

\section{METHODS}

Patients eligible for left lateral sectionectomy (LLS) of the liver will be recruited and randomised at the outpatient clinic. All randomised patients will undergo surgery in the setting of an ERAS programme. The experimental design produces two randomised arms (open and laparoscopic LLS) and a prospective registry. The prospective registry will be based on patients that cannot be randomised because of the explicit treatment preference of the patient or surgeon. Therefore, all non-randomised patients undergoing LLS will be approached to participate in the prospective registry, thereby allowing acquisition of an uninterrupted prospective series of patients. The primary endpoint of the ORANGE II trial is time to functional recovery. Secondary endpoints are post-operative LOS, percentage readmission, (liver-specific) morbidity, QOL, body image and cosmetic result, hospital and societal costs over 1 year, and long-term incidence of incisional hernias. It will be assumed that in patients undergoing laparoscopic LLS, length of hospital stay can be reduced by two days. A sample size of 55 patients in each randomization arm has been calculated to detect a 2-day reduction in LOS (90\% power and alfa $=0.05$ (two-tailed)).

\section{CONCLUSION}

The ORANGE II trial is a multicentre randomised controlled trial that will provide evidence on the merits of laparoscopic surgery in patients undergoing LLS within an enhanced recovery ERAS programme.

Trial registration: ClinicalTrials.gov NCT00874224. 


\section{BACKGROUND}

Liver resection for colorectal metastasis is the only potentially curative therapy, and has become the standard of care in appropriately staged patients, offering 5 -year survival rates of approximately 35-40\%.[1] For symptomatic benign lesions and those of uncertain nature or large size, liver resection is also a widely accepted treatment. Within the framework of optimizing post-operative recovery and/or producing a shorter length of stay (LOS) in hospital, laparoscopic surgery and enhanced recovery programmes have recently been introduced for liver surgery.

Laparoscopic liver resection was first described in 1995.[2] Over the past decade the method has gained wide acceptance for various liver resection procedures. [3-9] Multiple retrospective case series and reviews comparing open with laparoscopic liver resection indicate that laparoscopic liver resection can be used safely for both malignant and benign liver lesions.[10-15] Recent publications from expert centres show that a substantial part of the total volume of major and minor liver resections is performed laparoscopically, and results are good.[16,17] Laparoscopic liver resection is associated with shorter LOS, less post-operative pain, earlier recovery, and better quality of life (QOL). $[9,13,18,19]$ Comparing patients undergoing an open left lateral sectionectomy (LLS) of the liver with those undergoing laparoscopic LLS, both Vigano et al. and Carswell et al.[20,21] found no significant difference in operating time between the two groups. In addition, the median length of post-operative LOS was significantly less ( 6 vs. 9 days, $\mathrm{P}<0.01$ ) after laparoscopic resection.[3] Furthermore, no evidence of a compromised oncologic clearance in laparoscopic liver resection has been found.[3,13] However, recovery and LOS are not only dependent on the type of surgery or procedure, and other variables should also be taken into account.

The Enhanced Recovery After Surgery (ERAS) programme has been introduced to improve post-operative care. This multimodal programme, derived from Kehlet's pioneer work in the 1990s for multimodal surgical care, involves optimization of several aspects of the perioperative management of patients undergoing major abdominal surgery. In patients undergoing segmental colectomy, the ERAS programme enabled earlier recovery and consequently shorter LOS [22-25]. Furthermore, a reduction of post-operative morbidity in patients undergoing intestinal resection was reported [26-29]. These results stimulated liver surgeons of the ERAS-group (Maastricht, Edinburgh and Tromsö) to adapt the ERAS programme to patients undergoing open liver resection. Van Dam et al. [30] found a significantly reduced LOS after open liver resection when patients were managed within a multimodal ERAS programme. Besides a reduction in median total LOS from 8 to 6 days (25\%), the data also suggested that a further reduction in stay could be possible as there was a delay be- 
tween the recovery and actual discharge of the patients [30]. Moreover, Stoot et al. found retrospectively that there was a further reduction in LOS from 7 days to 5 days when patients were operated laparoscopically and managed within an ERAS programme.[31] In that study there was also a delay between recovery and actual discharge of the patients. Previously, Maessen et al. reported a median delay to discharge of 2 days after patients had functionally recovered after colonic surgery managed within an ERAS programme.[32] This delay is often linked to patient age, hospital logistics, and absence of social and/ or homecare support.

In most reported trials aiming at earlier recovery or a reduction in LOS, type of surgery and/or perioperative management were not standardized. In addition, the added value of laparoscopic LLS compared with open left lateral sectionectomy within an ERAS programme in terms of time to functional recovery, LOS in hospital, costs, and QOL has never been studied in a randomised controlled trial (RCT). However, randomization of patients undergoing open or laparoscopic liver resection is hazardous. It is to be expected that experienced centres will be reluctant to randomize patients because of the absence of clinical and patient equipoise for laparoscopic resection. To capitalize on both centres with and without preference for laparoscopic liver surgery, and to thereby acquire an uninterrupted prospective series of patients, an alternative trial design with two randomization arms (open versus laparoscopic surgery) and a prospective registry has been constructed for the ORANGE II trial. The combination of an RCT and a prospective registry will improve overall power and strengthen the external validity and generalizability of study results.[33-35]

\section{METHODS}

\section{ETHICS APPROVAL}

The study has been approved by the Medical Ethical Review Board of the Maastricht University Medical Centre, Maastricht, The Netherlands trial number NL 25591.068.08 / MEC 08-2-110. Ethics consent will also be obtained from the national or regional ethics boards in each participating country. Patients willing to participate in this trial will receive both verbal and written information at the time of recruitment in the outpatient clinic. In accordance with the local medical ethics committee all participating sites will provide an independent surgeon or physician if needed. An independent surgeon (M. Poeze) has been appointed for the Maastricht University Medical Centre to answer questions. Confidentiality is guaranteed by assigning the participators an encoded trial number. This indicates that only the physician with the decoding 'key' will know which code number has been assigned to any patient. All trial data will be saved during the trial and stored on a server, and patients will be asked 
to consent to future analysis of these data. Withdrawal from the trial at any time or for any reason will not hold any form of consequences for the patient, and data from these patients will be deleted.

\section{STUDY DESIGN}

The ORANGE II trial is a prospective superiority study with an experimental design, using two double-blinded randomised controlled arms and a prospective registry to determine whether laparoscopic surgery is to be preferred over open surgery in patients undergoing LLS and participating in an enhanced recovery programme. In the participating randomizing centres, patients, nurses and the ward physician (but not the operating surgeon) will be blinded for the type of intervention up to and including post-operative day (POD) 3. They will record the functional recovery criteria twice daily. Only the investigator and operating surgeons will know the actual procedure. The blinded ward physician(s) will decide on whether a patient will be discharged or not.

However, randomization of patients undergoing open or laparoscopic liver resection is hazardous as previously explained. Moreover, another potential source of bias exists when randomizing patients with a strong treatment preference. When patients cannot be blinded to their treatment allocation (POD 3) they may be resentful and demoralized if they do not receive their preferred treatment, and consequently they may have poor compliance. By contrast, patients receiving their preferred treatment may have above-average compliance. Thus to capitalize on centres both with and without preference for laparoscopic liver surgery, and thereby to acquire an uninterrupted prospective series of patients, all non-randomized patients undergoing a LLS will be approached to participate in the prospective registry. Registration of these patients is imperative to guarantee a consecutive series of patients and also because the absence of such a series may restrict generalization of the results, as randomised participants may not in fact be representative.[36] The combination of an RCT and a prospective registry will improve overall power and strengthen the external validity and generalizability of study results.[33-35] This non-randomised registry group will be analysed for centre and centre by treatment interaction as an observational study. Medical centres that wish to participate in this trial, but with liver surgeons early in the laparoscopic learning curve, will be accompanied during the procedure by an experienced proctoring laparoscopic HPB-surgeon.

\section{PRIMARY \& SECONDARY ENDPOINTS}

The primary endpoint of the ORANGE II trial is time to functional recovery. A patient is fully functionally recovered when all of the following five criteria are satisfied: 1) 
adequate pain control with oral analgesia; 2 ) restoration of mobility to an independent level; 3) absence of intravenous fluid administration; 4) ability to eat solid foods; and normal or decreasing serum bilirubin level and international normalized ratio.

It is medically justified to discharge patients when the criteria for full functional recovery are met and if the patient is willing to go home. Secondary endpoints include post-operative LOS in hospital, percentage of readmissions, total morbidity (both general and procedure related), composite endpoint of liver-surgery-specific morbidity, QOL, body image and cosmesis, reasons for delay of discharge after functional recovery, hospital and societal costs over 1 year, and long-term incidence of incisional hernias.

\section{Morbidity}

The preoperative morbidity status of patients will be measured using the American Society of Anaesthesiologists (ASA) scale. The Portsmouth modification of the Physiological and Operative Severity Score for the Enumeration of Mortality and Morbidity (P-POSSUM) will be used to evaluate the risk of perioperative morbidity and mortality. Post-operative morbidity is rationally predictable, with hemorrhagic complications occurring predominantly during surgery or in the early post-operative phase, and biliary complications, intra-abdominal abscess, or liver failure in the later postoperative phase. Wound infection and sepsis will be additional complications that require monitoring. Morbidity will be classified and analysed according to the validated classification for post-operative morbidity as described by Dindo et al.[37]

\section{Liver Resection-Specific Composite Endpoint}

In this trial, we will also use a well-defined liver surgery specific composite endpoint, as suggested by van den Broek et al.[38] This endpoint is a parameter composed of a combination of procedure-specific complications, which is considered as a single, dichotomous outcome: operative mortality, intra-abdominal haemorrhage, ascites, bile leakage, intra-abdominal abscess, and post-resectional liver failure. These components, which are all specific to liver surgery and have substantial clinical relevance, reflect complications rated as Dindo grade 3-5. A composite score of 1 (failure) will reflect the occurrence of at least one of the above liver-specific complications, and a score of 0 (success) will be assigned if none of these occur.

\section{Quality of Life}

To assess QoL in patients undergoing laparoscopic versus open LLS, the Dutch version of the EuroQol five dimension (EQ-5D) status test in Dutch centres and the translated EQ-5D for international centres will be used. The EQ-5D is a standardized instrument for use as a measure of health outcome, which consists of the five dimensions of mobility, self-care, usual activities, pain/discomfort, and anxiety/ depression, 
with three levels each and a rating on the EQ visual analogue scale (VAS; 0-100).[3941] Furthermore, the European Organization for Research and Treatment (EORTC) 30item post-cancer QOL questionnaire (QLQ-C30; with the liver metastases (LM21) module will be used for liver-specific treatment measurements.[42] Assessment of the patients' QOL will be performed at the time of consent, discharge and 10 days, 3, 6 and 12 months after discharge.

\section{Body Image and Cosmesis}

To evaluate differences in post-operative body image and cosmesis, the Body Image Questionnaire (BIQ) will be used [43,44], which consists of eight questions about body image and cosmesis. The body image assessment will be performed preoperatively at time of consent. Both the body image and cosmesis assessment will take place at discharge, and at 10 days, 3 months, 6 months and 12 months after discharge.

\section{Hospital and Societal Costs}

The economic evaluation will include a cost-utility analysis from a Dutch societal perspective. The incremental costs per quality adjusted life year (QALY) gained will be based on utility scores from the EQ-5D.[39-41] All hospital expenses (direct and indirect) related to both interventions will be monitored. In addition, a cost questionnaire offered at the regular follow-up consultation (3, 6 and 12 months) will help assess the societal and individual costs outside health care relating to patients' absence, impaired mobility, work, or normal daily activities. Unit prices will be based either on prices from the participating hospital financial departments or will be extrapolated using Dutch guidelines for cost calculation.[45]

\section{Incidence of Incisonal Hernias}

Incisional hernia after open surgery is a well-known complication of surgery, with an incidence of up to $20 \%$ after a 10 -year period.[46] In patients undergoing a sigmoid resection, Anderson et al. found that laparoscopic resection led to a significantly lower incidence of incisional hernia compared with open surgery.[47] Furthermore, in two retrospectively analysed series of patients who received a partial hepatectomy, different types of incisions were compared. D'Angelica et al. reported that the common incisions used for partial hepatectomy were the Mercedes incision and extended right subcostal (ERSC) incision, and that the ERSC incision provides adequate, safe access and is associated with fewer long-term wound complications (9.8\% vs 4.8\%, $\mathrm{P}<0.001)$.[48] More recently, Togo et al. reported frequencies of incisional hernia after median, J-shaped, right transverse incision with a vertical extension at the midline from the subumbilical region to the xiphoid process (RTVE), and reversed $\mathrm{T}$ incisions to be $6.3 \%, 4.7 \%, 5.4 \%$, and $21.7 \%$, respectively. A diagnosis of 'no hernia' required a minimum follow-up of 12 months.[49] 
To assess the incidence of incisional hernias in patients undergoing laparoscopic and open LLS, they will be contacted at a mean time of 1 year after resection to undergo ultrasonography or CT-scan to assess the incidence of incisional hernia.

\section{STUDY POPULATION}

Every patient requiring LLS will be identified and informed the outpatient clinic about open and laparoscopic liver resection. Only patients meeting the inclusion and exclusion criteria will be approached for randomization. After reading the ORANGE II trial patient information and being allowed 1 week for consideration, patients will be asked for their informed consent. All patients ineligible for randomization due to patient or surgeon preference will be approached for participation in the prospective registry. If patients express an explicit preference, they will be allocated to the prospective registry and interviewed to ascertain the reasons for their preferences. Personal written informed consent will be obtained for all groups. Randomization will be carried out through the ORANGE II trial website using web-based randomization software (TENALEA; www.tenalea.com) (see Figure 1 for trial flow-chart). Patients will be approached for randomized inclusion if they meet each of the following inclusion criteria: require LLS; willingness to participate in the study; able to understand the nature of the study and what will be required of them; are men or non-pregnant, non-lactating women between the ages of 18 and 80 years of age; have a body mass index of between 18 and 35; and have ASA grading of I to III.

The exclusion criteria are: liver resection other than LLS; underlying liver disease; unwillingness to participate; inability to give written informed consent; and ASA grading of IV to $\mathrm{V}$.

\section{ERAS-PROGRAMME}

All patients will participate in the ERAS liver programme, with a standardized perioperative management. For daily guidelines of the pre- and post-operative care of patients undergoing liver resection (Figure 2). 


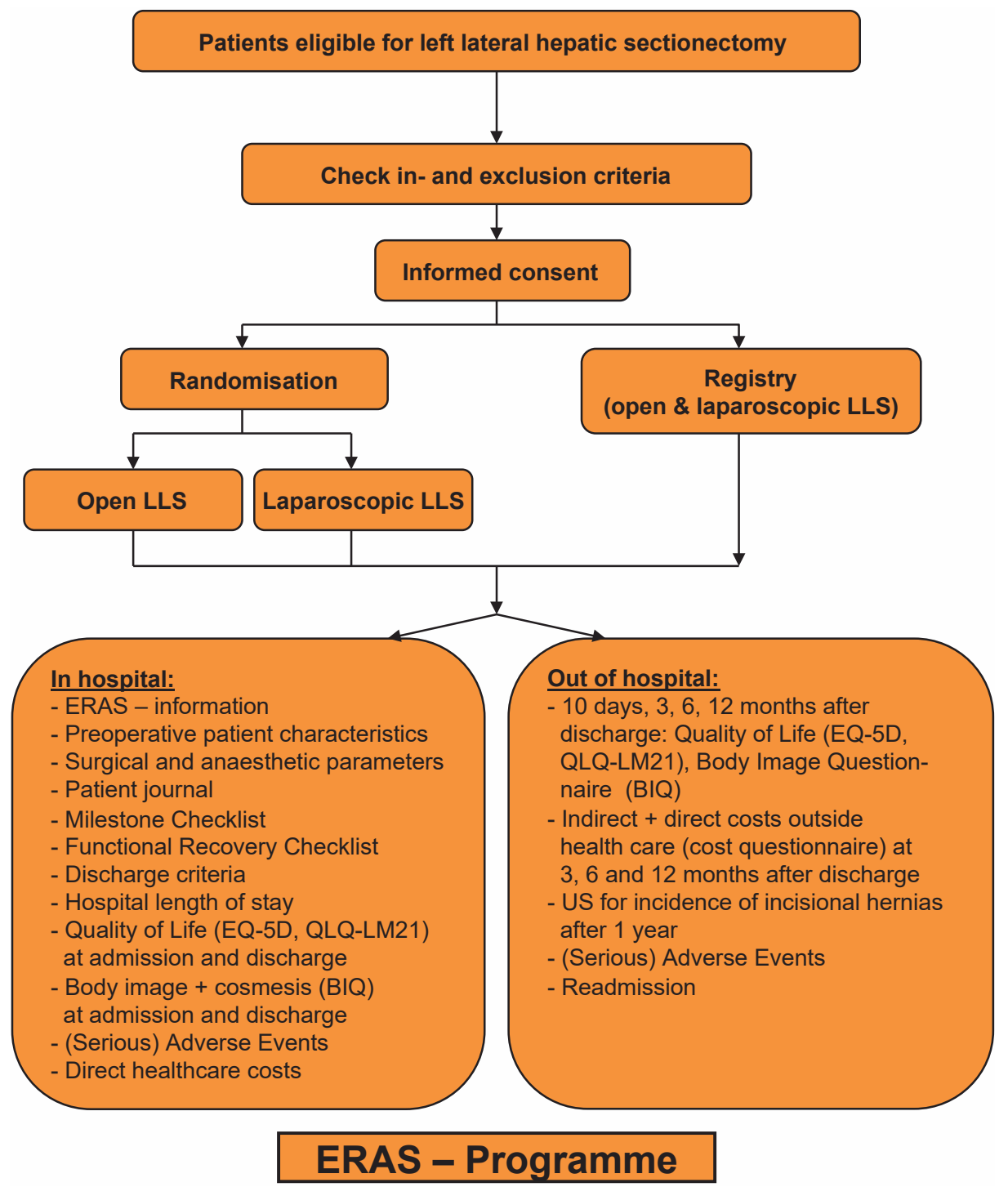

Figure 1. Orange II-Trial Flowchart. 
Day before surgery:

Normal oral nutrition up to 6 hours

before surgery

No pre-anaesthetic medication

Laboratory tests

\section{Day of surgery}

Carbohydrate drinks up to 2 hrs prior to surgery

Midthoracic epidural analgesia (low local anaesthetic + low dose opioid)

Short-acting i.v. anaesthetic agent

Preferably no nasogastric drainage, but

when used remove after surgery

Use warm i.v. fluids and upper and

lower body air-warming device

Avoid excessive i.v. fluids (CVP during

transection $<5 \mathrm{mmHg}$ )

No routine drainage of the peritoneal

cavity

Patient sent to recovery ward

Restart oral intake of water / nutrition

\section{Post Operative Day (POD) 1}

Patient sent to surgical ward

Patient mobilizes a minimum of four

times a day

Discontinuation of i.v. fluids

Patient drinks at least 1.5 litre

Normal diet

Continue portable epidural analgesia

(local

anaesthetic-low dose opioid) or PCA

Remove urinary catheter

Figure 2. Daily guideline of post-operative care of patients undergoing a hepatectomy in the ERAS programme
1000 mg aminocetophen 6 hourly

\section{Start laxatives}

Laboratory tests

\section{POD 2}

Continue portable epidural analgesia or PCA

Stop low dose opioids

Continue mobilization a minimum of

four times per day

1000 mg aminocetophen 6 hourly

Normal diet

Laxatives

\section{POD 3}

Stop epidural analgesia or PCA

\section{Start NSAID's}

Continue mobilization

Normal diet

Laboratory tests

Check discharge criteria

Outpatient appointment made on postoperative day 10,11 or 12

\section{POD 4}

Check discharge criteria

Patient receives cell phone number

HPB-surgeon on duty

Discharge
Laxatives

\section{FUNCTIONAL RECOVERY CRITERIA}

The evaluation of time to functional recovery will start on POD 0 and will be scored twice daily until discharge from the hospital. The discharge process starts at the preadmission counseling session, during which any special needs of the patients will be determined (for example, homecare or social support, transport. Before admittance, any problem that could delay discharge will be identified and addressed. Patients will only be discharged when they have met the five functional recovery criteria and are willing to go home. Reasons to delay discharge after functional recovery will be monitored and documented. Functional recovery criteria and LOS in hospital will be independently monitored and analysed. 


\section{Criterion I: Adequate pain control with oral analgesics}

Post-operative pain will be systematically registered twice daily using the validated verbally administered 11-point numeric rating scale (NRS-11, 0 to 10).[50-53] Members of a specialized pain team will ask patients to rate the intensity of their current pain on a scale of 0 (no pain) to 10 (worst possible pain), with pain rated as 'mild' (1 to 3) 'moderate' (4 to 6) or 'severe') 7 to 10 [54]. The NRS-11 seems to be better accepted by most patients and to be at least as sensitive and valid as the more traditional VAS ratings.[53]

\section{Criterion II: Independently mobile or at preoperative level}

To assess the difference between the preoperative and post-operative mobility level, the ERAS Mobility Scale (EMS) has been developed from the Groningen Activity Restriction Scale.[55] The EMS assesses 10 basic actions to compare the level of mobility before and after surgical intervention. When the patient is able to perform 8 of the 10 items, they are independently mobile. Patients will be assessed whether they are able or not to independently perform these basic actions fully. Daily the assessment will be repeated and compared with the preoperative baseline score until mobility at an independent or preoperative level is achieved.

\section{Criterion III: No intravenous fluids or medication administration}

\section{Criterion IV: Tolerance of solid food}

Fluid and solid food intake will be monitored and must return to normal, that is, when oral intake of water or normal food is resumed and continued for at least 24 hours. Furthermore the incidence of post-operative nausea and vomiting, which obviously influences intake, will be monitored post-operatively until day 6 using a scale ranging from 0 (no nausea) to 10 (worst possible nausea), and where necessary, be countered prophylactically by antiemetic treatment.

\section{Criterion V: Normal or decreasing serum bilirubin level and INR}

\section{STATISTICAL ANALYSIS}

\section{Sample size}

Because laparoscopic liver surgery focuses on accelerated recovery, time to functional recovery is used as the primary outcome parameter. Owing to the lack of hard evidence about the reduction in time to functional recovery after liver surgery, we have chosen to use the parameter that most accurately approaches our primary endpoint for our power calculation (LOS). Based on a retrospective analysis of 31 patients in both ERAS and non-ERAS settings, who have undergone LLS from 1990 to the present time, the mean \pm SD post-operative hospital stay for a LLS in the Maas- 
tricht University Medical Centre is $6 \pm 2.73$. It therefore seems that that in patients undergoing laparoscopic LLS, time to functional recovery is reduced in comparison to patients undergoing the open procedure. We are aiming for a reduction in time to functional recovery of 2 days. A sample size of $2 \times 40$ patients in the randomization arms will be sufficient to show a 2-day reduction with a power of $90 \%$ and a level of significance at alfa $=0.05$ (two-tailed, given a within-arm SD of 2.73 with effect size d $=0.73$ ). Assuming an expected withdrawal rate of $\leq 10 \%$ during the trial, the participation of at least 10 centres, and the required addition of one randomised patient per arm for every additional participating centre (C) to compensate for the loss of degrees of freedom incurred in the data analysis, which takes centre and treatment $x$ centre effects into account, a total sample size of $110(n=2 \times 55)$ will be required.

For all secondary outcome measures, the power will be $75 \%$ after correction for multiple testing with two-tailed alfa $=0.01$, assuming the same effect size $(d=0.73)$ as for the primary outcome. An interim analysis of the primary outcome, using Snapinn's method, will be performed after inclusion of $50 \%$ of the sample to avoid unnecessary inclusion of too many patients in this ORANGE II trial.[56]

\section{Descriptive statistics}

The primary outcome parameter of time to functional recovery and the secondary parameter of LOS in hospital will be given in days, with a median and range. Morbidity will be classified according to the classification described by Dindo et al. and defined as a dichotomous composite endpoint, while readmission will be given as a percentage. Scores for quality of life, body image and cosmesis will be given as mean and standard deviation per time point per treatment arm. Hospital costs will be given as median and range. Long-term incidence of incisional hernia will be reported and analysed.

\section{Univariate analysis}

The primary outcome measure of time to functional recovery will be measured in days, and will be analysed with fixed-effect regression that will take centre and treatment $\times$ centre interaction into account as fixed effects. If the actual number of centres and the sample size per centre allow random effects analysis, this will also be performed and this analysis will have the same power as the planned fixed effects analysis if the design effect does not exceed 1.2. With a sample size of 10 patients per centre, the design effect is 1.2 if the intraclass correlation (ICC) is 0.02 , where the ICC is based on treatment $\times$ centre interaction.[57]

All secondary outcomes as measured at discharge will be analysed by fixed-effect regression using linear regression for quantitative outcomes and logistic regression for binary outcomes, and including the baseline measure as a covariate to improve 
power and precision. In addition to P-values, confidence intervals for all effects will be reported. Morbidity will be classified as described by Dindo et al., but will be presented as raw data only because the required sample size for intervention effects on morbidity is much larger than the calculated sample size for this trial.[58]

\section{ECONOMIC EVALUATION}

The economic evaluation will include a cost-utility analysis from a societal perspective. The time horizon of this evaluation will be the same as the duration of the trial, that is, 12 months. All costs (direct and indirect) related to both interventions will be calculated. The final cost calculation of unit costs will be based on a combined bottom-up and top-down approach. In accordance with Dutch guidelines for cost calculation, indirect healthcare costs will not be taken into account. In addition, resource use will be measured by use of primary data that is registered in our case record forms (CRFs) by use simple checklists. Furthermore, a questionnaire will be used to survey the direct non-healthcare costs related to travelling, impaired mobility and domiciliary care (for normal daily activities). The incremental, indirect non-healthcare costs per QALY gained will be based on the utility scores from the EQ-5D.[39-41] For all direct healthcare costs, the unit prices will be based either on prices from the hospital financial department or the Dutch guidelines for cost calculation.[45]

\section{REGISTRY}

The prospective registry of patients who cannot be randomized because of explicit treatment preference on the part of the patient or surgeon will be analysed as an observational study. In addition, data from the registry will be analysed for interaction between treatment, centre, and study type (randomised or not). On condition that there is no interaction between treatment, centre, and study type, and that the observational study does not suffer from severe confounding (because adjusting for that strongly reduces the power of the observational study), pooling of both studies should give more power than separate analyses of either study. Possible confounders will be registered in the CRFs. The inclusion of the prospective registry in the trial design will create an uninterrupted case series, which will increase external validity and generalizability.

\section{DATA COLLECTION}

Data concerning patient characteristics, functional recovery, surgical and anaesthesiologic parameters, morbidity, LOS, QOL, patient compliance, and costs will be prospectively collected using both paper CRFs and an open source clinical trial software platform (OpenClinicaW; Ikaza Research, Cambridge, MA, USA) that uses e-CRFs for 
electronic data capture and clinical data management, which are validated and stored in compliance with good clinical practice guidelines. The e-CRFs will be stored in a secured database (Oracle Cor., Redwood Shores, CA, USA), and as stated previously, all patient data will be encoded to ensure privacy.

\section{MONITORING}

For this trial, a Data and Safety Monitoring Board (DSMB) has been appointed that will consist of three members: a chairperson, an independent statistician, and a medical specialist. In a concerted effort a DSMB charter will be developed, and all three members will sign a non-competing interest form. The DSMB will be responsible for safeguarding the interests of trial participants, assessing the safety and efficacy of the interventions during the trial, and monitoring the overall conduct of the clinical trial.

\section{INTENTION TO TREAT}

Analysis of all patients will be performed according to the intention-to-treat principle: patients will be analysed as randomized or as planned in the non-randomized prospective registry, and all patients will be included in the data analysis with proper methods for handling missing data.

\section{DISCUSSION}

Several authors have indicated that laparoscopic liver resection has many benefits over conventional open liver resection. However, this has never been proven in an $\mathrm{RCT}$, and what the primary endpoint should be for an RCT comparing open and laparoscopic liver resection is a subject to debate. Using either liver surgery-related mortality or liver surgery-specific morbidity as an endpoint is not feasible, because patient accrual would take many years and be a logistically major global effort [58]. LOS in hospital, time to recovery, long-term incisional hernias, body image, and costs are potential candidates because improvements in these are some of the possible benefits. Laparoscopic liver resection is appealing for many surgeons and patients, but the learning curve for the surgeon is thought to be long and costly for hospital budgets. However, operating times in laparoscopic LLS tend to be shorter, and may compensate for expenses in technology and consumables.[31,59] Moreover, the existing trials in liver surgery have not evaluated time to recovery or LOS in hospital after laparoscopic liver resection within an enhanced recovery programme. The more rapid recovery reported after enhanced recovery programmes may be further accelerated as a consequence of small incisions in laparoscopic surgery. In addition, learning curves for laparoscopic left lateral resection or anterior segments seem to be 
reasonably short for liver surgeons with advanced laparoscopic experience.[60] The question remains whether an RCT is necessary to prove that laparoscopy should be accepted as the preferred method to perform liver resection. In the Louisville consensus meeting on laparoscopic liver surgery, it was stated that laparoscopic LLS should be standard practice in experienced hands.[61] However, this may have been a subjective vision of a subset of opinion leaders, because long experience with both open and laparoscopic liver surgery was the main characteristic of those attending the meeting. Undoubtedly, the dissemination phase of laparoscopic liver surgery has started, and it is to be expected that many surgeons will adopt this technique in the future. A multinational multicentre prospective registry, a well-organised multicentre $\mathrm{RCT}$, training programmes, and quality control measures are of great importance during this adoption period. [33]

It is well recognized that a well-conducted double-blind RCT provides the highest level of evidence to prove the possible benefits of laparoscopic liver resection. However, performing an RCT in surgery is not without difficulties, and alternative trial designs may be necessary.[33,34,62] First, the intervention needs to be tested in a standardized environment, and the properties of the intervention should remain unchanged during the trial period. This seems impossible for an intervention such as laparoscopic liver surgery in a multicentre RCT. Experience varies between participating centres, and will vary over time. Moreover, local standards for perioperative care are different. Both LLS and the ERAS protocol provide the standardization needed. The learning curve of LLS is short in centres with experience in liver surgery and advanced laparoscopy. The use of proctor surgeons in centres with limited experience in laparoscopic liver surgery the operative techniques can be reasonably standardized, and this should eliminate learning curve influences on outcome parameters. Quality of the surgery can be assured by digital video recording.

Second, the intervention should be double-blinded. Although double blinding in a surgical trial is difficult, using a fixed abdominal dressing for 3 days after surgery is feasible, and should prevent both ward caregivers and patients from knowing the type of intervention. Third, it is reasonable to query whether this is now the right time to perform an RCT and whether the results of the trial will be valid for the more general surgical community. A recent review of the results of laparoscopic liver resection in 2,804 patients showed that laparoscopic liver resection in expert centres is feasible and safe for both minor and major liver resections.[36] The percentages of liver resections performed laparoscopically now range from $25 \%$ to $65 \%$ in highvolume expert centres such as University Hospital Southampton NHS (Southampton, UK), Henri Mondor (Paris, France), UPMC (Pittsburgh, USA), UZ Leuven (Leuven, Belgium) and Rikshospitalet (Oslo, Norway).[36,63] Although it is to be expected that many centres worldwide will adopt laparoscopic liver resection as a more or less 
standard procedure in the near future, there are still many patients and surgeons that prefer the open procedure long beyond the learning curve. In parallel with the development of laparoscopic liver surgery, 'fast-track' programmes in various areas of surgery, including liver surgery, are gaining popularity. Therefore, this seems to be the right time for this RCT to be performed. The multicentre character of the ORANGE II trial with randomization of patients and surgeons with treatment equipoise and a prospective registry to cover both surgeons who believe that based on their laparoscopic experience randomization is not ethically justified and patients with a strong treatment preference will provide external validity. This trial design capitalizes on rather than ignores the differences between patients, will provide more robust outcome data, and should lead to continuous performance monitoring after the trial.[35,62]

The key question clearly is as to whether this RCT is really necessary. The benefits of laparoscopic liver resection are not beyond reasonable doubt, and although data are becoming increasingly available, recent publications do not provide sound data on time to recovery. Worldwide, median LOS in hospital for open and laparoscopic resections varies from 4 to 8 days.[17, 30, 64-66] Reasons for delay in discharge and discharge location are often absent, and a clear definition of recovery has not been used to date in any of the publications. Departing from the standpoint that an RCT should be conducted, the question is which sample size should be used? In our opinion, a reduction of only 1 day in time to recovery or LOS in hospital after laparoscopic resection would be a disappointingly low gain. To prove such a reduction, 320 patients would be needed (alfa $=0.05$ and power of 90\%), making the trial unlikely to be accomplished. Based on available reports, a 2-day reduction should be possible $[17,31,66]$, and reduces the sample size to 110 patients undergoing LLS. This number is reasonably moderate, and it is to be expected that patient accrual will be accomplished within 1-2 years.

It should be realized that many centres have introduced laparoscopic liver surgery programmes in the absence of a central reporting or certifying agency. In our opinion, laparoscopic LLS should function as a model for further dissemination of laparoscopic techniques in hepatic surgery. The left lateral segment of the liver has been a natural first step for a laparoscopic resection given the peripheral anatomical location (thin liver segment, minimal requirement for biliary dissection, and ease of controlling the left portal pedicles and left hepatic vein), and has been proven to be safe and feasible with reproducible results. $[20,36]$ The implementation of the laparoscopic LLS may not only serve as a guide to develop and master programmes for major laparoscopic hepatic resections, but may also be used as an introduction for centres new to laparoscopic approaches in liver surgery. To adopt laparoscopic liver resection safely, certification for centres, surgeons, and units should be available through 
the International Hepatobiliary (HPB) Association, and national and international HPB associations should become involved in the goal of establishing training standards and credentials to ensure a high and consistent outcome. The ORANGE II trial in which techniques are standardized and a training and proctor programme is available, combined with the hybrid design of randomization and registry may help to provide a framework for controlled and safe implementation of laparoscopic liver resection across participating centres.

\section{CONCLUSION}

The international multicentre randomised controlled ORANGE II trial is based on the observations of more rapid recovery and discharge after laparoscopic liver resection, and more rapid recovery and discharge after open liver resection within an enhanced recovery programme. This is the first $\mathrm{RCT}$ to provide evidence on the merits of laparoscopic surgery in patients undergoing LLS within an enhanced recovery programme. 


\section{REFERENCES}

1. Ruers T, Bleichrodt RP: Treatment of liver metastases, an update on the possibilities and results. Eur J Cancer 2002, 38(7):1023- 1033.

2. Cuesta MA, Meijer S, Paul MA, de Brauw LM: Limited laparoscopic liver resection of benign tumors guided by laparoscopic ultra- sonography: report of two cases. Surg Laparosc Endosc 1995, 5(5):396401.

3. Carswell KA, Sagias FG, Murgatroyd B, Rela M, Heaton L, Patel AG, et al: Laparoscopic versus open left lateral segmentectomy. BMC Surg 2009, 9 (14):9.

4. Vigano L, Tayar C, Laurent A, Cherqui D: Laparoscopic liver resection: a systematic review. J Hepatobiliary Pancreat Surg 2009, 16(4):410-421.

5. Cherqui D: Laparoscopic liver resection. Br J Surg 2003, 90(6):644-646.

6. Dagher I, Di Giuro G, Dubrez J, Lainas P, Smadja C, Franco D: Laparoscopic versus open right hepatectomy: a comparative study. Am J Surg 2009, 198(2):173-177.

7. Dagher I, O'Rourke N, Geller DA, Cherqui D, Belli G, Gamblin TC, Lainas P, Laurent A, Nguyen KT, Marvin MR: M, Ravindra K, Fielding G, Franco D, Buell JF: Laparoscopic major hepatectomy: an evolution in standard of care. Ann Surg 2009, 250(5):856-860.

8. Abu Hilal M, Di Fabio F, Teng MJ, Lykoudis P, Primrose JN, Pearce NW: Single-centre comparative study of laparoscopic versus open right hepatectomy. J Gastrointest Surg 201 , 15(5):818-823.

9. Abu Hilal M, McPhail MJ, Zeidan B, Zeidan S, Hallam MJ, Armstrong T, Primrose JN, Pearce NW: Laparoscopic versus open left lateral hepatic sectionectomy: a comparative study. Eur J Surg Oncol 2008, 34:1285- 1288.

10. Abu Hilal M, Pearce NW: Laparoscopic left lateral liver sectionectomy: a safe, efficient, reproducible technique. Dig Surg 2008, 25:305-308.

11. Dagher I, Lainas P, Carloni A, Caillard C, Champault A, Smadja C, Franco D: Laparoscopic liver resection for hepatocellular carcinoma. Surg Endosc 2008, 22(2):372-378.

12. Dagher I, Proske JM, Carloni A, Richa H, Tranchart H, Franco D: Laparoscopic liver resection: results for 70 patients. Surg Endosc 2007, 21(4):619-624.

13. Lee KF, Cheung YS, Chong CN, Tsang YY, Ng WW, Ling E, Wong J, Lai PB: Laparoscopic versus open hepatectomy for liver tumours: a case control study. Hong Kong Med J 2007, 13(6):442-448.

14. O'Rourke N, Shaw I, Nathanson L, Martin I, Fielding G: Laparoscopic resection of hepatic colorectal metastases. HPB (Oxford) 2004, 6(4):230-235.

15. Troisi R, Montalti R, Smeets P, Van Huysse J, Van Vlierberghe H, Colle I, De Gendt S, de Hemptinne B: The value of laparoscopic liver surgery for solid benign hepatic tumors. Surg Endosc 2008, 22(1):38-44.

16. Nguyen KT, Gamblin TC, Geller DA: World review of laparoscopic liver resection-2,804 patients. Ann Surg 2009, 250(5):831-841.

17. Bryant R, Laurent A, Tayar C, Cherqui D: Laparoscopic liver resectionunderstanding its role in current practice: the Henri Mondor Hospital experience. Ann Surg 2009, 250(1):103-111.

18. Laurence JM, Lam VW, Langcake ME, Hollands MJ, Crawford MD, Pleass HC: Laparoscopic hepatectomy, a systematic review. ANZ J Surg 2007, 77 (11):948-953.

19. Alkari B, Owera A, Ammori BJ: Laparoscopic liver resection: preliminary results from a UK centre. Surg Endosc 2008, 22(10):2201-2207.

20. Carswell KA, Sagias FG, Murgatroyd B, Rela M, Heaton N, Patel AG: Laparoscopic versus open left lateral segmentectomy. BMC Surg 2009, 9:14.

21. Vigano L, Tayar C, Laurent A, Cherqui D: Laparoscopic liver resection: a systematic review. J Hepatobiliary Pancreat Surg 2009, 16:410-21.

22. Fearon KC, Ljungqvist O, Von Meyenfeldt M, Revhaug A, Dejong CH, Lassen K, Nygren J, Hausel J, Soop $\mathrm{M}$, Andersen J: Kehlet $\mathrm{H}$ : Enhanced recovery after surgery: a consensus review of clinical care for patients undergoing colonic resection. Clin Nutr 2005, 24(3):466-477.

23. Kehlet H, Wilmore DW: Multimodal strategies to improve surgical outcome. Am J Surg 2002, 183(6):630-641. 
24. Wilmore DW, Kehlet $\mathrm{H}$ : Management of patients in fast track surgery. BMJ Clinical research ed 2001, 322:473-476.

25. Lassen K, Soop M, Nygren J, Cox PB, Hendry PO, Spies C, von Meyenfeldt MF, Fearon KC, Revhaug A, Norderval S, Ljungqvist O, Lobo DN: Dejong $\mathrm{CH}$ : Consensus review of optimal perioperative care in colorectal surgery: enhanced recovery after surgery (ERAS) group recommendations. Arch Surg 2009, 144(10):961-969.

26. Basse $\mathrm{L}$, Madsen $\mathrm{J}$, Kehlet $\mathrm{H}$ : Normal gastrointestinal transit after colonic resection using epidural analgesia, enforced oral nutrition and laxative. Br J Surg 2001, 88(11):1498-1500.

27. Basse L, Raskov HH: Hjort Jakobsen D, Sonne E, Billesbolle P, Hendel HW, Rosenberg J, Kehlet H: Accelerated postoperative recovery programme after colonic resection improves physical performance, pulmonary function and body composition. Br J Surg 2002, 89(4):446-453.

28. Delaney CP, Zutshi M, Senagore AJ, Remzi FH, Hammel J, Fazio VW: Prospective, randomized, controlled trial between a pathway of controlled rehabilitation with early ambulation and diet and traditional postoperative care after laparotomy and intestinal resection. Dis Colon Rectum 2003, 46(7):851859.

29. Zutshi M, Delaney CP, Senagore AJ, Mekhail N, Lewis B, Connor JT, Fazio VW: Randomized controlled trial comparing the controlled rehabilitation with early ambulation and diet pathway versus the controlled rehabilitation with early ambulation and diet with preemptive epidural anesthesia/analgesia after laparotomy and intestinal resection. Am J Surg 2005, 189 (3):268-272.

30. van Dam RM, Hendry PO, Coolsen MM, Bemelmans MH, Lassen K, Revhaug A, Fearon KC, Garden OJ, Dejong $\mathrm{CH}$ : Initial experience with a multimodal enhanced recovery programme in patients undergoing liver resection. Br J Surg 2008, 95(8):969-975.

31. Stoot JH, van Dam RM, Busch OR, van Hillegersberg R, De Boer M: Olde Damink SW, Bemelmans MH, Dejong $\mathrm{CH}$ : The effect of a multimodal fasttrack programme on outcomes in laparoscopic liver surgery: a multicentre pilot study. HPB (Oxford) 2009, 11(2):140-144.

32. Maessen J, Dejong CH, Hausel J, Nygren J, Lassen K, Andersen J, Kessels AG, Revhaug A, Kehlet H, Ljungqvist O, Fearon KC: von Meyenfeldt MF: A protocol is not enough to implement an enhanced recovery programme for colorectal resection. Br J Surg 2007, 94(2):224-231.

33. McCulloch P: Developing appropriate methodology for the study of surgical techniques. J R Soc Med 2009, 102(2):51-55.

34. Gore SM: The consumer principle of randomisation. Lancet 1994, 343 (8888):58.

35. Brewin CR, Bradley C: Patient preferences and randomised clinical trials. BMJ 1989, 299(6694):313-315.

36. Nguyen KT, Gamblin TC, Geller DA: World review of laparoscopic liver resection-2,804 patients. Ann Surg 2009, 250:831-841.

37. Dindo D, Demartines N, Clavien PA: Classification of surgical complications: a new proposal with evaluation in a cohort of 6336patients and results of a survey. Ann Surg 2004, 240(2):205-213.

38. van den Broek MA, van Dam RM, van Breukelen GJ, Bemelmans MH, Oussoultzoglou E, Pessaux P, Dejong $\mathrm{CH}$, Freemantle N: Olde Damink SW: Development of a composite endpoint for randomized controlled trials in liver surgery. Br J Surg $201,98(8): 1138-1145$.

39. Lamers LM, McDonnell J, Stalmeier PF, Krabbe PF, Busschbach JJ: The Dutch tariff: results and arguments for an effective design for national EQ-5D valuation studies. Health Econ 2006, 15(10):11211132.

40. Lamers LM, Stalmeier PF, McDonnell J, Krabbe PF, van Busschbach JJ: Measuring the quality of life in economic evaluations: the Dutch EQ-5D tariff. Ned Tijdschr Geneeskd 2005, 149(28):1574-1578.

41. Langenhoff BS, Krabbe PF, Peerenboom L, Wobbes T, Ruers TJ: Quality of life after surgical treatment of colorectal liver metastases. Br J Surg 2006, 93(8):1007-1014.

42. Blazeby JM, Fayers P, Conroy T, Sezer O, Ramage J, Rees M: Validation of the european organization for research and treatment of cancer QLQLMC21 questionnaire for assessment of patient-reported outcomes during treatment of colorectal liver metastases. Br J Surg 2009, 96(3):291- 298.

43. Polle SW, Dunker MS, Slors JF, Sprangers MA, Cuesta MA, Gouma DJ, Bemelman WA: Body image, cosmesis, quality of life, and functional outcome of hand-assisted laparoscopic versus open restorative proctocolectomy: long-term results of a randomized trial. Surg Endosc 2007, 21(8):1301-1307. 
44. Dunker MS, Stiggelbout AM, van Hogezand RA, Ringers J, Griffioen G, Bemelman WA: Cosmesis and body image after laparoscopic-assisted and open ileocolic resection for Crohn's disease. Surg Endosc 1998, 12 (11):1334-1340.

45. Oostenbrink JB, Koopmanschap MA, Rutten FF: Standardisation of costs: the Dutch manual for costing in economic evaluations. Pharmacoeconomics 2002, 20(7):443-454.

46. Hoër J, Lawong G, Klinge U, Schumpelick V: Einflussfaktoren der narbenhernienenstehung retrospektive untersuchung an 2.983 laparotomierten patienten über einen zeitraum vno 10 jahren. Chirurg 2002, 73:474-480.

47. Andersen LP, Klein M, Gogenur I, Rosenberg J: Incisional hernia after open versus laparoscopic sigmoid resection. Surg Endosc 2008, 22(9):2026-2029.

48. D'Angelica M, Maddineni S, Fong Y, Martin RC, Cohen MS, Ben-Porat L, Gonen M, DeMatteo RP, Blumgart LH, Jarnagin WR: Optimal abdominal incision for partial hepatectomy: increased late complications with Mercedes-type incisions compared to extended right subcostal incisions. World J Surg 2006, 30(3):410-418.

49. Togo S, Nagano Y, Masumoto C, Takakura H, Matsuo K, Takeda K, Tanaka K, Endo I, Shimada H: Outcome of and risk factors for incisional hernia after partial hepatectomy. J Gastrointest Surg 2008, 12(6):11 5-1120.

50. Paice JA, Cohen FL: Validity of a verbally administered numeric rating scale to measure cancer pain intensity. Cancer Nurs 1997, 20(2):88-93.

51. McGuire DB: Comprehensive and multidimensional assessment and measurement of pain. J Pain Symptom Manage 1992, 7(5):312-319.

52. Dorrepaal KL, Aaronson NK, van Dam FS: Pain experience and pain management among hospitalized cancer patients. A clinical study. Cancer 1989, 63(3):593-598.

53. Jensen MP: The validity and reliability of pain measures in adults with cancer. J Pain 2003, 4(1):2-21.

54. Krebs EE, Carey TS, Weinberger M: Accuracy of the pain numeric rating scale as a screening test in primary care. J Gen Intern Med 2007, 22 (10):1453-1458.

55. Suurmeijer TP, Doeglas DM, Moum T, Briancon S, Krol B, Sanderman R, Guillemin F, Bjelle A, van den Heuvel WJ: The Groningen Activity Restriction Scale for measuring disability: its utility in international comparisons. Am J Public Health 1994, 84(8):1270-1273.

56. Snapinn SM: Monitoring clinical trials with a conditional probability stopping rule. Stat Med 1992, 11(5):659-672.

57. van Breukelen GJ, Candel MJ, Berger MP: Relative efficiency of unequal versus equal cluster sizes in cluster randomized and multicentre trials. Stat Med 2007, 26(13):2589- 2603.

58. van den Broek MA, van Dam RM, Malago M, Dejong CH, van Breukelen GJ, Damink SW: Feasibility of randomized controlled trials in liver surgery using surgery-related mortality or morbidity as endpoint. Br J Surg 2009, 96(9):1005-1014.

59. Koffron AJ, Auffenberg G, Kung R, Abecassis M: Evaluation of 300 minimally invasive liver resections at a single institution: less is more. Ann Surg 2007, 246:385-392. discussion 392-384.

60. Vigano L, Laurent A, Tayar C, Tomatis M, Ponti A, Cherqui D: The learning curve in laparoscopic liver resection: improved feasibility and reproducibility. Ann Surg 2009, 250(5):772-782.

61. Buell JF, Cherqui D, Geller DA, O'Rourke N, lannitti D, Dagher I, Koffron AJ, Thomas M, Gayet B, Han HS, Wakabayashi G, Belli G, Kaneko H, Ker CG, Scatton O, Laurent A, Abdalla EK, Chaudhury P, Dutson E, Gamblin C, D’Angelica M, Nagorney D, Testa G, Labow D, Manas D, Poon RT, Nelson H, Martin R, Clary B, Pinson WC, Martinie J, Vauthey JN, Goldstein R, Roayaie S, Barlet D, Espat J, Abecassis M, Rees M, Fong Y, McMasters KM, Broelsch C, Busuttil R, Belghiti J, Strasberg S: Chari RS; World Consensus Conference on Laparoscopic Surgery: The international position on laparoscopic liver surgery: The Louisville Statement, 2008. Ann Surg 2009, 250(5):6.

62. McCulloch P, Taylor I, Sasako M, Lovett B, Griffin D: Randomised trials in surgery: problems and possible solutions. BMJ 2002, 324(7351):1448-1451.

63. Kazaryan AM, Pavlik Marangos I, Rosseland AR, Rosok BI, Mala T, Villanger O, Mathisen O, Giercksky KE, Edwin B: Laparoscopic liver resection for malignant and benign lesions: ten-year Norwegian singlecenter experience. Arch Surg 145:34-40. 
64. Topal B, Fieuws S, Aerts R, Vandeweyer H, Penninckx F: Laparoscopic versus open liver resection of hepatic neoplasms: comparative analysis of shortterm results. Surg Endosc 2008, 22(10):2208-2213.

65. Pessaux P, Regimbeau JM, Dondero F, Plasse M, Mantz J, Belghiti J: Randomized clinical trial evaluating the need for routine nasogastric decompression after elective hepatic resection. Br J Surg 2007, 94(3): 297-303.

66. Ito K, Ito H, Are C, Allen PJ, Fong Y, DeMatteo RP, Jarnagin WR, D’Angelica MI: Laparoscopic versus open liver resection: a matched-pair case control study. J Gastrointest Surg 2009, 13(12):2276-2283. 



\section{Chapter}

\section{Randomized controlled trial of open versus laparoscopic left lateral hepatic}

sectionectomy within an enhanced recovery ERAS $^{\circledR}$ programme (ORANGE II - Study)

Wong-Lun-Hing EM, van Dam RM, van Breukelen GJP, Tanis PJ, Ratti F, van Hillegersberg R, Slooter GD, de Wilt JHW, Liem MSL, de Boer MT, Klaase JM, Neumann UP, Aldrighetti LA, Dejong CHC for the ORANGE II Collaborative Group 


\section{ABSTRACT}

\section{BACKGROUND}

Laparoscopic left lateral sectionectomy (LLLS) has been associated with shorter hospital stay and reduced overall morbidity compared with open left lateral sectionectomy (OLLS). Strong evidence has not, however, been provided.

\section{METHODS}

In this multicentre double-blind RCT, patients (aged 18-80 years with a BMI of 18-35 $\mathrm{kg} / \mathrm{m} 2$ and ASA fitness grade of III or below) requiring left lateral sectionectomy (LLS) were assigned randomly to OLLS or LLLS within an enhanced recovery after surgery (ERAS) programme. All randomized patients, ward physicians and nurses were blinded to the procedure undertaken. A parallel prospective registry (open nonrandomized (ONR) versus laparoscopic non-randomized (LNR)) was used to monitor patients who were not enrolled for randomization because of doctor or patient preference. The primary endpoint was time to functional recovery. Secondary endpoints were length of hospital stay (LOS), readmission rate, overall morbidity, composite endpoint of liver surgery-specific morbidity, mortality, and reasons for delay in discharge after functional recovery.

\section{RESULTS}

Between January 2010 and July 2014, patients were recruited at ten centres. Of these, 24 patients were randomized at eight centres, and 67 patients from eight centres were included in the prospective registry. Owing to slow accrual, the trial was stopped on the advice of an independent Data and Safety Monitoring Board in the Netherlands. No significant difference in median (i.q.r.) time to functional recovery was observed between laparoscopic and open surgery in the randomized or nonrandomized groups: 3 (3-5) days for OLLS versus 3 (3-3) days for LLLS; and 3 (3-3) days for ONR versus 3 (3-4) days for LNR. There were no significant differences with regard to LOS, morbidity, reoperation, readmission and mortality rates.

\section{CONCLUSIONS}

This RCT comparing open and laparoscopic LLS in an ERAS setting was not able to reach a conclusion on time to functional recovery, because it was stopped prematurely owing to slow accrual.

Registration number: NCT00874224 (https://www.clinicaltrials.gov). 


\section{INTRODUCTION}

The left lateral segments of the liver can be resected by both open and laparoscopic approaches. The latter has become increasingly popular after the Louisville Statement of 2008, where experts concluded that laparoscopic left lateral sectionectomy (LLS) was a safe and effective approach for the management of surgical liver disease in the hands of experienced hepatobiliary and laparoscopic surgeons.[1] Later reviews, based mainly on retrospective data, showed favourable clinical outcomes after laparoscopic resection.[2,3] Studies specifically comparing open and laparoscopic LLS have hitherto been based on retrospective designs or with small sample size.[4,5] A meta-analysis of non-randomized studies showed a reduction in duration of operation, shorter overall length of hospital stay (LOS) and reduced morbidity after laparoscopic LLS.[6] This difference in LOS was, however, associated with significant heterogeneity among the included studies.

Enhanced recovery after surgery (ERAS) programmes have been introduced in patients undergoing minor and major liver resections. Multiple studies [7-15] have shown that these programmes are feasible, safe and effective in reducing median LOS in both open and laparoscopic resection. Data available at the time of design of this study also suggested that a further reduction in LOS after liver resection could be achieved when the observed delay between patient recovery and actual discharge was minimized, as reported for colonic resections.[10,16] Day of discharge from hospital is dependent on multiple factors, including patient expectations, local discharge logistics and cultural differences between countries, hospitals and surgeons. LOS may therefore be considered an inappropriate endpoint for comparison of surgical interventions. Within the ERAS programme for liver surgery, a composite endpoint has been defined: time to functional recovery. This endpoint, representing medical readiness for discharge, consisted of clear and objectively measurable criteria. A patient was considered functionally recovered if they had a normal or decreasing serum bilirubin level, good pain control with oral analgesia only, tolerance of solid food, no intravenous fluid support and independent mobility at the preoperative level.[10] Functionally recovered patients were generally capable of independently performing activities of daily living and were independent of hospital care.

The aim of this study was to compare open and laparoscopic liver surgery in a randomized, controlled, multicentre and blinded setting, in which all patients received a standardized liver resection within a standardized perioperative care programme, based on a standardized recovery outcome measure. A parallel registry to the randomized controlled arms was created to study an uninterrupted series for external validity. The hypothesis was that in patients undergoing laparoscopic LLS (LLLS), 
time to functional recovery would be reduced by 2 days compared with that in those having open LLS (OLLS).

\section{METHODS}

\section{STUDY DESIGN AND PARTICIPANTS}

This study (ORANGE II) was designed as a double-blind RCT with a parallel prospective registry of patients who could not be randomized owing to patient or surgeon preference. Patients were eligible for inclusion in the randomization if they required a liver LLS for accepted indications, if they were men or non-pregnant, non-lactating women aged $18-80$ years with a BMl of $18-35 \mathrm{~kg} / \mathrm{m} 2$ and an American Society of Anesthesiologists (ASA) grade of III or less. Exclusion criteria were: planned liver resection other than LLS, ASA grade above III, and underlying liver disease diagnosed before surgery.

Representatives of the ORANGE II study group from Maastricht University Medical Centre coordinated the trial and analysed the data. The study protocol was approved by medical ethics committees at each participating centre. Centres were approached by e-mail and could participate if laparoscopic and open liver surgery were performed on a routine basis and if an ERAS liver programme had been implemented. Fourteen European sites obtained ethical approval to enroll patients; twelve were located in the Netherlands, one in Germany and one in Italy. The study protocol was registered online at ClinicalTrials.gov (NCT00874224), and has been published.[17] The aim of the study was to compare LLLS with OLLS in terms of time to functional recovery (primary endpoint). The hypothesis was that time to functional recovery would be reduced by 2 days in patients undergoing LLLS.

\section{RANDOMISATION AND MASKING}

Patients were approached for participation in the outpatient clinic. All provided written informed consent before preoperative assessment. They received information and counselling related to the study intervention, ERAS programme and other studyrelated procedures. Patients were assigned randomly before admission in a 1:1 ratio to either OLLS or LLLS. Randomization was performed by each local study coordinator using a web-based system (TENALEA ${ }^{\oplus}$; FormsVision, Abcoude, The Netherlands) and block randomization. Randomization was stratified according to treatment, centre, sex and ASA grade. The allocated procedure was communicated to the operating surgeon(s). All randomized patients, ward physicians and nurses were blinded to the 
type of intervention by the use of a large fixed abdominal dressing until postoperative day (POD) 3. Non-randomized patients were asked for permission to use their data. In doing so, they were assigned to the open non-randomized (ONR) or laparoscopic non-randomized (LNR) arm of the prospective registry, on the basis that this registry might increase the external validity of results obtained in the randomized study.[18,19]

\section{PROCEDURES}

The intraoperative surgical technique was not standardized; surgeons in participating centres were free to use their preferred technique and devices to gain intraabdominal access, perform hepatic parenchymal transection and maintain vascular control. Surgeons in each participating centre performed the allocated intervention based upon availability. Medical centres with liver surgeons early in the laparoscopic learning curve were assisted during the procedure by an experienced proctoring laparoscopic hepatopancreatobiliary (HPB) surgeon. Perioperative care for all patients in the study was standardized according to the ERAS programme and the perioperative care provided was based on daily guidelines (Table 1).

\section{OUTCOMES}

The primary outcome measure of this study for both the randomized and parallel cohorts was time to functional recovery. A patient was considered functionally recovered when all of the following criteria were fulfilled: adequate pain control with oral analgesia only; restoration of mobility to an independent or preoperative level; absence of intravenous fluid administration; ability to eat solid foods; and normal or decreasing serum bilirubin level or international normalized ratio (INR). The evaluation of time to functional recovery started on PODO and was scored until discharge from hospital using a standard checklist and patient diary. Patients were considered ready for discharge when the primary endpoint had been met, although it was up to the local logistics of each centre to define the actual moment of discharge. The delay between time to functional recovery and actual discharge was recorded and reasons for this delay were obtained.

Post-operative pain was registered twice daily using the validated, verbally administered, 11-point (0-10) numerical rating scale (NRS-11).[20,21] Centres were free to provide either epidural or intravenous patient-controlled analgesia. No indwelling wound catheters were used in participating centres. Members of a specialized pain team asked patients to rate the intensity of their current pain on a scale from 0 (no pain) to 10 (worst possible pain). A score of 1-3 was considered to be mild, 4-6 moderate and 7-10 severe.[22] 
To report the difference between preoperative and post-operative level of mobility, the ERAS Mobility Scale (EMS), derived from the Groningen Activity Restriction Scale [23], was used. The EMS utilizes ten items of basic actions to compare the level of mobility before and after surgical intervention. When the patient reached the preoperative EMS level, or had a positive score for eight of ten items, they were considered independently mobile.

Fluid and solid food intake was monitored, and a normal tolerance was required before discharge. Tolerance was considered to be normal when oral intake solid food was resumed and continued for at least $24 \mathrm{~h}$. At the time of design of the study it was decided to monitor the post-operative serum bilirubin concentration and INR to ensure that no patient was discharged with impaired liver function. Serum bilirubin levels and INR were measured before surgery and on POD1 and 3. Secondary outcomes were post-operative LOS, readmission rate, total morbidity according to the Clavien-Dindo classification [24], composite endpoint of liver surgery-specific morbidity [25], mortality, and reasons for delay in discharge after functional recovery.

\section{DATA COLLECTION AND PATIENT SAFETY}

Data were collected using both paper case report forms (CRFs) and an open-source clinical trial software platform (OpenClinica ${ }^{\circledR}$; Ikaza Research, Cambridge, Massachusetts, USA) in compliance with good clinical practice guidelines. The e-CRFs were stored in a secured database (Oracle Corporation, Redwood Shores, California, USA). A baseline assessment of mobility was performed on the day of admission. Venous blood samples were drawn before and after surgery, on POD1 and 3. During admission, surgical details, data on time to functional recovery and complications were collected with a patient diary, a milestone checklist and standardized adverse event forms.

An independent Data and Safety Monitoring Board (DSMB) in the Netherlands evaluated the progress and quality of the trial and examined safety endpoints for each consecutive group of 25 patients. Baseline characteristics and serious adverse events were listed and presented in an unblinded fashion. Recommendations made by the DSMB were communicated to the medical ethics review committee of Maastricht University Medical Centre and all participating centres. 
Table 1 Perioperative care according to the enhanced recovery after liver surgery programme

\begin{tabular}{|c|c|}
\hline & Daily guideline \\
\hline Day before surgery & $\begin{array}{l}\text { Normal oral nutrition up to } 6 \mathrm{~h} \text { before surgery No preanaesthetic medication } \\
\text { Laboratory tests }\end{array}$ \\
\hline Day of surgery & $\begin{array}{l}\text { Carbohydrate drinks up to } 2 \mathrm{~h} \text { before surgery Mid-thoracic epidural analgesia (local } \\
\text { anaesthetic } \\
\text { + low-dose opioid) } \\
\text { Short-acting i.v. anaesthetic agent } \\
\text { Preferably no nasogastric drainage, but when used remove after surgery } \\
\text { Use warm i.v. fluids, and upper and lower body air-waming device } \\
\text { Avoid excessive i.v. fluids } \\
\text { CVP during transection }<5 \mathrm{mmHg} \\
\text { No routine drainage of peritoneal cavity Patient sent to recovery ward } \\
\text { Restart oral intake of water/nutrition }\end{array}$ \\
\hline POD 1 & $\begin{array}{l}\text { Patient sent to surgical ward } \\
\text { Patient mobilizes a minimum of four times a day Discontinuation of i.v. fluids } \\
\text { Patient drinks at least } 1.5 \text { litres Normal diet } \\
\text { Continue portable epidural analgesia (local anaesthetic + low-dose opioid) or PCA } \\
\text { Remove urinary catheter } 1000 \mathrm{mg} \text { paracetamol 6-hourly Start laxatives } \\
\text { Laboratory tests }\end{array}$ \\
\hline POD 2 & $\begin{array}{l}\text { Continue portable epidural analgesia or PCA Stop low-dose opioids } \\
\text { Continue mobilization a minimum of four times daily 1000mg paracetamol 6-hourly } \\
\text { Normal diet Laxatives }\end{array}$ \\
\hline POD 3 & $\begin{array}{l}\text { Stop epidural analgesia or PCA Start NSAIDs } \\
\text { Continue mobilization Normal diet Laboratory tests } \\
\text { Check discharge criteria } \\
\text { Outpatient appointment made for POD10, } 1 \text { or } 12\end{array}$ \\
\hline POD 4 & $\begin{array}{l}\text { Check discharge criteria } \\
\text { Patient given mobile phone number of HPB surgeon on duty } \\
\text { Discharge }\end{array}$ \\
\hline
\end{tabular}

i.v., Intravenous; POD, post-operative day; CVP, central venous pressure; PCA, patient-controlled analgesia; NSAID, non-steroidal anti-inflammatory drug; HPB, hepatopancreatobiliary.

\section{STATISTICAL ANALYSIS}

Time to functional recovery was used as the primary endpoint. Owing to lack of data on the reduction in time to functional recovery after liver surgery in an ERAS programme, a decision was made to use LOS for the purpose of power calculation, because this approached the primary endpoint most accurately. Based on a retrospective analysis of 31 patients in both ERAS and non-ERAS settings, who had undergone LLS from 1990 to 2010, the mean(s.d.) value for post-operative LOS after LLS in Maastricht University Medical Centre was 6.0(2.7) days. Thus a reduction in time to functional recovery of 2 days seemed feasible.

At 90 per cent power and alfa $=0.05$ (two-tailed), a sample size of $2 \times 40$ patients in the randomization arms would be sufficient to detect this difference (two-tailed testing was planned to allow detection of an (unexpected) increase in time to functional 
recovery after LLLS compared with OLLS, and to be consistent with the two-sided confidence intervals to be reported). Assuming an expected withdrawal rate of 10 per cent or less, the participation of at least ten centres, and the required addition of one randomized patient per arm for every additional participating centre to compensate for the loss of degrees of freedom incurred in the data analysis (which takes centre and treatment $\times$ centre effects into account), a total sample size of $110(2 \times$ 55) was required. Patients were analysed according to the intention-to-treat principle, and analysis was performed with SPSS ${ }^{\circledR}$ software using Windows ${ }^{\oplus}$ version 21.0 (IBM, Armonk, New York, USA).

After each group of 25 included patients, a report was sent to the DSMB. An interim analysis was planned after randomization and completion of follow-up of 50 per cent of the total sample size. The DSMB provided the principal investigator with recommendations: no action needed, early stopping (due to clear benefit/ harm of a treatment, futility, or new external evidence), extending recruitment or follow-up, stopping a single arm of the multi-arm trial, or sanctioning and/or proposing protocol changes. Assumption of normality was checked using the Shapiro-Wilk test. Continuous numerical data were summarized by the median (i.q.r.) value per treatment arm. Analysis was performed with $X^{2}$ or Fisher's exact tests for binary outcomes, and Mann-Whitney $\mathrm{U}$ or $\mathrm{t}$ tests for continuous outcomes, depending on their normality. For the primary outcome time to functional recovery alfa $=0.05$ (two-tailed) and for the secondary outcomes alfa $=0.01$ (two-tailed) were used to correct for multiple testing.

Post hoc analyses to assess milestones during recovery of patients and compliance with elements of the ERAS protocol were also performed. To describe the compliance with individual ERAS elements per study group and centre, an overall compliance and the between-centre range was used. Per element, an 80 per cent cut-off value was set to qualify as compliant.

The outcome analyses were repeated with multiple linear regression to adjust for patient age, sex, ASA grade and centre effects. Differences between individual surgeons within the same centre with respect to time to functional recovery, LOS, and difference between time to functional recovery and LOS were also examined. 


\section{RESULTS}

\section{ENROLMENT AND RANDOMISATION}

From January 2010 to 1 July 2014, ten of 14 centres that had ethical approval recruited patients for this study. A total of 104 patients were assessed for eligibility and 97 were included (Fig 1). Only 29 participants were randomized: 14 to OLLS and 15 to LLLS. The remaining 68 patients were included in the prospective registry. Some five patients were excluded after randomization: four required a larger hepatic resection and surgery was postponed in one woman because of pregnancy. One patient in the open arm of the prospective registry was also excluded after a preoperative change of procedure. No 30-day dropouts were observed in the RCT or prospective registry. A total of 91 patients ( 24 randomized and 67 prospective registry) were included in the intention-to-treat analysis. The DSMB did not express any objections to continuation of the trial after the first two reports (October 2012 and April 2013). In the third report of January 2014, however, the DSMB expressed concerns about the ORANGE II study group, because of an accrual rate of 24 per cent in the RCT.

In accordance with recommended criteria for accrual and scientific progress [26], a trial should be closed if it is open for more than 24 months with an accrual rate of less than 25 per cent. Therefore, the DSMB advised continuation of the trial for a maximum of 6 months. Because enrolment remained slow, a decision was made by the investigators to stop the trial on 1 July 2014.

\section{PREFERENCE}

Sixty-seven (73.6 per cent) of the 91 included patients in this study had surgery based on preference for either the open or laparoscopic procedure, usually surgeon preference: nine of 13 patients (69 per cent) in the open arm and 39 of 54 (72 per cent) of those in the laparoscopic arm of the prospective registry.

\section{PATIENT DEMOGRAPHICS AND SURGICAL OUTCOME}

Baseline patient characteristics (Table 2) and surgical outcomes (Table 3) were distributed equally between the groups in the randomized part study (OLLS versus LLLS), as well as in the prospective registry (ONR versus LNR). There appeared to be more patients with a history of previous abdominal surgery in the LNR group and a longer median duration of surgery in the LLLS group, but after correction for multiple testing these differences were not significant. 


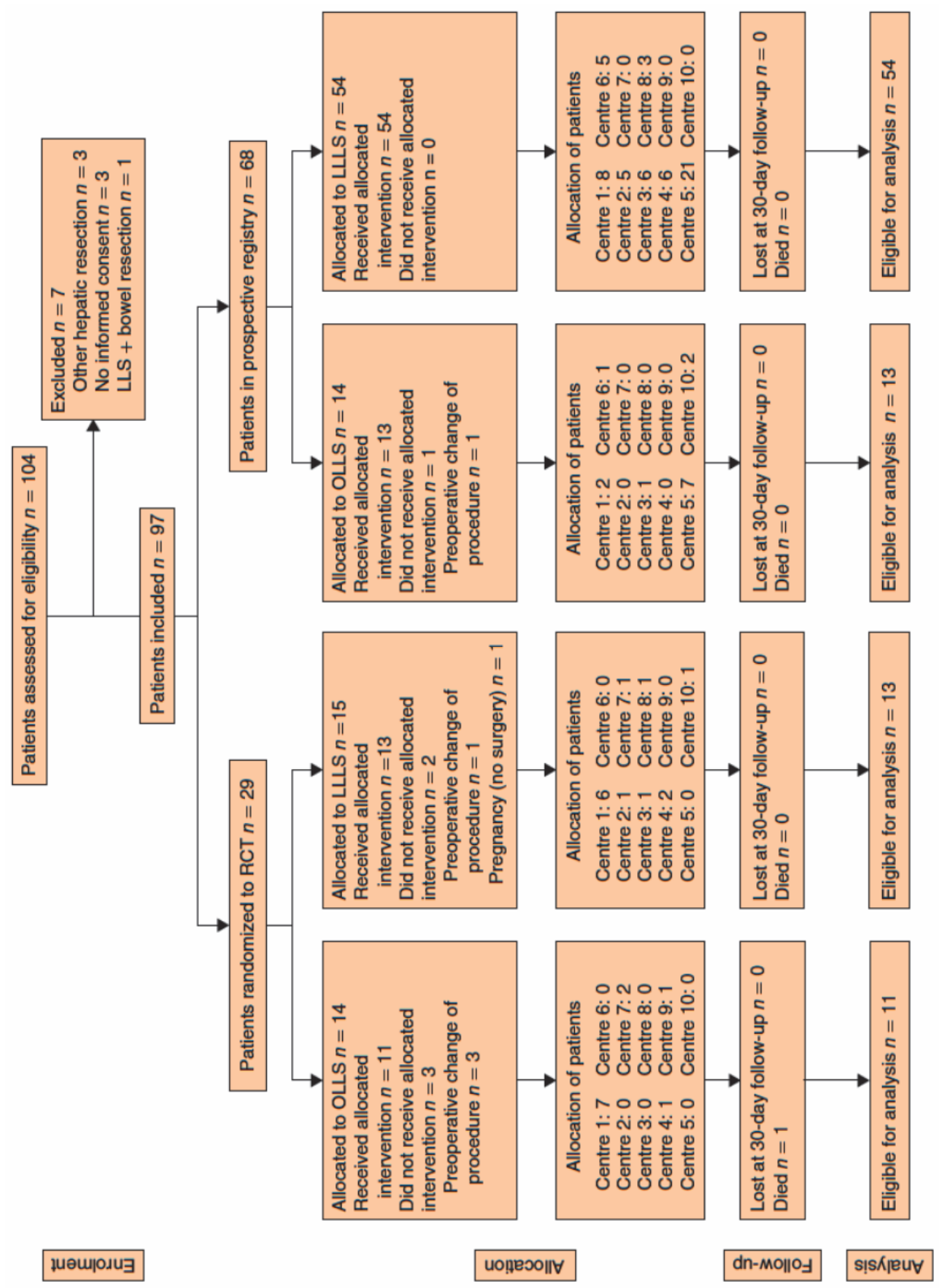

Figure 1. CONSORT diagram for the trial. LLS, left lateral sectionectomy; OLLS, open left lateral sectionectomy; LLLS, laparoscopic left lateral sectionectomy 
Table 2. Patient demographics

\begin{tabular}{|c|c|c|c|c|c|c|}
\hline & \multicolumn{3}{|l|}{$\mathrm{RCT}$} & \multicolumn{3}{|l|}{ Registry } \\
\hline & OLLS $(n=11)$ & LLLS $(n=13)$ & P\# & ONR $(n=13)$ & LNR $(n=54)$ & P\# \\
\hline Age (years)* & $58(52-70) \neq \neq$ & $67(55-73) \neq \neq$ & $0.361^{* *}$ & $53(46-64)$ & $63(45-72)$ & $0.219^{* *}$ \\
\hline Sex ratio (M: F) & $5: 6$ & $9: 4$ & 0.408 & $8: 5$ & $26: 28$ & $0.386+\dagger$ \\
\hline BMI $(\mathrm{kg} / \mathrm{m} 2)^{*}$ & $\begin{array}{l}28.7 \\
(25.5-33.9) \neq \neq\end{array}$ & $\begin{array}{l}27.1 \\
(25.3-28.5) \neq \neq\end{array}$ & $0.361^{* *}$ & $\begin{array}{l}23.5 \\
(22.0-27.2)\end{array}$ & $\begin{array}{l}24.7 \\
(22.5-29.2)\end{array}$ & $0.306^{* *}$ \\
\hline ASA fitness grade & & & $0.252^{* *}$ & & & $0.851^{* *}$ \\
\hline 1 & $3(27)$ & $1(8)$ & & $4(31)$ & $17(31)$ & \\
\hline II & $7(64)$ & $9(69)$ & & $8(62)$ & $30(56)$ & \\
\hline III & $1(9)$ & $3(23)$ & & $1(8)$ & $7(13)$ & \\
\hline Indication for surgery & & & 0.182 & & & $0.267+\dagger$ \\
\hline Colorectal metastasis & $6(55)$ & $11(85)$ & & $7(54)$ & $20(37)$ & \\
\hline Other & $5(45)+$ & $2(15) \ddagger$ & & $6(46) \S$ & 34 (63)ף & \\
\hline $\begin{array}{l}\text { Previous abdominal } \\
\text { surgery }\end{array}$ & $9(82)$ & $11(85)$ & 1.000 & $9(69)$ & $24(44)$ & $0.048+t$ \\
\hline $\begin{array}{l}\text { Preoperative chemo- } \\
\text { therapy }\end{array}$ & $3(27)$ & $9(69)$ & 0.100 & $3(23)$ & $14(26)$ & 1.000 \\
\hline
\end{tabular}

Values in parentheses are percentages unless indicated otherwise; *values are median (i.q.r.). OLLS, open left lateral sectionectomy; LLLS, laparoscopic left lateral sectionectomy; ONR, open non-randomized left lateral sectionectomy; LNR, laparoscopic non-randomized left lateral sectionectomy. †Adenoma (2), hepatocellular carcinoma (HCC) (1), haemangioma (1), focal nodular hyperplasia (FNH) (1);

‡HCC (1), multilocular biliary cyst (1); §HCC (3), metastatic melanoma (1), liver abscess (1), metastatic breast cancer (1); ๆHCC (3), haemangioma (4), adenoma (5), FNH (7), inflammatory lesions (2), echinococcosis (1), hepatic cyst (1), haemangioma (1). \#Fisher's exact test, except **Mann-Whitney $U$ test and †† $X^{2}$ test (all two-tailed). $\neq \neq$ Variable with normal distribution: Shapiro-Wilk $\mathrm{P}>0.050$; Mann-Whitney $U$ test results are shown, but $t$ test leads to the same conclusion. alfa $=0.01$ for all baseline variables to correct for multiple testing.

\section{PRIMARY OUTCOME}

Time to functional recovery did not significantly differ between OLLS and LLLS groups, or between ONR and LNR groups (Table 4). In the OLLS group, the median time to functional recovery was $3(3-5)$ days, compared with $3(3-3)$ days in the LLLS group ( $P=0.284)$. The same median time to functional recovery was found in the registry groups: 3 (3-3) days for ONR versus $3(3-4)$ days for $L N R(P=0.529)$. Subanalysis of individual functional recovery criteria revealed quicker tolerance of solid food in favour of the LNR group (2 (1-2) days versus $1(1-1)$ day following ONR; $P=0.002$ )

\section{SECONDARY OUTCOMES}

Median LOS did not differ significantly following OLLS compared with LLLS: 4.5 (4-6) versus $4(3-5)$ days respectively $(P=0.049)$ (note that alfa $=0.01$ for secondary outcomes in view of multiple testing). Median LOS in the prospective registry was also 
comparable: 5 (4-7) days for ONT versus 4 (3-5) days for LNR ( $P=0.064)$. The reasons for delayed discharge after functional recovery per group are shown in Table 4. Overall 39, 18 and 10 per cent of the delay was logistical or medical in nature, or based on patient request, respectively.

Table 3. Surgical outcomes

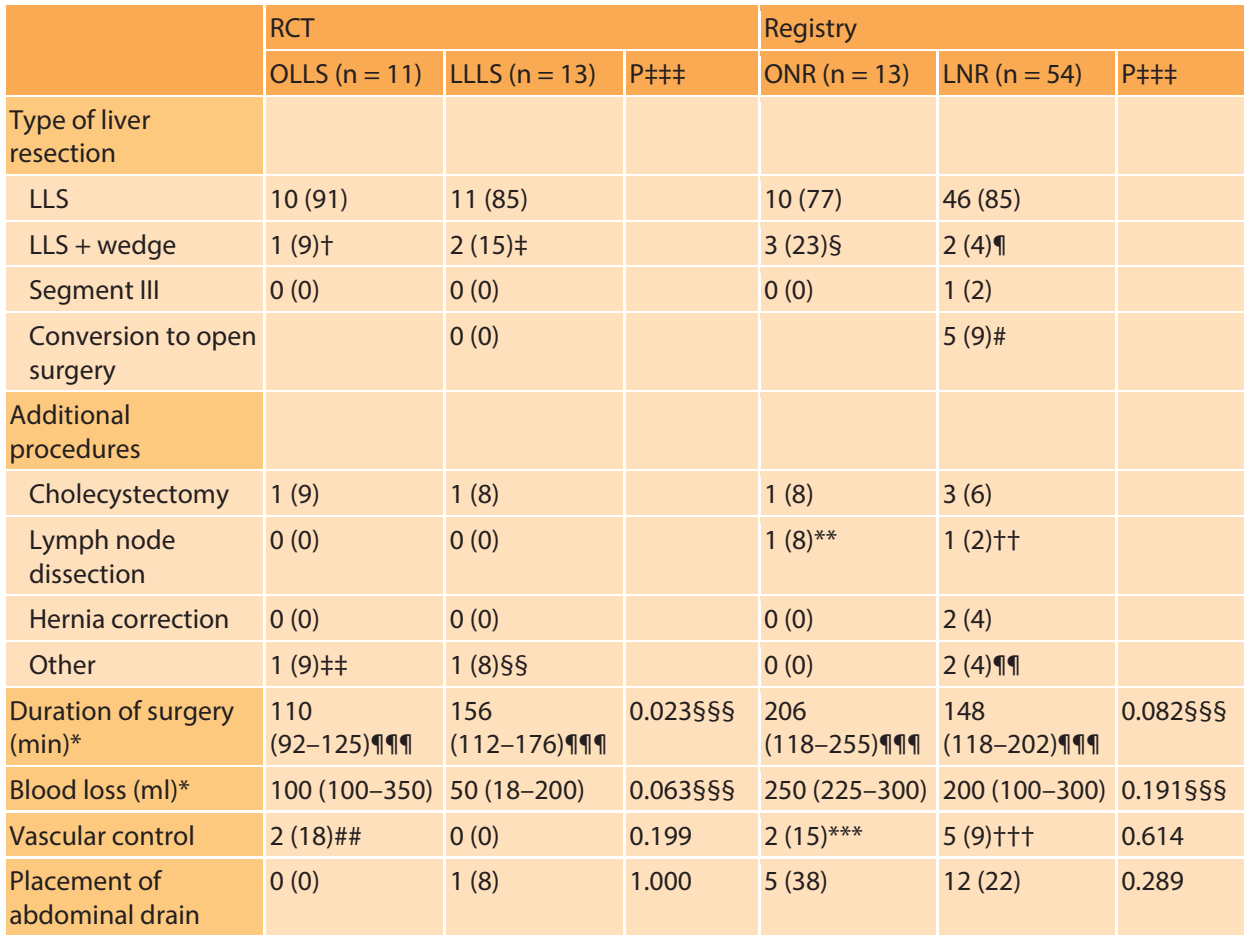

Values in parentheses are percentages unless indicated otherwise; *values are median (i.q.r.). OLLS, open left lateral sectionectomy; LLLS, laparoscopic left lateral sectionectomy; ONR, open non-randomized left lateral sectionectomy; LNR, laparoscopic non-randomized left lateral sectionectomy; LLS, left lateral sectionectomy. †Segment IVB; łsegment IVB (2); §segments V, IVB and VIII; ๆsegment VI and segment IVB (2). \#Reason for conversion: tumour to close to vascular structures (1), adhesions (1), bleeding from aberrant left hepatic artery (1), size of lesion (1), infiltration of diaphragm (1).

**Hepatoduodenal ligament+omentum minus+left gastric artery+coeliac artery+gastroduodenal artery. ††Omentum minus; キładhesiolysis; §§transversostomy; 凤ी radiofrequency ablation (1), partial diaphragm resection (1). \#\#Pringle (1), Kelly clamp (1); ***Pringle (2);

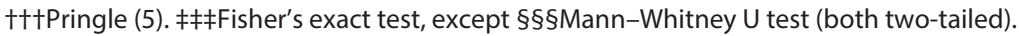

ๆๆๆVariable with normal distribution: Shapiro-Wilk P >0.050; Mann-Whitney U test results are shown, but t test leads to the same conclusion. alfa $=0.01$ for all secondary outcomes to correct for multiple testing. 
Table 4. Functional recovery and length of hospital stay

\begin{tabular}{|c|c|c|c|c|c|c|}
\hline & \multicolumn{3}{|l|}{$\mathrm{RCT}$} & \multicolumn{3}{|l|}{ Registry } \\
\hline & $\mathrm{RCT}$ & Registry & $P \neq \neq \neq$ & ONR $(n=13)$ & $\operatorname{LNR}(n=54)$ & $P \neq \neq \neq$ \\
\hline & $\operatorname{OLLS}(n=11)$ & $\operatorname{LLLS}(n=13)$ & $\mathrm{P}+$ & ONR $(n=13)$ & $\operatorname{LNR}(n=54)$ & $\mathrm{P}+$ \\
\hline $\begin{array}{l}\text { Functional recovery } \\
\text { (days) }\end{array}$ & $3(3-5)$ & $3(3-3)$ & 0.284 & $3(3-3)$ & $3(3-4)$ & 0.529 \\
\hline $\begin{array}{l}\text { Adequate pain control } \\
\text { with oral analgesia } \\
\text { only }\end{array}$ & $3(2-3)$ & $3(2-3)$ & 0.539 & $3(3-4)$ & $2(2-3)$ & 0.017 \\
\hline $\begin{array}{l}\text { Independent mobility } \\
\text { or preoperative level }\end{array}$ & $3(3-4)$ & $3(2-3)$ & 0.071 & $3(3-4)$ & $3(2-3)$ & 0.240 \\
\hline No intravenous fluid & $2.5(2-3) \S$ & $2(1-3) \S$ & 0.273 & $2(1-4)$ & $2(1-2)$ & 0.308 \\
\hline Tolerance of solid food & $1(1-1)$ & $1(1-1)$ & 0.738 & $2(1-2)$ & $1(1-1)$ & 0.002 \\
\hline $\begin{array}{l}\text { Normal or decreasing } \\
\text { serum bilirubin level }\end{array}$ & $2.5(1-3)$ & $1(1-3)$ & 0.232 & $0(0-1)$ & $1(0-2)$ & 0.161 \\
\hline \multicolumn{7}{|l|}{$\begin{array}{l}\text { Post-operative } \\
\text { milestones (days) }\end{array}$} \\
\hline Free oral fluids & $0(0-1)$ & $0(0-0)$ & 0.563 & $1(0-1)$ & $1(0-1)$ & 0.202 \\
\hline $\begin{array}{l}\text { Removal of indwelling } \\
\text { urinary catheter }\end{array}$ & $3(2-3)$ & $2 \cdot 5(1-3)$ & 0.140 & $3(3-6)$ & $2(1-3)$ & 0.031 \\
\hline First flatus & $1(1-2)$ & $1(1-2)$ & 0.446 & $2(1-3)$ & $2(1-2)$ & 0.076 \\
\hline First stool & $3(2-4) \S$ & $2(2-3) \S$ & 0.307 & $3(3-4) \S$ & $2(2-3) \S$ & 0.138 \\
\hline LOS (days) & $4.5(4-6)$ & $4(3-5)$ & 0.049 & $5(4-7)$ & $4(3-5)$ & 0.064 \\
\hline $\begin{array}{l}\text { Difference (LOS - } \\
\text { functional recovery) } \\
\text { (days) }\end{array}$ & $1(0-3)$ & $1(1-2)$ & 0.832 & $2(1-3)$ & $1(0-2)$ & 0.042 \\
\hline Delay in discharge* & $8(73)$ & 9 (69) & $1.000 \neq$ & $11(85)$ & $23(43)$ & $0.090 \neq$ \\
\hline \multicolumn{7}{|l|}{$\begin{array}{l}\text { Reasons for delay in } \\
\text { discharge* }\end{array}$} \\
\hline Logistical & 2 of $10(20)$ & $5(38)$ & & $6(46)$ & $11(20)$ & \\
\hline Medical & 3 of $10(30)$ & $1(8)$ & & $2(15)$ & $5(9)$ & \\
\hline Patient preference & 2 of $10(20)$ & $2(15)$ & & $0(0)$ & $2(4)$ & \\
\hline Unknown & 1 of $10(10)$ & $1(8)$ & & $3(23)$ & $15(28)$ & \\
\hline
\end{tabular}

Values are median (i.q.r.) unless indicated otherwise; *values in parentheses are percentages. †One patient died in hospital and was never discharged. OLLS, open left lateral sectionectomy; LLLS, laparoscopic left lateral sectionectomy; ONR, open non-randomized left lateral sectionectomy; LNR, laparoscopic nonrandomized left lateral sectionectomy; LOS, length of hospital stay. ¥Mann-Whitney $U$ test, except §Fisher's exact test (both two-tailed). IVariable with normal distribution: Shapiro-Wilk P >0.050; MannWhitney $\mathrm{U}$ test results are shown, but $\mathrm{t}$ test leads to the same conclusion. alfa $=0.05$ for primary outcome, and $\mathrm{alf} a=0.01$ for all secondary outcomes to correct for multiple testing.

Overall morbidity was the same for open and laparoscopic procedures, with no significant differences between Clavien-Dindo complication severity grades [24] or the composite endpoint for liver surgery-related morbidity (Table 5). 
Table 5. Complications

\begin{tabular}{|c|c|c|c|c|c|c|}
\hline & \multicolumn{3}{|l|}{$\mathrm{RCT}$} & \multicolumn{3}{|l|}{ Registry } \\
\hline & OLLS $(n=11)$ & $\operatorname{LLLS}(n=13)$ & $P \neq$ & ONR $(n=13)$ & $\operatorname{LNR}(n=54)$ & $P \neq$ \\
\hline Overall morbidity & $4(36)$ & $1(8)$ & 0.141 & $2(15)$ & $7(13)$ & 1.000 \\
\hline \multicolumn{7}{|l|}{ Clavien-Dindo grade } \\
\hline No morbidity & $7(64)$ & $12(92)$ & & $1(85)$ & $47(87)$ & \\
\hline I & $1(9)$ & $0(0)$ & & $0(0)$ & $0(0)$ & \\
\hline ॥ & $2(18)$ & $0(0)$ & & $1(8)$ & $5(9)$ & \\
\hline III & $0(0)$ & $1(8)$ & & $1(8)$ & $1(2)$ & \\
\hline IV & $0(0)$ & $0(0)$ & & $0(0)$ & $1(2)$ & \\
\hline V (30-day mortality) & $1(9)$ & $0(0)$ & & $0(0)$ & $0(0)$ & \\
\hline $\begin{array}{l}\text { Major morbidity ( } \geq \\
\text { grade III) }\end{array}$ & $1(9)$ & $1(8)$ & 1.000 & $1(8)$ & $2(4)$ & 0.482 \\
\hline Composite endpoint* & $1(9)$ & $0(0)$ & 0.458 & $1(8)$ & $2(4)$ & 0.482 \\
\hline $\begin{array}{l}\text { Readmission in }<30 \\
\text { days }\end{array}$ & $0(0)$ & $0(0)$ & & $0(0)$ & $1(2)$ & 1.000 \\
\hline \multicolumn{7}{|l|}{ Complications } \\
\hline Wound infection & $1(9)$ & $1(8)$ & & $0(0)$ & $1(2)$ & \\
\hline Pneumonia & $0(0)$ & $0(0)$ & & $0(0)$ & $2(4)$ & \\
\hline $\begin{array}{l}\text { Intra-abdominal } \\
\text { haemorrhage }\end{array}$ & $0(0)$ & $0(0)$ & & $1(8)$ & $0(0)$ & \\
\hline $\begin{array}{l}\text { Intra-abdominal } \\
\text { abscess }\end{array}$ & $0(0)$ & $0(0)$ & & $0(0)$ & $1(2)$ & \\
\hline $\begin{array}{l}\text { Postresectional liver } \\
\text { failure }\end{array}$ & $0(0)$ & $0(0)$ & & $0(0)$ & $1(2)$ & \\
\hline Pulmonary embolism & $1(9)$ & $0(0)$ & & $0(0)$ & $0(0)$ & \\
\hline Cardiac arrest & $1(9)$ & $0(0)$ & & $0(0)$ & $0(0)$ & \\
\hline Othert & $2(18)$ & $0(0)$ & & $2(15)$ & $3(6)$ & \\
\hline
\end{tabular}

Values in parentheses are percentages. OLLS, open left lateral sectionectomy; LLLS, laparoscopic left lateral sectionectomy; ONR, open non-randomized left lateral sectionectomy; LNR, laparoscopic non-randomized left lateral sectionectomy. *Ascites, postresectional liver failure, bile leakage, intra-abdominal haemorrhage, intra-abdominal abscess and operative mortality. +Persistent pain (2), hypertension (2), infected epidural insertion site (1), urinary tract infection (1), dyspnoea of unknown origin (1). ¥Fisher's exact test (two-tailed). alfa=0.01 for all secondary outcomes to correct for multiple testing.

A total of five patients developed major morbidity (grade III or above). One patient in the open arm of the RCT died after developing a pulmonary embolism and cardiac arrest. One randomized patient developed a wound infection after LLLS, which was re-explored under local anaesthesia. In the open arm of the registry, one patient required surgery after a post-operative intra-abdominal bleed with haemodynamic instability. In the laparoscopic arm of the registry, one patient was admitted to the ICU for postresectional liver failure, and one was readmitted and received percutaneous radiological drainage after developing an intra-abdominal abscess. 


\section{COMPLIANCE WITH THE ERAS PROTOCOL}

No group was fully compliant with all protocol items. The OLLS, LLLS, ONR and LNR groups were compliant (more than 80 per cent) with between 10 and 14 of the 22 ERAS elements (Table 6). Post-operative epidural analgesia was provided to 82, 69, 77 and 65 of patients in the OLLS, LLLS, ONR and LNR groups respectively. No data were available to score the elements ileus prevention (laxatives) and provision of oral analgesia on POD1.

\section{REGRESSION ANALYSES}

Repeating the outcome analyses with multiple linear regression to adjust for patient age, sex, ASA grade and centre effects essentially confirmed the results of the MannWhitney $U$ tests. However, analysis of residuals showed a clear outlier in both the open surgery arm of the RCT and the registry with respect to the outcome LOS. Therefore, all analyses, non-parametric as well as regression, were repeated. Without those outliers, the new results increased both $P$ values for LOS to greater than 0.100 . Finally, owing to the very small sample size, differences between surgeons within the same centre could not be evaluated.

\section{DISCUSSION}

This RCT comparing open and laparoscopic LLS in an ERAS setting was not able to reach a meaningful conclusion on time to functional recovery because it had to be stopped prematurely owing to poor recruitment. No difference in time to functional recovery was found after LLLS compared with the OLLS in the randomized trial, but this analysis is underpowered. A prospective registry of all patients not randomized due to surgeon or patient preference also failed to show a difference in functional recovery. Considering the secondary endpoints, no differences between surgical procedures were observed with regard to blood loss, duration of surgery, LOS, morbidity, reoperation, readmissions and mortality rates.

The main contributor to poor recruitment was individual surgeons' preference for the laparoscopic procedure. This lead to a preference : randomization ratio of almost 3 : 1. Clinical equipoise was assumed at the time of design and start of this study. Based on a worldwide survey among HPB surgeons, an RCT and prospective register comparing open and laparoscopic techniques was considered necessary.[27] The majority of participating centres in the study had indicated that they considered a trial to be feasible and were willing to randomize patients. It was on this basis that it was deemed not necessary to perform a feasibility study. It is clear, however, that 
clinical equipoise was no longer present during the recruitment period. A recent expert statement from the International Consensus Conference for Laparoscopic Liver Resection held at Morioka, Japan, in 2014 stated that minor laparoscopic liver resection, including LLS, has become standard practice [28], and this evolving change in surgical attitudes is likely to have influenced the present study.

Table 6. Overall compliance to elements of the enhanced recovery after surgery protocol per study group

\begin{tabular}{|c|c|c|c|c|}
\hline & \multicolumn{2}{|l|}{$\mathrm{RCT}$} & \multicolumn{2}{|l|}{ Registry } \\
\hline & OLLS $(n=11)$ & $\operatorname{LLLS}(n=13)$ & ONR $(n=13)$ & $\operatorname{LNR}(n=54)$ \\
\hline \multicolumn{5}{|l|}{ Preoperative } \\
\hline Counselling & $100(100-100)$ & $100(100-100)$ & $100(100-100)$ & $100(100-100)$ \\
\hline Minimal preoperative fasting & $100(100-100)$ & $100(100-100)$ & $100(100-100)$ & $100(100-100)$ \\
\hline No anxiolytic premedication & $82(0-100)$ & $77(0-100)$ & $85(0-100)$ & $78(33-100)$ \\
\hline \multicolumn{5}{|l|}{ Perioperative } \\
\hline Thoracic epidural analgesia/i.v. PCA & $100(100-100)$ & $100(100-100)$ & $100(100-100)$ & $100(100-100)$ \\
\hline Prevention of hypothermia & $100(100-100)$ & $100(100-100)$ & $100(100-100)$ & $100(100-100)$ \\
\hline CVP monitoring $(<5 \mathrm{mmHg})$ & $36(0-50)$ & $31(0-100)$ & $62(0-100)$ & $91(20-95)$ \\
\hline No drainage of peritoneal cavity & $100(100-100)$ & $92(0-100)$ & $62(57-100)$ & $59(33-100)$ \\
\hline No standard nasogastric drainage & $91(86-100)$ & $100(100-100)$ & $85(0-100)$ & $78(88-100)$ \\
\hline Commence intake of water/free fluids & $64(0-86)$ & $85(50-100)$ & $13(0-100)$ & $98(19-100)$ \\
\hline Early mobilization & $27(0-100)$ & $77(50-100)$ & $31(0-100)$ & $87(52-100)$ \\
\hline PONV prophylaxis & $55(0-100)$ & $77(0-100)$ & $54(17-100)$ & $63(17-100)$ \\
\hline Antithrombotic prophylaxis & $100(100-100)$ & $100(100-100)$ & $100(100-100)$ & $100(100-100)$ \\
\hline Antibiotic prophylaxis & $100(100-100)$ & $100(100-100)$ & $100(100-100)$ & $100(100-100)$ \\
\hline \multicolumn{5}{|l|}{ POD 1-3 } \\
\hline Daily review of discharge criteria & $100(100-100)$ & $100(100-100)$ & $100(100-100)$ & $100(100-100)$ \\
\hline Ileus prevention (laxatives) & - & - & - & - \\
\hline Free fluids/normal diet on POD 1 & $100(100-100)$ & $100(100-100)$ & $92(50-100)$ & $98(95-100)$ \\
\hline $\begin{array}{l}\text { Intravenous fluids discontinued on } \\
\text { POD } 1\end{array}$ & $9(0-14)$ & $31(0-50)$ & $23(0-50)$ & $28(17-67)$ \\
\hline Oral analgesia on POD 1 & - & - & - & - \\
\hline Normal diet on POD 2 & $100(100-100)$ & $100(100-100)$ & $77(0-100)$ & $93(50-100)$ \\
\hline Removal of urinary catheter on POD 3 & $27(0-43)$ & $46(0-100)$ & $8(0-50)$ & $37(0-100)$ \\
\hline Stop epidural/i.v. PCA on POD 3 & $73(50-100)$ & $100(100-100)$ & $54(0-100)$ & $76(50-100)$ \\
\hline Full mobilization on POD 3 & $55(0-100)$ & $92(50-100)$ & $77(0-100)$ & $78(50-100)$ \\
\hline
\end{tabular}

Values are percentages with between-centre ranges in parentheses. OLLS, open left lateral sectionectomy; LLLS, laparoscopic left lateral sectionectomy; ONR, open non-randomized left lateral sectionectomy; LNR, laparoscopic non-randomized left lateral sectionectomy. i.v., Intravenous; PCA, patient-controlled analgesia; CVP, central venous pressure; PONV, post-operative nausea and vomiting; POD, post-operative day. 
The slow accrual might also be related to the lower incidence of LLS than an anticipated 10 per cent of the total volume of liver resections. Replacement of LLS by parenchyma-saving strategies using metastasectomy or local ablation procedures may also have been a contributing factor to slow recruitment.

Despite these limitations, the study has several strengths. No RCT has compared open and laparoscopic liver surgery. Other studies comparing open and laparoscopic LLS $[4,5,29-31]$ were of relatively small size and retrospective in nature. The addition of a prospective registry of patients who were not randomized owing to surgeon or patient preference was of value, reflecting daily practice in many units performing liver surgery.[18,19]

In the present series of 67 LLLS and 24 OLLS procedures undertaken in conjunction with an ERAS programme, patients were functionally recovered after 3 days. Although median LOS tended to be slightly shorter in the laparoscopic groups, this difference was not significant, and the study was not powered to detect a difference in LOS. The clinical relevance of a difference of less than 1 day can be questioned. A delay to discharge after functional recovery was observed in all groups, and there is clearly the opportunity for a further reduction in LOS if discharge logistics could be optimized.[14,16] Minimization of this gap between recovery and discharge could reduce hospital costs.

Lessons learned from this trial could prove valuable for the design and execution of future surgical trials. Surgical RCTs are often difficult to undertake successfully and pose particular practical and methodological challenges.[32] Blinding is frequently difficult to perform, and care must be taken to choose an objectively measurable outcome.[33] The present study, however, confirmed the practicality of blinding patients through the use of large abdominal dressings.[34,35] Double-blinding could not be guaranteed as ward physicians read operation details accidentally. A proctoring surgeon assisted surgeons in their learning curve to ensure quality. Regression analyses in this study revealed no influence of individual surgeons on the primary outcome, supporting the view that this approach may overcome the surgical learning curve as a confounder.[32] The timing of the conduct of a surgical trial is also important.[32] When a new technique is introduced, there is a window of opportunity to conduct a trial. Once surgeons believe the new intervention is superior, randomization becomes difficult. This surgeon preference was the major cause of failure to recruit to this RCT. It is important that investigators ensure the presence of clinical equipoise. To assess this adequately, a feasibility study seems generally advisable to generate objective evidence that the main trial will not fail, at least due to a perceived lack of equipoise. 


\section{CONTRIBUTORS}

The following are members of the ORANGE II Collaborative Group: T. Terkivatan (Erasmus Medical Centre, Rotterdam, The Netherlands), C. Verhoef (Erasmus Medical Centre, Rotterdam, The Netherlands), R. J. Porte (University Medical Centre Groningen, Groningen, The Netherlands), J. W. Haverman (University Medical Centre Groningen, Groningen, The Netherlands), O. R. Busch (Academic Medical Centre, Amsterdam, The Netherlands), M. A. Boermeester (Academic Medical Centre, Amsterdam, The Netherlands), M. G. Besselink (Academic Medical Centre, Amsterdam, The Netherlands), I. Q. Molenaar (University Medical Centre Utrecht, Utrecht, The Netherlands), I. H. M. Borel Rinkes (University Medical Centre Utrecht, Utrecht, The Netherlands), K. Bosscha (Jeroen Bosch Hospital, Den Bosch, The Netherlands), J. R. van der Vorst (Leiden University Medical Centre, Leiden, The Netherlands), J. W. D. de Waard (Westfriesgasthuis, Hoorn, The Netherlands), M. F. Gerhards (Onze Lieve Vrouw Gasthuis, Amsterdam, The Netherlands), G. A. Patijn (Isala, Zwolle, The Netherlands), M. Schmeding (University Hospital Aachen, Aachen, Germany; European HPB Centre Aachen-Maastricht), J. N. Primrose (University Hospital Southampton, Southampton, UK), M. Abu Hilal (University Hospital Southampton, Southampton, UK), I. Dagher (Hôpitaux Universitaires Paris Sud, Paris, France), A. Laurent (Hôpital Henri-Mondor, Paris, France), B. Topal (University Hospital Leuven, Leuven, Belgium), B. Edwin (Oslo University Hospital, Oslo, Norway), K. Lassen (Oslo University Hospital, Oslo, Norway) E. B. van Duyn (Medisch Spectrum Twente, Enschede, The Netherlands), A. W. Ambergen (Department of Methodology and Statistics, Maastricht University Medical Centre,Maastricht, The Netherlands) S. W. Olde Damink (Maastricht University Medical Centre, Maastricht, The Netherlands; European HPB Centre Aachen-Maastricht), M. H. Bemelmans (Maastricht University Medical Centre, Maastricht, The Netherlands; European HPB Centre Aachen-Maastricht).

\section{ACKNOWLEDGEMENTS AND FUNDING}

The authors acknowledge the HPB surgical departments of Maastricht University Medical Centre and University Hospital Aachen, and the Dutch Liver Surgery Group for their support. They also express their gratitude to J. N. Primrose for his continuing involvement in and constructive feedback to the ORANGE II study. The authors thank all patients for their participation, and local clinical personnel and research staff involved in recruitment and data collection. In addition, they thank DSMB members ( $M$. A. Boermeester, I. H. M. Borel Rinkes and A.W. Ambergen) for their time, expert input and advice. 
The ORANGE II trial was funded predominantly by the Profiling Fund of Maastricht University Medical Centre, Maastricht, The Netherlands (number PF 298). The trial was also funded by the participating centres of the ORANGE II study group and supported by an unrestricted grant from Medtronic, Dublin, Ireland. Medtronic and other funders had no influence on the design of the trial, no access to trial data, and no influence on the communication of trial results. 


\section{REFERENCES}

1. Buell JF, Cherqui D, Geller DA, O'Rourke N, lannitti D, Dagher I et al. The international position on laparoscopic liver surgery: the Louisville Statement, 2008. Ann Surg 2009; 250: 825-830.

2. Nguyen KT, Gamblin TC, Geller DA.World review of laparoscopic liver resection - 2804 patients. Ann Surg 2009; 250: 831-841.

3. Reddy SK, Tsung A, Geller DA. Laparoscopic liver resection. World J Surg 2011; 35: 1478-1486.

4. Abu Hilal M, McPhail MJ, Zeidan B, Zeidan S, Hallam MJ, Armstrong T et al. Laparoscopic versus open left lateral hepatic sectionectomy: a comparative study. Eur J Surg Oncol 2008; 34: 1285-1288.

5. Aldrighetti L, Pulitanò C, Catena M, Arru M, Guzzetti E, Casati M et al. A prospective evaluation of laparoscopic versus open left lateral hepatic sectionectomy. J Gastrointest Surg 2008; 12: 457-462.

6. Rao A, Rao G, Ahmed I. Laparoscopic left lateral liver resection should be a standard operation. Surg Endosc 2011; 25: 1603- 1610.

7. Hendry PO, van Dam RM, Bukkems SF, MzKeown DW, Parks RW, Preston T et al. Randomized clinical trial of laxatives and oral nutritional supplements within an enhanced recovery after surgery protocol following liver resection. Br J Surg 2010; 97: 1 98- 1206.

8. Lin DX, Li X, Ye QW, Lin F, Li LL, Zhang QY. Implementation of a fast-track clinical pathway decreases postoperative length of stay and hospital charges for liver resection. Cell Biochem Biophys 2011; 61: 413-419.

9. MacKay G, O’Dwyer PJ. Early discharge following liver resection for colorectal metastases. Scott Med J 2008; 53: 22-24.

10. van Dam RM, Hendry PO, Coolsen MM, Bemelmans MH, Lassen K, Revhaug A et al. Initial experience with a multimodal enhanced recovery programme in patients undergoing liver resection. Br J Surg 2008; 95: 969-975.

11. Coolsen MM,Wong-Lun-Hing EM, van Dam RM, van der Wilt AA, Slim K, Lassen K et al. A systematic review of outcomes in patients undergoing liver surgery in an enhanced recovery after surgery pathways. HPB (Oxford) 2013; 15: 245-251.

12. Schultz NA, Larsen PN, Klarskov B, Plum LM, Frederiksen HJ, Christensen BM et al. Evaluation of a fasttrack programme for patients undergoing liver resection. Br J Surg 2013; 100: 138-143.

13. Ni CY, Yang Y, Chang YQ, Cai H, Xu B, Yang F et al. Fast-track surgery improves postoperative recovery in patients undergoing partial hepatectomy for primary liver cancer: a prospective randomized controlled trial. Eur J Surg Oncol 2013; 39: 542-547.

14. Stoot JH, van Dam RM, Busch OR, van Hillegersberg R, De Boer M, Olde Damink SW et al. The effect of a multimodal fast-track programme on outcomes in laparoscopic liver surgery: a multicentre pilot study. HPB (Oxford) 2009; 11: 140-144.

15. Jones $C$, Kelliher L, Dickinson M, Riga A,Worthington T, Scott MJ et al. Randomized clinical trial on enhanced recovery versus standard care following open liver resection. Br J Surg 2013; 100: 10151024.

16. Maessen J, Dejong CH, Hausel J, Nygren J, Lassen K, Andersen J et al. A protocol is not enough to implement an enhanced recovery programme for colorectal resection. Br J Surg 2007; 94: 224-231.

17. van Dam RM,Wong-Lun-Hing EM, van Breukelen GJ, Stoot JH, van der Vorst JR, Bemelmans MH et al. Open versus laparoscopic left lateral hepatic sectionectomy within an enhanced recovery ERAS ${ }^{\circledR}$ programme (ORANGE II-trial): study protocol for a randomised controlled trial. Trials 2012; 13: 54.

18. Brewin CR, Bradley C. Patient preferences and randomised clinical trials. BMJ 1989; 299: 313-315.

19. Gore SM. The consumer principle of randomisation. Lancet 1994; 343: 58.

20. Paice JA, Cohen FL. Validity of a verbally administered numeric rating scale to measure cancer pain intensity. Cancer Nurs 1997; 20: 88-93.

21. McGuire DB. Comprehensive and multidimensional assessment and measurement of pain. J Pain Symptom Manage 1992; 7: 312-319.

22. Krebs EE, Carey TS,Weinberger M. Accuracy of the pain numeric rating scale as a screening test in primary care. J Gen Intern Med 2007; 22: 1453-1458. 
23. Suurmeijer TP, Doeglas DM, Moum T, Briançon S, Krol B, Sanderman R et al. The Groningen Activity Restriction Scale for measuring disability: its utility in international comparisons. Am J Public Health 1994; 84: 1270-1273.

24. Dindo D, Demartines N, Clavien PA. Classification of surgical complications: a new proposal with evaluation in a cohort of 6336 patients and results of a survey. Ann Surg 2004; 240: 205-213.

25. van den Broek MA, van Dam RM, van Breukelen GJ, Bemelmans MH, Oussoultzoglou E, Pessaux P et al. Development of a composite endpoint for randomized controlled trials in liver surgery. Br J Surg 2011; 98: 138-1145.

26. Dana-Faber/Harvard Cancer Center. Accrual and Scientific Progress by the Scientific Review Committee (SOP no.: COM-102). http://www.dfhcc.harvard.edu/fileadmin/DFHCC_Admin/Clinical_Trials/CRO/ Policies_and_Procedures-SOPs/COM-102_Version_10.pdf?PHPSESSID=645544e7b583b68fe5338434cf b89bc5 [accessed 12 May 2014].

27. Wong-Lun-Hing EM, Lodewick TM, Stoot JH, Bemelmans MH, Olde Damink SW, Dejong $\mathrm{CH}$ et al. A survey in the hepatopancreatobiliary community on ways toenhance patient recovery. HPB (Oxford) 2012; 14: 818-827.

28. Wakabayashi G, Cherqui D, Geller DA, Buell JF, Kaneko H, Han HS et al. Recommendations for laparoscopic liver resection: a report from the second international consensus conference held in Morioka. Ann Surg 2015; 261: 619-629.

29. Carswell KA, Sagias FG, Murgatroyd B, Rela M, Heaton N, Patel AG. Laparoscopic versus open left lateral segmentectomy. BMC Surg 2009; 9: 14.

30. Endo Y, Ohta M, Sasaki A, Kai S, Eguchi H, Iwaki K et al. A comparative study of the long-term outcomes after laparoscopy-assisted and open left lateral hepatectomy for hepatocellular carcinoma. Surgical Laparosc Endosc Percutan Tech 2009; 19: e171-e174.

31. Tang CN, Tai CK, Ha JP, Siu WT, Tsui KK, Li MK. Laparoscopy versus open left lateral segmentectomy for recurrent pyogenic cholangitis. Surg Endosc 2005; 19: 1232-1236.

32. Cook JA. The challenges faced in the design, conduct and analysis of surgical randomised controlled trials. Trials 2009; 10: 9.

33. Lilford R, Braunholtz D, Harris J, Gill T. Trials in surgery. Br J Surg 2004; 91: 6-16.

34. Katkhouda N, Mason RJ, Towfigh S, Gevorgyan A, Essani R. Laparoscopic versus open appendectomy: a prospective randomized double-blind study. Ann Surg 2005; 242:439-448.

35. Seiler CM, Deckert A, Diener MK, Knaebel HP,Weigand MA, Victor $\mathrm{N}$ et al. Midline versus transverse incision in major abdominal surgery: a randomized, double-blind equivalence trial (POVATI: ISRCTN60734227). Ann Surg 2009; 249: 913-920. 

This chapter is embargoed until 19-05-2018

\section{Chapter}

Open versus Iaparoscopic hemihepatectomy withinan ERAS programme (ORANGE II PJUS-Drial): study protocol for a randomized controlled trial

Fichtinger $\mathrm{R}^{*}$, Wong-Lun-Hing EM*, Aldrighetti L, Troisi R, Sutcliffe R, Abu Hilal M, Besselink M, Aroori S, Fretland Å, Menon K, d'Hondt M, Neumann UP, Lucidi V, White S, Sergeant G, Fusai G, van Breukelen GJP, Primrose JN and van Dam RM on behalf of the ORANGE II PLUS Study Group.

* BOTH have contributed equally to this manuscript and share first authorship. 


\section{Chapter 1}

Summary, discussion and future perspectives 


\section{SUMMARY AND DISCUSSION}

Liver resection gives patients with colorectal liver metastases the only change of cure. Also for primary malignancies and benign lesions liver resection is a widely accepted treatment. To offer patients the best chance of successful recovery after liver surgery, surgeons not only have to choose the best surgical procedure, but they must also aim for optimal pre-, intra- and post-operative conditions. The laparoscopic technique has been added to the liver surgeon's armamentarium and may be better than the standard technique of open liver resection. An Enhanced Recovery After Surgery (ERAS) programme can standardize and optimize perioperative elements during the patient's admission and support the patient towards a full and accelerated recovery. Perhaps the combination of both laparoscopic liver surgery and an ERAS programme could result in the best outcomes for the patient. Since minimal incisions are a key element of ERAS, minimal invasive surgery may be a key element itself.

This thesis focuses on the current role, dissemination and worldwide adoption of an ERAS programme in liver surgery, the investigation and evaluation of the potential role of specific (new) elements in an ERAS protocol (Part I), the implementation status of (laparoscopic) liver surgery from a Dutch and international perspective, and comparison of open and laparoscopic liver surgery in a randomised controlled setting (Part II).

\section{PART I: OPTIMIZED RECOVERY AFTER HEPATIC SURGERY}

Chapter 1 presents an overview of the elements of the Enhanced Recovery After Surgery (ERAS) programme for liver surgery. For each element the quality of evidence is discussed with a recommendation (Table 1).

Chapter 2 describes the results of an international survey on ways to enhance patient recovery after liver surgery. The survey was sent to hepatopancreatobiliary centres worldwide and questioned liver surgeons on their experience with enhanced recovery programmes and laparoscopic liver surgery. Both strategies are associated with faster recovery and may work synergistically. Results showed that a large majority of HPB centres had experience with laparoscopic liver surgery. The liberal adoption of laparoscopic liver surgery, even in low-volume HPB centres, seemed in conflict with standards of evidence-based practice in the medical community. On the other hand, the dissemination of enhanced recovery programmes in liver surgery was still limited in 2010, although there was substantial support for implementation. Also, liver surgeons considered a randomized controlled trial or a prospective register necessary to compare the outcomes of open and laparoscopic techniques. In the 
Netherlands the first laparoscopic liver resections were documented in 1990s, while the first laparoscopic liver resection within an ERAS programme was performed in 2008. Gradually new initiatives have been designed to get prospective and controlled data on open versus laparoscopic liver surgery. Currently, the results of two randomized controlled trials (ORANGE 2 Plus - Trial and Oslo - CoMet Study) are awaited and recently a new consensus statement of international liver surgeons has been published.[2]

Table 1. ERAS liver programme recommendations

\begin{tabular}{|l|l|l|}
\hline Element & Evidence level & Recommendation grade \\
\hline Preoperative counselling & C & Strong \\
\hline Minimal preoperative fasting & B & Strong \\
\hline No pre-anaesthetic premedication & A & Weak \\
\hline Antithrombotic prophylaxis & A & Strong \\
\hline Antibiotic prophylaxis & A & Strong \\
\hline Balanced anaesthesia with short-acting agents & C & Strong \\
\hline Epidural anaesthesia / analgesia & B & Weak \\
\hline Balanced intraoperative fluid management & A & Strong \\
\hline Prevention of hypothermia & A & Strong \\
\hline PONV prophylaxis & C & Strong \\
\hline Incision of minimal length & C & Strong \\
\hline No routine drainage of the peritoneal cavity & B & Strong \\
\hline No nasogastric drainage & A & Strong \\
\hline Provision of oral analgesia & A & Strong \\
\hline Prevention of post-operative ileus & C & Weak \\
\hline Early removal of urinary catheter & D & Weak \\
\hline Early start oral intake & A & Strong \\
\hline Early mobilisation & C & Strong \\
\hline
\end{tabular}

Quality of evidence and recommendations were evaluated according to the GRADE guideline]: $A=H i g h, B$ = Moderate, $\mathrm{C}=$ Low, $\mathrm{D}=$ Very low.

To assess the outcomes of ERAS protocols applied in liver surgery and published until October 2011, a systematic review of the literature was performed in Chapter 3. In total six studies could be included in the analysis. It demonstrated that implementation of an ERAS programme did not affect morbidity, mortality or re-admission rates. Analysis also suggested a reduction in length of stay in favour of patients managed within an ERAS setting. It must be mentioned that the reporting of adherence to the various elements of the protocol was rather low in the included studies, and that this hampered a good comparisons of the studies. Two studies in the systematic review assessed the time to functional recovery, which was significantly lower than total length of stay and can be considered as a more objective outcome. The use of time to functional recovery as a primary outcome measure in future studies was advised in 
order to enhance quality and comparability. Also, at the time of this systematic review there were no RCTs available comparing fast-track with standard care. A recent systematic review with inclusion of two RCT's comparing ERAS with conventional care supported the findings of a reduced length of stay and showed even a reduction in medical morbidity.[3]

In Chapter 4, European HPB centres were evaluated to assess whether current perioperative practice in hepatic surgery was actually based on ERAS principles. The study was started with the assumption that many centres had already adopted ERAS elements in liver surgery after implementation of fast-track protocols for patients undergoing colonic resection or as part of evidenced-based treatment for patients. The study demonstrated a substantial variation of perioperative care among centres that perform liver resections. Some elements of the ERAS program, e.g., preoperative counseling and minimal preoperative fasting, had already been generally adopted. However, other elements in the perioperative phase, such as avoidance of drains and nasogastric tube, and post-operative phase, e.g. early resumption of oral intake, early mobilization, and use of recovery criteria, could be further optimized. In line with previously reported data, a delay was found between discharge and time to functional recovery (FR).[4, 5] A limitation of the assessment is mainly the retrospective design. However, this design was deliberately chosen so as to not influence the behavior of medical and nursing staff in perioperative care during a full prospective assessment.

An important aspect after liver surgery is safe and effective pain control. Not only will it reduce numerous post-operative complications, it can also facilitate early mobilization and may result in earlier recovery. Pain relief may be a powerful technique to modify surgical stress responses, and it may thereby reduce incidence of postoperative organ dysfunction and improve outcome. Adequate analgesia may also reduce pulmonary complications and post-operative paralytic ileus.[6] Traditionally, post-operative pain is managed with intravenous patient-controlled analgesia (PCA) or with continuous indwelling epidural catheters. In Chapter $\mathbf{5}$ we examine the value of intramuscular continuous infusion of bupivacaine (CIB) via a wound catheter combined with intravenous PCA, compared with epidural analgesia after major hepatic surgery. A risk after major liver surgery is the development of post-operative coagulopathy. The use of epidural analgesia may therefore be contraindicated. The combination of CIB + PCA in this study provided pain control equivalent to that of continuous epidural analgesia. No significant differences in the numbers of patients experiencing severe pain were observed between the two groups. Importantly, patients in the CIB + PCA group consumed lower total volumes of opioids, had lower post-operative morbidity and a decreased length of stay. The partly retrospective design and an inherent bias of surgeon preference may have influenced results. On 
the other hand, the investigation of a large and uninterrupted cohort of patients submitted to major hepatectomy, and thus at risk for post-operative coagulopathy and the development of epidural hematoma, receiving this type of analgesia has not been previously reported. Continuous infusion of bupivacaine combined with PCA can replace epidural analgesia and can avoid the occurrence of rare complications of epidural analgesia.

The use of abdominal drains is another element in liver surgery still subject of debate. The ERAS programme advocates abandoning standard prophylactic abdominal drainage after partial hepatectomy. Routine drainage may be unnecessary, possibly harmful and uncomfortable for patients. In Chapter 6 we describe the 10-year experience of tertiary referral centre with a no-drain policy in an ERAS environment with 90-day resection-surface-related (RSR) morbidity and RSR-reinterventions as primary endpoints. An overall 20\% surgical morbidity, 15\% RSR-complication, and 12\% RSRreintervention rate was observed in 538 patients. The majority of RSR-complications could be managed with radiologic drainage and reoperations were only rarely necessary. Major liver resection was identified as an independent risk factor for RSRsignificant morbidity and RSR-reinterventions. These results are in line with results published by other HBP-centres[7-12] and confirm the safety and feasibility of a nodrain policy after partial hepatectomy in an ERAS-based care programme.

\section{PART II: LAPAROSCOPIC LIVER SURGERY}

In Chapter 7 we present a historical overview on the introduction of laparoscopic liver surgery in the Netherlands. In 1990s the first laparoscopic hepatectomies were performed, but only limited experience was gained in the decade thereafter. Compared to other pioneering countries the Netherlands seemed slow with the implementation of the minimally invasive technique. The initial experience with laparoscopic liver resections was further evaluated with a case-control comparison of patients undergoing open and laparoscopic left lateral sectionectomy (LLS) during 2000-2008. A significant difference in length of hospital stay, blood loss and operation time could be demonstrated in favour of the laparoscopically operated patients without compromising morbidity. Finally, the implementation status of laparoscopic liver surgery during 2010 was examined with a nationwide survey. The 30 out of 37 responding centres performed 966 hepatic resections of which only 49 were laparoscopic resections (5\%).

To prospectively evaluate the merits of laparoscopic liver surgery a randomized controlled trial was designed. Chapter $\mathbf{8}$ shows the protocol for an international multicentre randomized controlled study comparing open versus laparoscopic left lateral 
sectionectomy (LLS) within an ERAS programme: ORANGE II - Trial. This investigated the added value of laparoscopy in minor hepatectomy. A prospective registry of all patients that were not randomised because of surgeon or patients preference was added to the design of the trial to allow acquisition of an uninterrupted prospective series of patients. Primary endpoint of the trial was time to functional recovery (composite endpoint defined by five criteria). It was hypothesized that time to functional recovery could be reduced by two days in patients undergoing laparoscopic LLS compared to open LLS.

In Chapter 9 we present the results of the ORANGE II - Trial. From January 2010 to July 2014 a total of 91 patients (24 randomised and 67 prospective registry) were prospectively studied. Although the results showed no reduced time to functional recovery in favour of the laparoscopic group, this first RCT comparing open and laparoscopic LLS in an ERAS setting was not able to definitively conclude on the primary endpoint: time to functional recovery. It had to be stopped prematurely due to slow accrual in the RCT. The main reason for the slow accrual was a clear surgeon's preference for the laparoscopic procedure. Also, this study showed that laparoscopic LLS could be performed with low morbidity, reoperation, readmission and mortality rates. To date there has not been an RCT in liver surgery comparing open and laparoscopic liver surgery and this multicentre attempt to provide strong evidence on open versus laparoscopic LLS is not likely to be repeated. The prospective registry of patients that could not be randomised increases the external validity of this study. Long-term follow up results of this study are awaited.

Finally, in Chapter 10 we present a protocol for an international randomised controlled trial comparing open versus laparoscopic hemihepatectomy (i.e. major hepatectomy) within an ERAS programme. This study was designed to provide the HPB surgical community with level A evidence on the value of laparoscopic hemihepatectomy. The open procedure to resect the left or right hemiliver is already an accepted treatment for the resection of liver tumours (mostly colorectal liver metastases). There is still debate on the value of laparoscopic technique in major liver resections. It was demonstrated that in expert hands major anatomical laparoscopic liver resections were feasible with good efficacy and safety. However, the results are based on case-series and no prospective controlled evidence is available on short-term, oncologic and patient reported outcomes. The ORANGE II PLUS - trial is now running in several international expert centres and will provide evidence on the primary endpoint: time to functional recovery. Other endpoints to be studied are hospital length of stay, morbidity, mortality, operative parameters (intraoperative blood loss, operation time), patients-reported outcomes (quality of life, body image), oncologic outcomes (time to adjuvant chemotherapy initiation, resection margin, overall five-year survival) and costs. 
In summary, this thesis outlines that in modern liver surgery several elements of the proposed ERAS programme have already been implemented. Full use of a fast-track liver protocol is advisable to optimize and accelerate patient recovery. Good adherence to all elements of such a protocol is essential. In addition, new evidence on (liver-surgery) specific perioperative care elements needs to be appreciated and adopted into protocols if feasible. In the Netherlands laparoscopic liver surgery was only minimally implemented compared with other countries until 2010 . A controlled comparison of open versus laparoscopic left lateral sectionectomy was unable to definitively concluded on the primary endpoint, time to functional recovery, as the study was stopped prematurely due to slow accrual in the RCT and a clear surgeon preference for laparoscopy. Furthermore, laparoscopic liver surgery has gained popularity among Dutch liver surgeons, and minor laparoscopic liver surgery is now considered standard of care in line with international consensus.[2] Long-term follow-up and ongoing randomized controlled trials will provide more definitive evidence on the merits of major laparoscopic liver surgery, oncologic outcome and patient-reported outcomes.

\section{FUTURE PERSPECTIVES}

\section{OPTIMIZED RECOVERY AFTER SURGERY}

Abundant evidence has been presented that ERAS protocols are safe and effective. [3] Surprisingly, an ERAS protocol for liver surgery has not yet been formally established and published. The ERAS society is a leading international body and it has published several evidence-based protocols to support surgeons and other professionals. To ensure standardization of care and to provide patients with optimal perioperative care, it is desirable that a consensus guideline for enhanced recovery after liver surgery is developed by experts. A recent review[3], including recent prospective (randomized controlled) studies[14-16], again confirms improvement of length of stay and post-operative morbidity. Not only is it important for an ERAS liver protocol to be published and embraced by international liver surgeons, it is also key to periodically and systematically re-evaluate elements of the protocol to ensure the protocol is up-to-date and supported by recent literature. New evidence should be evaluated and, if necessary, elements of the protocol should be revised or newly added. The ERAS society should adopt a leading role in this process, thereby propagating standardization and an evidenced-based approach of patient care.

In the introduction current elements of the ERAS protocol in liver surgery have been described and assessed based on the available evidence. Examples of new elements that could be evaluated for adoption in previously described ERAS liver protocols[5, 
$14,15,17]$ are the use of a pulmonary recruitment manoeuvre (manual inflations of the lung with the patient in Trendelenburg position) to reduce post-operative pain after liver surgery[18], stimulation of gut function with gum chewing[19], other methods of post-operative analgesia with fewer side-effects (transversus abdominis plane block[20], wound catheters[21-23]), and medication attenuating the stress response[24]. Most post-operative elements are introduced to the patient upon return on the ward. However, some patients stay up to 24 hours in the recovery room. Besides provision of good pain control, it may be possible to implement other elements already in the recovery room. ERAS elements that may be introduced there are early intake, providing chewing gum and early mobilization. Some individual elements in fast-track programmes, such as advancement of oral intake, early mobilization and laparoscopic surgery, have been associated with early recovery after colon cancer surgery[25]. However, if all elements are successfully achieved, it is more likely that not one single element in the multimodal ERAS programmes will result in the much desired accelerated recovery of patients, but the implementation of a programme as a whole. As shown in colorectal surgery, there may also be a synergetic effect of ERAS combined with laparoscopy.[26]

Once a protocol has been implemented it is important to maintain a good adherence to the protocol to ensure consistent benefit for the patient.[27] This adherence, however, is the main problem in optimization of recovery. During the initial phase of implementation all involved personnel are keen and alert to adhere to all elements. After the initial implementation adherence to the protocol guidelines should be maintained by post-implementation strategies, such as periodic evaluation and education.[28] It has already been proven in colonic surgery, that a structured implementation strategy can result a good sustainability.[29]

\section{LAPAROSCOPIC LIVER SURGERY}

The minimally invasive approach for liver surgery is here to stay. The last few years it several studies have shown that, besides minor laparoscopic liver surgery, also major laparoscopic liver surgery is associated with similar or improved short-term outcome compared with open major hepatectomy.[30] In expert hands intraoperative blood loss, complications, and conversions rate are more than acceptable for laparoscopic left hemihepatectomy.[31] A recent meta- analysis comparing case-matched laparoscopic liver resections to open liver resections ( $N=2900$ cases) demonstrated no increased mortality and significantly less complications, transfusions, blood loss, and hospital stay in favor of laparoscopic liver resection.[32] In the recent Morioka consensus minor laparoscopic liver resection was confirmed to be standard practice. A still increasing number of surgeons are adopting the laparoscopic technique. With regards to major laparoscopic liver resection experts judged that the introduction is 
still in an exploration phase, and cautious diffusion is still warranted.[2] The international experts joining the consensus further advised participation and encouraged participation in already open prospective trials and registries. Currently on-going trials are therefore supported by the experts in the field of (laparoscopic) liver surgery. In the near future more evidence on the value of laparoscopic hepatectomy will be provided by the results of the ORANGE 2 Plus - Trial (Chapter 10) and the OsloCoMet study[33]. The ORANGE 2 Plus - Trial compares open versus laparoscopic hemihepatectomy within an ERAS programme and the Oslo-CoMet study compares laparoscopic versus open liver resection for colorectal metastases. Both studies will give liver surgeons more solid evidence regarding laparoscopic major liver surgery, oncologic outcome, long-term follow-up, costs and patient-reported outcomes.

During the conception of this thesis there has also been a shift in surgical strategy regarding the extent of hepatic resection. Besides the discussion on the technique (laparoscopic versus open), there is also an increasing interest in parenchymal saving strategies.[34, 35] A two-stage approach or formal liver resection may be less frequently required with the advancements of intraoperative imaging and operating techniques.[36] Occurrence of post-operative liver failure is to be prevented, but oncologic margins should be respected.[37, 38] A parenchyma-sparing strategy and accurate preoperative prediction of the function of the future remnant liver are the future for a tailored approach for each patient.

Improved levels of evidence, standardized reporting of outcomes, and assuring proper training are the next challenges of laparoscopic liver surgery.[32] Not only can RCT's or other prospective studies add to the continuing development of laparoscopic liver surgery, also the critical appraisal of hepatectomies performed in the past can improve quality. Auditing by national or international associations will give liver surgeons insight into the quality of their own operations, but also into the performance of other colleagues. (International) benchmarks may be defined for outcome parameter, such as mortality, morbidity and R0-resection margins. Ultimately, this continuing evaluation could result in centralization of (laparoscopic) liver surgery, as large volume centres may perform better than centres performing only a limited number of (laparoscopic) resections per year. A good example of a well functioning auditing system is the Dutch Institute for Clinical Auditing (DICA). On 1st July 2013 the Dutch Hepatobiliary Audit (DHBA) was started, which resulted in the publication of the first annual report. Future reports will provide insight in the actual quality of liver surgery in the Netherlands.

The ultimate goal for a surgeon would be to have a tailored approach for each candidate for liver surgery. This is a future in which the surgeon is able to select patients fit enough to undergo surgery, in which he is able to predict individual operative 
risks and in which he is able to predict post-operative outcomes. The selection of patients in liver surgery is an important issue. Not only do surgeons have to determine resectability, it is also vital to assess the patient's ability to tolerate the operation and to predict whether removal of liver disease will improve long-term survival.[39] Recent developments aim on assessing and improving the patients' preoperative fitness before surgery. A 4-week prehabilitation programme can improve cardiopulmonary exercise testing and QoL before liver resection. Consequently, this may impact on perioperative outcome.[40] Further studies are necessary, but in the future a predefined cut-off value in patients undergoing hepatic resection may be used for predicting which patients will experience morbidity or are fit enough to undergo surgery.[41] A completely different approach to select patient for liver surgery and to predict outcome is the use of "big" data. Nowadays patient data is more and more readily available in digital patient files, electronic case record forms and prospective registries. These data could lead to large database that may be used for riskmodelling. 


\section{REFERENCES}

1. Guyatt, G.H., A.D. Oxman, R. Kunz, et al., Going from evidence to recommendations. BMJ, 2008. 336(7652): p. 1049-51.

2. Wakabayashi, G., D. Cherqui, D.A. Geller, et al., Recommendations for laparoscopic liver resection: a report from the second international consensus conference held in Morioka. Ann Surg, 2015. 261 (4): p. 619- 29.

3. Hughes, M.J., S. McNally, and S.J. Wigmore, Enhanced recovery following liver surgery: a systematic review and meta-analysis. HPB (Oxford), 2014. 16(8): p. 699-706.

4. Maessen, J., C.H. Dejong, J. Hausel, et al., A protocol is not enough to implement an enhanced recovery programme for colorectal resection. Br J Surg, 2007. 94(2): p. 224-31.

5. van Dam, R.M., P.O. Hendry, M.M. Coolsen, et al., Initial experience with a multimodal enhanced recovery programme in patients undergoing liver resection. Br J Surg, 2008. 95(8): p. 969-75.

6. Kehlet, H. and K. Holte, Effect of postoperative analgesia on surgical outcome. Br J Anaesth, 2001. 87(1): p. 62-72.

7. Fong, Y., M.F. Brennan, K. Brown, et al., Drainage is unnecessary after elective liver resection. Am J Surg, 1996. 171(1): p. 158- 62.

8. Fuster, J., J.M. Llovet, J.C. Garcia-Valdecasas, et al., Abdominal drainage after liver resection for hepatocellular carcinoma in cirrhotic patients: a randomized controlled study. Hepatogastroenterology, 2004. 51(56): p. 536-40.

9. Liu, C.L., S.T. Fan, C.M. Lo, et al., Abdominal drainage after hepatic resection is contraindicated in patients with chronic liver diseases. Ann Surg, 2004. 239(2): p. 194- 201.

10. Gurusamy, K.S., K. Samraj, and B.R. Davidson, Routine abdominal drainage for uncomplicated liver resection. Cochrane database of systematic reviews, 2007(3): p. CD006232.

11. 11. Imamura, H., Y. Seyama, N. Kokudo, et al., One thousand fifty-six hepatectomies without mortality in 8 years. Arch Surg, 2003. 138(11): p. 198-206; discussion 1206.

12. Jarnagin, W.R., M. Gonen, Y. Fong, et al., Improvement in perioperative outcome after hepatic resection: analysis of 1,803 consecutive cases over the past decade. Ann Surg, 2002. 236(4): p. 397-406; discussion 406-7.

13. Stoot, J.H., R.M. van Dam, O.R. Busch, et al., The effect of a multimodal fast-track programme on outcomes in laparoscopic liver surgery: a multicentre pilot study. HPB (Oxford), 2009. 11(2): p. 140-4.

14. Jones, C., L. Kelliher, M. Dickinson, et al., Randomized clinical trial on enhanced recovery versus standard care following open liver resection. Br J Surg, 2013. 100(8): p. 1015-24.

15. Ni, C.Y., Y. Yang, Y.Q. Chang, et al., Fasttrack surgery improves postoperative recovery in patients undergoing partial hepatectomy for primary liver cancer: A prospective randomized controlled trial. Eur J Surg Oncol, 2013. 39(6): p. 542-7.

16. Schultz, N.A., P.N. Larsen, B. Klarskov, et al., Evaluation of a fast-track programme for patients undergoing liver resection. Br J Surg, 2013. 100(1): p. 138-43.

17. Connor, S., A. Cross, M. Sakowska, et al., Effects of introducing an enhanced recovery after surgery programme for patients undergoing open hepatic resection. HPB (Oxford), 2013. 15(4): p. 294-301.

18. Pergialiotis, V., D.E. Vlachos, K. Kontzoglou, et al., Pulmonary recruitment maneuver to reduce pain after laparoscopy: a meta-analysis of randomized controlled trials. Surg Endosc, 2015. 29(8): p. 2101-8.

19. Ho, Y.M., S.R. Smith, P. Pockney, et al., A meta-analysis on the effect of sham feeding following colectomy: should gum chewing be included in enhanced recovery after surgery protocols? Dis Colon Rectum, 2014. 57(1): p. 15-26.

20. Johns, N., S. O'Neill, N.T. Ventham, et al., Clinical effectiveness of transversus abdominis plane (TAP) block in abdominal surgery: a systematic review and meta-analysis. Colorectal Dis, 2012. 14(10): p. e635-42.

21. Bertoglio, S., F. Fabiani, P.D. Negri, et al., The postoperative analgesic efficacy of preperitoneal continuous wound infusion compared to epidural continuous infusion with local anesthetics after colorectal cancer surgery: a randomized controlled multicenter study. Anesth Analg, 2012. 15(6): p. 1442-50. 
22. Raines, S., C. Hedlund, M. Franzon, et al., Ropivacaine for continuous wound infusion for postoperative pain management: a systematic review and meta-analysis of randomized controlled trials. Eur Surg Res, 2014. 53(1-4): p. 43-60.

23. Bell, R., S. Pandanaboyana, and K.R. Prasad, Epidural versus local anaesthetic infiltration via wound catheters in open liver resection: a meta-analysis. ANZ J Surg, 2015. 85(1-2): p. 16-21.

24. Srinivasa, S., A.A. Kahokehr, T.C. Yu, et al., Preoperative glucocorticoid use in major abdominal surgery: systematic review and meta-analysis of randomized trials. Ann Surg, 2011. 254(2): p. 183-91.

25. Vlug, M.S., S.A. Bartels, J. Wind, et al., Which fast track elements predict early recovery after colon cancer surgery? Colorectal Dis, 2012. 14(8): p. 1001-8.

26. Vlug, M.S., J. Wind, M.W. Hollmann, et al., Laparoscopy in combination with fast track multimodal management is the best peri-operative strategy in patients undergoing colonic surgery: a randomized clinical trial (LAFA-study). Ann Surg, 2011. 254(6): p.868-75.

27. Feroci, F., E. Lenzi, M. Baraghini, et al., Fasttrack colorectal surgery: protocol adherence influences postoperative outcomes. Int J Colorectal Dis, 2013. 28(1): p. 103-9.

28. Ament, S.M., F. Gillissen, A. Moser, et al., Identification of promising strategies to sustain improvements in hospital practice: a qualitative case study. BMC Health Serv Res, 2014. 14: p. 641.

29. Gillissen, F., S.M. Ament, J.M. Maessen, et al., Sustainability of an enhanced recovery after surgery program (ERAS) in colonic surgery. World J Surg, 2015. 39(2): p. 526-33.

30. Lin, N.C., H. Nitta, and G. Wakabayashi, Laparoscopic major hepatectomy: a systematic literature review and comparison of 3 techniques. Ann Surg, 2013. 257(2): p. 205-13.

31. Belli, G., B. Gayet, H.S. Han, et al., Laparoscopic left hemihepatectomy a consideration for acceptance as standard of care. Surg Endosc, 2013. 27(8): p. 2721-6.

32. Ciria, R., D. Cherqui, D.A. Geller, et al., Comparative Short-term Benefits of Laparoscopic Liver Resection: 9000 Cases and Climbing. Ann Surg, 2016. 263(4): p. 761-77.

33. Fretland, A.A., A.M. Kazaryan, B.A. Bjornbeth, et al., Open versus laparoscopic liver resection for colorectal liver metastases (the Oslo-CoMet Study): study protocol for a ranomized controlled trial. Trials, 2015. 16: p. 73.

34. Gold, J.S., C. Are, P. Kornprat, et al., Increased use of parenchymal-sparing surgery for bilateral liver metastases from colorectal cancer is associated with improved mortality without change in oncologic outcome: trends in treatment over time in 440 patients. Ann Surg, 2008. 247(1): p. 109-17.

35. Torzilli, G., F. Procopio, F. Botea, et al., One-stage ultrasonographically guided hepatectomy for multiple bilobar colorectal metastases: a feasible and effective alterna tive to the 2-stage approach. Surgery, 2009. 146(1): p. 60-71.

36. Abdalla, E.K., T.W. Bauer, Y.S. Chun, et al., Locoregional surgical and interventional therapies for advanced colorectal cancer liver metastases: expert consensus statements. HPB (Oxford), 2013. 15(2): p. 19-30.

37. Donadon, M., F. Procopio, and G. Torzilli, Tailoring the area of hepatic resection using inflow and outflow modulation. World J Gastroenterol, 2013. 19(7): p. 1049-55.

38. Fisher, S.B., P.J. Kneuertz, R.M. Dodson, et al., A comparison of right posterior sectorectomy with formal right hepatectomy: a dual-institution study. HPB (Oxford), 2013. 15(10): p. 753-62.

39. Weiss, M.J. and M.I. D'Angelica, Patient selection for hepatic resection for metastatic colorectal cancer. J Gastrointest Oncol, 2012. 3(1): p. 3-10.

40. Dunne, D.F., S. Jack, R.P. Jones, et al., Randomized clinical trial of prehabilitation before planned liver resection. Br J Surg, 2016. 103(5): p. 504-12.

41. Kasivisvanathan, R., N. Abbassi-Ghadi, A.D. McLeod, et al., Cardiopulmonary exercise testing for predicting postoperative morbidity in patients undergoing hepatic resection surgery. HPB (Oxford), 2015. 17(7): p. 637-43. 


\section{Chapter 2}

Nederlandse samenvatting 


\section{SAMENVATTING EN DISCUSSIE}

Leverresectie biedt patiënten met colorectale levermetastasen de enige vorm van behandeling met kans op genezing. Ook voor primaire maligniteiten en goedaardige tumoren is leverresectie een algemeen geaccepteerde behandeling. Om patiënten een zo goed mogelijke kans op herstel te bieden, moeten chirurgen niet alleen kiezen voor de beste operatieve benadering, ze dienen ook te streven naar optimale pre-, intra- en postoperatieve condities. De laparoscopische techniek is de afgelopen decennia toegevoegd aan het armentarium van de leverchirurg en deze laparoscopische benadering is mogelijk beter dan de standaard open leverresectie. Een Enhanced Recovery After Surgery (ERAS) programma, ookwel fast-track of versneld herstel na chirurgie protocol genoemd, zorgt voor de standaardisatie en optimalisatie van elementen in de zorg rondom leverchirurgie en draagt bij aan een sneller herstel. Mogelijk zorgt de combinatie van laparoscopische leverchirurgie met een ERAS programma voor de beste uitkomsten voor de patiënt.

Dit proefschrift onderzoekt de huidige rol, disseminatie en wereldwijde adoptie van het ERAS programma binnen de leverchirurgie, bekijkt en evalueert de potentiële rol van specifieke (nieuwe) elementen binnen een ERAS protocol (Deel I), bestudeert de rol van (laparoscopische) leverchirurgie vanuit een Nederlands en internationaal perspectief, en vergelijkt open en laparoscopische leverchirurgie in een gerandomiseerde en gecontroleerde omgeving (Deel II).

\section{DEEL I: VERBETERD HERSTEL NA LEVERCHIRURGIE}

Hoofstuk 1 biedt een overzicht van de elementen binnen het Enhanced Recovery After Surgery (ERAS) programma voor leverchirurgie. Voor elk element wordt er een aanbeveling gegeven op basis van de kwaliteit van het beschikbare wetenschappelijk bewijs (Tabel 1).

Hoofdstuk 2 beschrijft de resultaten van een internationale enquête over optimalisatie van herstel na leverchirurgie. Deze enquête werd wereldwijd verstuurd naar hepatopancreatobiliaire (HPB) chirurgische centra en vroeg leverchirurgen naar hun ervaringen met ERAS programma's en laparoscopische leverchirurgie. Beide strategieën worden geassocieerd met sneller herstel en mogelijk werken ze synergistisch. De resultaten van de enquête toonden aan dat een grote meerderheid van de HPB centra al ervaring had met laparoscopische leverchirurgie. Deze liberale adoptie van laparoscopische leverchirurgie, zelfs in laag-volume centra, leek tegen de standaard van de evidence-based werken binnen de gezondheidszorg in te gaan. Opmerkelijk is dat, ondanks het feit dat er voldoende wetenschappelijk bewijs voor handen is, in 
2010 de disseminatie van ERAS programma's binnen de leverchirurgie nog beperkt was. Verder gaven de leverchirurgen aan dat een gerandomiseerde studie of een prospectieve registratie noodzakelijk was om de uitkomsten na open en laparoscopische leverchirurgie goed met elkaar te kunnen vergelijken.

Table 1. ERAS liver programma aanbevelingen

\begin{tabular}{|l|l|l|}
\hline Element & Bewijs niveau & Aanbevelings graad \\
\hline Preoperatieve voorlichting & C & Sterk \\
\hline Beperkt preoperatief vasten & B & Sterk \\
\hline Geen anesthesiologische premedicatie & A & Zwak \\
\hline Antitrombose profylaxe & A & Sterk \\
\hline Antibiotica profylaxe & A & Sterk \\
\hline Evenwichtige anesthesie met kortwerkende medicatie & C & Sterk \\
\hline Epidurale pijnstilling & B & Zwak \\
\hline Gebalanceerde intra-operatieve vochttoediening & A & Sterk \\
\hline Preventie van hypothermie & A & Sterk \\
\hline PONV profylaxe & C & Sterk \\
\hline Incisies van minimale lengte & C & Sterk \\
\hline Geen standaard gebruik van abdominale drain & B & Sterk \\
\hline Geen neus-maagsonde & A & Sterk \\
\hline Standaard orale pijnstilling & A & Sterk \\
\hline Preventie van postoperatieve ileus & C & Zwak \\
\hline Vroege verwijdering van urinekatheters & D & Zwak \\
\hline Vroege start van orale intake & A & Sterk \\
\hline Vroege mobilisatie & C & Sterk \\
\hline
\end{tabular}

Kwaliteit van bewijs en aanbevelingen volgens de GRADE richtlijnen: $A=$ Hoog, $B=$ Gemiddeld, $C=L a a g$, $\mathrm{D}=$ Zeer laag.

In Nederland werden de eerste laparoscopische leverresecties uitgevoerd in de jaren '90, terwijl de eerste laparoscopische leverresectie binnen een ERAS porgamma pas in 2008 werd verricht. Geleidelijk zijn er nieuwe initiatieven ontstaan om prospectieve en gecontroleerde data te verkrijgen om open en laparoscopische leverchirurgie met elkaar te vergelijken. Momenteel worden de resultaten van twee gerandomiseerde controleerde studies (ORANGE 2 Plus - Trial en Oslo - CoMet Study) verwacht en is er recentelijk een consensus statement van een internationale groep leverchirurgen gepubliceerd.[2]

Om het resultaat van de invoering van het ERAS programma binnen de leverchirurgie te kunnen evalueren, hebben we een systematische review van de literatuur tot en met oktober 2011 verricht in Hoofdstuk 3. In deze systematisch review konden 6 studies worden geïncludeerd voor verdere analyse. Het werd duidelijk dat de implementatie van een ERAS programma binnen de leverchirurgie geen nadelige effecten 
had op de morbiditeit, mortaliteit of het aantal heropnames. De analyse liet ook een mogelijk reductie van de opnameduur zien na implementatie van een ERAS programma. Hierbij dient wel te worden opgemerkt dat de zorg, zoals beschreven in de elementen binnen het ERAS protocol, niet altijd goed werd nageleefd in de verschillende onderzoeken. Door de verschillende mate van compliance binnen de verschillende studies zijn de geïncludeerde studies minder goed met elkaar te vergeleken. Twee studies in de systematische review bekeken de tijd tot functioneel herstel (functional recovery, FR). Deze bleek significant korter dan de totale opnameduur en FR kan worden beschouwd als een objectievere uitkomstmaat. We adviseren om in toekomstige studies tijd tot functioneel herstel als primaire uitkomstmaat te gebruiken om zo de kwaliteit en vergelijkbaarheid te verbeteren. Een recentere systematisch review, waarin twee RCT's werden opgenomen waarin ERAS met conventionele zorg werd vergeleken, ondersteunt de eerder aangetoonde afname in opnameduur en een reductie in morbiditeit.[3]

In Hoofdstuk 4 hebben we onderzocht of Europese HPB centra daadwerkelijk perioperatieve zorg aanbieden die gebaseerd is op de ERAS principes. De studie ging uit van de hypothese dat de meeste centra elementen uit het ERAS programma al hadden geïmplementeerd binnen de leverchirurgie, aangezien ook het ERAS programma voor colorectale chirurgie al binnen deze ziekenhuizen was ingevoerd. Binnen de onderzochte ziekenhuizen was er substantiële variatie in de perioperatieve zorg bij leverchirurgie. Bepaalde elementen van het ERAS programma, zoals preoperatieve voorlichting en beperkte preoperatief vasten, waren algemeen ingevoerd. Van andere elementen binnen de perioperatieve en postoperatieve zorg bleek daarentegen dat ze verder geoptimaliseerd konden worden. Wij observeerden bijvoorbeeld, dat drains en neus-maagsondes nog frequent standaard werden gebruikt, dat er postoperatief geen gebruik werd gemaakt van ontslagcriteria, dat patiënten pas laat mobiliseerden en dat patiënten pas laat tijdens hun opname een normaal dieet werd aangeboden. Ook werd er vertraging gezien tussen het moment van functioneel herstel en het daadwerkelijk ontslag. Dit komt overeen met resultaten van eerdere studies.[4, 5] Een beperking van deze studie is de retrospectieve opzet, echter hier is met opzet voor gekozen om het gedrag van de medische staf en verpleging niet te beïnvloeden.

Een belangrijk aspect na leverchirurgie is veilige en effectieve pijnstilling. Goede pijnstilling kan de chirurgische geïnduceerde stress beïnvloeden en zal niet alleen zorgen voor een afname van postoperatieve complicaties, het kan ook zorgen voor snellere mobilisatie en een mogelijk sneller herstel. Zo kan adequate pijnstilling zorgen voor een afname in pulmonale complicaties en het optreden van postoperatieve ileus (stoppen of vertragen van darmpassage).[6] Traditioneel wordt postoperatieve pijnstilling verstrekt via intraveneuze patiënt-gecontroleerde pijnstilling (PCA) of via 
epidurale katheters. In Hoofdstuk $\mathbf{5}$ onderzoeken we de waarde van intramusculaire continue infusie van bupivacaïne (CIB) via wondkatheters gecombineerd met intraveneuze PCA versus epidurale pijnstilling na majeure leverresectie ( $\geq 3$ segmenten). Een risico na majeure leverresectie is het optreden van een postoperatieve stollingsstoornis. Om deze reden kan epidurale pijnstilling gecontra-indiceerd zijn. De combinatie van CIB + PCA bleek, vergeleken met epidurale pijnstilling, equivalente pijnstilling te kunnen bieden. Er waren geen significante verschillen tussen in het aantal patiënten met ernstige postoperatieve pijn. De patiënten in de CIB + PCA groep kregen totaal minder opiaten, hadden minder complicaties en een kortere opnameduur. Het retrospectieve design en de aanwezigheid van een chirurg-bias kan de resultaten hebben beïnvloed. Anderzijds, een groot en ononderbroken cohort van patiënten met dit type postoperatieve analgesie (CIB + PCA) die een majeure leverresectie ondergingen is niet eerder beschreven. Continue infusie van bupivacaïne gecombineerd met PCA lijkt een goed alternatief te zijn voor epidurale pijnstilling en mogelijke zeldzame complicaties van epidurale analgesie kunnen hiermee vermeden worden.

Het ERAS programma stelt dat er niet routinematig een abdominale drain moet worden achtergelaten na partiële leverresectie ("no-drain" beleid). Het routinematig plaatsen van deze drains kan onnodig, mogelijk schadelijk en oncomfortabel zijn voor patiënten. Het gebruik van abdominale drains na leverchirurgie is nog steeds onderwerp van discussie. In Hoofdstuk $\mathbf{6}$ beschrijven we 10-jaar ervaring van een tertiair HPB-centrum met een "no-drain" beleid binnen een ERAS programma. Primaire uitkomstmaten van deze studie waren 90-dagen resectie-oppervlak gerelateerde (ROG) morbiditeit and ROG-reïnterventies. Totaal werd er $20 \%$ chirurgische morbiditeit, 15\% ROG-complicaties en 12\% ROG-reïnterventies geobserveerd bij 538 patiënten die een leverresectie ondergingen. De meerderheid van de ROG-complicaties konden worden behandeld met radiologisch drainage en re-operaties waren maar zelden noodzakelijk. Majeure ( $\geq 3$ segmenten) leverresectie werd geïdentificeerd als een onafhankelijk risicofactor voor het ontstaan van significante ( $\geq$ Dindo-Clavien graad 3a) ROG-morbiditeit en de noodzaak van ROG-reïnterventies. De resultaten van deze studie komen overeen met de resultaten gepubliceerd door andere HPBcentra [7-12] en bevestigen de veiligheid en haalbaarheid van een "no-drain" beleid binnen een ERAS programma.

\section{DEEL II: LAPAROSCOPISCHE LEVERCHIRURGIE}

Hoofdstuk 7 geeft een historisch overzicht van de introductie van laparoscopische leverchirurgie in Nederland. In de jaren '90 werden de eerste laparoscopische leverresecties verricht, maar een decennium later was de ervaring met deze techniek nog 
beperkt. Vergeleken met andere pionierende landen bleek Nederland langzaam met de implementatie van de minimaal invasieve techniek binnen de leverchirurgie. De initiële ervaring met laparoscopische leverchirurgie is verder geëvalueerd met een case-control onderzoek, waarin open en laparoscopische resecties van leversegment 2 - 3 (laparoscopic left lateral sectionectomy (LLS)) tijdens 2000-2008 werden vergeleken. We observerden een significant verschil in opnameduur, bloedverlies, en duur van de operatie in het voordeel van laparoscopische geopereerde patiënten. Tevens was de morbiditeit tussen de groepen vergelijkbaar. Tot slot is de implementatiestatus van de laparoscopische leverchirurgie in 2010 onderzocht middels een nationale enquete. Er waren 30 responderende centra (37 centra aangeschreven) die in totaal 966 leverresectie verichtten, echter maar 49 (5\%) van deze resecties werden laparoscopisch uitgevoerd.

Om prospectief de waarde van laparoscopische leverchirurgie te kunnen onderzoeken is er een gerandomiseerd onderzoek met controlegroep (RCT) opgezet. Hoofdstuk 8 toont het protocol voor deze internationale multicentrum studie. In deze studie wordt open met laparoscopische leversegment 2-3 resectie (= LLS, Left lateral resection) vergeleken binnen een ERAS programma: de ORANGE II - studie. Naast de gerandomiseerde groepen is er ook een prospectieve registratie van patiënten, die niet gerandomiseerd konden worden door voorkeur van de chirurg of patient, toegevoegd. Deze toevoeging zorgt ervoor dat er een ononderbroken prospectieve serie van patiënten kan worden onderzocht. Het primaire eindpunt van de studie is tijd tot functioneel herstel (een samengesteld eindpunt bestaande uit vijf criteria). De hypothese is dat de tijd tot functioneel herstel in de groep patiënten die een laparoscopische LLS ondergaat twee dagen korter is dan bij de patiënten in de open LLS groep.

In Hoofdstuk 9 presenteren we de resultaten van de ORANGE II - studie. Tussen januari 2010 en juli 2014 werden in totaal 91 patiënten geïncludeerd ( 24 patiënten in de RCT en 67 patiënten in het prospectieve register). Hoewel de resultaten geen reductie in tijd tot functioneel herstel ten faveure van de laparoscopische groep lieten zien, kon uit deze eerste RCT waarin open met laparoscopische leverchirurgie werd vergeleken geen definitieve conclusie worden getrokken. De studie werd voortijdig gestaakt door een te trage inclusie van gerandomiseerde patiënten. De belangrijkste reden van trage inclusie was een duidelijke voorkeur van chirurgen voor de laparoscopische procedure (laparoscopische LLS). Deze studie liet wel zien dat laparoscopische leversegment 2-3 resecties konden worden uitgevoerd met een lage morbiditeit, weinig re-operaties en heropnames, en een lage mortaliteit. Tot op heden zijn er nog geen andere gerandomiseerde studies die open en laparoscopische leverchirurgie vergelijken. Deze multicentrum RCT zal waarschijnlijk niet nogmaals worden opgezet. De toevoeging van een prospectief register aan de studie zorgde 
voor een verhoging van de externe validiteit. De lange-termijn resultaten van deze studie worden nog verwacht.

Tot slot wordt er in Hoofdstuk 10 een protocol gepresenteerd voor een internationale RCT die open en laparoscopische hemihepatectomie vergelijkt binnen een ERAS programma (de ORANGE II Plus - studie). De open procedure om de linker of rechter hemilever te verwijderen is reeds een geaccepteerde operatie voor de behandeling van levertumoren (meestal colorectale metastasen). De waarde van laparoscopische leverchirurgie bij majeure resectie (>3 segmenten) is nog onduidelijk. In de handen van ervaren leverchirurgen lijkt majeure laparoscopische leverresectie ook veilig en haalbaar. De resultaten zijn echter gebaseerd op case-series en prospectief gecontroleerd bewijs ten aanzien van de korte termijn, oncologische en patiëntgerapporteerde resultaten is niet voorhanden. The ORANGE II PLUS - studie loopt momenteel in verschillende internationale HPB-centra en heeft als primair eindpunt: tijd tot functioneel herstel. Andere eindpunten die worden bestudeerd zijn de opnameduur, morbiditeit, mortaliteit, operatieve parameters (bloedverlies, operatieduur), patiënt-gerapporteerde uitkomstmaten (kwaliteit van leven, cosmetiek), oncologische uitkomsten (tijd tot start adjuvante chemotherapie, resectie marge, algemene 5-jaars overleving) en kosten.

Samenvattend laat dit proefschrift zien dat binnen de moderne leverchirurgie verschillende elementen van een ERAS-programma al geïmplementeerd zijn. Een volledige implementatie van een versneld herstel programma voor leverchirurgie wordt aanbevolen om het herstel van de patiënten te optimaliseren en te versnellen. Voor een optimaal resultaat is goede naleving essentieel en eventuele nieuwe evidencebased inzichten ten aanzien van (nieuwe) elementen binnen de perioperatieve zorg moeten kritisch worden bekeken en toegepast.

In Nederland was de laparoscopische leverchirurgie tot 2010 nog maar minimaal geïmplementeerd. Laparoscopische leverchirurgie is de laatste jaren populairder geworden onder Nederlandse leverchirurgen. Kleine leverresecties, waaronder de segment 2-3 resectie, dienen volgens een internationale consensus bij voorkeur laparoscopische uitgevoerd te worden.[2] Uit een prospectieve gecontroleerde studie naar open versus laparoscopische segment 2-3 leverresecties konden helaas geen definitieve conclusies worden getrokken, omdat de studie voortijdig werd gestopt door een te lage inclusie in de RCT en een duidelijke voorkeur van chirurgen voor de laparoscopische benadering. Een nog lopende RCT zal in de toekomst waarschijnlijk beter bewijs leveren over de waarde van laparoscopie bij majeure leverchirurgie, oncologische en patiënt-gerapporteerde eindpunten. 


\section{TOEKOMSTIGE PERSPECTIEVEN}

\section{OPTIMALISATIE VAN HERSTEL NA CHIRURGIE}

Er is inmiddels veel wetenschappelijk bewijs beschikbaar dat ERAS protocollen veilig en effectief zijn.[3] Het is daarom bijzonder dat een ERAS protocol voor leverchirurgie nog niet formeel is vastgelegd en gepubliceerd. De ERAS society is een toonaangevende internationale organisatie die een aantal evidence-based protocollen gepubliceerd heeft om chirurgen en andere professionals te ondersteunen. Om de zorg rondom leverchirurgie te standaardiseren is het wenselijk dat er een consensusrichtlijn voor optimaal herstel na leverchirurgie ontwikkeld wordt door deskundigen. Een recente review[3], inclusief recente prospectieve (gerandomiseerde gecontroleerde) studies [14-16], bevestigt opnieuw een kortere opnameduur en afname van postoperatieve morbiditeit. Het is niet alleen belangrijk dat een ERAS lever protocol wordt gepubliceerd en geaccepteerd door internationale leverchirurgen. Het is ook van belang om regelmatig en systematisch elementen van het protocol te evalueren om er zo voor te zorgen dat het protocol up-to-date is en ondersteund wordt door recente literatuur. Onderdelen van het protocol dienen zo nodig te worden herzien en nieuw elementen kunnen worden toegevoegd. De ERAS society moet hierin een leidende rol nemen, zodat standaardisatie en een evidence-based benadering van de patiëntenzorg wordt uitgedragen.

In de inleiding van dit proefschrift zijn de huidige elementen van het ERAS-protocol in de leverchirurgie beschreven en gewaardeerd op basis van de beschikbare publicaties. Voorbeelden van nieuwe elementen die mogelijk kunnen worden toegevoegd aan eerder beschreven ERAS lever protocollen [5, 14, 15, 17] zijn: het gebruik van een pulmonale rekrutering manoeuvre (handmatig beademingen van de long met de patiënt in Trendelenburg) om postoperatieve pijn te verminderen chirurgie [18], stimulering van de darmfunctie met kauwgom [19], implementatie van andere methoden van postoperatieve pijnstlling met minder bijwerkingen (transversus abdominis blokkade [20], wondkatheters [21-23]) en het gebruik van medicatie ter vermindering van de stressrespons[24]. De meeste postoperatieve elementen uit het ERAS programma worden geïntroduceerd bij terugkomst van de patiënt na zijn operatie op de afdeling. Sommige patiënten blijven echter tot 24 uur na de operatie op de verkoeverkamer. Naast het verschaffen van goede pijnbestrijding is het mogelijk om andere elementen al op de verkoeverkamer te introduceren: vroeg drinken van water, het kauwen van kauwgom en vroege mobilisatie. Bevordering van orale inname, vroege mobilisatie en laparoscopische chirurgie, zijn geassocieerd met vroeg herstel na een operatie.[25] 
Indien alle elementen met succes worden nageleefd, is het waarschijnlijk dat niet een enkel element, maar het gehele multimodale ERAS programma leidt tot het gewenste versnelde herstel. Zoals aangetoond binnen de colorectale chirurgie, kan er ook een synergetisch effect ontstaan wanneer het ERAS protocol wordt gecombineerd met laparoscopie.[26] Na implementatie is het belangrijk om een zorgprogramma goed te blijven naleven zodat een blijvend voordeel voor de patiënt kan worden gegarandeerd.[27] Deze naleving van het protocol is helaas het belangrijkste probleem in het proces van optimalisatie van herstel. Tijdens de eerste fase van de uitvoering van een nieuw zorgprogramma zijn alle betrokken medewerkers enthousiast en alert om zich te houden aan de richtlijn. Na de initiële implementatie dient naleving te worden gehandhaafd met post-implementatiestrategieën, zoals periodieke evaluaties en onderwijs.[28] Er is al aangetoond in de colonchirurgie dat een gestructureerde implementatie strategie kan resulteren in een goede duurzaamheid.[29]

\section{LAPAROSCOPISCHE LEVERCHIRURGIE}

De minimaal invasieve benadering voor leverchirurgie is inmiddels niet meer weg te denken. De afgelopen jaren is aangetoond in verschillende case-series dat naast de kleine laparoscopische leverchirurgie, ook majeure laparoscopische leverresecties geassocieerd worden met gelijke of verbeterde korte termijn resultaten.[30] In ervaren handen zijn het intra-operatieve bloedverlies, de complicaties en het conversie percentage meer dan acceptabel voor de laparoscopische linker hemihepatectomie.[31] Een recente meta-analyse, waarin laparoscopische leverresecties casematched werden vergeleken met open leverresecties $(N=2900)$, liet geen verhoogde mortaliteit en aanzienlijk minder complicaties, transfusies, bloedverlies en een korter verblijf in het ziekenhuis zien in het voordeel van laparoscopische chirurgie.[32] In de recente Morioka consensus werd bevestigd dat de laparoscopische benadering van kleine leverresecties als de standard dient te worden beschouwd. Met betrekking tot de majeure laparoscopische leverresecties ( $\geq 3$ segmenten) oordeelden experts dat de introductie nog in een verkennende fase zit en dat voorzichtige disseminatie van de techniek nog steeds gerechtvaardigd is.[2] De internationale experts die betrokken waren bij de consensus adviseerden, dat participatie en deelname aan lopende prospectieve studies en registraties wenselijk is. In de nabije toekomst zal er meer wetenschappelijk bewijs beschikbaar komen over de waarde van laparoscopische leverresecties, zodra de resultaten van de ORANGE 2 Plus - Trial (hoofdstuk 10) en de Oslo-Comet studie [33] worden gepubliceerd. De ORANGE 2 Plus - Trial vergelijkt open met laparoscopische hemihepatectomie binnen een ERASprogramma en de Oslo-Comet studie vergelijkt laparoscopische versus open leverresecties voor colorectale metastasen. Beide studies zullen leverchirurgen vermoedelijk een beter inzicht verschaffen ten aanzien van de plaats van (majeure) laparoscopi- 
sche leverchirurgie op het gebied van oncologische uitkomsten, lange-termijn follow-up, de kosten en de patiënt-gerapporteerde uitkomsten.

Tijdens het schrijven van dit proefschrift is er een verschuiving van chirurgische strategie ontstaan ten aanzien van de omvang van de leverresectie. Naast de discussie over de techniek (laparoscopische versus open) is er ook een toenemende focus op leverparenchym besparende technieken.[34,35] Een two-stage of formele leverresectie blijkt minder vaak nodig te zijn door de verbetering van de intra-operatieve beeldvorming en technieken.[36] Tevens dient postoperatief leverfalen voorkomen te worden, maar moeten oncologische marges worden gerespecteerd.[37, 38] Een parenchym-sparende strategie met een nauwkeurige preoperatieve voorspelling van de functie van de toekomstige restlever lijkt de toekomst voor een "tailored" benadering.

Beter wetenschappelijke ondersteuning, gestandaardiseerde rapportage van de resultaten, en het garanderen van een goede training zijn de volgende uitdagingen voor de laparoscopische leverchirurgie.[32] Niet alleen RCT's of andere prospectieve studies kunnen bijdragen aan een verdere ontwikkeling van laparoscopische leverchirurgie, ook de kritische beoordeling van leverresecties uitgevoerd in het verleden kan de kwaliteit verbeteren. Controle door nationale of internationale verenigingen zal leverchirurgen inzicht geven in de kwaliteit van hun eigen operaties, maar ook in de prestaties van andere collega's. (International) benchmarks kunnen worden gedefinieerd voor belangrijke uitkomsten, zoals mortaliteit, morbiditeit, en R0resectiemarges. Uiteindelijk kan deze continue evaluatie leiden tot centralisatie van (laparoscopische) leverchirurgie. Mogelijk presteren groot-volume centra beter dan centra met slechts een beperkt aantal (laparoscopisch) leverresecties per jaar. Een goed voorbeeld van een goed functionerend controlesysteem is het Nederlands Instituut voor Clinical Auditing (DICA). Op 1 juli 2013 werd de Nederlandse LeverAudit (DHBA) gestart en dit heeft geresulteerd in de publicatie van de eerste rapportages. Toekomstige verslagen zullen inzicht bieden in de werkelijke kwaliteit en kwantiteit van de leverchirurgie in Nederland.

Het uiteindelijke doel is om een aanpak op maat te kunnen bieden voor elke patiënt die leverchirurgie dient te ondergaan. Dit is een toekomst waarin de chirurg in staat is om patiënten te selecteren die fit genoeg zijn om geopereerd te worden, waarin hij individuele operatie risico's kan voorspellen en waarin hij de postoperatieve uitkomsten nauwkeurig kan inschatten. De selectie van patiënten in de leverchirurgie is een belangrijke kwestie. Niet alleen dienen chirurgen de resectabiliteit te bepalen, ook is het essentieel om in te kunnen schatten of een patiënt een operatie aankan. Tevens is het wenselijk om te kunnen voorspellen of de operatie de lange-termijn overleving verbetert.[39] Recente ontwikkelingen op dit gebied zijn gericht op de preoperatieve 
beoordeling en verbetering van de conditie van de patiënt. Een 4-weeks prehabilitatie programma kan de cardiopulmonale inspanningstesten en de kwaliteit van leven voor leverresectie verbeteren. Dit kan vervolgens van invloed zijn op perioperatieve uitkomsten.[40] Verder onderzoek op dit gebied is nog noodzakelijk, maar in de toekomst kan mogelijk een vooraf gedefinieerde cut-off waarde worden gebruikt voor patiënten die leverchirurgie dienen te ondergaan om zodoende te kunnen voorspellen welke patiënten een verhoogd risico lopen op complicaties en welke patiënten fit genoeg zijn om geopereerd te worden.[41] Een geheel andere benadering om patienten voor leverchirurgie te selecteren en om uitkomsten te voorspellen is het gebruik van "big" data. Tegenwoordig zijn patiëntgegevens steeds directer beschikbaar in de digitale patiëntendossiers, elektronische onderzoeksformulieren en prospectieve registers. Deze gegevens kunnen leiden tot grote databases die kunnen worden gebruikt voor het opstellen van risicomodellen. 


\section{REFERENCES}

1. Guyatt, G.H., A.D. Oxman, R. Kunz, et al., Going from evidence to recommendations. BMJ, 2008. 336(7652): p. 1049-51.

2. Wakabayashi, G., D. Cherqui, D.A. Geller, et al., Recommendations for laparoscopic liver resection: a report from the second international consensus conference held in Morioka. Ann Surg, 2015. 261 (4): p. 619- 29.

3. Hughes, M.J., S. McNally, and S.J. Wigmore, Enhanced recovery following liver surgery: a systematic review and meta-analysis. HPB (Oxford), 2014. 16(8): p. 699-706.

4. Maessen, J., C.H. Dejong, J. Hausel, et al., A protocol is not enough to implement an enhanced recovery programme for colorectal resection. Br J Surg, 2007. 94(2): p. 224-31.

5. van Dam, R.M., P.O. Hendry, M.M. Coolsen, et al., Initial experience with a multimodal enhanced recovery programme in patients undergoing liver resection. Br J Surg, 2008. 95(8): p. 969-75.

6. Kehlet, H. and K. Holte, Effect of postoperative analgesia on surgical outcome. Br J Anaesth, 2001. 87(1): p. 62-72.

7. Fong, Y., M.F. Brennan, K. Brown, et al., Drainage is unnecessary after elective liver resection. Am J Surg, 1996. 171(1): p. 158- 62.

8. Fuster, J., J.M. Llovet, J.C. Garcia-Valdecasas, et al., Abdominal drainage after liver resection for hepatocellular carcinoma in cirrhotic patients: a randomized controlled study. Hepatogastroenterology, 2004. 51(56): p. 536-40.

9. Liu, C.L., S.T. Fan, C.M. Lo, et al., Abdominal drainage after hepatic resection is contraindicated in patients with chronic liver diseases. Ann Surg, 2004. 239(2): p. 194- 201.

10. Gurusamy, K.S., K. Samraj, and B.R. Davidson, Routine abdominal drainage for uncomplicated liver resection. Cochrane database of systematic reviews, 2007(3): p. CD006232.

11. Imamura, H., Y. Seyama, N. Kokudo, et al., One thousand fifty-six hepatectomies without mortality in 8 years. Arch Surg, 2003. 138(11): p. 198-206; discussion 1206.

12. Jarnagin, W.R., M. Gonen, Y. Fong, et al., Improvement in perioperative outcome after hepatic resection: analysis of 1,803 consecutive cases over the past decade. Ann Surg, 2002. 236(4): p. 397-406; discussion 406-7.

13. Stoot, J.H., R.M. van Dam, O.R. Busch, et al., The effect of a multimodal fast-track programme on outcomes in laparoscopic liver surgery: a multicentre pilot study. HPB (Oxford), 2009. 11(2): p. 140-4.

14. Jones, C., L. Kelliher, M. Dickinson, et al., Randomized clinical trial on enhanced recovery versus standard care following open liver resection. Br J Surg, 2013. 100(8): p. 1015-24.

15. Ni, C.Y., Y. Yang, Y.Q. Chang, et al., Fasttrack surgery improves postoperative recovery in patients undergoing partial hepatectomy for primary liver cancer: A prospective randomized controlled trial. Eur J Surg Oncol, 2013. 39(6): p. 542-7.

16. Schultz, N.A., P.N. Larsen, B. Klarskov, et al., Evaluation of a fast-track programme for patients undergoing liver resection. Br J Surg, 2013. 100(1): p. 138-43.

17. Connor, S., A. Cross, M. Sakowska, et al., Effects of introducing an enhanced recovery after surgery programme for patients undergoing open hepatic resection. HPB (Oxford), 2013. 15(4): p. 294-301.

18. Pergialiotis, V., D.E. Vlachos, K. Kontzoglou, et al., Pulmonary recruitment maneuver to reduce pain after laparoscopy: a meta-analysis of randomized controlled trials. Surg Endosc, 2015. 29(8): p. 2101-8.

19. Ho, Y.M., S.R. Smith, P. Pockney, et al., A meta-analysis on the effect of sham feeding following colectomy: should gum chewing be included in enhanced recovery after surgery protocols? Dis Colon Rectum, 2014. 57(1): p. 115-26.

20. Johns, N., S. O'Neill, N.T. Ventham, et al., Clinical effectiveness of transversus abdominis plane (TAP) block in abdominal surgery: a systematic review and meta-analysis. Colorectal Dis, 2012. 14(10): p. e635-42.

21. Bertoglio, S., F. Fabiani, P.D. Negri, et al., The postoperative analgesic efficacy of preperitoneal continuous wound infusion compared to epidural continuous infusion with local anesthetics after colorectal cancer surgery: a randomized controlled multicenter study. Anesth Analg, 2012. 1115 (6): p. 1442-50. 
22. Raines, S., C. Hedlund, M. Franzon, et al., Ropivacaine for continuous wound infusion for postoperative pain management: a systematic review and meta-analysis of randomized controlled trials. Eur Surg Res, 2014. 53(1-4): p. 43-60.

23. Bell, R., S. Pandanaboyana, and K.R. Prasad, Epidural versus local anaesthetic infiltration via wound catheters in open liver resection: a meta-analysis. ANZ J Surg, 2015. 85(1-2): p. 16-21.

24. Srinivasa, S., A.A. Kahokehr, T.C. Yu, et al., Preoperative glucocorticoid use in major abdominal surgery: systematic review and meta-analysis of randomized trials. Ann Surg, 2011. 254(2): p. 183-91.

25. Vlug, M.S., S.A. Bartels, J. Wind, et al., Which fast track elements predict early recovery after colon cancer surgery? Colorectal Dis, 2012. 14(8): p. 1001-8.

26. Vlug, M.S., J. Wind, M.W. Hollmann, et al., Laparoscopy in combination with fast track multimodal management is the best perioperative strategy in patients undergoing colonic surgery: a randomized clinical trial (LAFA-study). Ann Surg, 2011. 254(6): p. 868-75.

27. Feroci, F., E. Lenzi, M. Baraghini, et al., Fasttrack colorectal surgery: protocol adherence influences postoperative outcomes. Int J Colorectal Dis, 2013. 28(1): p. 103-9.

28. Ament, S.M., F. Gillissen, A. Moser, et al., Identification of promising strategies to sustain improvements in hospital practice: a qualitative case study. BMC Health Serv Res, 2014. 14: p. 641.

29. Gillissen, F., S.M. Ament, J.M. Maessen, et al., Sustainability of an enhanced recovery after surgery program (ERAS) in colonic surgery. World J Surg, 2015. 39(2): p. 526-33.

30. Lin, N.C., H. Nitta, and G. Wakabayashi, Laparoscopic major hepatectomy: a systematic literature review and comparison of 3 techniques. Ann Surg, 2013. 257(2): p. 205-13.

31. Belli, G., B. Gayet, H.S. Han, et al., Laparoscopic left hemihepatectomy a consideration for acceptance as standard of care. Surg Endosc, 2013. 27(8): p. 2721-6.

32. Ciria, R., D. Cherqui, D.A. Geller, et al., Comparative Short-term Benefits of Laparoscopic Liver Resection: 9000 Cases and Climbing. Ann Surg, 2016. 263(4): p. 761-77.

33. Fretland, A.A., A.M. Kazaryan, B.A. Bjornbeth, et al., Open versus laparoscopic liver resection for colorectal liver metastases (the Oslo-CoMet Study): study protocol for a randomized controlled trial. Trials, 2015. 16: p. 73.

34. Gold, J.S., C. Are, P. Kornprat, et al., Increased use of parenchymal-sparing surgery for bilateral liver metastases from colorectal cancer is associated with improved mortality without change in oncologic outcome: trends in treatment over time in 440 patients. Ann Surg, 2008. 247(1): p. 109-17.

35. Torzilli, G., F. Procopio, F. Botea, et al., One-stage ultrasonographically guided hepatectomy for multiple bilobar colorectal metastases: a feasible and effective alterna tive to the 2-stage approach. Surgery, 2009. 146(1): p. 60-71.

36. Abdalla, E.K., T.W. Bauer, Y.S. Chun, et al., Locoregional surgical and interventional therapies for advanced colorectal cancer liver metastases: expert consensus statements. HPB (Oxford), 2013. 15(2): p. 19-30.

37. Donadon, M., F. Procopio, and G. Torzilli, Tailoring the area of hepatic resection using inflow and outflow modulation. World J Gastroenterol, 2013. 19(7): p. 1049-55.

38. Fisher, S.B., P.J. Kneuertz, R.M. Dodson, et al., A comparison of right posterior sectorectomy with formal right hepatectomy: a dual-institution study. HPB (Oxford), 2013. 15(10): p. 753-62.

39. Weiss, M.J. and M.I. D'Angelica, Patient selection for hepatic resection for metastatic colorectal cancer. J Gastrointest Oncol, 2012. 3(1): p. 3-10.

40. Dunne, D.F., S. Jack, R.P. Jones, et al., Randomized clinical trial of prehabilitation before planned liver resection. Br J Surg, 2016. 103(5): p. 504-12.

41. Kasivisvanathan, R., N. Abbassi-Ghadi, A.D. McLeod, et al., Cardiopulmonary exercise testing for predicting postoperative morbidity in patients undergoing hepatic resection surgery. HPB (Oxford), 2015. 17(7): p. 637-43. 



\section{chapter 13}

Valorisation 


\section{VALORISATION}

\section{INTRODUCTION}

Liver surgery can be performed for both benign and malignant tumours of the liver. Colorectal metastases are the indication for nearly $70 \%$ of all liver resections, and about $50 \%$ of all patients with a primary colorectal tumour will develop hepatic metastases. Primary and benign liver tumours account for $17 \%$ and $8 \%$ of indications for liver surgery in the Netherlands, respectively. Despite the worldwide interest in laparoscopic surgery, in 2014 the majority of all liver surgical procedures was still performed as an open procedure. Only $11 \%$ of all liver resections was performed completely laparoscopically. It is essential not only to offer patients the best surgical procedure, but also to provide patients the best evidence-based perioperative care to accommodate a good and quick recovery. The trend in the Netherlands, but also in the rest of the world, is towards further adoption of the laparoscopic technique and implementation of a structured perioperative care programme in liver surgery. With the still increasing healthcare spending in the Netherlands all new developments and treatments face scrutiny over costs. Laparoscopic liver resection itself may be more expensive, but if the combination with Enhanced Recovery After Surgery protocols leads to a shorter hospital length of stay, lower morbidity or better survival, the overall costs may be equivalent or even lower.

\section{RELEVANCE OF SCIENTIFIC RESULTS IN THIS THESIS}

The results reported in this thesis may have both social and economical impact. Costs play an ever more pivotal role in modern (surgical) care. Not only do surgeons and other clinicians look for ways to optimize and shorten the duration of admission of patients, nowadays the government and insurance companies also look for ways to improve patient care and reduce costs. As described in this thesis, minimization of the delay between functional recovery and actual discharge could prove to be the easiest and most tangible way to reduce costs. The length of hospital stay can be reduced by implementation of an ERAS programme and may be reduced if patients are operated laparoscopically. Results presented in this thesis show a benefit of the ERAS programme. However, this thesis has failed to demonstrate a reduced time to functional recovery and associated length of stay after laparoscopic left lateral sectionectomy. Future studies could and should be focused on finding the added value of laparoscopy in liver surgery. If laparoscopy truly leads to a quicker recovery of the patient and cost-effectiveness analyses also confirm a benefit, laparoscopy is likely to become the preferred procedure for liver surgery. A one or two day reduction in length of hospital stay could prove to be of significant value regarding costs. Currently, laparoscopic procedures are still more expensive than open liver surgery. Equally, laparoscopic 
procedures require more time in the operating room. This aspect of allocating more operating room time to liver resections, at a time where operating room capacity is scarce, may be important in future decision making. Waiting lists for cancer-related procedures may increase, if more procedures are done laparoscopically. If future studies fail to demonstrate a clinically significant difference in favour of laparoscopic liver surgery that also outweighs the costs, a situation could develop in which open liver surgery remains the standard. Laparoscopy may only be deemed beneficial in selected liver surgical procedures. Perhaps insurance companies will no longer compensate for laparoscopic procedures in the absence of evidence. However, there is another aspect to the comparison of open versus laparoscopic liver surgery: patient opinion. Patient-reported outcomes are being valued more and more. Evidence on patientreported outcomes on open versus laparoscopic liver surgery is limited and future results of the ORANGE II trials on laparoscopic versus open liver surgery could provide additional leverage in the debate.

\section{TARGET POPULATION}

Liver surgeons, other specialists involved in the care of patients diagnosed with liver tumours and patients themselves can benefit from the results presented in this thesis. It offers them new insights into expert opinions, developments, comparison of operative techniques and perioperative care strategies.

\section{INNOVATION AND FUTURE}

Projects in this thesis have lead to the development and design of new studies and collaborations. The multicentre international design of the ORANGE II Trials has resulted in a collaborating network of HPB-centres. A currently ongoing European multicentre study, the ORANGE II Plus - Trial, is a direct spin-off of the ORANGE II project. Through this spin-off, in which the merits of open and laparoscopic hemihepatectomy are compared, both surgeons and patients are likely to be presented with valuable new evidence. In the world of hepatic surgery this research has the potential to make a lasting footprint. The first results of this collaboration are to be expected in 2017. With a new network of expert HPB-centres in place, it seems inevitable that new multicentre research could get off to a flying start with broad European support.

In addition, based on results from this thesis and recent literature the Enhanced Recovery After Surgery (ERAS) programme for liver surgery is here to stay. There is robust evidence that should advocate implementation of a structured and evidence-based perioperative care programme. In the future this must also be further supported and controlled by the ERAS Society by the development and publication of official guidelines. 

Dankwoord 
Eindelijk is het zover, het boek is af!

Beste prof. Dejong, beste Kees, dank voor al het vertrouwen en de goede adviezen die je mij hebt gegeven. Ik bewonder je als promotor, professor van de HPB-groep, maar ook als mens om je altijd constructieve manier van communiceren, je humor en je leiderschap. Je was altijd snel met je feedback op projecten, waardoor het ook duidelijk was hoe mijn proefschrift eruit ging zien. Een van de eerste kennismakingen met de hele HPB-groep was een "Champagne-party". Deze was een jaar eerder in het leven geroepen om samen de jaarlijkse successen te vieren onder het motto: wie schrijft die blijft. Ik leerde je kennen als een begenadigd spreker en samen met onze HPB-groep zijn er inmiddels vele flessen champagne leeg gedronken.

Best dr. van Dam, Ronaldo, jij was het die toekomst in me zag als semi-arts op de afdeling Heelkunde in Maastricht. Je hebt daarna mijn inzet samen met Kees beloond door mij een promotieplek aan te bieden. Ik waardeer je creativiteit enorm en samen bedachten we projecten voor mijn promotie. Niet alle ideeën hebben het gehaald, maar je durft groots te denken en te dromen. Je stuurde me Europa in om een netwerk op te bouwen en steun te krijgen voor onze projecten. De ORANGE 2 - studies zijn inmiddels uitgegroeid tot een veel groter internationaal Europees succes, waar leverchirurgen graag in participeren. Er was wat vertraging op het einde en jouw oude, zelfs ingelijste data: 10-10-10, 11-11-11, 12-12-12, 13-13-13 flitsten even voorbij. $\mathrm{Nu}$ is het dan eindelijk zover, geen revisies meer, geen nieuwe deadlines: het boekje is af. Naast je begeleiding wil ik je bedanken voor de mooie avonturen die we hebben meegemaakt in o.a. Parijs, Cape Town, Belgrado en Dublin. Ik hoop dat er nog meer volgen!

De leden van de beoordelingscommissie wil ik graag bedanken voor hun tijd en het beoordelen van dit proefschrift, prof. Beets, prof. Buhre, prof. van der Hulst, prof. Primrose en dr. de Boer.

Dear prof. Aldrighetti, Luca, we met during a congress in South Africa. You were willing to participate in our newly launched ORANGE 2 Study and a collaboration was born. You warmly welcomed me during the initiation visit in Milan, Italy and your team has been off great support to our projects. As one of the main collaborators and centre with the biggest accrual I cannot thank you enough for your time and trust!

Dear Mr. Rees, Merv, during a congress in Dublin you told me you had gathered some interesting data on post-operative analgesia after liver resection. The subject fitted perfectly into my PhD-thesis and twice I came and visited Basingstoke, UK. Our collaboration has result in a good publication. I sincerely thank you for your trust and for giving me the opportunity to come to your hospital in Basingstoke (UK).

Dear prof Primrose, from the start you have been keen to be involved in the ORANGE collaboration and you have been the driving force behind the trial and funding in the 
UK. I feel honoured to have you in my dissertation committee. Thank you for your time and support!

Tevens bedank ik alle artsen, onderzoekers en ander personeel van de centra waarmee ik heb mogen samenwerken. In het bijzonder prof. Topal, prof. Busch, prof. Boermeester, prof Borel Rinkes dr. Terkivatan, prof. van Hillegersberg, prof. de Wilt, prof. Neumann, prof. Troisi, prof. Dagher, prof. Soubrane, prof. Neumann, prof. Laurent, prof. Dagher, prof. Cherqui, prof. Scatton, prof. Soubrane, prof. Edwin, prof. van Breukelen, dr. Abu Hilal, dr. Sutcliffe, dr. Besselink' dr. Aroor, dr. Fretland"' dr. d'Hondt, dr. Sergeant, dr. Fusai, dr. Slooter, dr. Klaase, dr. Ratti, dr. Welsh, dr Wells, dr. John, dr. Cresswell, dr. Hoekstra, dr. Huisman, dr. Tanis, dr Besselink, Mrs. Bonwitt, Mrs. Murray, Mrs. Mann en Mw. Stam. Zonder hen was dit proefschrift niet tot stand gekomen.

Beste dr. Bosscha, beste Koop, allereerste bedankt voor de kans die je me hebt gegeven om mezelf te bewijzen binnen de Heelkunde in het JBZ. Aanvankelijk kwam ik studies in dit proefschrift uitvoeren in het JBZ, aansluitend was ik welkom als ANIOS. Korte tijd daarna heb je me gesteund tijdens de sollicitatie voor de opleiding. Tot op heden ben je mijn opleider en dank ik je voor al je vertrouwen en steun.

Beste Joost, Jossos, het zit er op. Eindelijk is het deels door jouw opgestarte project afgerond. Als semi-arts heb je de fundering gelegd voor de ORANGE 2 - studie, maar ben je daarna een eigen succesvol pad gaan bewandelen via een promotie en opleiding in de regio Leiden. Ik waardeer het heel erg dat je mijn paranimf bent. Sinds 2003 zijn we vrienden en hebben we hebben talloze mooie momenten mogen delen. Van onze studententijd tot een promotie, de opleiding, vakanties en nu het stichten van een eigen gezinnetje. Dat er nog veel jaren mogen volgen!

Beste Mark, Markie aka prof. Hazebroek. Ook aan mijn zijde als paranimf. We zijn vrienden sinds je komst in 2004 naar Maastricht. Nadat velen in onze omgeving waren weggetrokken uit Maastricht, bleef jij achter voor een promotie bij de Cardiologie met Gitte en de kids. Het gewenste eten kreeg je niet altijd thuis, dus kwam je graag bij mij een vorkje meepikken. Je hebt al een tijdje een mooi gezinnetje en ik vind het knap hoe je alles weet te combineren. Wat dat betreft ben je een voorbeeld voor me en ik stel onze vriendschap enorm op prijs. Jij gaat later dit jaar trouwen en kort daarna promoveren. Ik kijk erna uit om samen met je te proosten!

Heren van het jaar 2003: Joost, Frank, Putten, Haan. We go way back. Alleen al over onze tijd in Maastricht kan een heel boek worden geschreven. In goede en slechte tijden zijn we er voor elkaar. Ik hoop dat dit nog lang zo mag blijven.

Beste Sjoerd, oud-dispuutsgenoot, oud-huisgenoot, maar bovenal vriend. We kennen elkaar sinds EP-4. Een huis waar vele mooie herinneringen en plannen zijn ontstaan. De surfvakanties in Portugal zijn onvergetelijk. Ik ben jaloers op de manier waarop jij je leven vorm hebt weten te geven. Af en toe hard werken, maar vooral veel tijd voor plezier en genieten van het leven met Jolien en Mila. 
Dear Mitch, you have always been a good friend to me since your arrival for your study in Maastricht. We have lived, enjoyed parties and travelled together. Since a couple of years you now happily live with Ruth en Emily in the USA, but we have always stayed in touch. I admire your open minded and worldly attitude. See you soon!

Lieve (Bredase) vrienden, Mark, Eric, Moniek, Rick, Evelien, Fay, Luuk, Britt, Ellen, Jaap, Wendy, Mark, Paul, Bianca, Madelon, Tess, Ivan, Bart, Claar, Hilde, Alex, Janneke, Rodney, Anne, Sandra, Jeroen, Nienke, Rob, Stephan, Maaike, Bryan, Marieke, Robbert, Eva en Erwin. Een deel heb ik enkele jaren geleden via Marieke leren kennen, maar sindsdien ben ik veel vrienden, gezellige feesten en etentjes rijker.

Heren van Nondejuke. Geweldige jaren hebben we in Maastricht meegemaakt. Ik ben trots dat ik lid ben geweest van dit mooie dispuut. We zien elkaar snel tijdens het lustrum!

Beste mannen van RBC 2012-2014, wat een mooie tijd was het om deel uit te maken van het voetbalteam. Een nieuwe uitdaging om "de club" weer op de kaart te zetten. Het eerste seizoen direct kampioen. Avonden stappen, de "autobusrally", de kampioensreis naar Malloroca. Het heen en weer reizen vanuit Maastricht naar Roosendaal was me het meer dan waard en ik had het voor geen goud willen missen!

Beste Paul, Paulus, partners in crime, klaar om de chirurgische wereld te veroveren. Tijdens onze opleiding zijn de cursussen, congressen, promoties, diensten en festivals een waar feest met jou. Ik waardeer onze vriendschap en ik kijk uit na de jaren die nog gaan volgen onder het moto "Mucht to learn you still have.. my Padawan ".

Beste Luc en Toine, niet alleen hebben jullie bijgedragen aan een belangrijk deel van dit proefschrift, ook onze avonturen bij de Chirurgencup, skydiven in Cape Town en de legendarische avonden en nachten in de Trinity, 31 en Cafe Caprice zal ik nooit vergeten. Luc, uiteindelijk heb je je promotie veel eerder afgerond, maar zijn we allebei nu in opleiding tot chirurg! Toine, je hebt een andere richting gekozen, maar ik wens je hierin ook veel success toe.

Beste Victor, dank voor je hulp en samenwerking. Zonder jouw hulp was dit boekje er nu niet geweest. Naast de wetenschappelijke samenwerking hebben we ook meerdere malen op congressen mogen genieten van "avondjes uit" in bijvoorbeeld de legendarische boeventent in Belgrado. Ik wens je veel gezondheid toe en uiteraard ook veel succes met de afronding van je eigen promotie.

Beste Robert, dank voor al je hulp aan en inzet voor het ORANGE-project. Als semiarts sprong je op een rijdende trein die inmiddels wereldwijd bekend is. Door jouw inzet is de ORANGE 2 Plus - studie nu bijna afgerond en zullen vele mooie publicaties volgen. Veel succes de komende tijd en ik kijk uit naar jouw boekje! 
Alle andere oud-collega's van de afdeling Heelkunde / het lab in het MUMC die ik nog niet heb genoemd, bedankt voor de fijne tijd. Prof. Olde Damink (Steven), Dr. Bemelmans (Marc), Dr. Stoot (Jan / Johnny Punch), Mariëlle, Liliane, Simon, Dirk, Robert-Jan, Aart, Freek, Froukje, Guy, Inca, Irene-Fleur, Irma, Mo, Joyce-Manyi, Maartje, Marlou, Kaatje, Kevin, Kim van Mierlo, Kim van Wijck, Kirsten, Lori, Luc, Mark, Nina, Robbert-Jan, Ruben, Kostan, Rutger en anderen die ik misschien nu vergeet.

Beste (oud)-collega's en staf van de afdeling Heelkunde in het JBZ. Wat een mooie plek om mijn opleiding te doorlopen. Ik geniet van de samenwerking en ben dankbaar voor jullie ondersteuning en voor alles wat jullie mij leren.

Lieve (schoon)familie, bedankt voor jullie interesse en steun die ik tijdens deze periode heb ervaren. Jullie bieden altijd een luisterend oor en ik ben blij dat we samen dit mooie moment kunnen delen.

Ralph en Luc, mijn lieve broers. Ik ben zo trots op jullie. Ik kan altijd bij jullie terecht en we zijn er voor elkaar. Alle drie opgegroeid in een warm nest en uitgevlogen door drie compleet verschillende paden te bewandelen. Ralph, mijn tweelingbroer, ik bewonder je humor, je inzet en doorzettingsvermogen. Het heeft je nu eindelijk gebracht waar je wil zijn en na wat omzwervingen zie ik dat je nu je plek hebt gevonden. Samen met Valerie vorm je een goed en gelukkig team en ik hoop dat de toekomst jullie veel goeds brengt. Luc, mijn broer(the), onze marketeer, sociaal beest, wat kan jij goed met mensen omgaan. Je bent een voorbeeld voor me met je creativiteit en door de manier waarop jij mensen benaderd en in hun waarde laat. Het maakt je niet voor niets zo succesvol in je huidige baan. Samen met Veronique ga je nieuwe avonturen aan en ik zal je daarin altijd steunen!

Lieve papa en mama, waar zou ik zijn zonder jullie. Altijd zijn jullie er voor mij met jullie onvoorwaardelijke steun en liefde. Ik voel me bevoorrecht met jullie als ouders aan mijn zijde. Jullie hebben me alle kansen geboden om te zijn wie ik nu ben en zonder jullie was dit proefschrift er nooit geweest. Ik ben dankbaar dat jullie samen met mij dit moment kunnen delen en ik hoop dat we nog lang in goede gezondheid het leven delen.

Lieve Marieke, mijn maatje, liefde van mijn leven. Sinds ik je ken is mijn leven veranderd en nooit meer hetzelfde geweest. Mooie, maar ook verdrietige momenten hebben we samen gedeeld. Ik bewonder je altijd positieve houding, je glimlach, je doorzettingsvermogen en je zorgzaamheid. Je geeft me de ruimte om te zijn wie ik ben. Je gaf me de ruimte in ons al drukke leven om aan mijn promotie te werken. Mijn proefschrift is nu eindelijk afgerond en ik kijk uit naar de nieuwe plannen die we samen zullen gaan maken. Inmiddels vormen we een gezinnetje met onze dochter Elise en er is een tweede kindje op komst. Ik kan me geen betere moeder voor onze kinderen wensen en hou zielsveel van je! Samen kunnen we de hele wereld aan! 



\section{List of Publications}




\section{LIST OF PUBLICATIONS}

Wong-Lun-Hing EM*, van Woerden $\mathrm{V}^{*}$, Lodewick TM, Bemelmans MH, Olde Damink SWM, Dejong $\mathrm{CHC}$, van Dam RM. Abandoning prophylactic abdominal drainage after hepatic surgery: 10 years of no-drain policy in an ERAS environment. Dig Surg. 2017 Mar 25. doi: 10.1159/000455246. [Epub ahead of print]

* Shared first authorship

Wong-Lun-Hing EM, van Dam RM, van Breukelen GJP, Tanis PJ, Ratti F, van Hillegersberg R, Slooter GD, de Wilt JHW, Liem MSL, de Boer MT, Klaase JM, Neumann UP, Aldrighetti LA, Dejong CHC on behalf of the ORANGE II Collaborative Group. Randomized clinical trial of open versus laparoscopic left lateral hepatic sectionectomy within an enhanced recovery after surgery programme (ORANGE II study). Br J Surg. 2017 Apr;104(5):525-535. doi: 10.1002

Wong-Lun-Hing EM, van Dam RM, Heijnen LA, Busch OR, Terkivatan T, van Hillegersberg R, Slooter GD, Klaase J, de Wilt JH, Bosscha K, Neumann UP, Topal B, Aldrighetti LA, Dejong $\mathrm{CH}$. Is current perioperative practice in hepatic surgery based on enhanced recovery after surgery (ERAS) principles? World J Surg. 2014 May; 38(5):1127-40. doi: 10.1007/s00268-013-2398-6.

Wong-Lun-Hing EM, van Dam RM, Welsh FK, Wells JK, John TG, Cresswell AB, Dejong $\mathrm{CH}$, Rees M. Post-operative pain control using continuous i.m. bupivacaine infusion plus patient-controlled analgesia compared with epidural analgesia after major hepatectomy. HPB (Oxford). 2014 Jul;16(7):601-9. doi:10.1111/hpb.12183.

Coolsen MM, Wong-Lun-Hing EM, van Dam RM, van der Wilt AA, Slim K, Lassen K, Dejong $\mathrm{CH}$. A systematic review of outcomes in patients undergoing liver surgery in an enhanced recovery after surgery pathways. HPB (Oxford). 2013 Apr;15(4):245-51. doi: 10.1111/j.1477-2574.2012.00572.x. Review.

Wong-Lun-Hing EM, Lodewick TM, Stoot JH, Bemelmans MH, Olde Damink SW, Dejong $\mathrm{CH}$, van Dam RM. A survey in the hepatopancreatobiliary community on ways to enhance patient recovery. HPB (Oxford). 2012 Dec;14(12):818-27. doi: 10.1111/j.1477-2574.2012.00546.x.

van Dam RM, Wong-Lun-Hing EM, van Breukelen GJ, Stoot JH, van der Vorst JR, Bemelmans MH, Olde Damink SW, Lassen K, Dejong CH; ORANGE II Study Group. Open versus laparoscopic left lateral hepatic sectionectomy within an enhanced recovery ERAS $^{\circledR}$ programme (ORANGE II-trial): study protocol for a randomised controlled trial. Trials. 2012 May 6;13:54. doi: 10. 1186/1745-6215-13-54.

Stoot JH, Wong-Lun-Hing EM, Limantoro I, Visschers R, Busch OR, Van Hillegersberg R, De Jong KM, Rijken AM, Kazemier G, Olde Damink SW, Lodewick TM, Bemelmans $\mathrm{MH}$, van Dam RM, Dejong $\mathrm{CH}$; Dutch Liver Collaborative Group. Laparoscopic liver 
resection in the Netherlands: how far are we? Dig Surg. 2012;29(1):70-8. doi: 10.1159/000335739. Review.

Fichtinger $R^{*}$, Wong-Lun-Hing EM*, Aldrighetti LA, Troisi R, Sutcliffe R, Abu Hilal M, Besselink M, Aroori S, Fretland A, Menon K, d'Hondt M, Neumann UP, Lucidi V, White $S$, Sergeant G, Fusai G, van Breukelen GJP, Primrose J, van Dam RM on behalf of the ORANGE II PLUS Study Group. Open versus laparoscopic hemihepatectomy within an ERAS programme (ORANGE II PLUS - Trial): study protocol for a randomised controlled trial. Submitted Trials December 2016.

* Shared first authorship. 

Curriculum Vitae 


\section{CURRICULUM VITAE}

Edgar Marinus Wong-Lun-Hing was born on September 22th, 1984 in 's- Hertogbosch, the Netherlands. After graduating from the Stedelijk Gymnasium in Breda, the Netherlands (2002) he first studied a year abroad at the Alliant International University of San Diego, USA. In 2003 he studied Health Sciences at the Maastricht University after not being selected in the numerus fixus of Medicine. In 2004 he started his first year of Medicine at Maastricht University and obtained his propaedeutic diploma in 2005. During his study he worked as a student researcher with Ronald van Dam (MD, $\mathrm{PhD}$ ) and Professor Cornelis C.H. Dejong (MD, PhD). He obtained his medical degree in 2010 and started a PhD project under supervision of Ronald van Dam (MD, PhD) and professor Cornelis C.H. Dejong (MD, PhD). Edgar was awarded an EAES-Research Grant in 2015 for his work on the ORANGE 2 Plus - Trial. Meanwhile he started working as a senior house officer in February 2014 at the Department of Surgery in the Jeroen Bosch Hospital in 's-Hertogenbosch. In November 2014 he started his surgical residency at the Jeroen Bosch Hospital (dr. K. Bosscha). He will continue his training in January 2018 at the University Medical Centre Utrecht (prof. dr. M.R. Vriens). He lives happely together with Marieke Vermeulen, and is the proud father of their daugther (Elise). 


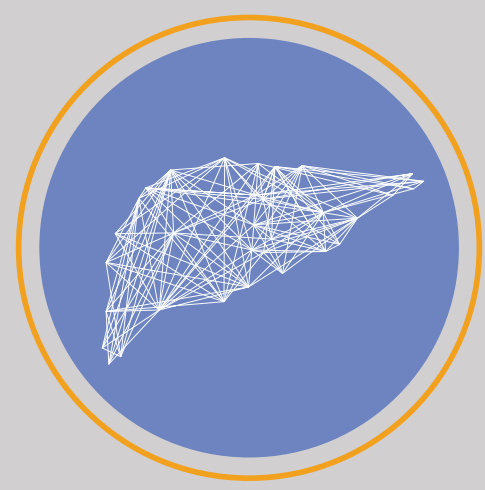

